\title{
Syndecan-4 in cell signaling and membrane trafficking
}

Citation for published version (APA):

Tkachenko, E. (2005). Syndecan-4 in cell signaling and membrane trafficking. [Doctoral Thesis, Maastricht University]. Universiteit Maastricht. https://doi.org/10.26481/dis.20050908et

Document status and date:

Published: 01/01/2005

DOI:

10.26481/dis.20050908et

Document Version:

Publisher's PDF, also known as Version of record

\section{Please check the document version of this publication:}

- A submitted manuscript is the version of the article upon submission and before peer-review. There can be important differences between the submitted version and the official published version of record.

People interested in the research are advised to contact the author for the final version of the publication, or visit the DOI to the publisher's website.

- The final author version and the galley proof are versions of the publication after peer review.

- The final published version features the final layout of the paper including the volume, issue and page numbers.

Link to publication

\footnotetext{
General rights rights.

- You may freely distribute the URL identifying the publication in the public portal. please follow below link for the End User Agreement:

www.umlib.nl/taverne-license

Take down policy

If you believe that this document breaches copyright please contact us at:

repository@maastrichtuniversity.nl

providing details and we will investigate your claim.
}

Copyright and moral rights for the publications made accessible in the public portal are retained by the authors and/or other copyright owners and it is a condition of accessing publications that users recognise and abide by the legal requirements associated with these

- Users may download and print one copy of any publication from the public portal for the purpose of private study or research.

- You may not further distribute the material or use it for any profit-making activity or commercial gain

If the publication is distributed under the terms of Article $25 \mathrm{fa}$ of the Dutch Copyright Act, indicated by the "Taverne" license above, 
Syndecan-4 in cell signaling and membrane trafficking 


\section{Syndecan-4 in cell signaling and}

\section{membrane trafficking}

\section{DISSERTATION}

To obtain the degree of Doctor

at the Maastricht University,

on the authority of the Rector Magnificus,

Prof. dr. G.P.M.F. Mols

in accordance with the decision of the Board of Deans,

to be defended in public

on Thursday September 82005 , at $12.00 \mathrm{hrs}$

by

Eugene Tkachenko 


\section{Supervisors:}

Prof.dr. M.J. Post

Prof.dr. M.Simons, Dartmouth College, United States

\section{Assessment committee:}

Prof.dr. F.C.S. Ramaekers (chairman)

Prof.dr. J.R. Couchman, Imperial College London, United Kingdom

Prof.dr. G. David, KU Leuven, Belgium

Dr. S. Heymans

Prof.dr. J.L. Waltenberger

Financial support was provided by the National Institutes of Health, American Heart Association and Dartmouth Medical School. 
"Many will think that they can with reason blame me, alleging...that my proofs are contrary to the authority of certain men held in great reverence by their unexperineced judgements, not considering that my works are the issue of simple and plain experience which is the true mistress."

Leonardo da Vinci 


\section{Contents}

Introduction $\quad 9$

$\begin{array}{lc}\text { Chapter } 1 & 13\end{array}$

Syndecans - new kids on the signaling block.

Chapter 2

31

Modulation of Microvascular Signaling by Heparan Sulfate Matrix:

Studies in Syndecan-4 Transgenic Mice.

Chapter 3

41

Growth Factor-specific Modulation of Cellular Response by Syndecan-4.

Chapter 4

57

Clustering induces redistribution of syndecan- 4 core protein into raft membrane domains.

\section{Chapter 5}

Fibroblast Growth Factor 2 Endocytosis In Endothelial Cells Proceed

Via Syndecan-4-dependent Activation of Rac1 and a Cdc42-dependent Macropinocytic Pathway.

\section{Chapter 6}

83

Syndecan-4 clustering induces migration in synectin dependent manner.

\section{Chapter 7}

Summary

Samenvatting 


\section{List of abbreviations}

BSA

CS

DMEM

$\mathrm{GAG}$

GPI

$\mathrm{EGF}$

EGFP

Erk

FACS

FBS

FcR

FcR-S4

FGF2

FLAER

GIPC

HA

HGF

HRP

HS

HUVEC

$\mathrm{kD}$

LDL.

NO

OST

PBS

PDGF

PDZ

PIP2

PKC

PPI/2A

RFPEC

R-PE

TIRF

WASP

S4

TGF $\beta$

TNF

VEGF bovine serum albumin

chondroitin sulfate

Dulbecco's modified Eagle's medium

glycosaminoglycan

glycosylphosphatidylinositol

epithelial growth factor

enhanced green fluorescent protein

extracellular signal regulated protein kinase

fluorescence-assisted cell sorting

fetal bovine serum

Fc receptor Ia CD64

Fc receptor-syndecan -4 chimera

fibroblast growth factor 2

Alexa-488-conjugated inactive variant of proaerolysin

GAIP c-terminus interacting protein

hemagglutinin

hepatocytes growth factor

horseradish peroxidase

heparan sulfate

human umbilical vein endothelial cells

kiloDalton

low density lipoprotein

nitric oxide

O-sulfotransferase

phosphate buffered saline

platelet-derived growth factor

postsynaptic density 95 , disk large, zona occludens-1

phosphatidylinositol 4,5-bisphosphate

protein kinase $\mathrm{C}$

protein phosphatase type $1 / 2 \mathrm{~A}$

rat fat pad endothelial cells

red-phycoerythrin

Total Internal Reflection Fluorescent Microscopy

Wiscott-Aldrich syndrome protein

syndecan -4

transforming growth factor $\beta$

tumor necrosis factor

vascular endothelial growth factor 


\section{Introduction}

The syndecan family contains four highly related transmembrane proteoglycans that are cellular signaling molecules in embryonic development, tumorigenesis and angiogenesis. Syndecan-4 is the most ubiquitously expressed member of this family. It is upregullated in various tumors as well as injured and ischemic tissues. A number of studies have concluded that syndecan- 4 plays an important role in many cell signaling pathways. However, to the surprise of many, syndecan-4 null mice are viable and healthy. While lacking visible developmental abnormalities, these mice exhibited defects under various stress conditions. Those include a high mortality following septic shock, and slow wound healing and muscle regeneration. Thus, syndecan-4, while not needed for embryonic development, may play an important role in an acute response settings

The syndecan-4 extracellular domain carries heparan and chondroitin sulfate chains that can bind a number of ligands including cell matrix proteins and various heparin-binding growth factors. One area of research in our laboratory involves fibroblast growth factor 2 (FGF2), one of the heparan-binding growth factors capable of binding syndecans. Our group, and others, have previously demonstrated that removal of heparan from the cell surface results in perturbed FGF2induced cell signaling.

Modulation of cell signaling by syndecan- 4 is determined not only by heparan sulfate chains bound to the extracellular portion, but also by unique properties of its cytoplasmic domain. Portions of the cytoplasmic domain are conserved in all members of the syndecan family and bind common intracellular partners. These include Src kinase, cortactin and several PDZ-domain containing proteins. In addition to the cytoplasmic common regions, each of the syndecans has a variable region in the cytoplasmic domain and these differences are thought to underlie the unique properties of each of the syndecans. Syndecan4 variable domain binds to $P K C \alpha, \alpha$-actinin and syndesmos. These variable domain interactions are responsible for the unique role played by syndecan-
4 among the syndecan family in controlling focal adhesion formations and regulating PKCa activity. The research in this thesis is aimed at identifying molecular mechanisms involving syndecan 4 that regulate the cellular responses important in postnatal vascular remodeling in endothelial cells.

To investigate the role of syndecan-4 in modulation of microvascular cell signaling we initially used a mouse transgenic model that overexpressed syndecan-4. We found that FGF2 treatment of microvessels isolated from these animals led to an increase in nitric oxide production. However, the increase in nitric oxide production is largely due to an increase in heparan and chondroitin sulfate mass and is not a specific syndecan-4 effect.

We then decided to investigate the cell signaling role of cytoplasmic tail of syndecan-4 by generating a series of constructs with mutagenized cytoplasmic tails. In these experiments we focused on syndecan-4's C-terminus PDZ-binding region and the middle variable domain region. Mutations that disrupted the PIP2/PKCa-binding region and the $\mathrm{PDZ}$-binding region led to altered responsiveness of endothelial cells to $\mathrm{FGF} 2$ in migration, cell proliferation and tube formation assays. Thus, disruption of the syndecan-4 signaling complex can perturb $\mathrm{FGF}-2$ induced cell response.

We hypothesized that the subcellular localization of syndecan- 4 can modulate the growth factor responsiveness. Thus we looked at the properties of syndecan- 4 containing membranes before and after FGF-2 treatment. $\mathrm{FGF}-2$ induced syndecan4 clustering results in a shift in syndecan to cholesterol rich membrane domains called lipid rafts. The exact role of lipid rafts is unclear; however, the fact that these regions are enriched in kinases and other signaling molecules suggest that they play a role in the assembly of signaling complexes.

Binding of a ligand to its receptor generally results in endocytosis of the receptor-induced signaling complex, leading to downregulation of cell signaling. Consequently, rate of receptor endocytosis may determine the strength of the 
cell signaling. Thus we decided to investigate the mechanisms associated with syndecan-4 internalization that are induced by FGF2 binding. We found that FGF2 binding to syndecan-4 results in a shift of the FGF2/syndecan-4 complex to lipid rafts and this complex is then internalized via the constitutive macropinocytic pathway. This uptake requires syndecan- 4 clustering-induced activation of Rac1 and basal activity of $\mathrm{CDC} 42$.

Both Racl and CDC42 are GTPases of the Rho-family that are important for migratory cell polarization. Thus, we hypothesized that the activation of Rac1 seen following syndecan-4 clustering may promote cell migration in addition to its role in the uptake of synedcan-4. To this end, we demonstrated, that in endothelial cells antibody clustering of syndecan-4 leads to polarization of Racl activity within the cell that results in increased cell migration. In contrast, cells expressing syndecan- 4 with a disrupted PDZ-binding domain do not show an increase in clustering-induced cell migration. Surprisingly, the PDZ-binding domain mutants exhibited high levels of Racl activity even in non-stimulated cells. Active Racl in these cells is distributed uniformly, whereas "normal" migratory cells primarily localize active Racl along the leading edge of the cell. As expected, cells expressing the PDZ-binding domain mutant also failed to form the typical trailing edge region of the cell with minimal Racl activity. These results have led us to propose that syndecan-4 clustering locally releases inhibition of Rac I via a PDZ-domain interacting protein, thus promoting migratory polarization of the cell.

Synectin is a PDZ-domain containing protein that is known to interact with the PDZ-binding domain of syndecan-4, and our group has previously demonstrated that synectin modulates cell migration in response to FGF2. We found that endothelial cells isolated from synectin knockout mice failed to migrate in response to antibody clustering of syndecan-4. They also exhibited a high basal level of Racl activity. Thus, our data suggest that syndecan-4 clustering induces cell migration by local activation of Racl in a synectin-dependent manner. This process is likely to involve internalization of a Racl-inhibiting signaling complex that would allow plasmamembrane targeting and activation of Racl.

This thesis demonstrates that perturbing the expression of syndecan-4 results in an altered cellular response to FGF2. These changes in FGF2dependent signaling in experiments performed here are a consequence of a number of syndecan 4 related events including changes in the cell surface heparan/chondroitin sulfate mass and perturbation of the FGF/syndecan signaling complex. It has been speculated before, that syndecan -4 regulates the localization of bound growth factors not only by shedding from the cell surface but also as a consequence of its plasma membrane localization and endocy tosis. We, for the first time, demonstrate and characterize the FGF2 dependent shift of the syndecan-4/FGF2 complex into lipid rafts followed by internalization. One of the unique properties of this uptake is that syndecan- 4 internalizes via constitutive macropinocytosis which is unusual for transmembrane proteins. Presumably, the large sulfate chains of syndecan-4 do not allow it to fit into smaller clathrin or caveolin coated vesicles. This work is the first evidence of the ligand induced targeting of a transmembrane protein to the macropinosomal endocytosis route.

Using antibody clustering, we have identified a novel migratory activity associated with syndecan4. Clustering of syndecan- 4 alone, in the absence of its associated growth factor tyrosine kinase receptors and integrin cell matrix proteins leads to cellular migration. This establishes syndecan -4 as an independent signaling molecule in addition to its previously described role as a co-receptor for other signaling molecules.

The main purpose of this thesis was to uncover molecular mechanisms of the role of syndecan4 in vascullar remodeling in the adult organism. We found that syndecan- 4 expression leads to an increase of the heparan mass that effects $\mathrm{NO}$ production in microvessels. Ligand induced clustering of syndecan-4 creates a signaling complex via the scaffolding protein, synectin. This complex regulates Racl activity, thus influencing stability of cell-extracellular matrix interactions, 
controlling membrane trafficking and promoting cellular migration; processes important in angiogenesis and tissue repair.

\section{In this thesis}

Chapter 1 is a general review of the role of syndecans in cell signaling.

Chapter 2 is a study of heparan sulfate matrix changes in syndecan 4 transgenic mice and their modulation of microvascular signaling events.

Chapter 3 describes the FGF-2 specific modulation of cell signaling by syndecan- 4 .

Chapter 4 is dedicated to the characterization of membrane structures containing syndecan- 4 before and after ligand binding.

Chapter 5 characterizes the mechanism of syndecan-4 dependent FGF-2 endocytosis.

Chapter 6 is a paper about the mechanism of migration induced by syndecan -4 clustering.

Chapter 7 contains concluding remarks and future directions. 


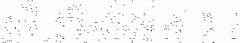

? 


\section{Chapter 1}

Syndecans - new kids on the signaling block

Eugene Tkachenko, John M. Rhodes, and Michael Simons

Circulation research 2005;96(5): 488-500. 


\section{Abstract}

\begin{abstract}
Cell-associated proteoglycans provide highly complex and sophisticated systems to control interactions of extracellular cell matrix components and soluble ligands with the cell surface. Syndecans, a conserved family of heparanand chondroitin-sulfate carrying transmembrane proteins, are emerging as central players in these interactions. Recent studies have demonstrated the essential role of syndecans in modulating cellular signaling in embryonic development, tumorigenesis and angiogenesis. In this review, we will focus on new advances in our understanding of syndecan-mediated cell signaling.
\end{abstract}

\section{Introduction}

Cells interactions with their environment are critical to a large number of processes including growth, migration, adhesion and apoptosis among many others. In addition to a variety of specialized receptor systems that have evolved to transmit signals from specific ligands, other systems have also evolved to inform cells of the broader extracellular context. Thus, adhesion receptors such as integrins can be activated by a number of extracellular matrix proteins while selectins and various cellular adhesion molecules participate in cell-cell interactions.

Over the last few years, it has become increasingly clear that cells possess yet another unique system that integrates signaling from circulating ligands such as growth factors and extracellular matrix proteins with other cellular receptor systems such as integrins. This unique function, carried out by the syndecan family of proteins, places them at the center of signal integration in the cell and has earned them the name of "tuners of transmembrane signaling"!

\section{Syndecan structure}

Syndecans are a family of transmembrane core proteins capable of carrying both heparan sulfate (HS) and chondroitin sulfate (CS) chains. While invertebrates have only one syndecan, four syndecan genes (syndecan$1,2,3,4)$ are present in vertebrates. Each syndecan has a short cytoplasmic domain, a single span transmembrane domain and an extracellular domain with atrachment sites for three to five HS or CS chains (Fig 1). The presence of HS chains allows interactions with a large number of proteins including heparin-binding growth factors, such as fibroblast growth factors (FGFs), vascular endorhelial growth factors (VEGFs), transforming growth factor
(TGF)- $\beta$, and platelet-derived growth factors (PDGFs). Furthermore, heparan sulfates facilitate interactions with various extracellular matrix proteins including fibronectin and plasma proteins such as antithrombin-1. The role of CS chains is less clear. A recent study has suggested that syndecan-1 and syndecan- 4 CS chains cooperate with HS chains in binding to the heparin-binding growth factors, midkine and pleitrophin ${ }^{2}$ and to the extracellular matrix protein laminin ${ }^{3}$.

\section{Extracellular domain}

The structural diversity of both HS and CS chains results from a series of post-translational modifications beginning with the attachment of the first hexosamine to the linkage region tetrasaccharide which is $\mathrm{O}$-linked to serine or threonine in the core transmembrane protein committing the oligosaccharide chain to either HS ( $N$-acetylglucosamine, uronic acid) or CS ( $N$-acetylgalactosamine, uronic acid) disaccharide polymer ${ }^{4}$. Then, HS and CS glycosaminoglycan (GAG) backbones are extended by different sets of polymerizing glycosyltransferases resulting in HS and CS chains of 20 to 80 disaccharides in average length. Then, these newly synthesized chains are modified by epimerization of glucuronic to iduronic acid residues and sulfation of the $\mathrm{C} 2$ position of glucuronic and/or iduronic acid. A myriad of specific CS (4-O and 6-O N-acetylgalactosaminyl) and HS (2-O, 3-O and 6-O N-acetylglucosaminyl and $\mathrm{N}$ deacetylase $/ N$-) sulfotransferases complete the decoration of these GAG chains (for further details see ${ }^{5}$ ).

Various combinations of enzymes involved in HS chain modifications produce unique binding motifs that selectively recognize different proteins. Thus, a specific combination of $2-O$ and $6-O$ sulfation is necessary for synthesis of the FGF2 binding site while 3- $O$-sulfotransferase 1 activity is needed for generation of the antithrombin-1 binding site. Modifications of sulfotransferase expression and activity can significantly modulate syndecans functions as demonstrated, for example, in the case of 2-O-sulfotransferase (2-OST) deficiency that results in marked abnormalities of FGF signaling. ${ }^{6}$. On the other hand, augmentation of 2-OST expression, as occurs in the setting of hypoxia, leads to enhanced FGF responsiveness?

The recent discovery of specific mammalian sulfatases (Sulf 1 and Sulf2) which can modify GAG chains extracellularly adds another layer of complexity to the system. Both Sulf1 and Sulf2 are secreted, HS specific 6-O-sulfatases ${ }^{8,9}$ and their activity can modify heparin binding growth factor signaling ${ }^{10}$. In quail, Qsulf1, 


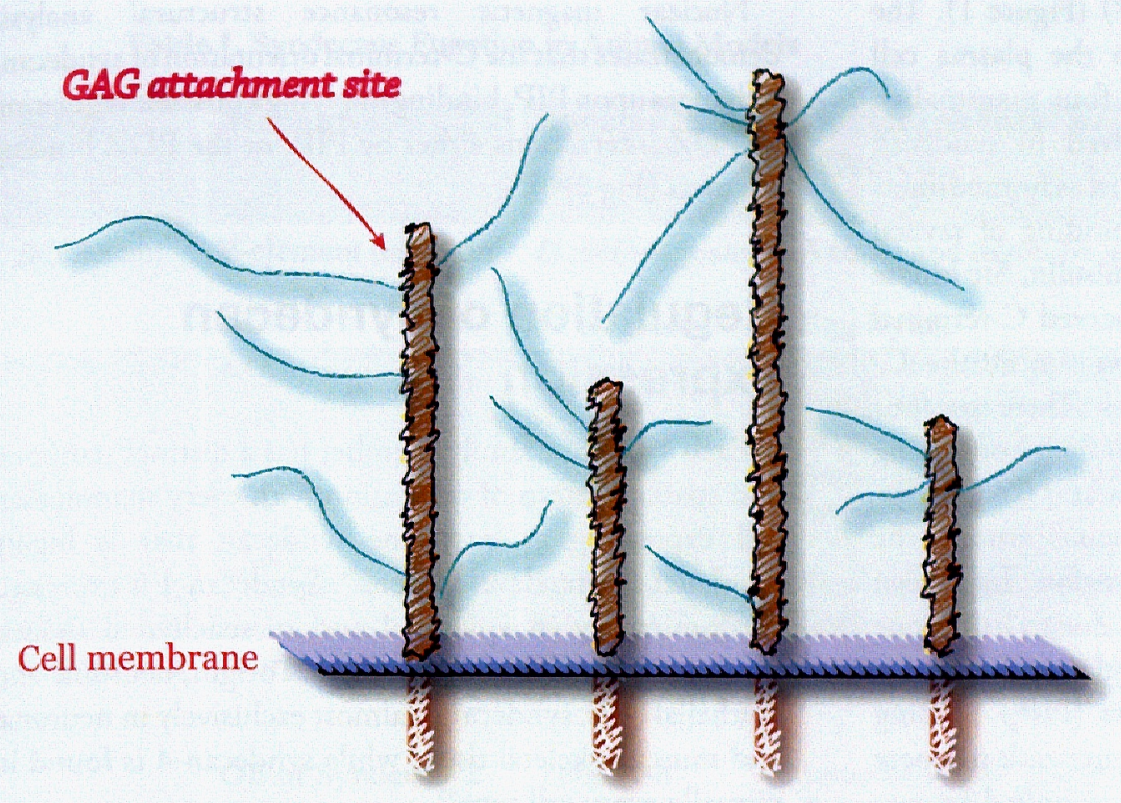

Syndecan 1 Syndecan 2 Syndecan 3 Syndecan 4
Figure 1. Syndecan structure.
$M W$ - molecular weight,
kD-kilodalton,
GAG-glycosaminoglycan,
C1- conserved domain 1 ,
$V$ - variable domain,
C2- conserved domain 2.

\section{Protein core MW $33 \mathrm{kD} \quad 23 \mathrm{kD} \quad 43 \mathrm{kD} \quad 22 \mathrm{kD}$}

\section{Syndecan1 \\ Syndecan 3 \\ Syndecan2 \\ Syndecan 4}

\begin{abstract}
Interacting
Proteins
\end{abstract}

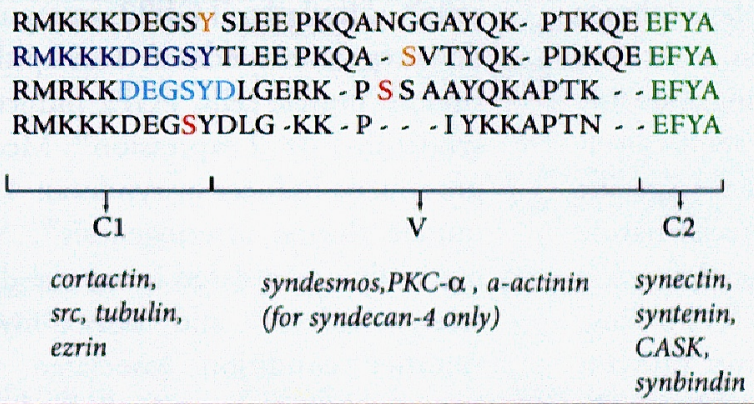

RMKKKDEGSY SLEE PKQANGGAYQK- PTKQE EFYA. RMKKKDEGSYTLEE PKQA - SVTYQK- PDKQE EFYA RMRKKDEGSYDLGERK - P S S AAYQKAPTK - - EFYA symbindin

\begin{abstract}
Lower panel.
Protein alignment of mouse syndecan cytoplasmic domains. Amino acids in color identify posttranslational or binding motifs: red - phosphorylation in situ, brown- phosphorylation in transfectants or a synthetic peptide, green - PDZ2 binding domains, dark blue - c-src or fyn kinase activity in a complex with cortactin, light blue - ezrin binding site.
\end{abstract}

the avian homolog of Sulf1 and Sulf2, has been shown to remodel HS on the cell surface to promote Wnt-1 signaling ${ }^{11}$, while in human cancer cell lines Hsulf1 expression inhibited FGF2 and HGF stimulation of cell growth $^{12}$.

It has been generally assumed that all syndecan $\mathrm{HS}$ and CS chains are created equal, that is, there is no preference for specific HS/CS sequences on specific syndecans ${ }^{13}$. However, a recent study has suggested that CS and HS chains on syndecan- 1 and syndecan- 4 are structurally different ${ }^{2}$. If confirmed, this will add yet more complexity to syndecan biology. In addition to interacting with extracellular protein via their HS and CS chains, the syndecan-4 core can directly engage in protein-protein interactions ${ }^{14}$. The extracellular domain of syndecan-4 binds specifically to human foreskin fibroblasts $\left(\mathrm{IC}_{50}=\right.$ $10^{-8} \mathrm{M}$ ), mouse aortic endothelial cells as well as other cell types while same species syndecan family members did not efficiently compete with these interactions ${ }^{14}$.

\section{Transmembrane and intracellular domains}

While the degree of conservation in the extracellular domain of syndecans is fairly low, the transmembrane domain (TM) is highly conserved. As with classic type I membrane protein architecture, syndecans have a singlepass TM. Uniquely though, the TM and a small sequence adjacent to it have a high affinity for self-association which, in the case of syndecan-4, has been shown to be required for protein kinase $\mathrm{C}-\alpha$ (PKC $\alpha)$ activation ${ }^{15}$.

The cytoplasmic domain, despite being relatively short, has a number of important regions. The domain is divided into three regions- conserved regions 1 and 2 
(C1 and $\mathrm{C2}$ ) and a variable region (V) (Figure 1). The Cl domain, immediately adjacent to the plasma cell membrane, is virtually identical in all four mammalian syndecans. It is thought to be involved in syndecan dimerization (all syndecans probably exist as homodimers and higher order olligomers) and in binding of several intracellular proteins including ezrin, tubulin, Src kinase and cortactin ${ }^{16.18}$. The universally conserved C-terminal $\mathrm{C} 2$ domain contains a PDZ2-binding site at the $\mathrm{C}$ terminal end and two tyrosine residues. There are four identified syndecan interacting PDZ domain-containing proteins - syntenin, synecrin, synbindin and CASK ${ }^{19-2 x}$.

The $\mathrm{V}$ domain is highly hererogeneous among the four mammalian syndecans. This region has been studied most extensively in syndecan- 4 due to its unique features. The syndecan- $4 \mathrm{~V}$-region sequence includes a phosphatidylinositol-(4,5)-bisphosphate $\left(\mathrm{PIP}_{2}\right)$ binding site that is involved in syndecan- 4 dimerization where two syndecan-4 cytoplasmic domains are linked by rwo $\mathrm{PIP}_{2}$ molecules in anti-parallel fashion (Fig 2) ${ }^{24}$.

In addition, PIP $P_{2}$ binding to the variable region plays a critical role in binding and activation of $\mathrm{PKC} \alpha$, an enzyme that plays a key role in syndecan-4 signaling (see below) $)^{15,25-29}$. Indeed, this feature places PKC $\alpha$ in the class of receptor-activared kinases, and allows it to play a role not dissimilar from that of integrin-linked kinases. a-Actinin and PKC- $\alpha$ compete for syndecan- 4 binding, possibly providing a mechanism for regulation of syndecan-4cytoskeletal interaction ${ }^{30}$. Another syndecan-4-specific binding protein is syndesmos ${ }^{31}$. While the precise nature of its interaction with syndecan-4 has not been defined, it requires both $\mathrm{Cl}$ and $\mathrm{V}$ syndecan-4 domains for binding. Syndesmos binding to focal adhesion adaptor proteins paxillin and Hic-5 may be an alternative to an $\alpha$-actinin mechanism, linking syndecan-4 to focal adhesions ${ }^{32}$.
Nuclear magnetic resonance structural analysis demonstrates that the $C$-terminal arientation of syndecan4 changes upon $\mathrm{PIP}_{2}$ binding implying a possible regulation of $\mathrm{PDZ}$ interactions either by $P I P_{2}$ or the $\mathrm{PDZ}$ binding partners (Fig 2) 24,33.

\section{Regulation of syndecan expression}

Each syndecan family member has a distinct temporal and spatial pattern of expression with every mammalian cell expressing at least one syndecan that is highly regulated during development ${ }^{34}$. Syndecan-1 is expressed predominantly in epithelial and mesenchymal tissues, syndecan- 2 in cells of mesenchymal origin, neuronal and epithelial cells, syndecan-3 almost exclusively in neuronal and musculoskeleral tissue while syndecan- 4 is found in virtually every cell type $e^{35}$.

Given their role in tuning numerous signaling events, it is not surprising that syndecan levels are tightly regulated. Growth factors play an important role in regulation of syndecan expression. Thus, TNF $\alpha$ upregulates syndecan-2 and downregulates syndecan- 1 in endothelial cells ${ }^{36}$. Similarly, TGFB2 upregulates syndecan -4 and downregulares syndecan-1 in epithelial cells ${ }^{37}$. In aortic smooth muscle cells, FGF2 induces syndecan-4 but not syndecan-1 or -2 expression ${ }^{38}$. Mechanical stress is also a prominent inducer of syndecan-4 expression in smooth muscle during arteriogenesis ${ }^{39}$. Syndecan- 4 levels are markedly upregulated in several disease states including arterial injury ${ }^{40}$ and acute myocardial infarction ${ }^{41}$. Another condition associated with a pronounced increase in syndecan-1 and -4 expression is wound healing ${ }^{42.43}$. While there are probably numerous factors

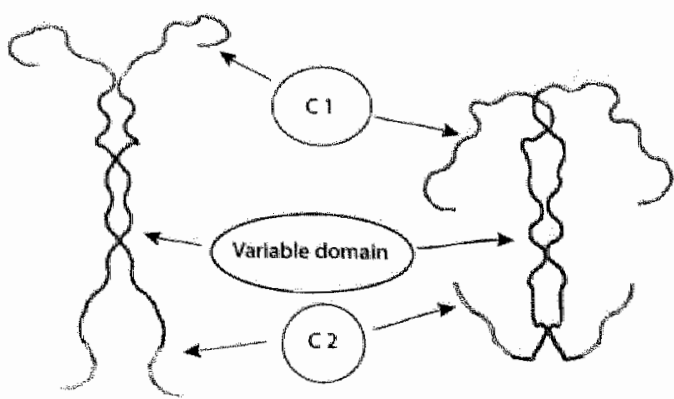

Syndecan-4
Syndecan-4 and PIP2
Figure 2. NMR structure of syndecan- 4 cytoplasmic domain in the presence and absence of PIP,

C1- conserved domain 1 , C2-conserved domain 2 .

Note that interaction with $\mathrm{PIP}_{2}$ results in reorientation of PDZ binding domains. 
Table I. Syndecans Function in Animal Models

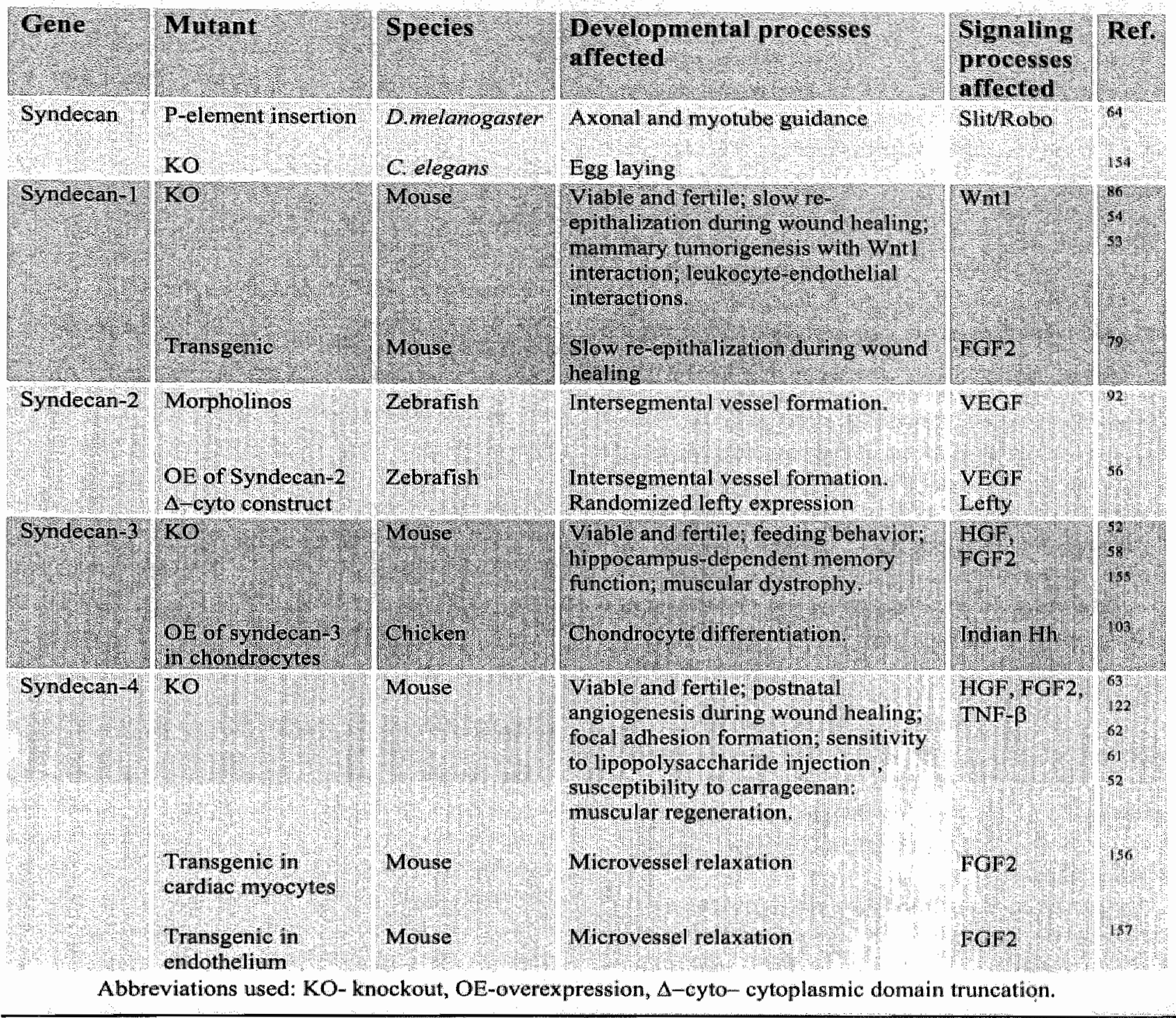

responsible for this increase, one interesting mediator is an inflammatory cell-derived peptide, PR 39 , that has a unique ability to markedly upregulate syndecan-1 and syndecan -4 expression in vitro and in wivo ${ }^{4,45}$.

Very litcle is known about regulation of syndecans2 and -3 expression. Syndecan-2 levels increase during transformation of fat cells into myofibroblasts, whereas the level of syndecan $-1,-3$ and -4 remains constant ${ }^{46}$. Syndecan-3 expression is highlly regulated during development. In rodents, its level in central nervous system rises at birth, peaks on day 7 , and then declines to the level of adult ${ }^{47}$. This period of high level of syndecan-3 expression corresponds with oligodendrocyte differentiation and myelin formation in the central nerwous system. The temporal dermal expression of syndecan-3 suggests the possibility of its involvement in feather development ${ }^{48}$. During chick embryo limb development, syndecan-3 is transiently expressed the period of mesenchymal condensationi ${ }^{49}$.

Interestingly, changes in one syndecan family member's gene expression may affect others. For example, increased syndecan-3 expression in satellite cells leads to the downregulation of syndecan-4-transduced FGF2 and HGF signaling ${ }^{50}$, while syndecan-3 expression is reduced in syndecan $-4^{-t}$ satellite cells. 


\section{Syndecans function in development}

Recent studies have begun clarifying the roles played by various syndecans during the developmental process (Table 1). Homozygous distuption of the syndecan1 gene in mice leads to viable offspring. The mice are grossly normal but demonstrate abnormally slow re-epirhelialization following injury ${ }^{51}$ and increased leukocyte adhesion ${ }^{52}$. Syndecan-1 appears to be involved in modulation of Wht-1 signaling as mammary glandspecific expression of Wnt-1 leads to development of tumors in wild type but not in the syndecan-1 knockout mice ${ }^{53}$.

Studies in zebrafish using anti-syndecan-2 morpholino oligonucleotides demonstrated that this syndecan plays an important role in vascular development involving modulation of VEGF signaling. Syndecan-2 knockdown resulted in suppression of intersegmencal vessels while formation of dorsal vessels (aorta, cardinal vein) was not affected $^{\text {sit }}$. Overexpression of VEGF ${ }_{165}$ in syndecan-2 morphans was not able to induce ectopic vessel formation, whereas co-expression of syndecan-2 and VEGF resulted in an increase of vessel formation compared with VEGF alone. Application of moderate doses of syndecan2 and VEGF morpholinos demonstrated synergistic inhibition of angiogenesis. Expression of cytoplasmic domain-truncated syndecan-2 mimics the phenotype produced by syndecan- 2 knockdown. Based on these data, syndecan-2 appears to potentiate VEGF-induced capillary sprouting.

Syndecan-2 is also involved in left-right asymmetry regulation (reviewed $\mathrm{in}^{35}$ ). In Xenopus syndecan-2 is phosphorylated by $\mathrm{PKC}-\gamma$ only in right animal cap ectodermal cells $s^{5,5}$. Overexpression of the cytoplasmic domain truncated form of syndecan -2 results in perturbed determination of left-right asymmetry of embryo and also randomizes expression of lefty, a left/right symmetry regulator ${ }^{35}$

Syndecan-3 levels in hypothalamus have been demonstrated to physiologically regulate feeding behavior and mice with homozygous disruption of both syndecan-3 alleles displayed reduced feeding behavior in response to food deprivation ${ }^{56}$ as well as impaired performance in tasks urilizing hippocampal functioning indicating learning and memory abnormalities ${ }^{57}$. They develop muscular dystrophy characterized by fibrosis, deteriorated locomotion, and hyperplasia of myonuclei and satellite cells ${ }^{50}$.

Syndecan-4 deficiency has generated much interest.
Null mice are wiable and ferrile but display a number of subtle defects. However, syndecan $-4^{-f-}$ embryos demonstrate much more frequent thrombi formation in the vessels of the placental labyrinth than the littermate controls resulting in much higher embryo loss and implicaring syndecarm-4 in regulation of blood dorting ${ }^{58}$. The adult syndecan-44-1- mice have increased mortality following lipopolysaccharide injection suggesting their inability to clear pathogens ${ }^{59}$ and to down regulate TNF $\beta$-induced suppression of interleukin- $1 \beta$ expression in macrophages $5 \%$. The syndecan- $4^{-/ 4}$ mice also have increased susceptibility to kappa-carrageenan induced renal damage presumably due to increased deposition in renal collecting ducts ${ }^{60}$.

Other interesting observations include impaired skin wound healing that is thought to be secondary to defective angiogenesis ${ }^{61}$. However, no other angiogenesis deficiency phenotypes have been reported to date. Finally, satellite cells from syndecan $-4^{-1-}$ mice fail to reconsticute damaged muscles suggesting that syndecan-4 presence is required for migration of these skeletal muscle progenitor cells $^{50}$. This may in part be due to the defective FGF2and HGF-induced acrivation of Erk-1/2 $2^{50}$.

\section{Modulation of outside-in signaling}

The preceding section demonstrates that disruption of various syndecan genes leads to phenotypes consistent with the "tuning" role of syndecans in signal transduction. The precise mechanism of this tuning has generated much interest and appears to be different for different syndecans. In the discussion that follows, while we will consider signaling events associated with individual syndecans, it should be kept in mind that considerable overlap berween various syndecan-mediated events probably exists and that the "specific" signaling events described for an individual syndecan may just as well reflect the limitation of our knowledge as the real biological specificities. Nevertheless, there is also a considerable degree of specificity. In particular, it is useful to think, in the signaling context, of syndecan-1 and syndecan- 3 as one subfamily and syndecan- 2 and 4 as another. This classification reflects both homology of variable domain between corresponding syndecans as well as functional similarities. For example, both syndecan1 and syndecan-3 expression is mostly associated with inhibition of cell growth while syndecan-2 and syndecan4 expression leads ro its stimulation. 


\section{Heparan and Chondroitin Sulfate Chains}

The way in which syndecans engage in signal transduction remains a matter of active research and controversy. The first and the oldest hyporhesis postulares that syndecans serve as co-receptors for various heparin binding growth factors. This is thought to occur due to GAG chains binding growth factors, thereby, restricting their presence to the membrane surface and facilitating their subsequent interactions wirh corresponding high affinity receptors ${ }^{62}$. Numerous studies have shown that inhibirion of HS chain synthesis grossly affects signaling. For example, heparinase treatment of cultured smooth muscle cells decreases their responsiveness to $F G F 2^{63}$ while heparinase treatment in vivo inhibits angiogenesis ${ }^{64}$.

Generic data is equally compelling. Inhibition of HS formation due to mutations of EXT1 and EXT2 genes which caralyze polymerization of glucuronic acid and $\mathrm{N}$ acetylglucosamine, the crucial step in HS synthesis, results in hereditary multiple exostoses, an autosomal skeletal disorder characterized by inappropriate chondrocyte proliferation and bone growth ${ }^{65}$. The defect is thought to be due to abnormal diffusion of hedgehog proteins ${ }^{66}$. A homozygous distuption of Ext-1 expression in mice results in gastrulation defects and early embryonic lethality ${ }^{67}$.

More subtle changes in the HS chain composition also have profound effects. Sulfation of borh $2-O$ and 6-O HS sites is thought to be required for formation of FGF binding sites. A homozygous deletion of 2-O ST results in mice that survive until birth, bur die perinatally because of the complete failure of kidney formation ${ }^{6}$. Similarly, a knockdown of the 6-O-sulfotransferase in Drosophila severely perturbs tracheal development, an FGF-dependent process ${ }^{6 .}$. Deletions of other genes involved in HS biosynthesis have equally profound phenorypic effects ${ }^{6 !}$.

In addition to HS-dependent signaling, syndecans also clearly can engage in protein-protein interacrions via their protein core ectodomains, an event that can also initiate intracellular signaling as will be discussed below. Furthermore, syndecan-growth factor interaction, wherher accomplished via the chain or the core-based interacrion, does not simply serve to present the factor to its high affinity receptor. Rather, such binding can initiate signaling events via the cytoplasmic syndecan domains that have their own unique aspects as will be further discussed. Finally, each of the syndecans has its own characteristic biology that we will briefly review.

\section{Syndecan-1 and cell-matrix interaction}

Syndecan-1 is an important regularor of cell-cell and cell-extracellular matrix interactions. Downregulation of its expression in epithelial cells by antisense $m$ RNA results in loss of cell polariry associared with a reduced level of E-cadherin on the cell surface, suggesting involvement in the epithelial-mesenchymal switch during development and in wound healing (reviewed in ${ }^{70}$ ). Overexpression of syndecan-1 or shedding of its ectodomain inhibits FGF2-induced cell proliferation ${ }^{7}$. Mice overexpressing syndecan-1 have delayed dermal wound repair due to the inhibitory effect of soluble syndecan-1 ectodomain ${ }^{72}$. However, under certain circumstances, heparinases can convert syndecan-1 ectodomain from an inhibiror to an activator of $\mathrm{FGF}^{2}$. This reaction enables $\mathrm{FGF} 2$ interaction with syndecan-4 (see below), although a specific protein sequence in the syndecan-1 ectodomain may also play a role ${ }^{74}$. The ability of syndecan-1 overexpression to inhibir cell growth and migration could be an explanation of the aggressive invasive behavior of tumor cells lacking syndecan- $1^{75,76}$.

Interestingly, downregulation of syndecan-1 expression in carcinoma cells results in impaired cell. spreading on vitronectin but not on fibronectin ${ }^{7}$. This seems to be mediated by the ability of syndecan-1 to modulate vitronectin interaction with its $\alpha v \beta 3$ integrin receptor since GPI-syndecan-1 extracellular domain construct expression in syndecan $1^{*}$ cells converts their "no spreading phenotype to normal spreading.

Syndecan-1 plays an important role in tegulation of inflammation $^{78}$ as suggested by increased leukocyteendothelial interactions in syndecan-1 null mice ${ }^{79}$. It also plays an important role in chemokine gradient formation for trans-endothelial and trans-epichelial migration of neutrophils (reviewed $\mathrm{in}^{78}$ ). "The former process is facilitared by an $1 \mathrm{~L}-8 /$ syndecan- 1 complex and regulated by shedding of syndecan-1 ${ }^{80}$. Trans-epithelial neutrophil migration is dependent on matrilysin= mediated shedding of syndecan 1 from the mucosal surface of epithelium ${ }^{81}$. As would be expected, matrixmetalloproteinase matrilysin deficient mice demonstrate impaired trans-epithelial migration of neutrophils.

Finally, syndecan-1 may also play a role in regulation of ephrin signaling that is involved in veno-arterial differentiation. Ephrin-B4 (EphB4) is expressed in venule endorhelium. Homozygous disruption of EphB4 or one of its ligands, ephrin-B2, results in fatal vascular defects ${ }^{82,83}$. Activarion of EphB4-positive endorhelial cells causes upregulation of syndecan-1 ${ }^{84}$ resulting in 
suppression of FGF2 signaling. However, in certain settings, the role of syndecan-1 could be the opposite, depending on the presence of heparinases. Degradation of heparan by platelet heparanase, for example, produces heparin-like heparan sulfate fragments, capable of promoting FGF2 mitogenicity ${ }^{73}$.

\section{Syndecan-2 and TGF- $\beta$ signaling}

Syndecan-2 is the predominant syndecan expressed during embryonic development. Although its role in adult cells has not been well established, recent studies suggest its involvement in regulating TGF- $\beta$ signaling. While TGF- $\beta$ can bind to HS chains, syndecan- 2 , but not other syndecans, binds TGF- $\beta$ directly via a proteinprotein interaction. Furthermore, syndecan-2 coimmunoprecipitates with the TGF- $\beta$ as well as with the type III TGF- $\beta$ receptor (betaglycan) ${ }^{85}$ and expression of a syndecan-2 mutant with a truncated cytoplasmic domain results in impaired response to TGF- $\beta^{85}$. These data correlate with a previously reported inability of cells overexpressing this construct to assemble laminin or fibronectin into a fibrillar matrix ${ }^{86}$.

The mechanism of syndecan-2/TGF- $\beta$ interactions is complex and not entirely clear (Fig 3). TGF- $\beta$ binding to betaglycan transfers it to the type II receptor which undergoes autophosphorylation and then transphosphorylates both betaglycan and the type I receptor. The phosphorylated type I/type II receptor complex then engages in downstream signaling. Betaglycan binds to synectin (GIPC) that retains betaglycan on the cell surface thus preventing its degradation ${ }^{87}$. However, synectin also binds syndecan-2. As already mentioned, expression of a syndecan-2 mutant with a truncated cytoplasmic domain increases plasma membrane betaglycan levels ${ }^{85}$. While an increase in syndecan-2 protein, increases type I and type II TGF- $\beta$ receptors expression and decreases betaglycan, probably as the consequence of competition for synectin binding ${ }^{85}$. This decrease in betaglycan expression possibly leads to disregulated activity of the type-I/type-II TGF- $\beta$ receptor complex.

Similar to syndecan-1, syndecan-2 may also play a role in ephrin signaling. Cell surface ephrin-Eph signaling induces clustering of syndecan-2 and recruitment of cytoplasmic molecules, which leads to localized actin polymerization via Rho family GTPases, N-WASP, and the Arp2/3 complex ${ }^{88}$.
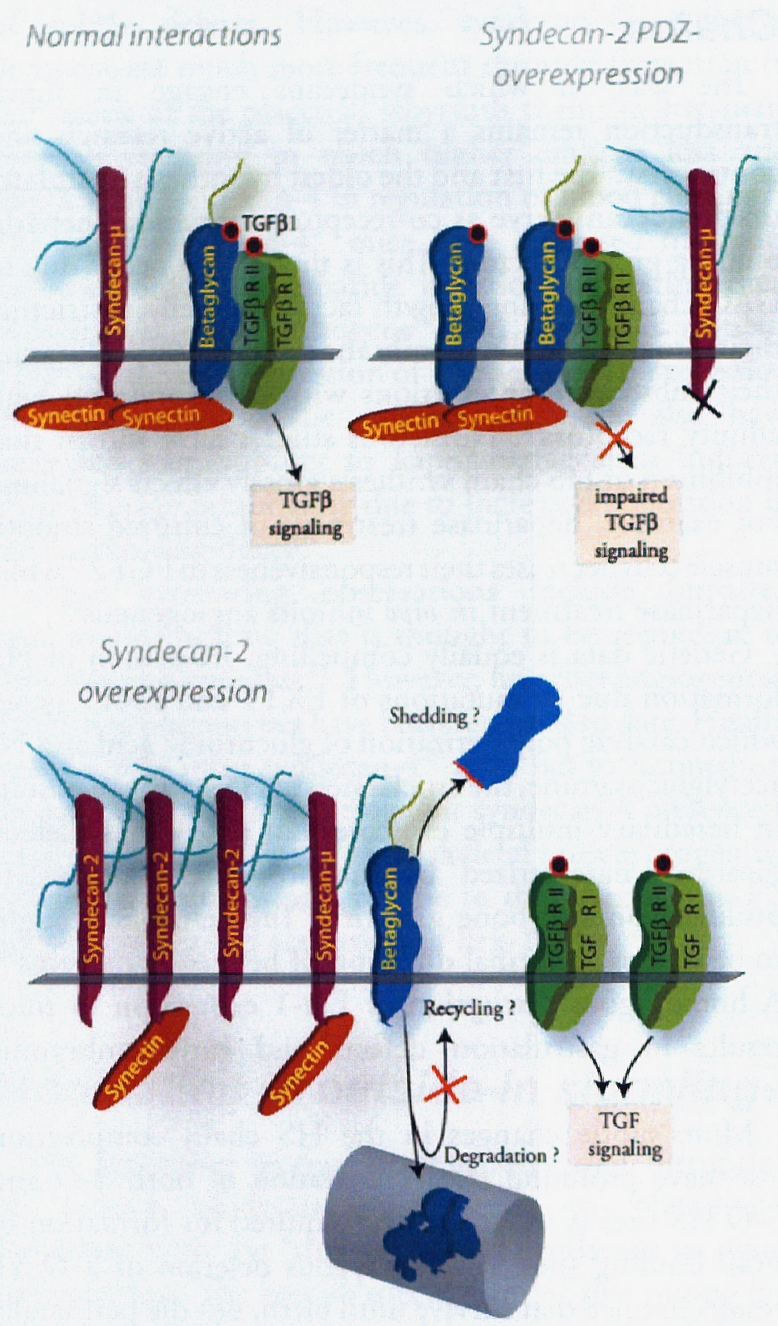

Figure 3. Modulation of TGF-b signaling by syndecan-2. Syndecan- 2 effects on TGF- $\beta$ signaling are shown for normal cells and cells overexpressing syndecan-2 constructs.

(Upper left) Under normal circumstances, TGF- $\beta$ binds to betaglycan which then transfers it to the TGF $\beta R 1 / R 2$ complex (Upper right) Expression of Syndecan-2 PDZ- mutant results in increase of betaglycan on the cell surface and impaired signaling. (Lower) In contrast, overexpression of full length syndecan-2 results in plasma membrane accumulation of TGF $\beta R$ I and II, and reduced levels of betaglycan (TGFBRIII). 


\section{Syndecan-3 and growth factors signaling}

Syndecan-3 plays an important role in regulation of skeletal muscle differentiation and development. Its levels are transiently elevated in the developing limb bud but are absent in adult skeletal muscle. Skeletal muscle myoblasts are held in an undifferentiated state until they receive signals to further differentiate. The maintenance of these cells in their undifferentiated state has been shown to be controlled by specific growth factors including FGF2, hepatocyte growth factor/scatter factor and TGF- $\beta^{89}$. Syndecan -3 inhibition results in expression of myogenin, a master transcription factor for muscle differentiation, and in accelerated skeletal muscle differentiation and myoblast fusion ${ }^{90}$.

In the model of skeletal muscle regeneration induced by barium chloride injection, syndecan- 3 showed the earliest and largest increase in satellite cells ${ }^{91}$. Myoblast grafting of $\mathrm{C}_{2} \mathrm{C}_{12}$ cells transfected with antisense syndecan-3 resulted in cells with a normal proliferation rate but defective in fusion and formation of skeletal muscle fibers. Further, examination of syndecan-3 null mice demonstrates mislocalization of MyoD (a myocyte differentiation transcription factor) and an aberrant differentiation of skeletal muscle ${ }^{50}$.

Syndecan-3 also appears to be involved in regulation of hedgehog signaling. Hedgehog ( $\mathrm{Hh}$ ) is a family of secreted signaling proteins that play an important role in embryogenesis and differentiation. One of the mammalian family of hedgehog $(\mathrm{Hh})$ members, indian $\mathrm{Hh}$ (iHh), is produced by prehypertrophic chondrocytes and regulates chondrocyte proliferation. Proper spatial and temporal regulation of $\mathrm{iHh}$ is regulated by syndecan-3 $3^{92}$.

\section{Syndecan-4, FGF signaling and the extracellular matrix}

Syndecan -4 has become the most extensively studied member of the syndecan family. The proteoglycan has a number of activities including modulation of FGF2 signaling, regulation of cell migration via cross-talk with $\beta 1$ integrin and control of adhesion via cytoskeletal modifications. All these various events are achieved via actions of a 33 amino acid cytoplasmic tail, one of the most overworked small proteins among the signaling giants.

\section{FGF signaling and endocytosis}

In addition to being able to bind FGF2 to HS chains and to present it to FGF tyrosine kinase receptors, syndecan-4 directly initiates a number of intracellular signaling events. The most direct demonstration of syndecan-4 signaling came from studies of syndecan4/glypican chimeras in endothelial cells. Expression of a full-length syndecan-4 (S4), syndecan-1 (S1), glypican-1 (G1) or of chimera constructs consisting of the ectoplasmic domain of glypican- 1 linked to the transmembrane/cytoplasmic domain of syndecan-4 (G1S4c) or of the ectoplasmic domain of syndecan-4 linked to the glypican-1 glycosylphosphatidylinositol (GPI) anchor (S4-GPI) significantly increased cell-associated HS mass and the number of low affinity FGF2-binding sites. However, only cells expressing S4 and G1-S4c constructs but not G1, S1, S4-GPI cells demonstrated enhanced responsiveness to FGF2. Thus, the presence of syndecan- 4 cytoplasmic domain and not simply an increase in the cell surface HS mass with a corresponding increase in the number of the low affinity FGF2 binding sites is required for signaling. However, removal of the syndecan- 4 HS chains also blocked enhanced FGF2 responsiveness demonstrating that both syndecan-4 HS chains and the syndecan- 4 cytoplasmic domain are required for FGF2 signaling ${ }^{93}$. Syndecan-3 cannot replace syndecan- 4 to promote FGF2 and HGF induced cell migration ${ }^{50}$.

Additional evidence of direct syndecan-4 signaling ability comes from studies in vascular smooth muscle cells expressing dominant-negative fibroblast growth factor receptor (FGF-R). FGF2 was able to transiently stimulate Erk 1/2 activation and induce cell migration, activities that were inhibited by removal of HS chains ${ }^{94}$. It should be noted that FGF2-induced Erk activation in the absence of functional FGF-R1 is transient and does not lead to cell proliferation.

The final piece of evidence demonstrating syndecan- 4 modulation of FGF2 signaling comes from studies that explored the effect of dominant-negative syndecan4 construct expression on endothelial cell responses to FGF2 and other growth factors. Introduction of syndecan -4 constructs with the mutated $\mathrm{PDZ}$ or $\mathrm{PIP}_{2}$ binding regions that, respectively, eliminated syndecan -4 ability to bind PDZ proteins or $\mathrm{PIP}_{2}$, inhibited FGF2 but not serum induced endothelial cell growth, migration, and the ability to form vascular structures on Matrigel ${ }^{27}$.

While it is clear that syndecan- 4 can modulate FGF2 signaling, the precise mechanism of this modulation is uncertain. A sustained activation of FGF2 signaling 
requires internalization and perhaps nuclear transport of the ligand". Syndecan-4 is directly involved in FGF2 endocytosis that proceeds in a clathrin- and dynaminindependent fashion and requires syndecan-4-dependent activation of $\operatorname{Racl}^{96}$. The sensitivity of this process to amiloride as well as co-localization of internalized FGF2 with dextran suggests that FGF2 uptake proceeds via macropinocytosis ${ }^{96}$. An interesting feature of this process is the fact that FGF2 uptake proceeds from lipid rafts, a specialized plasma membrane domain thought to be involved in signaling.

\section{Endocytosis, lipid rafts and caveolae}

Plasma membrane location of syndecan- 4 and its participation in FGF2 endocytosis raises the issue of its relation to lipid rafts, plasma membrane domains that provide fluid platforms to segregate membrane components and dynamically compartmentalize membranes (reviewed in ${ }^{77}$ ). Those phospholipid- and cholesterol-rich domains contain specific sets of proteins that include GPI-anchored proteins, doubly acetylated proteins (Src family tyrosine kinases), $G_{\alpha}$ subunit of heterotrimeric $G$ proteins and palmitylated proteins including endothelial nitric oxide synthase (eNOS) ${ }^{98.99}$.

While in unstimulated cellssyndecan- 4 is predominately present in the non-raft compartments, clustering with FGF2 or anti-syndecan-4 antibody induces its shift to lipid rafts ${ }^{100}$. This shift is necessary for the initiation of FGF2 endocytosis since its blockade by cholesterol depletion from the plasma cell membrane completely blocks FGF2 uptake ${ }^{96}$. Similarly, low density lipoprotein (LDL) causes clustering and clathrin independent uptake of syndecan-1,-2 and $-4^{101}$. In the model where syndecan-1 was used, LDL clustering also induced a shift of syndecan into the lipid rafts ${ }^{102}$.

Caveolae are subset of lipid rafts. They are flaskshaped invaginations of the plasma membrane ${ }^{103}$ which play a role in regulation of certain endocytic pathways and regulation of enzymes such as eNOS. A variety of protein and lipid signaling molecules are concentrated in caveolae. These include PKC, RhoGTPases and nonreceptor tyrosine kinases such as c-Src, Yes, Fyn, PI 3kinase, and phosphatidylinositol kinases among others ${ }^{103-}$ 105. Caveolins are the principal building blocks of caveolae and are usually accepted as its marker. Caveolin-1 oligomeric complex creates a stable membrane structure that transiently interacts with plasma membrane and endosomes. ${ }^{106}$.

Upon initiation of cell migration, pools of syndecans-1 and -4 and caveolin- 1 are direcred into the same retracting region of the moving cell ${ }^{107-109}$. Caveolin's property of inhibiting kinase activity of a variety of proteins involved in leading edge formation was speculated to play a key role in cell migration ${ }^{110}$. In contrast to the deactivating role of caveolin, syndecan- 4 is needed for activation of several kinases including focal adhesion kinase (FAK), which results in increased turnover of focal adhesions ${ }^{111-113}$. Silencing of caveolin-1 gene expression or introduction of a dominant negative mutant of syndecan-4́ leads to slow migration and impaired tube formation of endothelial cells on Matrigel ${ }^{27,107}$. Syndecan-4 and caveolin-1 knockout mice demonstrate reduced postnatal angiogenesis that may be related to the impairment of endothelial cell migration ${ }^{61,110}$.

While syndecan- 4 does not co-localize with caveolin-1 at the cell surface, syndecan-4- and caveolin-1-containing vesicles frequently move in tandem, presumably along microtubules ${ }^{100}$. Remarkably, internalization of caveolae depends on Src and PKC $\alpha$ activation ${ }^{114}$. The ability of syndecan- 4 to activate PKC $\alpha$ is well established and will be discussed in detail below. Similar to syndecan-3, it can also activate $\mathrm{Src}^{17}$. Thus, syndecan- 4 may be responsible for modulation of caveolae pinching from the plasma membrane in response to heparin binding growth factors ${ }^{15,116}$.

The association of syndecan- 4 with fast moving caveolin1-positive vesicles could also be used for a fast delivery of syndecan-4 pinosomal cargo to intracellular destinations. This process might be needed for proper distribution of macropinosome associated small GTPases leading to migratory polarization of the cell ${ }^{117,118}$. This interaction could be also involved in extracellular matrix turnover. Downregulation of caveolin-1 results in inhibition of fibronectin internalization and degradation ${ }^{119}$, suggesting the participation of fibronectin receptors such as integrins or syndecans in caveolae dependent uptake of fibronectin.

\section{Activation of $P K C \alpha$}

Another feature of syndecan-4 signaling is activation of PKC $\alpha$ in the absence of $\mathrm{Ca}^{2+}$. This unique ability of syndecan- 4 to activate a calcium-dependent PKC was first shown by $\mathrm{Oh}$ and colleagues to require core protein multimerization and the presence of $\mathrm{PIP}_{2}{ }^{15,120}$. Syndecan4 oligomerization in the presence of $\mathrm{PIP}_{2}$ depends on the phosphorylation status of the $\mathrm{Ser}^{183}$ site in its cytoplasmic domain ${ }^{27}$. Phosphorylation of this site markedly reduces its affinity for $\mathrm{PIP}_{2}^{26}$ and prevents $\mathrm{PKC} \alpha$ activation in vitro and in vivo ${ }^{26,121}$. Interestingly, the $\operatorname{Ser}^{183}$ site is 


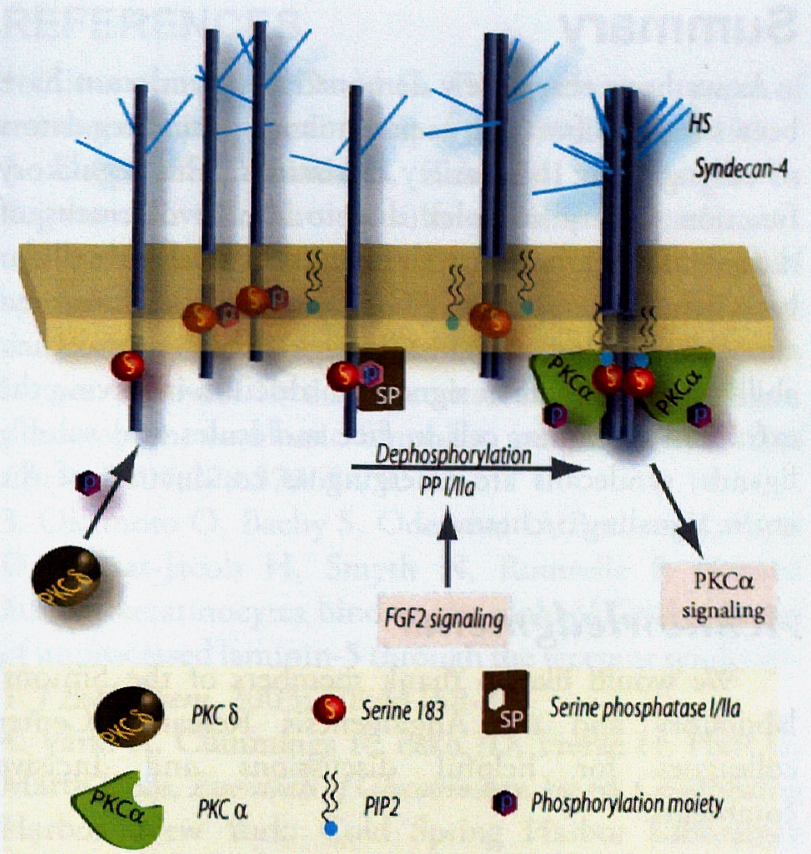

Figure 4. Syndecan-4-dependent modulation of PKC activity. Under normal circumstances Ser 183 site is phosphorylated by PKC $\alpha$. Exposure to FGF2 results in dephosphorylation of the site that in turn allows syndecan-4 oligomerization, binding of PIP2 and activation of PKC $\alpha$. Any signal that would activate PKCa would impair syndecan-4 dependent PKC $\alpha$ activation.

phosphorylated by $\mathrm{PKC} \delta^{28}$. This sets up a system that allows one PKC to regulate activity of another (Fig 4). The Ser dephosphorylation is carried out by as yet undefined Type I/Ila Serine phospharase ${ }^{121}$.

The molecular details of syndecan-4-dependent PKC $\alpha$ activation have not been established. The results of yeast two hybrid screening demonstrated that while a full-length $\mathrm{PKC} \alpha$ weakly binds the variable domain of syndecan- $4(4 \mathrm{~V})$, the $P K C \alpha$ constructs that lack the pseudosubstrate region or that encode only the whole catalytic domain interacted more strongly ${ }^{15,122}$. A mutation of $\mathrm{Tyr}^{192}$ in the syndecan-4 cytoplasmic domain abolished this interaction ${ }^{122}$. Interestingly, the corresponding binding site in the catalytic domain of PKC $\alpha$ (amino acid sequence 513-672) encompasses the regulatory autophosphorylation sites implicated in control of PKC activation and stability ${ }^{122}$. On the other hand, in vitro surface plasmon resonance studies suggested that binding affinity of a full length PKC $\alpha$ to the syndecan- 4 cytoplasmic domain is very low in the absence of $\operatorname{PIP}_{2}{ }^{26}$.

While the precise role of syndecan-4-dependent PKC $\alpha$ activation has not been defined, co-localization of the two proteins in focal adhesions ${ }^{120}$ suggests a role in cell adhesion, spreading and stress fiber formation. Studies in cultured fibroblasts have shown that overexpression of syndecan-4, but not a mutant lacking its cytoplasmic domain, specifically increases the level of endogenous PKC $\alpha$ and enhances the translocation of PKC $\alpha$ in the plasma cell membrane in general and in the membrane raft fractions in particular and increases the activity of membrane $\mathrm{PKC} \alpha^{123}$.

\section{Cell adhesion and the cytoskeleton}

The involvement of members of the syndecan family in regulation of cell adhesion suggests that these proteins likely modulate cytoskeletal rearrangements. Indeed, fibronectin binds to syndecan-4 HS chains and this interaction plays an important role in regulation of cell adhesion and spreading ${ }^{124}$. Fibroblasts use both integrin receptors and syndecan- 4 to induce Rho-dependent spreading in fibronectin ${ }^{125,126}$. Overexpression of syndecan-4 results in the flattening of CHO-K1 cells, promotion of focal adhesion formation and a decrease in cell migration ${ }^{127}$. Syndecan-4 null fibroblasts plated on fibronectin exhibit enhanced lamellipodia formation and increased level of Rac1 ${ }^{128}$ and low Rho"11 activities compared with wild type cells. Expression of syndecan- 4 in these knockout cells downregulates Rac1 activity ${ }^{128}$. In endothelial cells also plated on fibronectin, clustering of syndecan- 4 construct by antibody results in upregulation of Racl activity ${ }^{96}$. Those seemingly contrary results might be due to the differences in localization changes followed by binding to matrix versus soluble ligand. In this way, growth factors might modulate cell-matrix interactions by removal of the syndecan component via endocytosis ${ }^{96}$.

In vascular smooth muscle cells, shear stress causes syndecan-4 dissociation from the focal adhesions ${ }^{39}$. Overexpression of syndecan- 4 blocks this dissociation and also results in reduced mechanical stress-induced cell migration. This observation suggests that syndecan4 might be involved in regulation of smooth muscle migration during arteriogenesis.

Another role of syndecan- 4 involves regulation of fibronectin signaling and matrix contraction together with tenascin-C. Tenascin-C is an extracellular matrix protein involved in regulation of cellular response to fibronectin by preventing cell spreading (reviewed in $^{129}$ ). Syndecan-4 knockout fibroblasts, while spreading normally on a $2 \mathrm{D}$ matrix, fail to spread in a 3D fibronectin matrix, do not activate RhoA and, 
consequently, do not form focal adhesions and stress fibers. Anti-syndecan-4 anribody creatment of wild type fibroblasts similarly prevents spreading on fibronectin, decreases RhoA and activates focal adhesion kinase. Stimulation of RhoA by lysophosphatidic acid in syndecan $-4^{-1}$ cells rescues syndecan functions by activating RhoA and inducting cell spreading and matrix contraction. Addition of tenascin-C blocks spreading of control but not syndecan-4 $4^{-1}$ fibroblasts on a $2 \mathrm{D}$ fibronectin matrix while syndecan -4 overexpression overcomes this tenascin-C effect ${ }^{130}$.

Activated B-lymphocyres, when seeded on syndecan 4 antibodies, exhibit dramatic morphological changes ${ }^{i 31}$. The most profound being filopodial extensions, implying the possibility of CDC42 activation. Overexpression of a truncated form of syndecan-4 lacking an intracellular domain demonstrated that the extracellular domain is sufficient to generate a response, indicating the need for a transmembrane partner to transmit signal. One such potential partner is the chemokine receptor 4 (CXCR4). Syndecan-4, but neither syndecan-1 nor syndecan-2, co-immunoprecipitate with CXCR $4^{\| 32}$. This syndecan4/CXCR4 complex is likely a functional unit involved in chemokine stromal cell-derived factor-1 (SDF-1) binding that may play a role in SDF-1-dependent stem cells recruitment.

Syndecan-2 and -3 overexpression also induce filopodia formation in COS-1 and CHO K1 cells ${ }^{133,134}$. In the case of syndecan-2, this process is CDC42-dependent ${ }^{133.134}$. The deletion of V or $\mathrm{C} 2$ domains but not entire cytoplasmic part of syndecan-3 results in more filopodia formarion while extensive membrane blebbing is observed in cell expressing a $\mathrm{C} 2$-truncated mutant ${ }^{134}$. The blebs are distribured uniformly over the cell surface rather then next to the leading edge suggesting improper targeting or activation of Racl resulted to bleb formations away from cell edges as a possible mechanism.

Members of the ezrin-radixin-moesin (ERM) family have $\mathrm{NH}_{2}$ - and $\mathrm{COOH}$-terminal domains that associate with che plasma membrane and the actin cytoskeleton, respectively. Following overexpression of a constitutively active form of RhoA, association of syndecan- 2 with actin cytoskeleton through ezrin binding was observed in COS-1 cells ${ }^{16,18}$. Thus, ezrin provides RhoGTPases a regulated link between syndecan-2 and actin. The ezrin binding motif is identical between syndecan-2 and -4 implying the possibility of syndecan-4/ezrin interactions (Fig1) ${ }^{18}$. Such regulation of cytoskeleton by Rho GTPases promises to be one of the most important "tuning" functions of syndecans.

\section{Summary}

As we hope this review demonstrates, syndecans have been shown to function as porent and specific regularors of cell signaling in a variety of settings. This regulatory function is very complex due to the involvement of different family members, differences in level and cellular location of expression, GAG chains modifications, and extracellular domain shedding. Overall, given their ability to participate in signal transduction involving the extracellular matrix, cell surface molecules and soluble ligands; syndecans are emerging as conductors of the entire signaling orchestra.

\section{Acknowledgments}

We would like to thank members of the Simons' laboratory and the Angiogenesis Research Center colleagues for helpful discussions and incisive comments.

Supported in part by NIH grants HL62289 and HL63609 (MS) 


\section{REFERENCES}

1. Zimmermann P, David G. The syndecans, tuners of transmembrane signaling. Faseb /. 1999;13:S91-S100.

2. Deepa SS, Yamada S, Zako M, Goldberger $O$, Sugahara $\mathbb{K}$. Chondroirin sulfare chains on syndecan- $\mathbb{1}$ and syndecan-4 from normal murine mammary gland epithelial cells are structurally and functionally distinct and cooperare with heparan sulfate chains to bind growth factors. A novel function to control binding of midkine, pleiotrophin, and basic fibroblast growth factor. J Biol Chem. 2004;279:37368-76.

3. Okamoto O, Bachy S, Odenthal U, Bemaud J, Rigal D, Lortat-Jacob $H$, Smyth N, Rousselle P. Normal human keratinocytes bind to the alpha3LG4/5 domain of unprocessed laminin- 5 through the receptor syndecan1.J Biol Chem. 2003;278:44168-77.

4. Varki A, Cummings $R$, Esko JD, Freeze H, Hart $G_{\text {, }}$ Marth J, eds. Essentials of Glycobiology. 1st ed. Cold Spring Harbor, New York: Cold Spring Harbor Laboratory Press; 1999.

5. Esko JD, Selleck SB. Order out of chaos: assembly of ligand binding sites in heparan sulfate. Annu Rev Biochem. 2002;71:435-71.

6. Wilson VA, Gallagher JT, Merry CL. Heparan sulfate 2-O-sulfotransferase ( $\mathrm{Hs} 2 \mathrm{st}$ ) and mouse development. Glycoconj J. 2002;19:347-54.

7. Li J, Shworak NW, Simons M. Increased responsiveness of hypoxic endothelial cells to FGF2 is mediated by HIF-1alpha-dependent regulation of enzymes involved in synthesis of heparan sulfate FGF2-binding sites. / Cell Sci. 2002;115:1951-1959.

8. Morimoto-Tomita $M$, Uchimura $K$, Werb $Z$, Hemmerich S, Rosen SD. Cloning and characterization of two extracellular heparin-degrading endosulfatases in mice and humans. J Biol Chem. 2002;277:49175-85.

9. Ohto $T$, Uchida $H$, Yamazaki H, Keino-Masu $K$, Matsui A, Masu M. Identification of a novel nonlysosomal sulphatase expressed in the floor plate, choroid plexus and cartilage. Genes Cells. 2002;7:173-85.

10. Lai J, Chien J, Staub J, Avula R, Greene EL, Matthews TA, Smith DI, Kaufmann SH, Roberts LR, Shridhar V. Loss of HSulf-1 up-regulates heparin-binding growth factor signaling in cancer. J Biol Chem. 2003;278:2310717.

11. Ai $X$, Do AT, Lozynska $O$, Kusche-Gullberg $M$, Lindahl U, Emerson CP, Jr. QSulf1 remodels the 6-O sulfation states of cell surface heparan sulfate proteoglycans to promote Wnt signaling. I Cell Biol. 2003; 162:341-51.

12. Lai JP, Chien J, Strome SE, Staub J, Montoya DP,
Greene EL Smith DI, Roberts LR, Shridhar V. HSulf1 modulates HGF-mediated tumor cell invasion and signaling in head and neck squamous carcinoma. Oncogene. 2004:23:1439-47.

13. Shworak NW, Rosenberg RD. Heparan sulfate proteoglycans. In: Ware JA. Simons M, eds. Angrogenes is and Cardiovascular Diseane. New York: Oxford University Press: 1999:60-78.

14. McFall AJ, Rapraeger AC. Identification of an adhesion site within the syndecan-4 extracellutar protein domain. J Biol Chem. 1997;272:12901-12904.

15. Oh ES, Woods A, Couchman JR. Multimerization of the cytoplasmic domain of syndecan-4 is required for its ability to activate protein kinase C. / Bül Chem. 1997;272:11805-11811.

16. Granes F, Urena I, Rocamora N, Vilaro S. Exrin links syndecan-2 to the cytoskeleron./ Cell Sci. 2000;113:12671276.

17. Kinnunen $T$, Kaksonen $M$, Saarimen J, Kalkkinen N, Peng HB, Rauvala H. Cortactin-Src kinase signaling parhway is involved in $\mathrm{N}$-syndecan- dependent neurite outgrowth. / Biol Chem. 1998;273:10702-8.

18. Granes F, Berndt C, Roy C, Mangeat P, Reina $M_{3}$ Vilaro $S$. Identification of a novel Ezrin-binding site in syndecan-2 cytoplasmic domain. FEBS Lett. 2003;547:212-6.

19. Gao Y, Li M, Chen W, Simons M. Synectin, syndecan-4 cytoplasmic domain binding PDZ protein, inhibits cell migration. J Cell Physiol. 2000;184:373-9.

20. Groorjans JJ, Zimmermann P, Reekmans G, Smers A. Degeest G, Durr J, David G. Syntenin, a PDZ protein that binds syndecan cytoplasmic domains. Proc Natl Acad Sci US A. 1997;94:13683-8.

21. Cohen AR, Wood DF, Marfatia SM, Walther $Z$, Chishti AH, Anderson JM. Human CASK/LIN-2 Binds Syndecan-2 and Protein 4.1 and Localizes to the Basolateral Membrane of Epithelial Cells. / Cell Biol. 1998;142:129-38.

22. Hsueh YP, Yang FC, Kharazia V, Naisbitt $S$, Cohen $A R$, Weinberg RJ, Sheng M. Direct interaction of CASK/ LIN-2 and syndecan heparan sulfate proteoglycan and their overlapping distribution in neuronal synapses. $J$ Cell Biol. 1998;142:139-51.

23. Erhell IM, Hagihara K, Miura Y, Irie F, Yamaguchi Y. Synbindin, A novel syndecan-2-binding protein in neuronal dendritic spines. J Cell Biol. 2000;151:53-68. 24. Shin J, Lee W, Lee D, Koo BK, Han I, Lim Y, Woods A, Couchman JR, Oh ES. Solution structure of the dimeric cyroplasmic domain of syndecan-4. Biachemistry. $2001 ; 40: 8471-8$. 
25. Horowizz A. Simons M. Phosphorylarion of the Cytoplasmic Tail of Syndecan-4 Regulates Activation of Protein Kinase Calpha. I Biol Chem. 1998;273:2554825551.

26. Horowitz A, Murakami M, Gao $Y$, Simons $M$. Phosplatidylinositol-4,5-bisphosphate Mediates the Interaction of Syndecan-4 with Protein Kinase C. Biocliemistry. 1999;38:15871-15877.

27. Horowitz A, Tkachenko E, Simons M. Fibroblast growth factor-specific modulation of cellular response by syndecan-4. J Cell Biol. 2002;157:715-25.

28. Murakami M, Horowitz A, Tang S, Ware JA, Simons M. PKC-delta regulates PKC-alpha activity In a syndecan4 dependent manner. I Biol Cliem. 2002;277:2036720371.

29. Oh ES, Woods A, Lim ST, Theibert AW, Couchman JR. Syndecan-4 proteoglycan cytoplasmic domain and phosphatidylinositol 4,5- bisphosphate coordinately regulate protein kinase $\mathrm{C}$ activity. I Biol Chem. 1998:273: 10624-9.

30. Greene DK, Tumova S, Couchman JR, Woods A. Syndecan-4. Associates with alpha-Actinin. J. Biol. Chem. 2003;278:7617-7623.

31. Baciu PC, Saoncella S, Lee SH, Denhez F, Leurhardt D. Goetinck PF. Syndesmos, a protein that interacts with the cytoplasmic domain of syndecan-4, mediates cell spreading and actin cytoskeletal organization. $J$ Cell Sci. $2000 ; 113 \operatorname{Pr} 2: 315-24$.

32. Denhez F, Wilerox-Adelman SA, Baciu PC, Saoncella S, Lee $S_{1}$ French B, Neveu W, Goerinck PF. Syndesmos; a syndecan-4 cytoplasmic domain interactor, binds to the focal adhesion adaptor proteins paxillin and Hic-5.J Biol Chem. 2002.

33. Lee D, Oh ES, Woods A, Couchman JR, Lee W. Solution structure of a syndecan-4 cytoplasmic domain and its interaction with phosphatidylinositol 4,5bisphosphate. / Biol Chem. 1998;273:13022-9.

34. Bernfield $M$, Kokenyesi $R$, Kato $M$, Hinkes MT, Spring J, Gallo RL, Lose EJ. Biology of the syndecans: at family of transmembrane heparan sulfate proteoglycans. Annu. Rew Cell Biol. 1992;8:365-393.

35. Couchman JR. Syndecans: proteoglycan regulators of cell-surface microdomains? Nat Rev Mol Cell Biol. 2003;4:926-37.

36. Halden Y, Rek A, Atzenhofer W, Szilak L, Wabnig A, Kungl AJ. lnterleukin-8 binds to syndecan-2 on human endorhelial cells. Biochem J. 2004:377:533-8.

37. Dobra $K$, Nurminen $M$, Hjerpe A. Growth factors regulate the expression profile of their syndecan coreceptors and the differentiation of mesothelioma cells.
Anticancer Res. 2003;23:2435-44.

38. Cizmeci-Smith $G$, Langan E, Youkey J, Showalter LJ, Carey DJ. Syndecan-4 is a primary-response gene induced by basic fibroblast growth factor and arterial injury in vascular smooth muscle cells. Arterioscler Thromb Vasc Biol. 1997;17:172-80.

39. Li L, Chaikof EL. Mechanical stress regulates syndecan-4 expression and redistribution in vascular smooth muscle cells. Arterioscler Thromb Vast Biol. $2002: 22: 61-8$.

40. Geary RL, Koyama N, Wang TW, Vergel S, Clowes AW. Failure of heparin to inhibit intimal hyperplasia in injured baboon arteries. The role of heparin-sensitive and-insensitive pathways in the stimulation of smooth muscle cell migration and proliferation. Circulation. 1995;91:2972-81.

41. Li J, Brown $\mathbb{L F}$, Laham RJ, Volk R, Simons $M$. Macrophage-dependent regulation of syndecan gene expression. Circ Res. 1997;81:785-96.

42. Gallo R, Kim C, Kokenyesi R, Adzick NS, Bernfield M. Syndecans-1 and -4 are induced during wound repair of neonatal but nor fetal skin. I Invest Dermatol. 1996;107:676-83.

43. Oksala O, Salo T, Tammi R, Hakkinen L, Jalkanen $M$, Inki P, Larjaya $H$. Expression of proteoglycans and hyaluronan during wound healing. I Histochem Cytochem. 1995:43:125-35.

44. Gallo RL, Ono M, Povsic T, Page C, Eriksson E, Klagsburn $M$, Bernfield $M$. Syndecans, cell surface heparan sulfate proteoglycans, are induced by a prolinerich ancimicrobial peptide from wounds. Proc Natl Acd Sci USA. 1994;91:11035-11039.

45. Li J, Post M, Volk R, Gao Y, Li M, Metais C, Sato K, Tsai J, Aird W, Rosenberg RD, Hampton TG, Sellke F, Carmeliet P, Simons M. PR39, a peptide regulator of angiogenesis. Nat Med. 2000;6:49-55.

46. Weiner $\mathrm{OH}$, Zoremba $\mathrm{M}$, Gressner AM. Gene expression of syndecans and betaglycan in isolated rat liver cells. Cell Tissue Res. 1996;285:11-6.

47. Carey DJ, Conner K, Asundi VK, O'Mahony DJ, Stahl RC, Showalter L, Cizmeci-Smith G, Hartman J, Rothblum LI. cDNA cloning, genomic organization, and in vivo expression of rat $\mathrm{N}$-syndecan. $J$ Biol Chem. 1997;272:2873-9.

48. Song HK, Lee SH, Goetinck PF. FGF-2 signaling is sufficient to induce dermal condensations during feather development. Dev Dyn. 2004;231:741-9.

49. Gould SE, Upholt WB, Kosher RA. Characterization of chicken syndecan-3 as a heparan sulfate proteoglycan and its expression during embryogenesis. Dev Biol. 
$1995 ; 168: 438-51$.

50. Cornelison DD, Wilcox-Adelman SA, Goetinck PE, Rauvala H, Rapraeger AC, Olwin BB. Essential and separable roles for Syndecan-3 and Syndecan- 4 in skeletal muscle development and regeneration. Genes Dev. 2004;18:2231-6.

51. Stepp MA, Gibson HE, Gala PH, Iglesia DD, Pajoohesh-Ganji A, Pal-Ghosh S, Brown $M$, Aquino C, Schwartz AM, Goldberger O, Hinkes MT, Bernfield M. Defects in keratinocyte activation during wound healing in the syndecan-1-deficient mouse. I Cell Sci. 2002; 115:4517-31.

52. Reizes O, Benoit SC, Strader AD, Clegg DJ, Akunuru $S$, Seeley RJ. Syndecan-3 modulates food intake by interacting with the melanocortin/AgRP pathway. Ann NY Acad Sci. 2003;994:66-73.

53. Alexander CM, Reichsman F, Hinkes MT, Lincecum J, Becker KA, Cumberledge S, Bernfield M. Syndecan-1 is required for Wnt-1-induced mammary tumorigenesis in mice. Nat Genet. 2000;25:329-32.

54. Chen E, Hermanson S, Ekker SC. Syndecan-2 is essential for angiogenic sprouting during zebrafish development. Blood. 2004;103:1710-9.

55. Kramer KL, Barnette JE, Yost HJ. PKCgamma regulates syndecan-2 inside-out signaling during xenopus left-right development. Cell. 2002;111:981-90.

56. Reizes $\mathrm{O}$, Lincecum J, Wang $Z$, Goldberger $\mathrm{O}$, Huang L, Kaksonen M, Ahima R, Hinkes MT, Barsh GS, Rauvala $H$, Bernfield $M$. Transgenic expression of syndecan-1 uncovers a physiological control of feeding behavior by syndecan-3. Cell. 2001;106:105-16.

57. Ishiguro K, Kojima T, Muramatsu T. Syndecan-4 as a molecule involved in defense mechanisms. Glycoconj $/$. 2002;19:315-8.

58. Ishiguro $\mathrm{K}$, Kadomatsu $\mathrm{K}$, Kojima $\mathrm{T}$, Muramatsu $\mathrm{H}$, Nakamura $\mathrm{E}$, Ito $\mathrm{M}$, Nagasaka $\mathrm{T}$, Kobayashi $\mathrm{H}$, Kusugami $\mathrm{K}$, Saito $\mathrm{H}$, Muramatsu T. Syndecan-4 deficiency impairs the fetal vessels in the placental labyrinth. Dev Dyn. $2000 ; 219: 539-44$.

59. Ishiguro $K$, Kadomatsu K, Kojima $T$, Muramarsu $H$, Iwase $M$, Yoshikai $Y$, Yanada $M$, Yamamoto $K$, Matsushita T, Nishimura $M$, Kusugami $K$, Saito $H$, Muramatsu T. Syndecan-4 deficiency leads to high mortality of lipopolysaccharide-injected mice. I Biol Chem. 2001;276:47483-8.

60. Ishiguro K, Kadomatsu K, Kojima T, Muramarsu

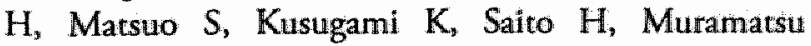
T. Syndecan-4 deficiency increases susceptibility to kappa-carrageenan- induced renal damage. Lab Invest. 2001;81:509-16.
61. Echtemeyer $\mathbb{F}$ Streit $M$, Wilcox-Adelman $S$, Saoncella S, Denhez F, Detmar M, Goetinck P. Delayed wound repair and impaired anglogenesis in mice lacking syndecan-4.J Clin Invest. 2001;107:R9-R14.

62. Nugent MA, Edelman ER. Kinetics of basic Gibroblast growth factor binding to its receptor and heparan sulfate proteoglycan: a mechanism for cooperactivity. Bucbemistry. 1992;31:8876-83.

63. Chu CL, Buczek-Thomas JA, Nugent MA. Heparan sulphate proteoglycans modulate fibroblast growth factor2 binding through a lipid raft-mediated mechanism. Biochem J. 2004;379:331-41.

64. Sasisekharan R, Moses MA, Nugent MA, Cooney $C L$, Langer $\mathbb{R}$. Heparinase inthibirs neovascularization. Proc Natl Acad Sci U S A. 1994;91:1524-8.

65. Duncan G, McCormick $C$, Tufaro $\mathbb{E}$. The link berween heparan sulfare and heredicary bone disease: finding a function for the EXT Family of putative tumor suppressor proteins. J Clin Imvest. 2001;108:51 1-6.

66. Bellaiche Y, The I, Perrimon N. Tour-velu is a Drosophila homologue of the putative tumour suppressor EXT-1 and is needed for Hh diffusion. Nature. 1998;394:85-8.

67. Lin X, Wei G, Shi Z, Dryer L, Esko JD, Wells DE, Matzuk MM. Disruption of gastrulation and heparan sulfate biosynthesis in EXT1-deficient mice. Dev Biol. 2000;224:299-311.

68. Kamimura K, Fujise M, Villa F, Izumi S, Habuchi H, Kimata $\mathbb{K}$, Nakato $\mathbb{H}$. Drosophila heparan sulfate 6-O sullfotransferase (dHS6ST) gene. Structure, expression, and function in the formation of the tracheal system. I Biol Chem. 2001;276:17014-21.

69. Lee JS, Chien CB. When sugars guide axons: insights from heparan sulphate proteoglycan mutants. Nat Rew Genet. 2004:5:923-35.

70. Couchman JR, Chen L, Woods A. Syndecans and cell adhesion. Int Rev Cytol. 2001;207:113-50.

71. Mali $M$, Elenius $K$, Miettinen $H M$, Jalkanen $M$. Inthibition of basic fibroblast growth factor induced growth promotion by overexpression of syndecan-1. $J$ Bial Chem. 1993;268:24215-22.

72. Elenius V, Gotre M, Reizes O, Elenius K, Bernfield M. Inhibition by the soluble syndecan-1 ectodomains delays wound repair in mice overexpressing syndecan-1. J Biol Chem. 2004:279:41928-35.

73. Kato $M$, Wang $H$, Kainulainen V, Fitzgerald ML, Ledbetter S, Ornitz DM, Bernfield M. Physiological degradation converts the soluble syndecan-1 ecrodomain from an inhibitor to a potent activator of FGF-2. Nat Med. 1998;4:691-7. 
74. Langford JK, Yang $Y_{*}$ Kieber-Emmons $T$, Sanderson RD. Identification of an invasion regulatory domain within the core protein of syndecan-1. J. Biol. Chem. 2004:M412451200.

75. Harada K, Masuda S, Hirano M, Nakanuma Y. Reduced expression of syndecan-1 correlates with histologic dedifferentiation, lymph node metastasis, and poor prognosis in intrathepatic cholangiocarcinoma. Hum Pathol. 2003;34:857-63.

76. Reiland J, Sanderson RD, Waguespack M, Barker $S A$, Long R, Carson DD, Marchetti D. Heparanase degrades syndecan-1 and perlecan heparan sulfate: functional implications for tumor cell invasion. / Biol Chem. 2004;279:8047-55.

77. Beauvais DM, Burbach BJ, Rapraeger AC. The syndecan-1 ectodomain regulates alphavbeta 3 integrin acrivity in human mammary carcinoma cells. / Cell Biol. 2004; 167:171-81.

78. Gotte M. Syndecans in inflammation. Faseb f. 2003;17:575-91.

79. Gotte M, Joussen AM, Klein C, Andre P, Wagner DD, Hinkes MT, Kirchhof B, Adamis AP, Bernfield M. Role of syndecan-1 in leukocyte-endothelial interactions in the ocular vasculature. Invest Opbthalmol Vis Sci. 2002;43:1135-41.

80. Marshall LJ, Randin LS, Brooks T, PC DP, Shute JK. Plasminogen activator inhibitor-1 supports IL-8mediated neutrophil transendothelial migration by intibition of the constituriwe shedding of endothelial IL-8/heparan sulfare/syndecan-1 complexes. $\int$ Immunol. $2003 ; 171: 2057 \% 65$.

81. Li Q, Park PW, Wilson CL, Parks WC. Matrilysin shedding of syndecan=1 regulates chemokine mobilization and transepithelial effux of neutrophils in acute lung injury. Call. 2002; 11 1:635-46.

82. Gerety SS, Wang HU, Chen ZF, Anderson DJ. Symmetrical mutant phenotypes of the receptor EphB4 and its specific rransmembrane ligand ephrin-B2 in cardiovascular development. Mol Cell. 1999;4:403-14. 83. Wang HU, Chen ZF, Anderson DJ. Molecular distinction and angiogenic interaction between embryonic arteries and veins revealed by ephrin-B2 and its receptor Eph-B4. Cell. 1998;93:741-53.

84. Yuan $K$, Hong TM, Chen JJ, Tsai WH, Lin MT. Syndecan-1 up-regulated by ephrinB2/EphB4 plays dual roles in inflammatory angiogenesis. Blood. 2004;104:1025-33.

85. Chen L, Klass C, Woods A. Syndecan-2 regulates transforming growth factor-beta signaling. $\int \mathrm{Biol}$ Chem. 2004;279:15715-8.
86. Klass CM, Couchman JR, Woods A. Control of extracellular matrix assembly by syndecan- 2 proteoglycan. J Cell Sci. 2000;113 ( Pt 3):493-506.

87. Blobe GC, Liu X, Fang SJ, How T, Lodish HF. A novel mechanism for regulating transforming growth factor beta (TGF-beta) signaling. Functional modulation of type III TGF-beta receptor expression through interaction with the PDZ domain protein, GIPC. / Biol Chem. 2001;276:39608-17.

88. Irie F, Yamaguchi Y. EPHB receptor signaling in dendritic spine development. Front Biosci. 2004:9:136573.

89. Brunetti A, Goldfine ID. Role of myogenin in myoblast differentiation and its regulation by fibroblast growth factor. J Biol Chem. 1990;265:5960-3.

90. Fuentealba L, Carey DJ, Brandan E. Antisense inhibition of syndecan-3 expression during skeletal muscle differentiation accelerates myogenesis through a basic fibroblast growth factor-dependent mechanism. I Biol Chem. 1999;274:37876-84.

91. Casar JC, Cabello-Verrugio C, Olguin H, Aldunate R, Inestrosa $\mathrm{NC}$, Brandan $\mathbb{E}_{\text {. . Heparan sulfate proteoglycans }}$ are increased during skeletal muscle regeneration: requirement of syndecan-3 for successful fiber formation. J Cell Sci. 2004;117:73-84.

92. Shimo T, Gentili C, Iwamoto M, Wu C, Koyama E, Pacifici $M$. Indian hedgehog and syndecans- 3 coregulate chondrocyte proliferation and function during chick limb skeletogenesis. Dev Dyn. 2004;229:607-17.

93. Volk R, Schwartz JJ, Li J, Rosenberg RD, Simons $M$. The role of syndecan cytoplasmic domain in basic fibroblast growth factor-dependent signal transduction. J Biol Chem. 1999;274:24417-24.

94. Chua CG, Rahimi N, Forsten-Williams K, Nugent MA. Heparan sulfate proteoglycans function as receptors for fibroblast growth factor-2 activation of extracellular signal-regulated kinases 1 and 2. Circ Res. 2004:94:31623.

95. Bryant DM, Wylie FG, Stow JL. Regulation of Endocytosis, Nuclear Translocation, and Signaling of FGFR1 by E-Cadherin. Mol. Biol. Cell 2004:E04-090845 .

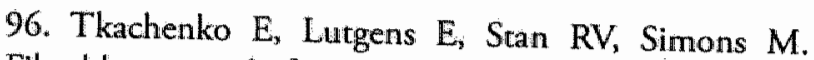
Fibroblast growth factor 2 endocyrosis in endorhelial cells proceed via syndecan-4-dependent activation of Racl and a Cdc42-dependent macropinocytic pathway.. J Cell Sci. 2004;117:3189-99.

97. Simons K, Vaz WL. Model systems, lipid rafts, and cell membranes. Annu Rev Biophys Biomol Struct. 2004;33:269-95. 
98. Brown DA, London E. Structure and function of sphingolipid- and cholesterol-rich membrane rafts. J Biol Chem. 2000;275:17221-4.

99. Simons K, Toomre D. Lipid rafts and signal transduction. Nat Rev Mol Cell Biol. 2000;1:31-9.

100. Tkachenko $E$, Simons $M$. Clustering induces redistribution of syndecan-4 core protein into raft membrane domains. J Biol Chem. 2002;277:19946-51.

101. Fuki IV, Kuhn KM, Lomazov IR, Rothman VL, Tuszynski GP, lozzo RV, Swenson TL, Fisher EA, Williams $\mathrm{KJ}$. The syndecan family of proteoglycans. Novel receptors mediating internalization of atherogenic lipoproteins in vitro. J Clin Invest. 1997;100:1611-22.

102. Fuki IV, Meyer ME, Williams KJ. Transmembrane and cytoplasmic domains of syndecan mediate a multistep endocytic pathway involving detergent-insoluble membrane rafts. Biochem J. 2000;351 Pt 3:607-12.

103. Stan RV. Structure and function of endothelial caveolae. Microsc Res Tech. 2002;57:350-64.

104. Liu J, Oh P, Horner T, Rogers RA, Schnitzer JE. Organized endothelial cell surface signal transduction in caveolae distinct from glycosylphosphatidylinos itol-anchored protein microdomains. I Bial Chem. 1997:272:7211-22.

105. Kawamura $S$, Miyamoto $S$, Brown JH. Initiation and transduction of stretch-induced RhoA and Racl activation through caveolae: cytoskeletal regulation of ERK translocation. / Biol Chem. 2003;278:31111-7.

106. Pelkmans L, Burli T, Zerial M, Helenius A Caveolinstabilized membrane domains as multifunctional transport and sorting devices in endocytic membrane traffic. Cell. 2004;118:767-80.

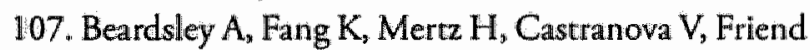
S, Liu J. Loss of caveolin-1 polarity impedes endorhelial cell polarization and directional movement. $/$ Biol Chem. 2004.

108. Borset $M$, Hjertner $O$, Yaccoby $S$, Epstein J, Sanderson RD. Syndecan-1 is targeted to the uropods of polarized myeloma cells where it promotes adhesion and sequesters heparin-binding proteins. Blood. 2000;96:2528-2536.

109. Baciu PC, Goetinck PF. Protein kinase $C$ regulates the recruitment of syndecan- 4 into focal contacts. $\mathrm{Mol}$ Biol Cell. 1995;6:1503-13.

110. Woodman SE, Ashton AW, Schubert W, Lee H, Williams TM, Medina FA, Wyckoff JB, Combs TP, Lisanti MP. Caveolin-1 knockout mice show an impaired angiogenic response to exogenous stimuli. Am J Pathol. 2003;162:2059-68.

111. Wilcox-Adelman SA, Denhez F, Goetinck
PF. Syndecan-4 modulates focal adhesion kinase phosphorylation. I Biol Cbem. 2002;277:32970-7.

112. Mukai $M$, Togawa $A_{2}$ Imamura $F_{8}$ Iwasalei $T$, Ayaki $M$, Mammoto $T$, Nakamura $H$, Tatsuta $M$, Inoue $M$. Sustained tyrosine-phosphorylation of FAK through Rho-dependent adhesion to fibronectin is essential for cancer cell migration. Anticancer Res. 2002;22:3175-84. 113. Hsia DA, Mitra SK, Hauck CR, Streblow DN, Nelson JA. Ilic D, Huang S, Li E, Nemerow GR。 Leng J, Spencer KS, Cheresh DA, Schlaepfer DD. Differential regulation of cell motility and invasion by FAK. $J$ Cell Biol. 2003; 160:753-67.

114. Shajahan AN, Timblin BK, Sandoval R, Tiruppathi C, MalikAB, Minshall RD. Role of Src-induced dynamin2 phosphorylation in caveolae-mediated endocytosis in endothelial cells. J Biol Chem. 2004;279:20392-400.

115. Chen J, Braet F, Brodsky S, Weinstein T, Romanow V, Noiri E, Goligorsky MS. VEGF-induced mobilization of caveolae and increase in permeability of endothelial cells. Am J Physiol Cell Physiol. 2002;282:C1053-63.

116. Gleizes PE, Noaillac-Depeyre J, Amalric F, Gas N. Basic fibroblast growth factor (FGF-2) internalization through the heparan sulfate proteoglycans-mediated pathway: an ultrastructural approach. Eur J Cell Biol. 1995;66:47-59.

117. Schlunck G, Damke H, Kiosses WB, Rusk N, Symons $\mathrm{MH}$, Waterman-Storer CM, Schmid SL, Schwartz MA. Modulation of rac localization and function by dynamini. Mol Biol Cell. 2004; 15:256:67.

118. del Pozo MA, Alderson NB, Kiosses WW, Chiang $\mathrm{H}-\mathrm{H}_{\text {w }}$ Anderson RGW, Schwartz MA. Integrüns Regulate Rac Targeting by Internalization of Membrane Domains. Science. 2004:303:839-842.

119. Sortile J, Chandler J. Fibronectin Matrix Turnower Occurs through a Caveolin-1 Dependent Process. Mol Biol. Cell. 2004:E04-08-0672.

120. Oh ES, Woods A, Couchman JR, Syndecan-4t proteoglycan regulates the distribution and activity of protein kinase C. J Biol Chem. 1997;272:8133-6.

121. Horowitz A, Simons M. Regulation of Syndecan-4 phosphorylation in vivo. J Biol Chem. 1998;273:109148.

122. Lim ST, Longley RL, Couchman JR, Woods A. Direct binding of syndecan -4 cytoplasmic domain to the catalytic domain of protein kinase $\mathrm{C}$ alpha (PKC alpha) increases focal adhesion localization of $\mathrm{PKC}$ alpha. J Biol Chem. 2003;278: 13795-802.

123. Keum E, Kim Y, Kim J, Kwon S, Lim Y, Han I, Oh ES. Syndecan-4 regulates localization, activity and stability of protein kinase C-alpha. Biochem $\mathrm{J}$. 
2004;378:1007-14.

124. Woods A, Longley RL, Tumova $S$, Couchman JR Syndecan-4 binding to the high affinity heparin-binding domalin of fibronectin drives focal adhesion formation in fibroblasts. Arch Biachem Biophys. 2000;374:66-72.

125. Saoncella $S$, Echtermeyer F, Denhez F, Nowlen JK, Mosher DF, Robinson SD, Hynes RO, Goetinck PF. Syndecan 4 signals cooperatively with integrins in a Thodependent manner in the assembly of focal adhesions and actin stress fibers. Proc Natl Acad Sci US A. 1999;96:2805-2810.

126. Bass MD, Humphries MJ. Cytoplasmic interactions of syndecan-4 orchestrate adhesion recepror and growth factor receptor signalling. Biachem J. 2002;368:1-15.

127. Longley RL, Woods A, Fleetwood A, Cowling GJ, Gallagher JT, Couchman JR. Control of morphology, cytoskeleton and migration by syndecan 4 . I Cell Sci. 1999;112:3421-31.

128. Saoncella S, Calautti E, Neveu W, Goetinck PF. Syndecan 4 regulates ATF-2 transcriptional activity in a Racl-dependent manner. J Biol Chem. 2004;279:471726.

129. Midwood KS, Williams LV, Schwarzbauer JE. Tissue repair and the dynamics of the excracellular matrix. Int $J$ Biochem Cell Biol. 2004;36:1031-7.

130. Midwood KS, Valenick LV, Hsia H, Schwarzbauer JE. Co-Regulation of Fibronectin Signaling and Matrix Contraction by Tenasein-C and Syndecan-4. Mol Biol Cell. 2004 .

131. Yamashita $Y$, Oritani $K$, Miyoshi EK, Wall $R$, Bernfield $M$, Kineade PW. Syndecan-4 is expressed by $B$ lineage lymphocytes and can transmit a signal for formation of dendritic processes. I Immunol. 1999;162:5940-8.

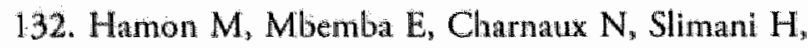
Brule S, Saffar L, Vassy R, Prost C, Lievre N, Starzec A, Gattegno L. A syndecan-4/CXCR4́ complex expressed on human primary lymphocytes and macrophages and HeLa cell line binds the CXC chemokine stromal cellderived factor-1. Glycobiology. 2004;14:31 1-23.

133. Granes F, Garcia R, Casaroli-Marano RP, Castel S, Rocamora N, Reina M, Urena JM, Vilaro S. Syndecan2 induces filopodia by active cdc42Hs. Exp Cell Res. $1999 ; 248: 439-56$.

134. Berndt C, Montanez E, Villena J, Fabre $M_{*}$ Vilaro $S$, Reina $M$. Infuence of cytoplasmic deletions on the filopodia-inducing effect of syndecan-3. Cell Biol Int. 2004;28:829-833.

135. Steïgemann P, Molitor A, Fellert $S$, Jackle $H$, Vorbruggen $G$. Heparan sulfate proteoglycan syndecan promotes axonal and myotube guidance by slit/robo signaling. Cur Biol. 2004;14:225-30.

136. Minniti AN, Labarca $M$, Hurtado $C$, Brandan $E$. Caenorthabditis elegans syndecan (SDN-1) is required for normal egg laying and associares with the nervous system and the vulva. / Cell Sci. 2004; 117:5179-90.

137. Kaksonen M, Pavlov I, Voikar V, Lauri SE, Hienola A, Riekki R, Lakso M, Taira T, Rauvala H. Syndecan3-deficient mice exhibit enhanced LTP and impaired hippocampus-dependent memory. Mol Cell Neurasci. 2002;21:158-72.

138. Li J, Parovian C, Hampton TG, Merais C, Tkachenko E, Sellke FW, Simons M. Modulation of Microvascular Signaling by Heparan Sulfate Marrix: Studies in Syndecan-4 Transgenic Mice. Microvasc Res. 2002;64:38-46.

139. Zhang $Y$, Li J, Partovian C, Selike FW, Simons M. Syndecan-4 modulates basic fibroblast growth factor 2 signaling in vivo. Am J Physial Heart Circ Physiol. 2003;284: $\mathrm{H} 2078-82$. 


\section{Chapter 2}

Modulation of Microvascular Signaling by Heparan Sulfate Matrix: Studies in Syndecan-4 Transgenic Mice

Jian Li, Chohreh Partovian, Jianyi Li, Thomas G. Hampton, Caroline Metais, Eugene Tkachenko, Frank W. Sellke, and Michael Simons

Microvascular Research 2002; 64(1):38-46. 


\section{Abstract}

The onset of tissue ischemia is associated with significant changes in the expression of heparan sulfate-(HS) carrying core proteins that, in turn, lead to alterations in composition of the extracellular HS matrix. Since HS can bind numerous growth factors and cytokines, such changes in the HS matrix content can have profound effects on the ability of these factors to interact with their target cells. To investigate the role of increased HS matrix content on microvascular function, we used myosin heavy chain (MHC) promoter to overexpress a HS-carrying core protein, syndecan4, In cardiac myocytes in mice. Mice expressing the transgene (MHC-S4) demonstrated a significant increase in nitric oxide (NO) release in the coronary effluent in response to fibroblast growth factor 2 (FGF2, 1 $\mathrm{mg} / \mathrm{mL}$ ) administration despite similar expression levels of NO synthase genes II and III (INOS and eNOS, respectively). In vitro studies of coronary microvessels derived from MHC-S4 mice demonstrated increased relaxation response to FGF2 compared to control mice. At the same time, vasodilator response to adenosine diphosphate (ADP) was significantly impaired in MHC-S4 micederived microvessels. Addition of exogenous HS to microvessels derived from control mice enhanced FGF2-Induced vasodilation while inhibiting ADP induced vasomotion. The vasomotor activity of the endothelial receptor-independent agent (A23187) and the endothelium-independent agent (sodium nitroprusside) was not affected by heparan sulfate. These results demonstrate that alterations in HS production have a profound and heterogeneous effect on endothelial receptordependent vasodilators and point to a novel role of the HS matrix in regulation of microvascular homeostasis.

\section{Introduction}

Cell surface heparan sulfares play an important role in control of signaling of a variety of heparin binding growth factors, including fibroblast growth factor 2 (FGF2) $[1,2]$. This can be achieved either directly [3, 4] or by regulating presentation of these factor to their high-affinity receptors $[5,6]$. In addition, in the case of FGF2 as well as of orher heparin binding growth factors, HS in the extracellular matrix (ECM) can sequester these proteins, thus protecting them from degradation [7], and can regulate their transport through the matrix [8]. Thus, any alteration-increase or decrease-or change in composition of the extracellular matrix heparan sulfaces may have a significant impact on microvascular environment, including signal transduction in endorhelial cells. In this study we set out to test whether increased expression of HS on cardiac myocytes and their subsequent shedding into the extracellular matrix in normal nonischemic hearts would alter vascular responses to endothelium-dependent and -independent agonists.

Heparan sulfares are carried on three major classes of core proteins-transmembrane syndecans, glycosylphosphatidylinositoll (GPI) anchored glypicans, and the extracellular core protein perlecan. All three classes of core proteins are capable of carrying heparan sulfates and, to date, no difference in the HS chain composition derived from the different cores has been established [8]. Thus, theoretically, HS derived from any of these sources would have equal impact on the ECM-related processes. While perlecan HS chains are already present in the matrix due to the extracellular lacation of the core protein, glypicans and syndecans are equally capable of adding their HS chains to the mix due to shedding of their extracellular HS-carrying domains [9]. While regulation of the shedding processes is nor fully understood, the presence of inflammarory cells and activation of extracellular proteases clearly enhance it $[4,20]$.

To explore the role of the ECM heparan sulfates in the regulation of microvasculature, we generated transgenic mice carrying syndecan-4 core protein gene under control of MHC promoter. Syndecan-4 is one of the four members of syndecan family members that is ubiquitously expressed in various cell types, including myocytes and endothelial cells. The onset of tissue injury or ischemia is associated with a rapid increase in syndecan $-4 \mathrm{mRNA}$ and protein levels that far exceeds changes in the levels of other HS-carrying proteoglycans, including glypican-1 and syndecan-1 [10]. Therefore, syndecan-4-derived HS is the principal type of HS chain deposited in the matrix under these conditions. We have recently demonstrated that, unlike other HS-carrying proteins, syndecan-4 has the ability to directly mediate FGF2 signaling in endothelial cells by virtue of its cytoplasmic domain [3]. Therefore, in order to study the effect of syndecan-4-derived matrix HS on microvascular environment, and, at the same time, to avoid the direct syndecan -4 signaling effects, we choose to target its expression to cardiac myocytes. In this setting, effects of the syndecan-4 transgene expression will be limited to the matrix/cell surface deposition of its shed extracellular domains that carry heparan sulfate chains.

To assess the effect of changes in the HS ECM composition, we examined the ability of several endothelium- dependenc and -independent vasoactive 
agents, including FGF2, adenosine diphosphare (ADP), and sodium nitroprusside (SNP), to affect microvascular responses. We find that increased HS content augmented FGF2-mediated vasodilation while decreasing ADP response. This change in the vasodilatory response was directly attributable to enhanced (FGF2) or reduced (ADP) ability to induce nitric oxide (NO) release. At the same time, vasomotor responses to other tested agonists were not affected. Thus, alteration in the HS ECM content exerts complex and heterogeneous effects on microvascular homeostasis.

\section{Materials and methods}

\section{Generation of Transgenic Mice Lines}

Full-length rat syndecan- 4 cDNA was linked to the 3 end of mouse MHC promoter [11] (a gift of Dr. J.Robbins, University of Cincinnati) and the 5 end of human growth hormone polyadenylation signal sequence in the pBluescript SKO. The construct was then microinjected into ferrilized eggs of C57BL/6 mice. Polymerase chain reaction analysis of tail genomic DNA was carried out using a forward primer 5-CCAAGGAACTGGAAGAGATGA GGTCATTC-3 corresponding to the rat syndecan-4 sequence and a reverse primer 5-GCCAAGGTGGGTA GATCACCTGAGATTAGG-3 corresponding to the 5 end sequence of human growth hormone. Four different transgenic lines were generated and used in the study.

\section{In Vitro Microvascular Studies}

The left anterior descending coronary artery from hearts of MHC-S4 ( $n=6$ ) and age/strain matched controls $(\mathrm{n}=6)$ was dissected using a 10-60X dissecting microscope (Olympus Optical, Tokyo, Japan). Microvessels were placed in a Plexiglas microvessel chamber, cannulated with dual glass micropipetres measuring $40-80 \mathrm{~m}$ in diameter, and secured with a 10-0 nylon monofilament suture (Ethicon, Somerville, NJ) as previously described. For all measurements, the vessels were washed three times with a Krebs buffer solution and allowed to equilibrate in the buffer solution 15-30 min between interventions. Vessels were bathed in Mops buffer maintained at $37^{\circ}$ and aerated with room air. The microvessels (mean diameter $=125.2 \pm 10.1 \mathrm{~m}$ ) were imaged with the use of an inverted microscope connected to a video camera and the internal lumen diameter wasmeasured with an electronic imaging apparatus (Living Systems, Burlington, VT). Vessels were precontracted with the thromboxane A2 analog U46619 by $30 \%$ of the baseline diameter prior to application of a vasodilator agent.

Vascular responses to FGF2 (109-104 M; R\&D Systems, Minneapolis, MN) serotonin (5-HT, 109-104 M; Sigma, St. Louis, MO) adenosine-5-diphosphate (ADP, 109-104 $\mathrm{M}_{*}$ Sigma), and SNP (109-104 $M_{\text {; Sigma) were examined. Selected experiments were }}$ performed following 20 min of pretreatment with 104 mol/L NG-nitro-l-arginine (L-NNA, Sigma) or $1 \mathrm{~g} /$ $\mathrm{mL}$ of heparan sulfare (Sigma). All drugs were applied extraluminally. Measurements were made and recorded 2-3 min after drug administration, when the response was stabilized. One to four interventions were performed on each vessel. The order of drug administration was randomly selected.

\section{RNA Analysis}

For the RNA analysis of syndecan-4 expression in MHC-syndecan-4 mice, total RNA was isollated from the heart $(n=12)$, brain, liver, lung, kidney, and intestine $(\mathrm{n}=4)$ using TriReagent (Sigma). For Northern blots, $10 \mathrm{~g}$ of total RNA were fractionated on $1.3 \%$ formaldehydeagarose gels and transferred to GeneScreen Pllus (DuPonc) filters. The syndecan-4, FGF2, FGF-R1, and eNOS cDNA probes were labeled with $-\left[{ }^{32}\right.$ P]deoxycytidine triphosphate (New England Nuclear) with a randompriming labeling kit (Boehringer, Indianapolis, IN) and purified of unincoporated nucleoride using MicroSpin S-200 HR Columns (Amersham Pharmacia Biotech, Piscataway NJ). Following hybridizations, the blots were washed and the gene expression was determined using autoradiography. Isolated Heart Preparation For studies of $\mathrm{NO}$ release from the myocardium in response to $\mathrm{FGF} 2$, freshly excised heares from MHCsyndecan-4 transgenic $(n=6)$ and age-and-strainmatched control mice $(n=6)$ were mounted on a Langendorff perfusion apparatus as previously described [12]. NO concentration in the coronary effluent was measured by using an amperometric sensor (ISONO, World Precision Instrument; Inc., Sarasota, FL). The principle of measurement and the electrode design have previously been described [13]. The probe was calibrated before each set of experiments using a standard chemical method which has been adapted to generate known concentrations of $\mathrm{NO}$. To this end, $\mathrm{KNO} 2(0.05 \mathrm{mM})$ was used as a generator of NO in the $\mathrm{KI}(0.1 \mathrm{M})$ and $\mathrm{H} 2 \mathrm{SO} 4(0.1 \mathrm{M})$ mixture based on the following equation:

$2 \mathrm{KNO}_{2}+2 \mathrm{KI}+2 \mathrm{H}_{2} \mathrm{SO}_{4}+2 \mathrm{NO}+\mathrm{I}_{2}+2 \mathrm{H}_{2} \mathrm{O}+2 \mathrm{~K}_{2} \mathrm{SO}_{4}$

Following calibration and after $20 \mathrm{~min}$ of perfusion 
with either vehicle or $1 \mu \mathrm{g} / \mathrm{mL}$ FGF2 (Chiron Corp, Sunnyvale, $C A$ ) the electrode was positioned in the effluent to measure the arrount of $\mathrm{NO}$ released from dhe coronary sinus.

\section{Primary Cell Isolation and Culture}

Primary microvascular endothelial cells were isolated from hearts of adult MHC-syndecan-4 (MHCS4) transgenic and control mice. Freshly extracted hearts were quickly dipped into ice-cold $70 \%$ ethanol for $20 \mathrm{~s}$ and the atria were then discarded. The ventricular tissue was minced into $1-\mathrm{mm} 3$ pieces and diges ed in $\mathrm{Ca} 2$ and $\mathrm{Mg} 2$ free Hank's solution containing $2 \mathrm{mg} /$ $\mathrm{mL}$ collagenase II (Worthington Biochemical Co.) with agitation for $30 \mathrm{~min}$ at $37^{\circ}$. An additional digestion was performed by adding $0.3 \mathrm{mg} / \mathrm{mL}$ trypsin for $30 \mathrm{~min}$ at $37^{\circ}$. Following digestions, the cells wereplated onto laminin coared dishes for $1 \mathrm{~h}$ and unatcachedcells were discarded. The remaining cells were washed with PBS three times and cultured in Dulbecco's modified Eagle's medium (DMEM) supplemented with $20 \%$ fetal bovine serum (FBS). Cells in the second passage were used for experiment in this study.

For primary cardiac myocyres isolation, freshly extracted hearts from adult MHC-S4 transgenics and control mice were perfused with Tyrode solution $10.1 \mathrm{M}$ $\mathrm{NaCl}, 5 \mathrm{mM} \mathrm{KCl}, 1 \mathrm{mM} \mathrm{MgCl}, 10 \mathrm{mM}$ Hepes, and 10 $\mathrm{mM}$ glucose, $\mathrm{pH} \mathrm{7.4)}$ for $15 \mathrm{~min}$ at $37^{\circ}$. At that point, $1 \mathrm{mg} / \mathrm{mL}$ collagenase II (Worthington Biochemical Co.) was added to further digest the hears for another $15 \mathrm{~min}$ at $37^{\circ}$. Following the completion of digestion, atria were discarded and the remaining tissue was quickly minced under a microscope into $1-\mathrm{mm} 3$ pieces. Cells were harvested from the enzyme solution by centrifugation and the fresh culture medium (DMEM-15\% FBS) was added to resuspend the cells. To enrich the myocyte population, a differential adhesion step was used. The dissociated heart cell suspensions were preincubated in $100-\mathrm{mm}$ cell culture dishes for $60 \mathrm{~min}$ at $37^{\circ}$, allowing fibroblasts to atrach. The remaining unartached cells (containing mostly myocytes) were collected and plated into 24-well cell culture dishes in DMEM-15\% FBS and allowed to attach for 2 to $3 \mathrm{~h}$ and used immediately for the experiments.
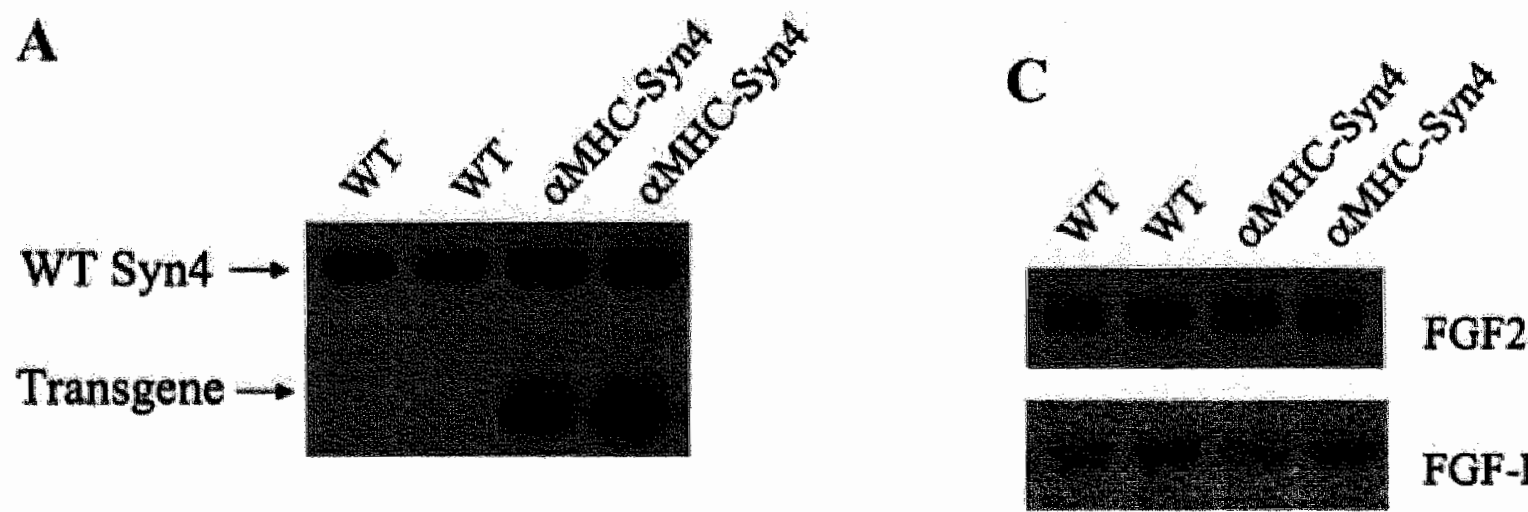

FGF-R

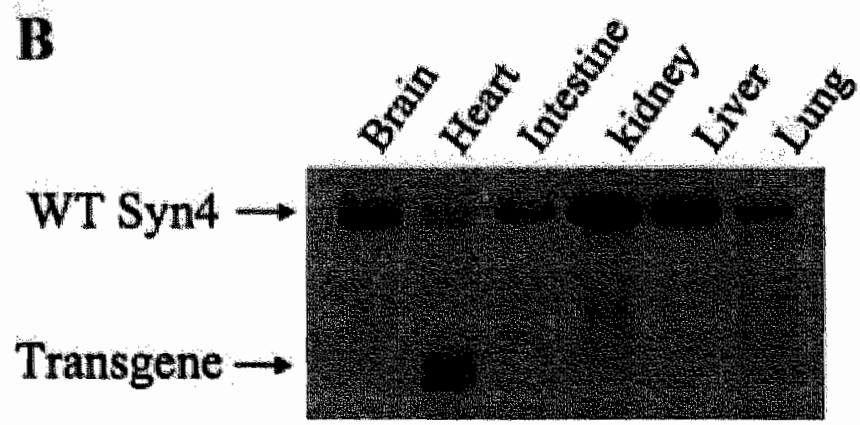

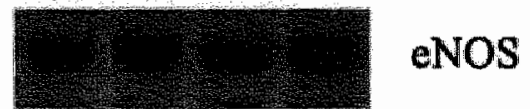



Fig. 1. Syndecan-4 transgene expressed in MHC-syndecan-4 transgenic mice.

Northern blot analysis of syndecan-4 expression in the heart $(A)$ and other organs $(B)$. Note the presence of the transgene band in the heart of MHC-S4 mice. Effect of syndecan-4 expression in the heart on mRNAlevels of FGF2, FGF-R1, and eNOS is shown in (C). Note similar levels of expression in both wild-type (WT) and MHC-S4 mice. 


\section{Results}

\section{Myocyte Syndecan-4 Expression Increased FGF2-Induced Nitric Oxide Release}

To study the effect of syndecan-4 expression in normal cardiac myocytes on microvascular function, we generated four different transgenic mice lines carrying full-length rat syndecan-4 cDNA under control of MHC promoter. All transgenic lines grew and bred normally compared with the wild-type mice. As expected, syndecan-4 transgene expression was confined to the heart (Figs. 1A and 1B) and restricted to cardiac myocytes (not shown). The transgene expression had no effect on expression of basic fibroblast growth factor (bFGF or FGF2), its receptor 1 (FGF-R1), or endothelial nitric oxide synthase (eNOS; Fig. 1C).

FGF2 has been shown to dilate resistance vessels by inducing release of nitric oxide. To assess the effect of myocyte syndecan-4 expression on FGF2-induced NO

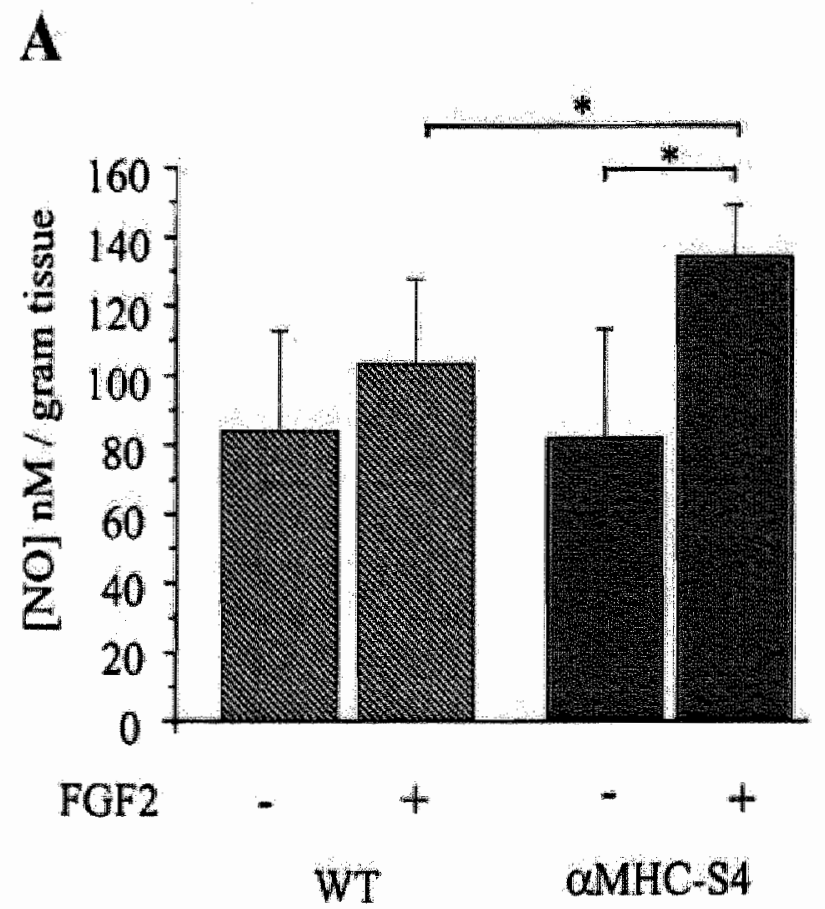

release, we first measured $\mathrm{NO}$ concentration in the coronary effuent from hearts of wild-type and $\mathrm{MHC}$ S4 transgenic mice. While baseline levels of NO were similar in both groups, after perfusion with FGF2 (1 $\mu \mathrm{g} / \mathrm{mL}$ ), NO release increased more than $80 \%$ in $\mathrm{MHC}$ S4 mice but only $20 \%$ in the control mice(control vs MHC-S4: $82.0 \pm 22$ vs $83.9 \pm 16 \mathrm{nM} / \mathrm{g}$ tissue at baseline $\mathrm{P}=\mathrm{ns} ; 135.3 \pm 14.7$ vs $\| 03.0 \pm 24 \mathrm{nM} / \mathrm{g}$ following $\mathrm{FGF} 2$ stimularion, $\mathrm{P}<0.05$ ) (Fig. 2A).

To document that increased NO release was indeed secondary to syndecan-4 expression in cardiac myocytes, we carried out in vitro measurements of $\mathrm{NO}$ release from isolated primary endothelial cells and myocytes derived from hearts of control or MHC-S4 mice. While endothelial cells from both mice groups demonstrated a similar magnitude of NO release in response to $\mathrm{FGF2}(16.5 \pm 6.7$ vs $20.4 \pm 5.2 \mathrm{nM}$, control vs MHC-S4, $\mathrm{P}=\mathrm{ns}$ ), myocytes isolated from hearts of MHC-S4 mice had produced significantly greater amounts of NO compared to cardiac myocytes from the control mice (Fig. 2B),

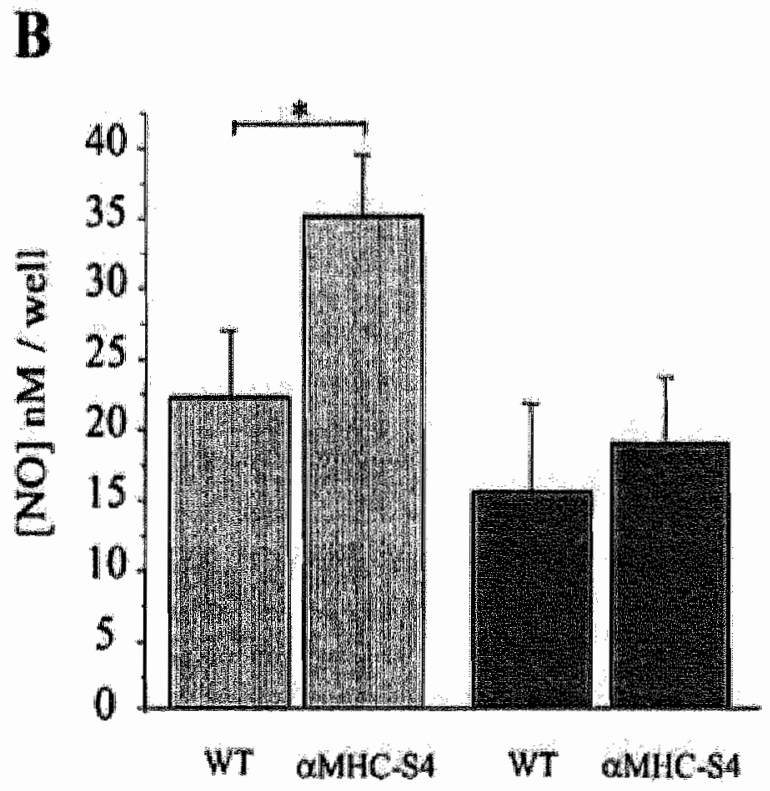

Myocytes Endothelial Cells

Fig. 2. Effect of syndecan-4 expression on FGF2-induced nitric oxide release.

(A) The amount of NO release induced by FGF2 was tested in a Langendorf preparation of hearts from MHC-S4 (gray bars) and wildtype (WT, hatched bars) mice. Note a significant increase in NO release in MHC-S4 hearts ("P<0.05 FGF2 vs no FGF2 and MHC-S4 vs WT).

(B) NO release by primary cardiac myocytes (gray bars) and endothelial cells (stippled bars) from aMHC-S4 and wild-type mice. Note a significant increase in FGF2-induced NO release in myocytes but not endothelial cells ( ${ }^{*}<0.05$ with FGF2 vs without FGF2). Data are shown as the mean $\pm \mathrm{SD}$. 


\section{Changes in Heparan Sulfate Matrix Have Differential Effects on Endothelial Receptor-Dependent Responses}

To assess the effect of myocyte syndecan expression on function of myocandial microvasculature, we studied in vitro responses of preconstricted coronary arterial microvessels from MHC-S4 and wild-type mice hearts to various agonists. A direct vasodilator, nitroprusside, and an endothelial receptor-independent vasodilator, A23187, had similar magnitude effects on microvessels from both MHC-S4 and control mice hearts (Figs. $3 A$ and $3 B$ ). Treatment with the endothelial receptordependent agonist serotonin also resulted in a similar extent of vasodilation in the MHC-S4 and control mice vessels (Fig. 3C). On the other hand, FGF2 was significantly more potent in vessels derived from $\mathrm{MHC}$ S4 mice hearts (Fig. 4A), while ADP response was substantially inhibited in these mice (Fig.4B). In both cases, wasodilation was inhibited by I-NNA (Figs. 4A and $4 \mathrm{~B}$ ), implying that $\mathrm{NO}$ release is responsible for this effect.

Since microvessels themselves do not express syndecan -4 , the differences in these responses could have arisen from the presence of shed, endothelial-cell-surface-bound extracellular domains of syndecan- 4 that would largely consist of heparan sulfate chains. To test the effect of the presence of shed HS chains on FGF2 and ADP responses, we assessed the ability of these agents to vasodilate coronary microvessels from normal (control) mice hearts in the presence or absence of exogenous HS chains in the buffer: We found that, similar to microvessels from MHCS4 mice "the addition of HS to microvessels from the control mice potentiates vasodilatory response to FGF2 (Fig. 4C) while inhibiting $A \mathrm{AP}^{3}$-induced vasodilation (Fig. 4B). Both FGF2 and ADP induce vasodilation by stimulating $N O$ release. Therefore, we have examined the effect of exogenously added HS chains on $\mathrm{NO}$ releasein response to these agents by endothelial cells in culture. Similar to findings in the microvessels assays, addition of HS stimulated FGF2-induced NO release while inhibiting ADP-induced release (Fig. 4D).

\section{Discussion}

The major finding of this study is that an alteration in the extracellular matrix heparan sulfate content has a significant and heterogeneous impact on endothelial cell signaling. In particular, whille FGF2 signaling was enhanced (as measured by $\mathrm{NO}$ release and microvascular

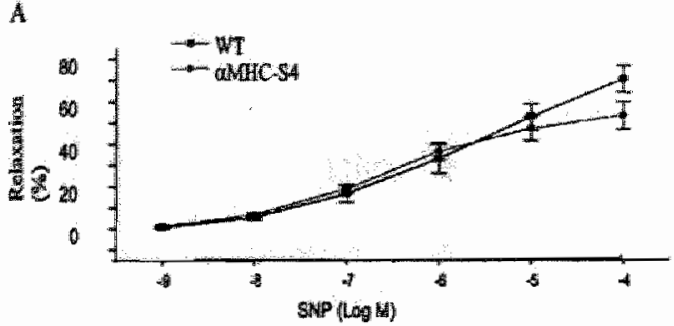

B
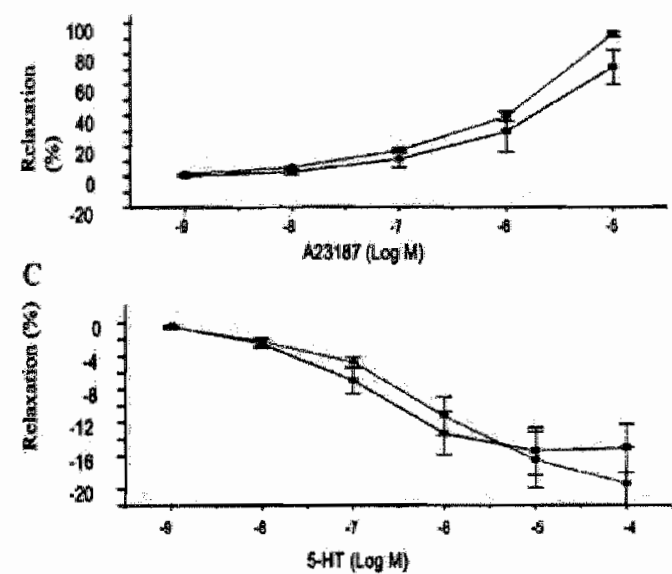

Fig. 3. In vitro response of mouse cardiac microvessels. In vitro responses of precontracted cardiac microvessels from MHC-syndecan-4 (F) and wild-type (WT) (F) mice to the endothelium-independent vasodilator sodium nitroprusside (SNP) $(A)$, endothelium-receptor-independent vascdilator A23187 (B), and endothelium-receptor-dependent agonist serotonin (C) are shown. Response is plotted as percentage change in diameter of precontracted vessels over a concentration range of the agonist. Note similar responses in microvessels from both WT and MHCsyndecan-4 mice hearts. Data are expressed as the mean $\pm \mathrm{SE}$.

vasodilation), microwasculature responses to $A D P$ were inhibited and responses to serotonin, nitroprusside, and the calcium ionophore A23187 were unchanged. The ability of heparan sulfates to alter responses to heparinbinding growth factors and other molecules has been long acknowledged $[14,15]$. In particular, FGF2 ability to induce $\mathrm{NO}$ release, critical to its ability to induce vasodilation [15], is fully dependent on HS-mediated binding to its high-affinity receptor [16-18]. Ar the same time, heparin can alsoinduce vasodilation. This activity has been attributed to activation of NO release as well as activation of K[ATP] channels. However, the contribution of endogenous matrix HS to microvascular homeostasis and the effect of altered HS concentration on activity of orther vasodilators such as VEGF or ADP have not been investigated.

In this study we have altered the myocyte cell surface 

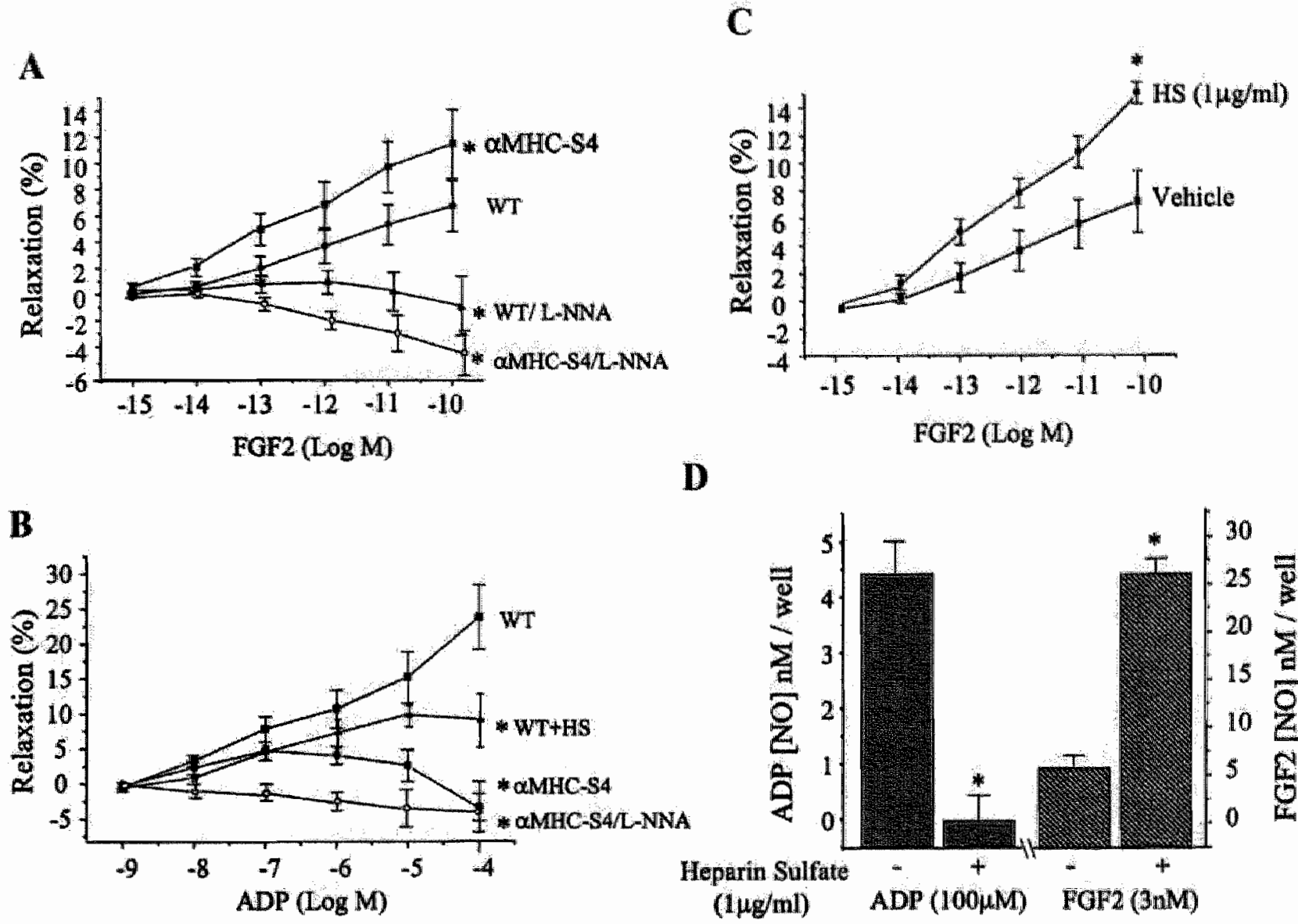

D

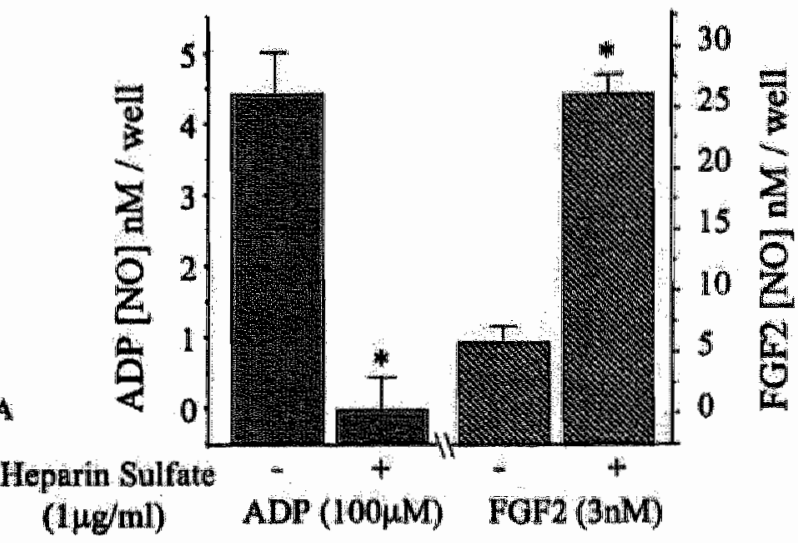

Fig. 4. Effect of syndecan-4 expression on FGF2 and ADP signaling.

In vitro response of microvessels derived from MHC-S4 (F) and wild-type (WT) (F) mice hearts to FGF2 (,$C)$ and $A D P(B)$ was carried out in precontracted microvessels.

(A) Note signilicantly greater degree of vasodilation induced by FGF2 in microvessels from MHC-\$4 compared to WT mice ("P<0.05, MHC-S4 ws WT). Pretreatiment with I-NNA fully blocks FGF2-induced vasodilation.

(B) In contrast to FGF2, ADP induced significantly less vasodillation in microwessels from MHC-S4 compared to WT hearts ("P<0.05, MHC-S4 vs WT). Addition of exogenous heparan sulfate chains $(\mathrm{HS}, 1 \mathrm{~g} / \mathrm{mL}$ ) to microvessels from WT mice significantly inhibited ADP. induced vasodilation ("P<0.05,WT + HS vs WT). Similarly to FGF2, LNNA inhibits ADP-induced wasodilation.

(C) Addition of exogenous heparan sulfate chains (HS, $1 \mathrm{~g} / \mathrm{mL}$ ) 10 microvessels from WT mice significantly enhanced FGF2 induced vasodilation ( ${ }^{*}<<0.05$, HS vs vehicle).

(D) Effect of exogenous heparan sulfate ( $\mathrm{HS}, 1 \mu \mathrm{g} / \mathrm{mL}$ ) on FGF2 and ADP-induced nitric oxide release was in primary endothelial cells derived from control mice hearts. Note enhanced release of NO in the presence of HS chains in the case of FGF2 (hatched bars) and reduced NO release in the case of ADP (gray bars). Data are expressed as the mean \pm SD. "P<0.05 agonist vs/no agonist. 
and the ECM HS content by tranggenic expression of the syndecan-4 gene under the control of the cardiac myocyte-specific (MHC) promoter. Despite significantly increased syndecan-4 expression in MHC-S4 transgenics, baseline NO release from the hearts of these mice was not different from that of control mice when studied in toto on a Langendorff preparation. As expected, FGF2 induced greater $\mathrm{NO}$ release from MHC-S4 compared to control mice hearts. Furthermore, treatment of isolated primary cardiac myocytes derived from MHC-\$4 mice with FGF2 resulted in greater $\mathrm{NO}$ release compared to NO release from cardiac myocytes isolated from control mice hearts. This finding is in accord with the abovestated expectations, since syndecan-4 expression on myocyte cell surface will enhance FGF2 binding and signaling [3].Ac the same time, there was no difference in FGF2-induced NO release from primary endothelial cells derived from MHC-S4 or control mice. Both endothelial cells and myocytes derived from the hearts of MHC-S4 transgenics possess increased cell-surface HS content-myocytes duc to cell-type-specific expression of syndecan-4 and endothelial cells due to syndecan-4 shedding from myocytes. However, since procedures employed for isolation of both cell types involve extensive enzymaric digestion of tissue, only the cells capable of regenerating HS-carrying core proteins, i.e., cardiac myocytes, would be expected to show enhanced FGF2 response. The fact that this response is, indeed, due to the increased presence of shed (extracellular) HS chains is illuserated by the fact that addition of exogenous HS chains to primary endothelial cells from control mice results in enhanced $\mathrm{NO}$ release.

The other evidence of the effect of cell surface HS on FGF2-induced $\mathrm{NO}$ release comes from studies of coronary microvasculature. Unlike the case of primary cell isolarion, preparation of coronary vessels does not result in disruption of cell-surface-absorbed heparan sulfates, since it requilres enzymatic digestion, and not simply washing, to remove cell-surface-associated HS chains. Thus, we have observed a significandy larger vasodilatory response to $\mathrm{FGF} 2$ in vessels derived from MHC-S4 compared to control mice. This conclusion is supported by the observation that addition of HS chains to microvessels from control mice hearts results in enhanced FGF2-induced vasodillation. Taken together, these experiments clearly demonstrate that increased expression of syndecan-4 core protein in cardiac myocytes results in amplified production of $\mathrm{NO}$ by these myocytes in response to FGF2 and that increased HS chain shedding accounts for increased responsiveness of coronary microvessels in these hearts to FGF2. This conclusion is also supported by our previous observations documenting increased cellsurface-associated HS mass following expression of HS-carrying core proreins in general and syndecan- 4 in particular [3].

To explore the effect of these changes in the matrix HS content on the ability of other vasoactive agents to induce microvascular responses, we have examined activity of ADP, serotonin, and A23187. Increased shedding of syndecan-4 derived HS produced a significant inhibition of ADP-induced vasodilation. This was demonstrated both in studies of MHC-S4 micederived microvessels and in control mice microvessels in the presence of exogenously added HS chains. Since both FGF2- and ADP-induced vasodilation requires $\mathrm{NO}$ release, it is logical to assume that the presence of shed HS chains has a differential effect on the ability of these molecules to stimulate NO production. In accordance with this hypothesis, the addition of HS chains to cultured primary endothelial cells stimulated FGF2-induced NO release while inhibiting ADP ability to g enerate $N O$. If is entirely unclear why alterations in the HS cell surface and/or matrix contents resulted in such a profound inhibition of ADP activity. One possibility is that $\mathrm{HS}$ chains block $A D P$ binding to its receptor either directly or indirectly by altering its conformation. Alcernatively, ADP may be sequestered by the HS chains away from its site of action.

These changes in the HS matrix content had little impact on the ability of another endothelial receptordependent agonist, serotonin, to induce vasodilation, nor have they affected the vasodilatory activity of the endotheliumreceptor-independent agent $\mathrm{A} 23187$ or the endotheliumindependent drug nitroprusside. In previous studies of microvascular responses in chronically ischernic porcine hearts, we have observed enhanced vasodilation in response to FGF2 that was attributed to increased FGF receptor expression [19]. At the same time, there were no changes in response to sodium nitroprusside and $A D P$ response was suppressed. Since syndecan-4 expression is known to be increased in these settings, increased FGF2 responsiveness may have been due to in equal measure to increased syndecan- 4 as well as FGF receptor expression. Furthermore, decreased ADP responsiveness fits well with the data from the current study.

A number of factors can alter syndecan-4 expression, including ischemia and inflammation. In the postinfarct heart, the presence of blood-derived macrophages is required for increased syndecan-4 expression [10]. Similarly, arterial injury is also associated with enhanced 
syndecan -4 expression [20] and both serum and FGF2 have been reported to increase syndecan-4 levels in smooth-muscle cells [21]. In addition, two other proteins have been shown to induce syndecan-4 levels: a peptide PR39 $[10,22]$ and TNF [23].

Expression of other HS-carrying core proteins is also alrered in a number of disease states, including tissue injury and hypoxia [7]. Since HS chains found on different core proteins are thought to be structurally similar, alteration in expression of any these proteins can have a similar effect on growth factor signaling. In summary, alterations in the extracellular matrix heparan sulfate chain composition can have a significant and heterogeneous effect on endothelial cell responses and may account for changes in microvascular responses observed in the ischemic myocardium.

\section{Acknowledgments}

Supported in part by the AHA Scientist Development Award 9930077 (JL), NIH Grants HL62289 and P50 HL63609 (M.S.), and HL46716 (F.W.S.).

\section{REFERENCES}

1. Rapraeger, A. C., Guimond, S., Krufka, A., and Olwin, B. B. (1994). Regulation by heparan sulfate in fibroblast growth factor signaling. Methods Enxymol. $245,219-240$.

2. Delehedde, M., Seve, M., Sergeant, N., Wartelle, I., Lyon, M., Rudland, P. S., and Fernig, D. G. (2000). Fibroblast growth factor- 2 stimulation of $\mathrm{p} 42 / 44 \mathrm{MAPK}$ phosphorylacion and ikappa B degradation is regulated by heparan Sulfate/Heparin in rat mammary fibroblasts. J. Biol. Chem. 275, 33905-33910.

3. Volk, R., Schwartz, J. J., Li, J., Rosenberg, R. D., and Simons, M. (1999). The role of syndecan cytoplasmic domain in basic fibroblast growth factor-dependent signal transduction. J. Biol. Chem. 274, 24417-24424.

4. Tumova, S., Woods, A., and Couchman, J. R. (2000). Heparan sulfate proteoglycarns on the cell surface: Versatile coordinators of cellular functions. Int. J. Biochem. Cell. Biol. 32, 269-288.

5. Nugent, M. A., and lozzo, R. V. (2000). Fibroblast growth factor-2. Int. J. Biochem. Cell. Biol. 32, 115120.

6. Stauber, D. J., DiGabriele, A. D., and Hendrickson, W. A. (2000). Structural interactions of fibroblast growth factor receptor with its ligands. Proc. Natl. Acad. Sci. USA $97,49-54$.

7. Bernfield, M., Go“ tte, M., Park, P. W., Reizes, O., Fitzgerald, M. L., Lincecum, J., and Zako, M. (1999). Functions of cell surface heparan sulfate proteoglycans. Annu. Rev. Biochem. 68, 729-777.

8. Rosenberg, R. D., Shworak, N. W., Liu, J, Schwartz, J. J., and Zhang, L. (1997). Heparan sulfate proteoglycans of the cardiovascular system. ]. Clin. Invest. 99, 20622070.

9. Kainulainen, V., Wang, H., Schick, C., and Bernfield M. (1998). Syndecans, heparan sulfate proteoglycans, maintain the proteolytic balance of acute wound fluids. J. Biol. Chem. 273, 11563-11569.

10. Li, J., Brown, L. F., Laham, R. J., Volk, R., and Simons, M. (1997). Macrophage-dependent regulation of syndecan gene expression. Circ. Res. 81, 785-796.

11. Palermo, I., Gulick, J., Colbert, M., Fewell, J., and Robbins, J. (1996). Transgenic remadeling of the contractile apparatus in the mammalian heart. Circ. Res. $78,504-509$.

12. Hampton, T. G., Amende, I., Fong, J, Laubach, V. E., Li, J., Metais, C., and Simons, M. (2000). Basic FGF reduces stunning wia a NOS2-dependent pathway in coronary-perfused mouse hearts. Am. J. Physiol. Heart Circ. Physiol. 279, H260-H268. 
13. Shibuki, K. (1990\%. An electrochemical microprobe for detecting nitric oxide release in brain tissue. Neurosci. Res. (NY) 9, 69-76.

14. Templeton, D. M. (1992), Proteoglycans in cell regulation. Crit.Rev. Clin. Lab. Sci, 29, 141-184.

15. Tiefenbacher, C. P, and Chilian, W. M. (1997). Basic fibroblast growth factor and heparin influence coronary arteriolar tone by causing endothelium-dependent dilation. Cardiovasc. Res. 34,411-417.

16. Ornitz, D. M., and Itoh, N. (2001). Fibroblast growth factors, Genome Biol. 2, 3005.

17. Lin, X., Buff, E. M., Perrimon, N., and Michelson, A. M. (1999). Heparan sulfate proteoglycans are essential for FGF receptor signaling during Drosophila embryonic development. Development 126, 3715-3723.

18. Klint, P., and Claesson-Welsh, L. (1999). Signal transduction by fibroblast growth factor receptors. Front. Biosci. 4, D165-D177.

19. Sellke, F. W., Wang, S. Y., Stamler, A., Lopez, J. J., Li, J. L., J., and Simons, M. (1996). Enhanced microvascular relaxations to VEGF and $\mathrm{BFGF}$ in chronically ischemic porcine myocardium. Am. J. Physiol. 271: H713$\mathrm{H} 720$.

20. Nikkari, S. T., Jarvelainen, H. T., Wight, T. N., Ferguson, M., and Clowes, A. W. (1994). Smooth muscle cell expression of extracellular matrix genes after arterial injury. Am. J. Pathol. 144, 1348-1356.

21. Cizmeci-Smith, G., Langan, E., Youkey, J., Showalter, L. J., and Carey, D. J. (1997). Syndecan-4 is a primary response gene induced by basic fibroblast growth factor and arterial injury in vascular smooth muscle cells. Arterioscler. Thromb. Vasc. Biol. 17, 172-180.

22. Gallo, R. L., Ono, M., Povsic, T., Page, C., Eriksson, E. Klagsburn, M., and Bernfield, M. (1994). Syndecans, cell surface heparan sulfate proteoglycans, are induced by a proline-rich antimicrobial peptide from wounds. Proc. Nat. Acad. Sci. USA 91, 11035-11039.

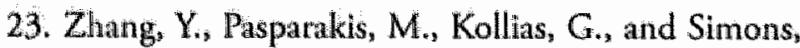
M. (1999). Myocyte-dependent regulation of endothelial cell syndecan-4 expression: Role of TNF-alpha. J. Biol. Chem. 274, 14786-14790. 


\section{Chapter 3}

\section{Growth Factor-specific Modulation of Cellular Response by Syndecan-4}

Arie Horowitz, Eugene Tkachenko, and Michael Simons

Journal of Cell Biology 2002;157: 715-725. 


\section{Abstract}

Proteoglycans participate in growth factor Interaction with the cell surface through their heparan sulfate chains (HS), but it is not known if they are otherwise involved in growth factor signaling. It appears now that the syndecan4 core protein, a transmembrane proteoglycan previously shown to bind phosphatidylinositol 4,5-bisphosphate (PIP) and activate protein kinase C (PKC) $\alpha$, participates in mediating the effects of fibroblast growth factor 2 (FGF2) on cell function. Mutations in the cytoplasmic tail of syndecan-4 that either reduced its affinity to $\mathrm{PIP}_{2}\left(\mathrm{PIP}_{2}\right)^{-}$, or disrupted its $\mathrm{PDZ}$-dependent binding (PDZ), produced a FGF2-specific dominant-negative phenotype in endothelial cells, as evidenced by the marked decline of their migration and proliferation rates, and by the impairment of their capacity to form tubes. In both cases the molecular mechanism was determined to consist of a decrease in the syndecan-4-dependent activation of PKC $\alpha$. This decrease was caused either by inhibition of FGF2-induced syndecan-4 dephosphorylation in the case of the $\mathrm{PDZ}^{-}$mutation, or by disruption of basolateral targeting of syndecan-4 and its associated PDZ-dependent complex in the case of the $\mathrm{PIP}_{2}-$ mutation. These results suggest that PKC $\alpha$ activation and PDZ-mediated formation of serine/threonine phosphatase-containing complex by syndecan -4 are downstream events of FGF2 signaling.

\section{Introduction}

The participation of $\mathrm{HS}$ chains in binding numerous soluble ligands and extracellular matrix proteins (Bernfield et al., 1999) drew increased attention once HS presence on the cell surface was shown to be required for FGF2dependent cell growth (Rapraeger et al., 1991). The list of HS-binding soluble ligands has grown significantly, culminating recently in the finding that syndecan-1atcached HS chains promote the tumorigenic response to Wnt-1 (Alexander et al, 2000).

The potential role of the HS-carrying core of the proteoglycans in mediating the cellular response to growth factors received lietle attention, however, despite earlier indications of their response to extracellular signals, such as the recruitment of syndecan- 4 to focal adhesions (Baciu and Goetinck, 1995; Woods and Couchman, 1994). The possibility of fulfilling specific functional roles seems particularly relevant to the syndecan core proreins, all of which share a distinct and highly conserved cytoplasmic tail. One of the motifs common to all the syndecans is a carboxy-terminal PDZ (Postsynaptic densicy 95, Disk large, Zona occludens-1)-binding motif, now known to bind at least four PDZ domain-containing partners (Cohen er al., 1998; Ethell et al., 2000; Gao et al., 2000; Grootjans et al., 1997; Hsueh et al., 1998). Similar to other $\mathrm{PDZ}$ proteins, these binding partners very likely serve as adaptors between the syndecans and additional members of larger complexes.

Syndecan-4, the most widely spread member of the family, differs in its sequence from the other three syndecans by a unique $\mathrm{PIP}_{2}$-binding 7-residue motif located in the middle of its 28-amino acid- long cytoplasmic tail (Horowitz et al., 1999; Lee et al., 1998). Syndecan -4 has been implicated in signal transduction (Volk et al., 1999) and in the activation of PKCa (Oh et al., 1997b). $\mathrm{PIP}_{2}$ appears to underlie the signaling activity of the cytoplasmic tail of syndecan-4, serving as a binding interface (Horowitz et al., 1999) and an essential cofactor for $\mathrm{PKC} \alpha$ activation (Oh et al., 1998), as well as a facilitator of the tail's multimerization (Oh et al., 1997a). These properties are regulated by the phosphorylation of $\mathrm{S}^{18 *}$, located 4 residues away from the amino-cerminus of the $\mathrm{PIP}_{2}$-binding motif (Horowitz and Simons, 1998a). Once phosphorylared, the affinity of the cytoplasmic tail for $\mathrm{PIP}_{2}$ and its capacities to oligomerize and activate PKCa in the presence of PIP $_{2}$ are sharply reduced (Simons and Horowirz, 2001).

Given the HS-dependence of the activity of several growth factors, and the in vivo-observed increase in syndecan-4 expression during growth factor-regulated healing from injury (Gallo et al., 1994; $\mathrm{Li}$ et al., 1997; Nikkari et al., 1994), we asked whether the molecular attributes of syndecan- 4 listed above are relevant to growth factor signaling. Using FGF2 as a HS-binding growth factor prototype, we found that disruption of either the $\mathrm{PIP}_{2}$ or $\mathrm{PDZ}$ binding domains of syndecan4 conferred a dominant negative phenotype in regard to this growth factor, but not to serum or to epithelial (EGF) and platelet-derived (PDGF) growth factorinduced response.

These data suggest, therefore, that syndecan -4 selectivity regulates FGF2 signaling in endothelial cells. 


\section{Results}

\section{Site-directed mutations in syndecan-4 confer dominant- negative effects on FGF2 signaling in endothelial cells}

We addressed the potential role of syndecan-4 in regulating the cellular response to FGF2 by transfecting rat fat pad endothelial cells (RFPEC), which express syndecan-4 endogenously (Kojima et al., 1992), with hemagglutinin (HA)-tagged wild type (S4) syndecan-4, or with HA-tagged syndecan-4 constructs mutated at two key sites (Fig. 1a). In the first construct $\left(\mathrm{PIP}_{2}{ }^{-}\right)$, the three consecutive residues $Y^{192} \mathrm{KK}$ in the cytoplasmic tail of syndecan-4 were mutated to LQQ, a mutation that drastically reduces the $\mathrm{PIP}_{2}$ affinity of the cytoplasmic tail and inhibits its $\mathrm{PIP}_{2}$-mediated activation of $\mathrm{PKCa}$ (Horowitz er al., 1999). In another construcr ( $\mathrm{PDZ}^{-}$), the carboxy-terminal residue $\left(A^{202}\right)$ was deleted, thereby abolishing PDZ-dependent binding of syndecan-4 (Songyang et al., 1997). Finally, a PIP ${ }_{2}^{-/ P D Z-~ c o n s t r u c t ~}$ combined the feacures of the other two constructs.

In order to measure the expression level of the introduced constructs, as well as the effect of exogenous construct expression on endogenous syndecan-4 levels, we immunoblotted total cell lysates from each of the cell lines with antibodies to syndecan- 4 and to $\mathrm{HA}$ (Fig. 1b). The syndecan-4 immunoblot represents the sum of endogenous and transfected syndecan- 4 proteins, while the HA immunoblot assesses the amount of transfected syndecan -4 . The immunoblots showed on average a 2 fold increase in the expression level of the exogenous constructs over the endogenous syndecan- 4 protein in the transfected cell lines, excluding the $\mathrm{PIP}_{2}-$ cells, where the mutated syndecan- 4 variant is not recognized by the antibody against the cytoplasmic tail used in these experiments, since the $\mathrm{YKK} \rightarrow \mathrm{LQQ}$ mutation disrupts its epitope (data not shown).

To find whether these mutations perturbed FGF2 signaling, we examined several potentially susceptible cell functions. Migration rate in response to FGF2 treatment was measured by a wounding assay of confluent cell monolayers. The migration rates of cells expressing either $\mathrm{PIP}_{2}^{-}$or $\mathrm{PDZ}^{-}$syndecan-4 mutants were similar to each other and 3-fold lower than the migration rate of vectortransfected RFPEC (Fig. 2a). At the same time, migration of cells carrying the combined $\mathrm{PIP}_{2}-/ \mathrm{PDZ}^{-}$mutation was not different from controls. In agreement wirh our previous observations (Volk et al., 1999), the migration
Fig. 1: (A) Schemes of syndecan-4 cytoplasmic tail constructs used in the study.

From left to right: WT cytoplasmic tail (S4; solid cylinder - PIP ${ }_{2}$ binding domain, solid sphere - $C$-terminal $A^{202}$ residue) $\mathrm{PIP}_{2}$ $\left(Y^{192} K K \rightarrow L Q Q\right)$ mutation (void cylinder), $P D Z$ - (deletion of the C-terminal $\mathrm{A}^{202}$ residue) mutation, and $\mathrm{PIP}_{2}-1 \mathrm{PDZ}-$ icombination of both mutations).



(B) Protein levels of exogenous and endogenous syndecan-4 in transfected cell clones.

Top: immunoblots for total syndecan-4 protein levels, using antiserum specific to the cytoplasmic tail of syndecan-4, and a histogram representing the densitometric values of each band (in arbitrary units).

Bottom: as above, using HA taig antibody. Aliquots of cell Iysale containing equal masses of

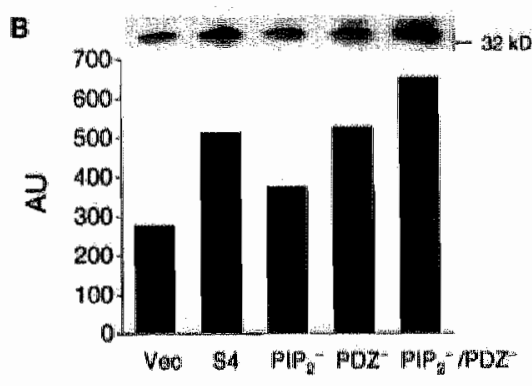
total protein were. immunoprecipitated from each cell group with antiserum specific to the ectoplasmic tail of syndecan 4 . Glycosaminoglycan chains were digested prior to gel electrophoresis.

rate of RFPEC overexpressing $\$ 4$ was even higher than vector-transfected cells (relative gap closure of $0.34 \pm 0.09$, versus $0.27 \pm 0.03$, respectively; $n=12, p=0.023$; see Fig. 2a). Cell growth in response to FGF2 over a period of 3 days was measured by proliferation assays with the same cell clones used in the migration assays. Cells expressing either the $\mathrm{PIP}_{2}$ or $\mathrm{PDZ}$ mutants had 3-5-fold lower proliferation rates in comparison to vector-transfected cells, while cells expressing the $\mathrm{PIP}_{2}-/ \mathrm{PDZ}^{-}$mutation had the same proliferation rate as vector controls, a 
A
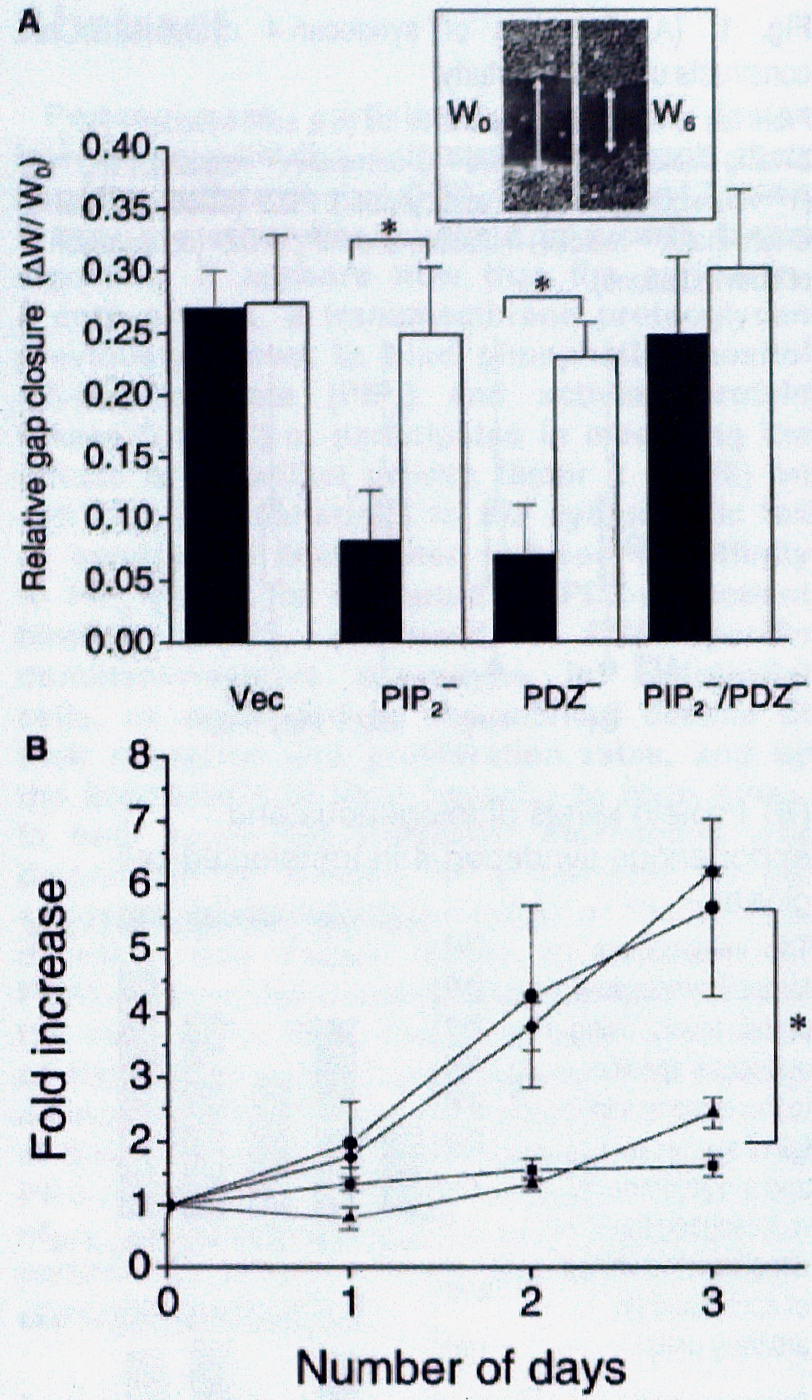

C
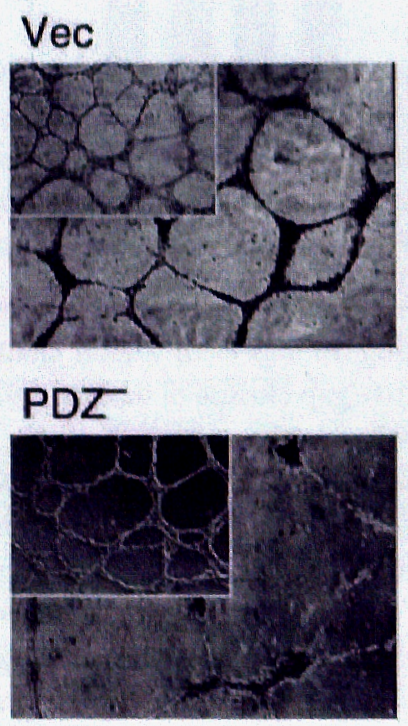

pattern similar to the results of the migration assays (Fig. 2b). Finally, tube formation on extracellular matrix basement in response to FGF2 by cell clones expressing the $\mathrm{PIP}_{2}^{-}$or $\mathrm{PDZ}^{-}$syndecan- 4 mutations, but not the $\mathrm{PIP}_{2}-/ \mathrm{PDZ}^{-}$mutation, was also markedly impaired in comparison with the continuous and articulated tube networks formed by vector-transfected cells (Fig. 2c), or by S4-overexpressing RFPEC (data not shown).

The combined results of the migration, proliferation, and tube formation experiments indicate that both the $\mathrm{Y}^{192} \mathrm{KK} \rightarrow \mathrm{LQQ}$ substitution and the $\mathrm{A}^{202}$ deletion conferred a dominant-negative phenotype on RFPEC when co-expressed with endogenous syndecan-4. This effect was FGF2-specific, since when performed in the presence of $10 \%$ serum (Fig. 2a, 2c), or in the presence of either EGF or PDGF AB (25 ng/ml each; data not shown) migration and tube formation by $\mathrm{PIP}_{2}^{-}$and by $\mathrm{PDZ}^{-}$cells did not differ from those of vector-transfected cells.

\section{$\mathrm{PIP}_{2}-$ mutation impairs syndecan-4 targeting to the basolateral region}

To elucidate the mechanism of the dominant-negative effect of the mutations in the cytoplasmic tail of syndecan4, we compared the cellular distribution of each mutated syndecan -4 variant to that of the endogenous molecule. Staining of untransfected RFPEC with the antibody to

Fig. 2: Effects of syndecan-4 mutations on cell function.

(A) Migration of RFPEC as measured in "wounding" assays (inset). Cells were starved in 0.5\% FBS for 24 hrs, scratched, and incubated for another $6 \mathrm{hrs}$, either with $0.5 \% \mathrm{FBS}$ and $20 \mathrm{ng} / \mathrm{ml}$ FGF2 (solid bars), or with 10\% FBS alone (void bars). Gap size was measured immediately before $\left(\mathrm{W}_{0}\right)$ and after $\left(\mathrm{W}_{6}\right)$ the $6 \mathrm{hr}$ incubation period $\left(\Delta W=W_{0}-W_{6}\right)$. Data shown as mean $\pm S$.D. $n=12 \div 18 ; *-p<0.05$.

(B) Fold increase in cell number relative to day 0 , as measured in RFPEC proliferation assays. Cells were starved as above, and then treated with $20 \mathrm{ng} / \mathrm{ml} \mathrm{FGF2} \mathrm{(} \mathrm{n}=3$ ). Cells were counted immediately before FGF2 application, then at 24,48 , and 72 hrs after it. Data shown as mean \pm S.D., $n=4 ; *-p<0.05$ (diamonds - vector-transfected control cells; triangles - $\mathrm{PIP}_{2}-$ cells; squares - PDZ- cells; circles - PIP,-IPDZ- cells).

(C) Tube formation assays on extracellular matrix basement (Matrigel ${ }^{\mathrm{TM}}$, Beckton Dickinson). Cells were starved as above, then treated for $24 \mathrm{hrs}$ either with $0.5 \% \mathrm{FBS}$ and $20 \mathrm{ng} / \mathrm{ml}$ FGF2, or with $10 \%$ FBS alone (insets), and imaged immediately. Each cell line was assayed in duplicate. Note that all cell lines formed normal tube networks when treated with 10\% FBS. 
Fig. 3: Cellular distribution of endogenous and transfected syndecan-4 in RFPEC.

Top, phase (left panel) and immunofiuorescence (right panel) images of the same untransfected RFPEC labeled with 1:50 diluted syndecan-4 cytoplasmic tail antiserum. Arrows, Golgi apparatus, arrowheads, cell junctions. Nuclear staining in the right panel is due to non-specific immunolabeling.

Bottom, confocal immunofluorescence images of RFPEC doubly labeled with $1 \mu \mathrm{g} / \mathrm{ml} \mathrm{HA}$ antibody (Roche), and with $2.5 \mu \mathrm{g} / \mathrm{ml}$ antibody to GM130 (Transduction Laboratories), showing the distribution of HA-tagged WT syndecan-4 (\$4, left panel), GM-130 Golgi marker (center), and an overlay of both images (bars, $25 \mu \mathrm{m}$ ). Note the distribution of both endogenous and WT overexpressed syndecan-4 (S4) along cell junctions and in the Golgi apparatus.
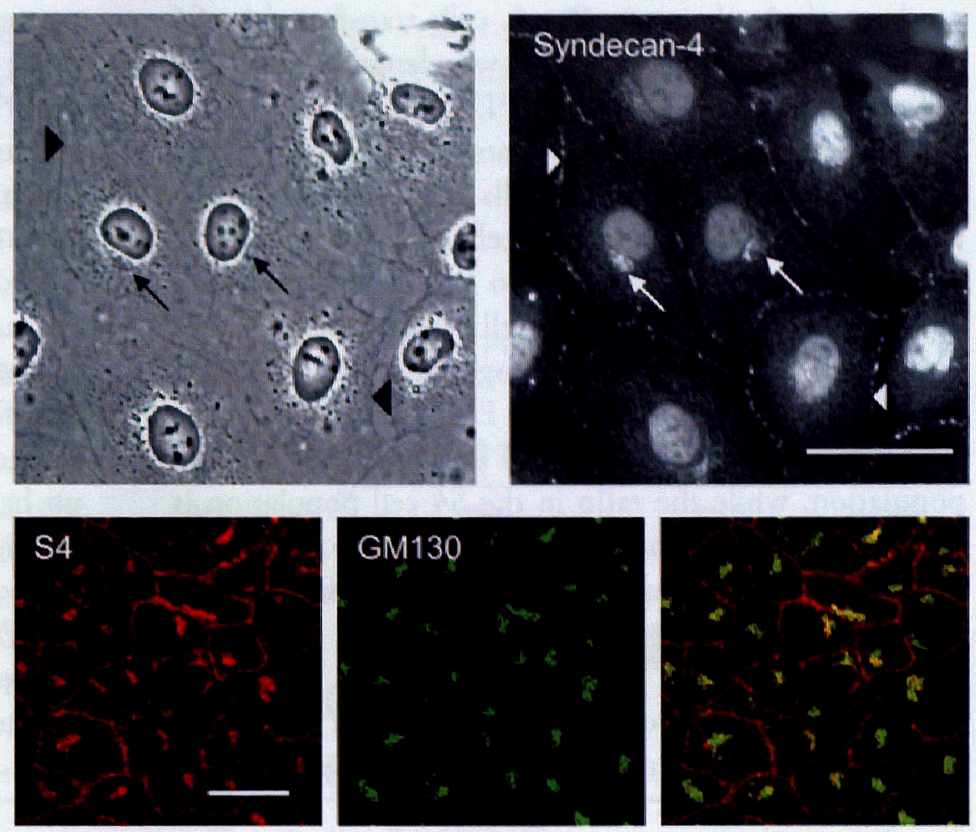

syndecan- 4 demonstrated the presence of the proteoglycan along the cell borders and in the perinuclear region (Fig. 3, top panels). S4 expressed in RFPEC assumed a similar distribution (Fig. 3, bottom panels). The perinuclear location coincided with the Golgi apparatus, as shown by overlap with the staining for the Golgi scaffold protein GM130 (Nakamura et al., 1995).

Both the $\mathrm{PIP}_{2}^{-}$and the $\mathrm{PIP}_{2}^{-} / \mathrm{PDZ}^{-}$syndecan- 4 variants maintained their Golgi localization, but were no longer present in the basolateral region (Fig. $4 \mathrm{a}$ and $4 \mathrm{c}$, respectively). In contrast with the cellular distribution of the $\mathrm{PIP}_{2}^{-}$and the $\mathrm{PIP}_{2}^{-} / \mathrm{PDZ}^{-}$syndecan- 4 mutants, the distribution of the PDZ mutant (Fig. 4b) did not differ from that of the endogenous syndecan- 4 , indicating that syndecan -4 is targeted to the basolateral region by its association with $\mathrm{PIP}_{2}$, rather than with a $\mathrm{PDZ}$ protein.

To further examine the effect of the $\mathrm{PIP}_{2}^{-}$mutation on the surface targeting of syndecan-4, the $\mathrm{S}_{4}, \mathrm{PIP}_{2}{ }^{-}$and $\mathrm{PIP}_{2}-/ \mathrm{PDZ}^{-}$variants were transfected into $\mathrm{RFPEC}^{-}$via a bicistronic EGFP-expressing plasmid. Each cell group was scanned at both $488 \mathrm{~nm}$, the EGFP emission wavelength, and at $580 \mathrm{~nm}$, the emission wavelength of the redpycoerythrin fluorophore conjugated to the secondary antibody used to detect the HA-tagged exogenous
Fig. 4: The distribution of syndecan-4 mutants in RFPEC.

(A) $\quad \mathrm{PIP}_{2}$-expressing cells doubly immunolabeled with syndecan-4 cytoplasmic tail antiserum (left panel) and HA antibody (center). Note that the distribution of the $\mathrm{PIP}_{2}-$ syndecan-4 (center panel) was restricted to the Golgi, while native syndecan-4 (left panel) is localized both to the Golgi and along cell borders, as in the top right panel of Fig. 3 . Nuclei appear in this and in parts $b$ and $c$ due to non-specific binding of the syndecan -4 antiserum.

(B) PDZ- cells doubly immunolabeled with syndecan-4 cytoplasmic tail antiserum (left panel) and HA antibody (center panel). Note that the distribution of the PDZ syndecan-4 was similar to that of HA-tagged WT syndecan-4 in Fig. 3, bottom left panel.

(C) $\quad \mathrm{PIP}_{2}-\mathrm{IPDZ}-$ cells doubly immunolabeled with syndecan-4 cytoplasmic tail antiserum (left panel) and $\mathrm{HA}$ antibody (center panel). Note that the distribution of the $\mathrm{PIP}_{2}-\mathrm{PDZ}^{-}$syndecan-4 was similar to that of $\mathrm{PIP}_{2}$ - syndecan-4 in Fig. $4 \mathrm{a}$, center panel.

Panels on the right are overlays of the left and center panels

Bars are $25 \mu \mathrm{m}$.

\author{
B
}

A
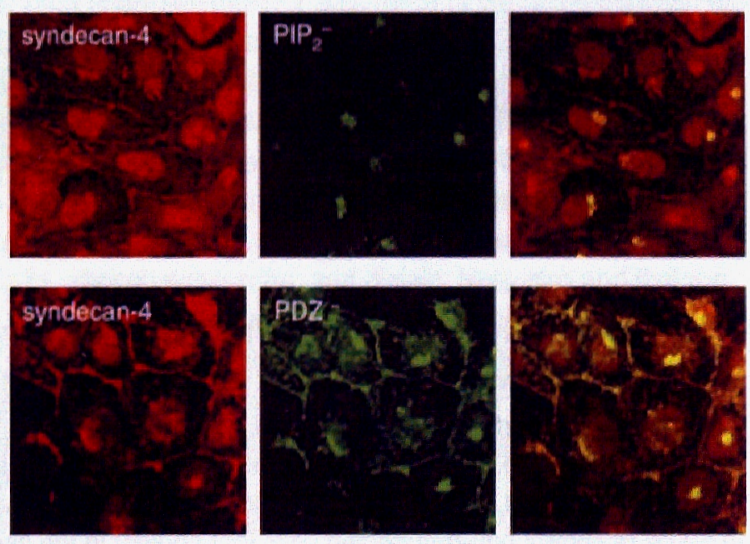

C
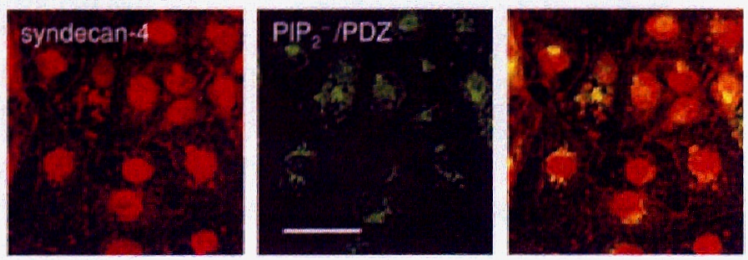
syndecan-4. As shown in Fig. 5, cells transfected by $\$ 4$ (panel b) had high counts at both wavelengths, while cells expressing the $\mathrm{PIP}_{2}{ }^{-}$and $\mathrm{PIP}_{2}-\mathrm{PDZ}$ - mutants (panels $\mathrm{c}$ and $d$, respectively) had low counts at $580 \mathrm{~nm}$, similar to the vector-transfected control cells (a). Note that though the fraction of EGFP-expressing cells out of the total $\mathrm{PIP}_{2}$ cell population is low relative to the EGFP expressing fractions in the other three the cell populations, the ratio between the cell fraction expressing both EGFP and $\mathrm{PIP}_{2}$ and the fraction expressing only EGFP $(1: 20)$ is similar to the corresponding ratio $(1: 25)$ in the $\mathrm{PIP}_{2}^{-} / \mathrm{PDZ}^{-}$cell population, while the ratio in the $\$ 4$ cell population is much higher $(1: 3)$. These results confirm the conclusion drawn from the immunofluorescence experiments that the $\mathrm{PIP}_{2}-$ syndecan- 4 mutant is not present on the cell surface.

The sequestration of the $\mathrm{PIP}_{2}^{-}$mutated syndecan4 to the Golgi apparatus may potentially reduce the presence of endogenous syndecan- 4 on the cell surface, if the two could form hetero-oligomers. In that case, the lower responses of the $\mathrm{PIP}_{2}^{-}$cells to FGF2 observed in the functional assays (Fig. 2) may result not only from the presence of the mutated form of syndecan- 4 , but more trivially, from the resulting deficit in the available FGF binding sites along the syndecan-4-associated HS chains. To test this possibility, we quantified the amount of syndecan-4 present on the cell surface in vectortransfected and $\mathrm{PIP}_{2}^{-}$cells by FACS, using an antibody against the ectoplasmic domain of syndecan-4. Since we have already shown (Figs. $4 \mathrm{a}$ and 5a) that the PIP variant of syndecan -4 is not present on the cell surface, the antibody would detect only the endogenous syndecan -4 . The FACS results (Fig. 5b) show no significant differences between the amounts of syndecan -4 molecules present on the surface of vector-transfected and $\mathrm{PIP}_{2}$ - cells.
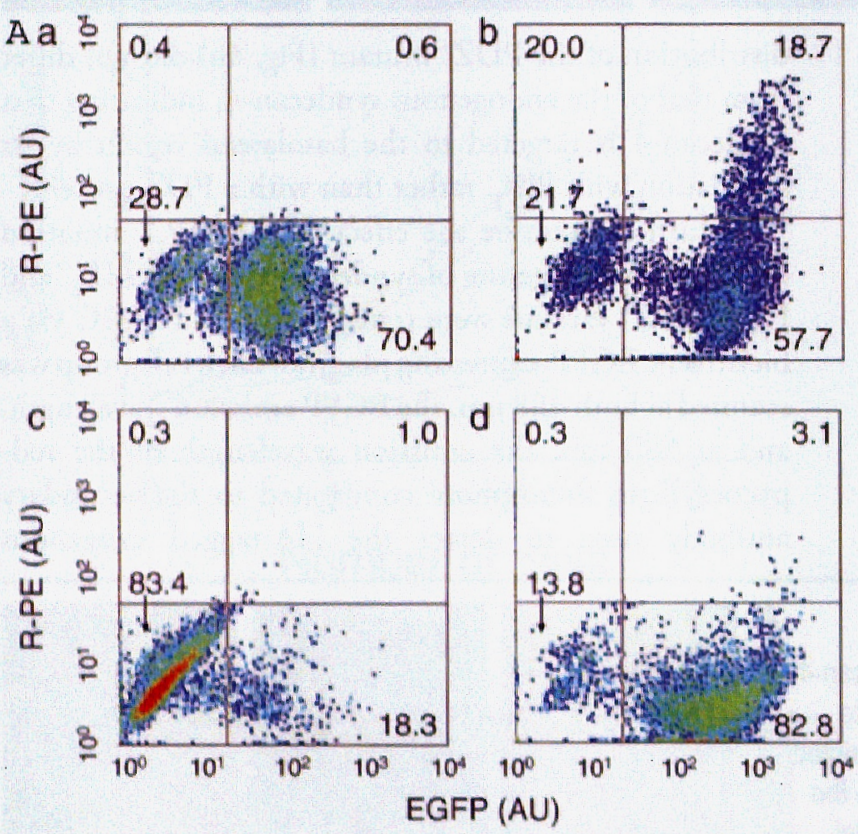

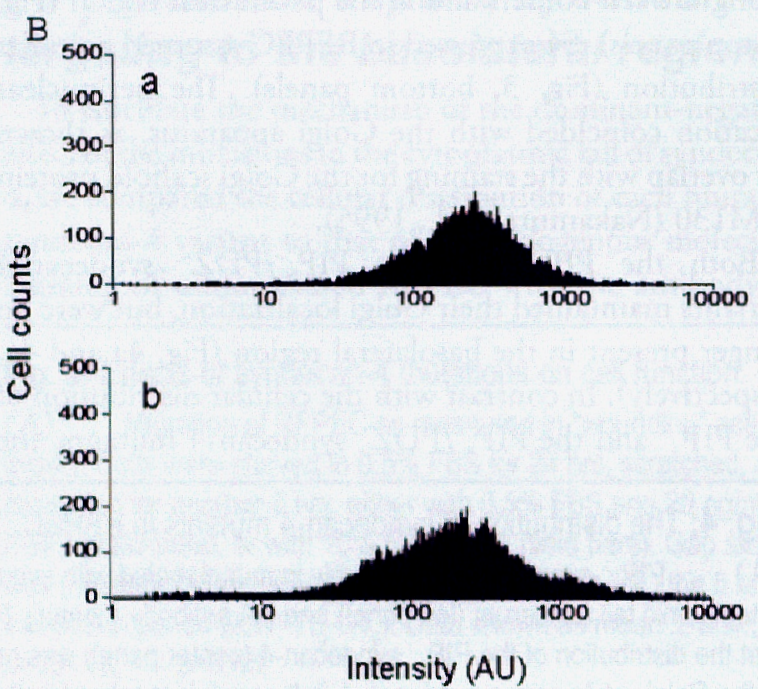

Fig. 5: FACS analysis of exogenous and endogenous syndecan-4 expression levels.

(A) Distributions of pIRES2-EGFP vector transfected (a), HA-WT overexpressing (b), $\mathrm{PIP}_{2}^{-}$-transiected (c), and $\mathrm{PIP}_{2}$-/PDZ"transfected cells (d) as a function of their fluorescence intensities at $488 \mathrm{~nm}$ (EGFP, horizontal axis, arbitrary units, AU) and at $580 \mathrm{~nm}$ (R-PE, vertical axis), corresponding to the EGFP protein levels expressed either alone (a) or in tandem with each syndecan-4 variant (b, $c, d)$, and to the cell surface expression levels of the syndecan-4 variants, respectively. The quadrants were drawn so as to enclose near to $100 \%$ of control non-transfected cells (not shown) in the lower right quadrant. Numbers in corners denote the percentage of the cell population in each quadrant. Quasi colors denote count density (red - high, blue - low).

(B) Intensity distribution (in arbitrary units) of cells labeled with antiserum to the syndecan-4 ectoplasmic domain followed by anti-rabbit lgG-Alexa 594, showing the levels of cell surface expression of endogenous syndecan-4 in vector-transfected (a) and PIP ${ }_{2}^{-}$ expressing (b) cell lines. 


\section{$\mathrm{PIP}_{2}^{-}$and PDZ- mutations reduce syndecan-4-associated activity of $\mathrm{PKCa}$}

An established signaling role of syndecan- 4 is the modulation of FGF2-stimulated $\mathrm{PIP}_{2}$-dependent PKC $\alpha$ activity (Horowitz and Simons, 1998a; Oh et al., 1997b). Since the activity of this PKC isoenzyme has been previously linked to the promotion of cell growth (Besson and Yong, 2000; Cai et al., 1997; Kolch et al., 1993; Kolch et al., 1996; Lallena et al., 1999; Schonwasser et al., 1998), migration (Harrington et al., 1997), and tube formation (Wang et al., 2002), we studied the effect of $\mathrm{PIP}_{2}^{-}$and $\mathrm{PDZ}^{-}$mutations on $\mathrm{PKC} \alpha$ activity in these cells. To this end, we assayed the activity of PKC $\alpha$ coimmunoprecipitated with HA-tagged syndecan-4 core proteins from the RFPEC clones expressing S4, PIP ${ }_{2}^{-}$, $\mathrm{PDZ}^{-}$or $\mathrm{PIP}_{2}^{-} / \mathrm{PDZ}^{-}$syndecan-4 constructs, before and after FGF2 stimulation.

FGF2 treatment increased syndecan- $4 / \mathrm{PIP}_{2}$-dependent PKC $\alpha$ activity 8-fold in syndecan-4-overexpressing RFPEC relative to untreated cells of the same type (Fig. 6a). On the other hand, syndecan-4-dependent PKC $\alpha$ activity in cells expressing $\mathrm{PIP}_{2}^{-}, \mathrm{PDZ}^{-}$, or $\mathrm{PIP}_{2}^{-} / \mathrm{PDZ}^{-}$ syndecan -4 constructs was not increased by FGF2. No significant FGF2-induced relative increases in syndecan4-associated kinase activities were observed when instead of $\mathrm{PIP}_{2}$ the assays were done in the presence of $\mathrm{Ca}^{2+}$, diacylglycerol, and phosphatidylserine. The absolute level of the $\mathrm{Ca}^{2 *}$-dependent activity of PKC $\alpha$ is typically higher by $20 \%$ than its activity in the presence of $\mathrm{PIP}_{2}$ and the cytoplasmic tail of syndecan-4 (Horowitz and Simons, 1998a). The fact that the $\mathrm{Ca}^{2 *}$-dependent PKC $\alpha$ activities of all the cell lines tested did not significantly differ from each other (Fig. 6a), either with or without FGF2 treatment, indicates that similar amounts of PKC $\alpha$ were immunoprecipitated in all cases. Similar to the functional assays described above, the increase in the syndecan-4-associated kinase activity was specific to FGF2, as no significant differences were found between the syndecan-4-associated kinase activities in serumtreated versus untreated cells. Since the kinase activities were measured ratiometrically for each cell line (FGF2 or serum-treated vs. untreated cells), they were not affected by variations between different cell lines in the absolute amounts of syndecan-4-associated PKC $\alpha$.

Though the binding of PKCa to the cytoplasmic tail of syndecan- 4 is well documented (Horowitz and Simons, 1998a; Oh et al., 1997b), we verified that the measured kinase activity in these assays was produced by

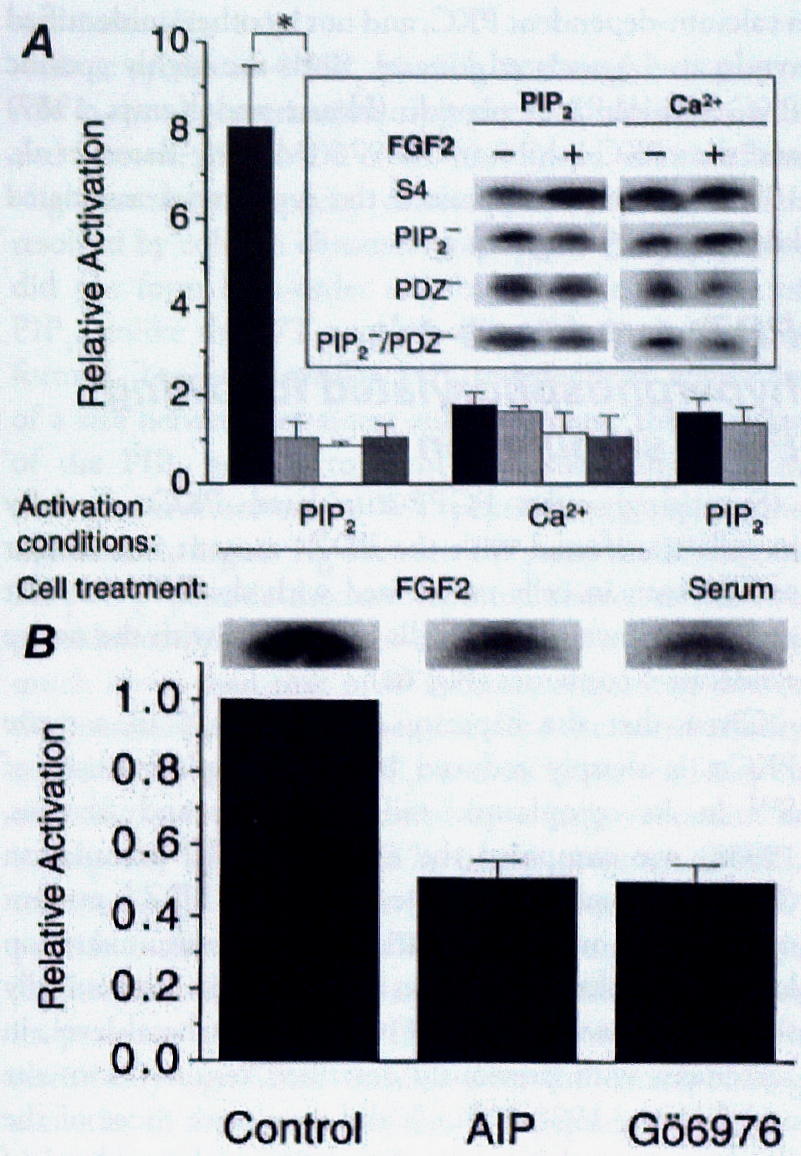

Fig. 6: Syndecan-4-associated kinase activities.

(A) Relative kinase activities of HA immunoprecipitates from RFPEC starved in $0.5 \%$ FBS for $24 \mathrm{hrs}$, then incubated for another 20 min either without or with $20 \mathrm{ng} / \mathrm{ml} \mathrm{FGF2,} \mathrm{or} \mathrm{with} 10 \%$ FBS. Data shown as mean \pm S.D. $(n=3)$ of the ratios between the kinase activity immunoprecipitated from FGF2- or FBS-treated cells, and from non-treated cells of the same type. Note that the kinase activity of S4 cells was increased significantly by FGF2 treatment relative to other cell lines, and that this relative increase was observed only when the immunoprecipitates where assayed in the presence of $\mathrm{PIP}_{2}$, but not when assayed in the presence of $\mathrm{Ca}_{2+}+$, phosphatidylserine, and diolein. Note also and that the $\mathrm{PIP}_{2}$-dependent kinase activities immunoprecipitated from $\$ 4$ and $\mathrm{PIP}_{2}$-expressing cells did not significantly differ from each other when cells were treated with FBS instead of FGF2 (black bars - S4 cells; light gray - $\mathrm{PIP}_{2}{ }^{-}$cells; white - $\mathrm{PDZ}^{-}$cells; dark gray $-\mathrm{PIP}_{2}$ - $/ \mathrm{PDZ}$ - cells).

(B) Effects of PKC autoinhibitor peptide (AIP, $100 \mathrm{nM}$ ), or of Gö6976 (10 $\mathrm{nM}$ ), on kinase activities (mean \pm S.D., $n=3$ ) of anti HA immunoprecipitates from RFPEC in the presence of $\mathrm{Ca} 2+$, phosphatidylserine, and diolein. Results are relative to the kinase activity of untreated control samples (insets in $A$ and B: representative phosphaimages of PKC $a$ optimal substrate peptide bands, used for quantifying the kinase activities of antiHA precipitates). 
a calcium-dependent PKC, and not by other unidentified syndecan-4-associated kinases. Both the highly specific PKC autoinhibitor peptide (House and Kemp, 1987) and the cPKC inhibitor Gö6976 (Martiny-Baron et al., 1993) effecrively suppressed the syndecan- 4 associated kinase activity (Fig, 6b).

\section{PDZ- syndecan-4 is \\ hyperphosphorylated following FGF2 stimulation}

Surprisingly, the FGF2-stimulated PKCa activity in cells transfected with the $\mathrm{PDZ}^{-}$mutant was similar to that seen in cells transfected with the $\mathrm{PIP}_{2}{ }^{-}$mutant and much lower than in cells transfected with the native syndecan-4 construct (Fig. 6a).

Given that the capacity of syndecan-4 to activate PKCa is sharply reduced by the phosphorylation of $S^{183}$ in its cytoplasmic tail (Horowitz and Simons, 1998a), we compared the effect of FGF2 stimulation on the phosphorylation level of the PDZ mutant to its effect on the $\$ 4$ varianc. FGF2 administration lowered the phosphorylation levels of $\$ 4$ in a statistically significant manner (Fig. 7) relative to its basal level, in agreement with previously described results (Horowitz and Simons, 1998a), but it did not lower those of the PDZ $Z^{-}$mutant. Moreover, the phosphorylation level of the PDZ mutant after FGF2 treatment was significantly higher than its basal level. "This increase may reflect the dependence of the phosphorylation level on a dynamic balance berween the opposing actions of a kinase and a phosphatase. "The dephosphorylarion of the $\mathrm{PDZ}^{-}$mutant would be impaired if the association of syndecan- 4 with the putative phosphatase were mediated by a PDZ adaptor protein. Consequently, the activity of the kinase that phosphorylates Ser ${ }^{183}$, which could conceivably be elevated by FGF2, would be unopposed by the phosphatase, resulting in an effective increase in the phosphorylation level of syndecan-4.

Since it is likely that the $\mathrm{PDZ}^{-}$mutant and the endogenous syndecan-4 copolymerize, the abolishment of the binding of the putative phosphatase may affect the phosphorylation levels of both syndecan-4 variants. As the currently available antibodies cannot separate between the endogenous and the exogenous syndecan- 4 species, we were able to measure the effect of FGF2 on the phosphorylation level of only the total syndecan-4 population, which was not significantly changed (Fig. 7). This outcome could be attributed to opposing and mutually canceling changes in the phosphorylation levels

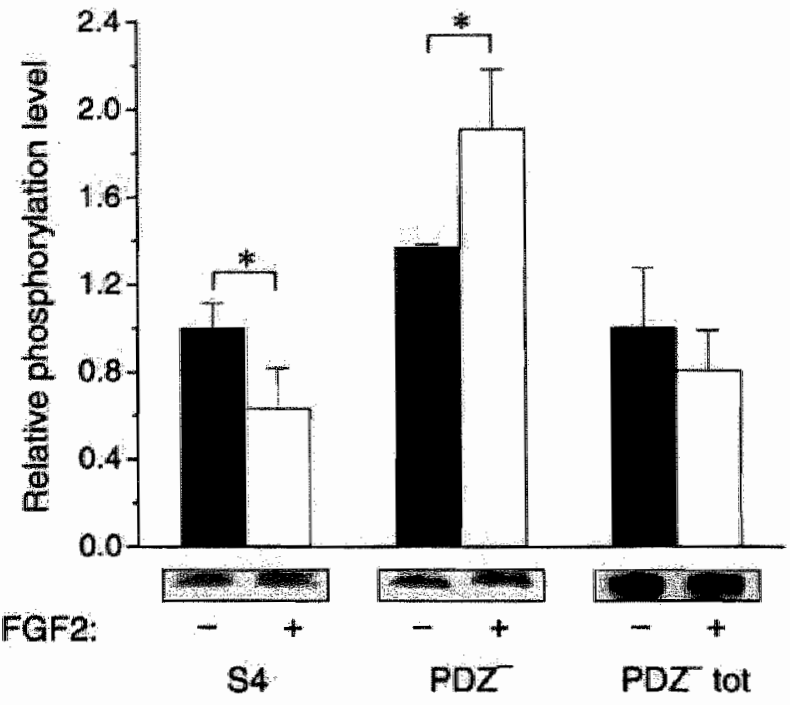

Fig. 7: Phosphorylation levels of syndecan-4.

Data shown as means \pm S.D. ( $n=3$ ) of syndecan -4 phosphorylation levels measured as described in Materials and Methods. Cells were incubated in 0.5\% FBS either without (black bars), or with (white bars) $20 \mathrm{ng} / \mathrm{ml}$ FGF2 starting 2 hrs before radio labeling, for a total of 4 hirs. Note the significant difference $(*-p<0.05$ ) between the phosphorylation levels of $S 4$ and PDZ- before and after FGF2 treatment (tot - total syndecan-4 population in the celli). Insets, immunoblots of representative samples from each cell group and condition.

of the endogenous and PDZ syndecan-4 populations in response to $\mathrm{FGF} 2$, thus implying that the expression of the PDZ mutant did not significantly affect the phosphorylation level of endogenous syndecan-4.

\section{PIP $P_{2}^{-}$mutation reduces syndecan-4 $P_{P} P_{2}$-dependent oligomerization and activation of $P K C \alpha$}

The capacity of syndecan-4 to activate PKCO is dependent on its affinity to $\mathrm{PIP}_{2^{*}}$ and on its tendency to oligomerize in the presence of this phosphoinositide (Horowitz and Simons, 1998a). The potent suppression of PKCa activity and of several cell functions by the $\mathrm{Y}^{192} \mathrm{KK} \rightarrow \mathrm{LQQ}$ mutation implies that the $\mathrm{PIP}{ }_{2}^{-}$ mutant has a dominant negative effect when expressed on a background of endogenous syndecan-4. Therefore, we investigated the effect of mixing $\mathrm{PIP}_{2}^{-}$mutated cytoplasmic syndecan-4 tail peptide with the WT tail peptide on the combined affinity of the mixture to $P_{2}$ in vitro. As little as $25 \%$ of $\mathrm{PIP}_{2}^{-}$peptide in the total WT/PIP ${ }_{2}^{-}$mixture increased the apparent $K_{p}$ of the mixture by 3 orders of magnitude compared with that of the WT peptide alone, as measured by surface plasmon 
Peptide fraction $(\%)$

\begin{tabular}{lcccc}
\hline$W T$ & 100 & 75 & 50 & 0 \\
\hline$P I P_{z}-$ & 0 & 25 & 50 & 100 \\
\hline$K_{d}$ & $10 \pm 2 n M$ & $9.1 \pm 1.8 \mu M$ & $24.3 \pm 0.0 \mu M$ & $940 \pm 3.3 \mu M$
\end{tabular}

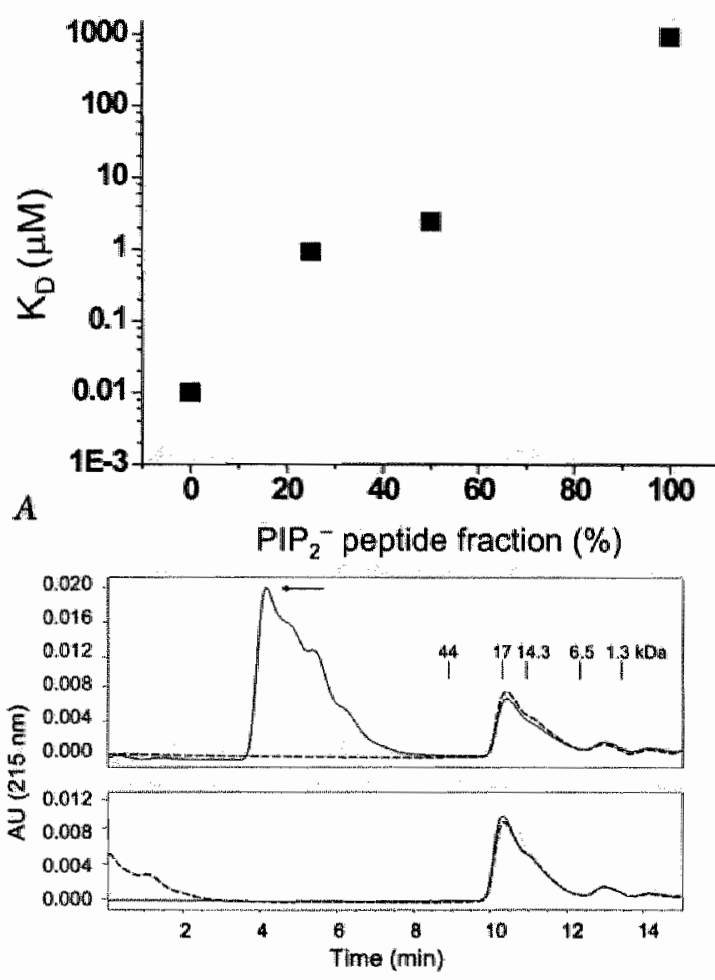

B

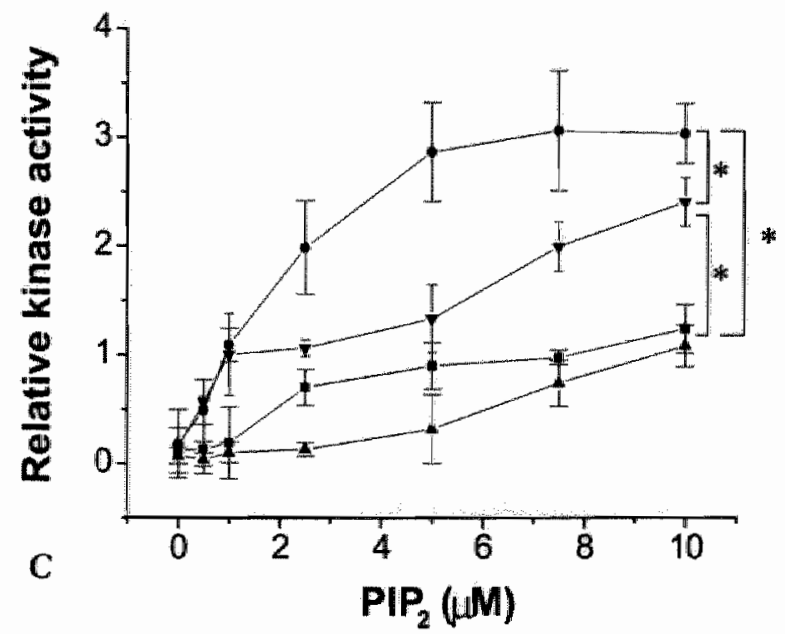

Fig. 8: In vitro experiments with synthetic WT and mutated syndecan-4 cytoplasmic tail peptides.

(A) Dependence of surface plasmon resonance-measured apparent first order equilibrium constants (KD) between $\mathrm{PIP}_{2}$ and $\mathrm{PIP}_{2}$-NT peptide mixtures on $\mathrm{PIP}_{2}$ - peptide fraction. Note the gradual elevation in KD value upon increasing the $\mathrm{PIP}_{2}-$ peptide fraction. resonance (Fig. 8a).

Since syrdecan-4-PIP binding is thought to play a role in the oligomerization of syndecan-4 tails (Horowitz and Simons, 1998a; Oh ex al, 1997a), we examined the oligomerization capacity of the $\mathrm{PIP}_{2}^{-}$peptide. When resolved by column chromatography, the $\mathrm{PIP}_{3}^{-}$peptides did not form high-order oligomers in the presence of $\mathrm{PIP}_{2^{3}}$ unlike the WT peprides (Fig, 8b). Both peptides formed, however, smaller $\mathrm{PIP}_{2}$-independent oligomers of a size between tetramers and hexamers. The capacity of the $\mathrm{PIP}_{2}$ peptide to form low-order oligomers in the same manner as the WT peptide may explain the significantly higher $\mathrm{K}_{\mathrm{D}}$ becween $\mathrm{PIP}_{2}$ and the $25 \%: 75 \%$ $\mathrm{PIP}_{2}^{-}:$WT peptide mixture reported above, as the two peptides could form hetero-oligomers of a $\mathrm{PIP}_{2}$ affinity much lower than that of WT homo-oligomers, due to the presence of the $\mathrm{PIP}_{2}-$ peptide. The decreased affinity of the $\mathrm{PIP}_{2}-$ peptide to $\mathrm{PIP}_{2}$, and its lower tendency to oligomerize were accompanied by a large reduction in its capacity to activate PKC $\alpha$ in the presence of $\mathrm{PIP}_{2}$ * relative to the WT peptide (Fig. 8c). Though the PDZ peptide is shorter than the WT peptide only by a single residue, the $\mathrm{C}$-terminal alanine, the $\mathrm{PKCa}$ activity in its presence at $2.5 \mu \mathrm{M} \leq\left[\mathrm{PIP}_{2}\right] \leq 10 \mu \mathrm{M}$ was lower in a statistically significant manner than the corresponding activities in the presence of the WT peptide, but higher than those of the $\mathrm{PIP}_{2}$ mutant.

\section{Discussion}

We have described a novel mechanism regulating growth factor signaling, distinctive both for its specificity to FGF2 (us. serum), as well as for the pivotal role of syndecan-4. The main feature of this signaling parhway is activation of $\mathbb{P K C} \alpha$ by the syndecan $-4 / \mathrm{PIP}_{2}$ complex in response to FGF2 stimulation. This process is controlled by the phosphorylation of $S^{183}$ in the cytoplasmic tail

(B) Column elution profiles of WT (top) and $\mathrm{PIP}_{2}$ - (bottom) cytoplasmic tail peptides with (continuous line) and without (dashed line) PIP ${ }_{z}$. Note the formation of high order oligomers by the WT (arrow) but not by the $\mathrm{PIP}_{2}$ - peptide in the presence of $\mathrm{PIP}_{2}$. Note also that both peptides are not present as monomers but form smaller oligomers of similar sizes, both in the presence and absence of $\mathrm{PIP}_{2^{*}}$

(C) Dependence of the in vitro activity of recombinant PKC $\alpha$ on PIP2 concentration, in the absence (squares) and in the presence of $1 \mu \mathrm{M}$ WT (circles), $P_{2}$ - (up-turned triangles), or $\mathrm{PDZ}^{-}$(down-turned triangles) cytoplasmic tail peptides (mean $\pm S . D ., n=3-6 ;-p<0.05$ ). The mean kinase activity measured at $1 \mu \mathrm{M}$ PIP2 with $1 \mu \mathrm{M}$ WT peptide was used as a unitary reference value. 
of syndecan-4 that down regulates the response to FGF2 by preventing $\mathrm{PIP}_{2}$-dependent oligomerization of syndecan- 4 and the subsequent activation of PKCa.

Our working model of this mechanism (Fig. 9) consists of the following steps:

(1) FGF2 binding to its high affinity tyrosine kinase receptor induces the activation of a putative serine/ threonine protein phosphatase type 1/2A (PP1/2A) (Horowitz and Simons, 1998b), which is associated with the cytoplasmic tail of syndecan- 4 through a PDZ adaptor protein.

(2) The PP1/2A dephosphorylates $\operatorname{Ser}^{183}$ in the membrane-proximal domain of the syndecan- 4 cytoplasmic tail, which is normally maintained at a high basal phosphorylation level. As the heparan sulfate chains carried by proteoglycans can reach estimated lengths of $80 \mathrm{~nm}$ (Kato et al., 1994), the dephosphorylation is likely to occur in a trans, rather than a cis mode in regard to the syndecan- 4 molecule carrying the FGF2-binding HS chain. Since syndecan-4 is a transmembrane protein, this dephosphorylation may similarly occur in the Golgiresiding syndecan-4.

(3) Dephosphorylation of syndecan-4 sharply increases its affinity to $\mathrm{PIP}_{2}$ (Horowitz and Simons, 1998a). $\mathrm{PIP}_{2}$ binding, in turn, facilitates the multimerization of syndecan -4 .

(4) The clustered syndecan- $4 / \mathrm{PIP}_{2}$ complex activates PKC $\alpha$, which associates with syndecan-4 through PIP $_{2}$ (Horowitz et al., 1999).

The existence of this regulatory mechanism is suggested by our observations that expression of $\mathrm{PIP}_{2}^{-}$or $\mathrm{PDZ}^{-}$ syndecan-4 mutants on a background of endogenous syndecan- 4 inhibits cell response to FGF2, but not to serum or to the HS binding EGF and PDGF $A B$, in a dominant-negative manner. In the case of the $\mathrm{PIP}_{2}^{-}$ mutation, the mistargeting of the mutant syndecan -4 leads to Golgi sequestration of its PDZ-binding partner. The critical role of this sequestration is emphasized by the lack of dominant-negative effects of the double $\mathrm{PIP}_{2}^{-} / \mathrm{PDZ}^{-}$syndecan- 4 mutation. In the case of the $\mathrm{PDZ}^{-}$deletion, FGF2 treatment would lead to an increase in the extent of syndecan-4 phosphorylation, and, consequently, would decrease PKC $\alpha$ activation due to the low affinity of phosphorylated syndecan -4 for PIP $_{2}$ (Horowitz et al., 1999).

A recent study on syndecan -4 knockout mice reported that the proliferative response of skin fibroblasts extracted from these mice did not differ from the response of cells from wild type mice (Echtermeyer et al., 2001). The difference between this finding and the significantly reduced proliferation rates of cells expressing the $\mathrm{PIP}_{2}-$ or $\mathrm{PDZ}^{-}$syndecan-4 mutants that we observed may stem from each of the following reasons: (a) as explained above, the expression of these mutants interferes with the function of endogenous syndecan- 4 . This acrive perturbation of a signaling parhway was not present in the mouse syndecan $-4^{-1-}$ cells; (b) differences between cell types (fibroblasts versus endothelial cells) used in the two studies; (c) assuming that Echtermeyer et al. used the same medium as in their migration assays (the medium used in their proliferation assays is not described), the $2 \%$ serum present in this medium may have contained other growth factors that compensated for the impaired response to $\mathrm{FGF} 2$.

\section{PIP $_{2}^{-}$mutation: effect on plasma membrane targeting of syndecan-4}

One interesting and unexpected finding in this study is the fact that $\mathrm{PIP}_{2}$ binding, rather than the interaction with a PDZ protein, targets syndecan-4 to the plasma membrane. The data supporting this observation include immunofluorescence staining showing reduced expression of the $\mathrm{PIP}_{2}^{-}$and $\mathrm{PIP}_{2}^{-} / \mathrm{PDZ}^{-}$mutants in the basolateral region and virtual absence of syndecan4 variants containing the $\mathrm{PIP}_{2}^{-}$mutation from the cell surface as demonstrated by FACS. Similarly, deletion of the PDZ morif in the syndecan-2 cytoplasmic tail did not eliminate its incorporation into the plasma membrane (Ethell and Yamaguchi, 1999).

The Golgi apparatus is a known site of $\mathrm{PIP}_{2}$ synthesis (Godi et al., 1999; Jones et al., 2000), and the involvement of $\mathrm{PIP}_{2}$ in protein sorting is suggested by preliminary observations (Morrow and Weidman, Mol. Biol. Cell, vol. 11 (suppl.), 280a, 2000). The actual targeting mechanism is, however, still unknown. The results of the FACS experiments (Fig. 5a) show that the $\mathrm{PIP}_{2}^{-}$ mutation precluded not only the basolateral targeting, but also the overall incorporation of syndecan- 4 in the plasma membrane.

The dominant-negative phenotype exhibited by the $\mathrm{PIP}_{2}-$ mutant suggests that it disrupts a syndecan-4dependent protein complex involved in mediating FGF2 signaling. Interestingly, it is the presence of the $\mathrm{PIP}_{2}^{-}$ mutant and not a mere absence of syndecan-4 from the cell, that impairs cellular function. This conclusion is supported by studies of the $\mathrm{PIP}_{2}^{-} / \mathrm{PDZ}^{-}$mutant that does not cause a similar dominant-negative phenotype, yet it is similarly absent from the plasma membrane (Fig. $4 \mathrm{c}$ ), and by a recently described syndecan-4 knockout mice (Ishiguro et al., 2000). We propose, instead, that the 
Fig. 9: Schematic representation of FGF2 signal transduction mediated by syndecan-4.

(FGFR - FGF2 tyrosine kinase receptor; HS/CS - heparan or chondroitin sulfate side chains). See Discussion for details.

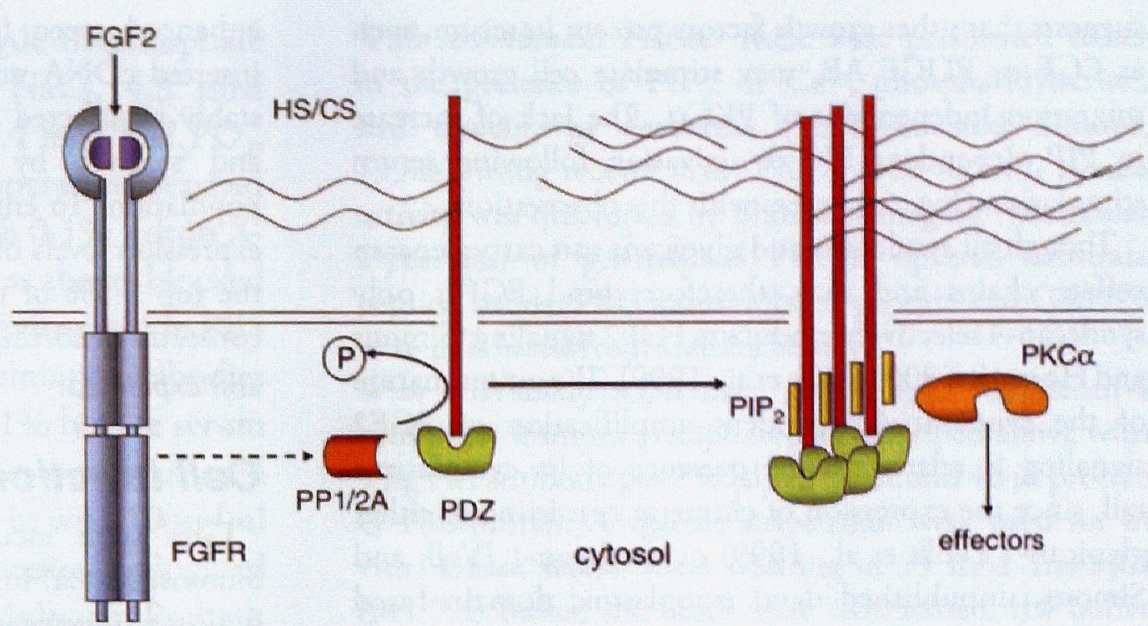

the phosphatase and kinase.

The hyperphosphorylated $\mathrm{PDZ}^{-}$mutant has reduced tendencies to oligomerize and bind $\mathrm{PIP}_{2}$, resulting in a diminished capacity to activate PKC $\alpha$ (Horowitz and Simons, 1998a). Moreover, its presence in the plasma membrane may interfere with the oligomerization, $\mathrm{PIP}_{2}$ binding, and activation of PKC $\alpha$ by dephosphorylated endogenous syndecan-4. This loss of syndecan-4dependent activation of $\mathrm{PKC} \alpha$ in response to FGF2 may then account for the dominant negative effects of the $\mathrm{PDZ}^{-}$mutation.

It should be noted that the lower activity of PKC $\alpha$ in the presence of the $\mathrm{PDZ}^{-}$peptide compared to the WT peptide (Fig. 8c) leaves open the possibility that the induction of a dominant negative phenotype by the PDZmutation can be caused by reduction in PKC $\alpha$ activity, similar to the $\mathrm{PIP}_{2}^{-}$cells. While it is not obvious how deletion of a single $\mathrm{C}$-terminal residue in the cytoplasmic tail of syndecan-4 produces this effect, the deletion could conceivably affect the conformation of the $\mathrm{PIP}_{2}$-binding motif and hence reduce its affinity to $\mathrm{PIP}_{2}$.

\section{FGF2-specificity of the syndecan-4 signaling pathway}

Another intriguing observation in this study is the apparent FGF2-specificity (vs. serum, EGF, and PDGF) of the syndecan -4 signaling pathway. This specificity may stem in part from the choice of functional assays used in this study, as both cell migration (Harrington et al., 1997) and proliferation (Besson and Yong, 2000; Schonwasser et al., 1998) have been linked to the activation of $P K C \alpha$, the kinase regulated by syndecan -4 . However, not all FGF2-induced signaling events may necessarily be regulated in this fashion. The fact that unlike FGF2, serum stimulation of cell growth and proliferation is not affected by the $\mathrm{PIP}_{2}^{-}$and $\mathrm{PDZ}^{-}$syndecan- 4 mutants, 
suggests that other growth factors present in serum, such as $\mathbb{E G F}$ or PDGF $\mathrm{AB}$, may stimulate cell growth and migration independent of $P$.KCa. The lack of increase in $\mathrm{PIP}_{2}$-dependent $\mathrm{PKCa}$ activation following serum stimulation (Fig. 6a) agrees with this observation.

Though all syndecans and glypicans can carry heparan sulfate chains and may, therefore, bind FGF2, only syndecan-4 selectively modulares FGF2 signaling (Simons and Horowirz, 2001; Volk er al., 1999). The unique nature of the syndecan-4-dependent amplification of FGF2 signaling is related to the presence of its cytoplasmic tail, since the expression of chimeras consisting of either glypican-1 (Volk et al., 1999) or syndecan-1 (Volk and Simons, unpublished data) ectoplasmic domain fused to the transmembrane and cytoplasmic domains of syndecan-4 mimics the positive effects of intact syndecan4 overexpression on cell proliferation and migration. These findings, together with the results of the current study, suggest that $\mathrm{PIP}_{2}$ binding, and the concomitant ability to acrivate $P K C \alpha$, underlie the unique capacity of syndecan-4 among the cell surface proteoglycans to regulate FGF2 signaling.

In summary, we describe a novel signal transduction pathway that involves selecrive regulation of endothelial cell migration and proliferation by FGF2 via syndecan -4 .

\section{Materials and methods}

\section{cDNA constructs, mutagenesis, and transfection}

Syndecan-4 cDNA containing an ectoplasmic HA tag (Shworak er al., 1994) was subcloned into MSCV retroviral vector (Hawley et al., 1994) between its EcoRI and Bglll sites. Sitedirected mutations were incroduced into syndecan-4 cDNA by PCR-mediated oligo mutagenesis (QuikChange, Stratagene). The vector was delivered into RFPEC by either retroviral (as described, ref. (Volk et al., 1999)) or liposome-mediated transfection (LipofectAmine Plus, Invitrogen). In both cases, stably transfected cells were selected by neomycin resistance $(0.4 \mathrm{mg} / \mathrm{ml}$ Geneticin, Invitrogen). Syndecan4 expression levels were assessed by immunoblotring cell lysates as described (Horowitz and Simons, 1998a), with $50 \mathrm{mU} / \mathrm{ml}$ horseradish peroxidase-conjugated $3 \mathrm{~F} 10 \mathrm{HA}$ antibody (Roche).

Alternatively, the HA-tagged syndecan-4 CDNA constructs were inserted between the Xhol and EcoRI restriction sites of a bicistronic mammalian expression plasmid (pIRES2-EGFP, Clontech) that co-expresses enhanced green fluorescent protein (EGFP) and the inserted cDNA under a single promoter. RFPEC were stably transfected by LipofectAmine 2000 (Invitrogen) and selected by neomycin resistance as a pooled population. To enrich each pool with cells having high expression levels of the transfected protein, only cells in the top 2-5\% of the population as determined by $2-3$ consecutive sorring rounds (see below), were rerained and expanded.

\section{Cell function assays}

Cells were incubated as described. (Horowitz and Simons, 1998a) in M199 medium (Invitrogen) with the indicated supplements. Cell migration was measured by "wounding" assays (Tang et al., 1997) in which cells were grown to sub-confluence in 6-well plates, then starved for $24 \mathrm{hrs}$ in $0.5 \%$ serum. The cell layer was scratched with a piperte tip, producing a gap approximately $2 \mathrm{~mm}$ wide. The gap width was measured at marked locations from images taken by inverted microscope (TMS-F, Nikon) immediately after the scratching, and again $6 \mathrm{hrs}$ later at the same locations. Proliferation and rube formation assays were done as described (Volk et al., 1999). All experiments were repeated with two clones of cells stably transfected with each syndecan-4 variant. Neomycin was withdrawn from the culture medium at least 24 hrs before the cell function assays, as well as before all other experiments with stably transfected RFPEC, to prevent artifacts caused by neomycin sequestration of $\mathrm{PIP}_{2}$ (Gabev et al., 1989).

\section{Fluorescence-assisted cell sorting (FACS)}

To measure the amount of exogenous syndecan 4 present on the cell surface, cells were dissociated from plates (non-enzymatic solution, Sigma), labeled with $1 \mu \mathrm{g} / \mathrm{ml}$ antibody to HA (Roche), followed by $10 \mu \mathrm{g} /$ $\mathrm{ml}$ of anti-rat IgG conjugated to red-pycoerythrin ( $\mathrm{R}$ $P E$; Jackson Immunologicals) and sorted automatically (FACScan, Beckton Dickinson). Detection of the surface expression of both exogenous and endogenous syndecan4 was done similarly, using a 1:50 dilution of antiserum to the ectoplasmic domain of syndecan-4 (Shworak et al., 1994), and $10 \mu \mathrm{g} / \mathrm{ml}$ of anti-rabbit $\mathrm{IgG}$ conjugated to Alexa-594 (Molecular Probes). To derect the overall cellular expression of exogenous syndecan-4, cells were scanned at the EGFP-emitted wavelength $(488 \mathrm{~nm})$.

Immunofuorescence

RFPEC were plated in chamber slides (Nalge 
Nunc), fixed with $2 \%$ formaldehyde in phosphate buffered saline (PBS; $137 \mathrm{mM} \mathrm{NaCl}, 4.3 \mathrm{mM}$ $\mathrm{Na}_{2} \mathrm{HPO}_{4} \cdot 7 \mathrm{H}_{2} \mathrm{O}, 2.7 \mathrm{mM} \mathrm{KCl}, 1.4 \mathrm{mM} \mathrm{KH}_{2} \mathrm{PO}_{4}$, $\mathrm{pH} 7.3$ ), for $10 \mathrm{~min}$ at room temperature, washed twice with PBS, permeabilized with $0.1 \%$ Triton X$100 / \mathrm{PBS}$ for $10 \mathrm{~min}$, washed again as above, blocked with 3\% bovine serum albumin (Invitrogen) in PBS for $30 \mathrm{~min}$, and incubated with primary antibodies at the indicated concentrations in 1\% bovine serum albumin in PBS for 3 hrs. The slides were washed 4 times as above, and incubated for $1 \mathrm{hr}$ with $10 \mu \mathrm{g} / \mathrm{ml}$ of the appropriate secondary antibodies conjugated either to Alexa 488, or Alexa 594 (Molecular Probes), washed again as before, and mounted with ProLong medium (Molecular Probes). Slides were imaged by laser-scanning confocal microscopy (Radiance2000, Bio-Rad).

\section{Immunoprecipitation}

Cells were lysed and immunoprecipitated as described (Horowitz and Simons, 1998a; Horowitz and Simons, 1998b), using $80 \mu \mathrm{l}$ anti-HA affinity matrix (Roche) suspension per $750 \mu \mathrm{l}$ cell lysate. Alternatively, endogenous or HA-tagged syndecan- 4 was immunoprecipitated with $10 \mu$ cytoplasmic tail antiserum (Shworak et al., 1994), or with $5 \mu \mathrm{g}$ HA antibody (3F10, Roche) per $750 \mu \mathrm{l}$ cell lysate, respectively, and $40 \mu \mathrm{l}$ suspension of protein G Plus/protein A agarose (Oncogene). Where indicated, glycosaminoglycan chains were digested as described (Horowitz and Simons, 1998b).

\section{Surface plasmon resonance}

Experiments were carried out as described (Horowitz et al , 1999), using 28 amino acid-long (Horowitz and Simons, 1998a) syndecan-4 cytoplasmic tail peptides (Genemed Synthesis) as ligands, and $\mathrm{PIP}_{2}$ (Sigma) as analyte.

\section{Column chromatography}

Synthetic syndecan-4 cytoplasmic tail peptides (1 $\mu \mathrm{M})$, either alone, or mixed with $\mathrm{PIP}_{2}(2 \mu \mathrm{M})$ in $0.1 \mathrm{M}$ phosphate $\mathrm{pH} 7.4$ and $20 \%$ acetonitrile, were injected $(22.5 \mu \mathrm{l})$ into a $300 \times 6 \mathrm{~mm}$ silica $(5 \mu \mathrm{m}$ spheres, 60 ه pores) HPLC (Waters, 515 Pump, 2487 Absorbance Detector)-mounted column (YMC). Elution profiles corresponding to light absorbance at $210 \mathrm{~nm}$ were recorded digitally (Millenium ${ }^{32}$, Waters).

Kinase assays
With recombinan PKCa. These were performed either in the presence of $\mathrm{PIP}_{2}$, or $\mathrm{Ca}^{2 *}$, phosphatidylserine, and diolein, as described (Horowitz and Simons, 1998a), using mecombinant PKCa (120 ng/ml). Kinase acrivity was quantified by phospho-imaging (Molecular Dynamics) of gel-resolved PKCBI optimal substrate peptide bands. PKC autoinhibitor peptide and Gö6976 were purchased from Calbiochem.

With immunoprecipitated syndecan-4. Syndecan-4. complexes immunoprecipitated as described above with $5 \mu \mathrm{g} \mathrm{HA}$ ancibody per $750 \mu \mathrm{l}$ cell lysate and $40 \mu \mathrm{l}$ protein $G$ Plus/protein A agarose suspension were used for in vitro kinase assays. After washing in $25 \mathrm{mM}$ Tris- $\mathrm{HCl}$ ( $\mathrm{pH}$ 7.4) buffer, the beads were sedimented, the buffer removed and replaced with $30 \mathrm{ml}$ kinase assay buffer containing either $\mathrm{PIP}_{2}$, or $\mathrm{Ca}^{2 *}$, phosphatidylserine, and diolein, as described (Horowitz and Simons, 1998a). The assay was sropped by adding $10 \mu \mathrm{l} \times 4$ Laemmli sample buffer (final concentration 2\% SDS, $10 \%$ glycerol, $0.5 \%$ $\beta$-mercaptoethanol, $0.004 \%$ bromophenol blue, $50 \mathrm{mM}$ Tris- $\mathrm{HCl}, \mathrm{pH} \mathrm{6.8)}$ and boiling for 4 min. Kinase activicy was quantified as in the recombinant PKC $\alpha$ assays.

\section{Measurement of syndecan-4 phosphorylation level}

RFPEC in $100 \mathrm{~mm}$ plates were grown for $24 \mathrm{hrs} \mathrm{in}$ phosphate-free DMEM (Invitrogen) supplemented. with $0.5 \%$ fetal bovine serum (FBS), and radiolabeled for 4 hrs with $0.5 \mathrm{mCl} / \mathrm{ml}^{32} \mathrm{P}$-orthophosphoric acid (New England Nuclear). Cells were washed with tris-buffered saline $(137 \mathrm{mM} \mathrm{NaCl}, 25 \mathrm{mM}$ Tris$\mathrm{HCl}, \mathrm{pH} \mathrm{7.4)}$, and scraped off in $0.5 \mathrm{ml} \mathrm{lysis} \mathrm{buffer}$ $\left(150 \mathrm{mM} \mathrm{NaCl}, 20 \mathrm{mM} \mathrm{Nal}, 20 \mathrm{mM} \mathrm{Nap} \mathrm{P}_{2} \mathrm{O}_{7}\right.$, $5 \mathrm{mM}$ EDTA, $5 \mathrm{mM}$ EGTA, $1 \mathrm{mM} \mathrm{Na} \mathrm{VO}_{4}, 1$ mM PMSE, 1\% Triton X-100, 50 mM HEPES, pH 7.4) supplemented with protease inhibitor cocktail (Complete, Boehringer). Cell lysates were precleared by incubation with $1 \mu g$ non-immune rat $\lg$ (Sigma) and $20 \mu$ Protein G Plus/ Protein A agarose bead suspension at $4^{\circ} \mathrm{C}$ for $1 \mathrm{hr}$. Following agarose bead sedimentation, the cleared samples were supplemented with $80 \mu \mathrm{l}$ of anti-HA affinity matrix bead suspension (Roche) or with $10 \mu \mathrm{l}$ cytoplasmic tail antiserum (Shworak et al., 1994) and $40 \mu$ suspension of protein G Plus/protein A agarose (Oncogene) and incubated in rotating tubes over night at $4{ }^{\circ} \mathrm{C}$. The beads were sedimented, washed three times in heparinase digestion buffer 
$(50 \mathrm{mM} \mathrm{NaCl}, 4 \mathrm{mM} \mathrm{CaCl}, 20 \mathrm{mM}$ Tris- $\mathrm{HCl}, \mathrm{pH}$ 7.4), and glycosaminoglycan chains were digested as described (Horowitz and Simons, 1998b). The immunoprecipitated syndecan-4 core protein was dissociated from the beads by a 10 min incubation in $40 \mu \mathrm{L} \mathrm{Laemmli}$ sample buffer at $95^{\circ} \mathrm{C}$. Samples were resolved on $12 \%$ Tris-Glycine gels (BioRad), and the bands corresponding to the cytoplasmic tail of syndecan- 4 were identified by immunoblotting with a peroxidase-conjugated antibody to the $\mathrm{HA}$ tag (Roche). The bands were excised and the ${ }^{32} \mathrm{P}$ lev el was measured by scintillation counter (Beckman).

\section{Acknowledgements}

Supported in part by the American Heart Association Scientist Development Grant 9730282N (AH), and by National Institutes of Health grants HL62289 and P50 HL63609 (MS). We thank N. Shworak for syndecan-4 cDNA and antiserum, R. Hawley for MSCV plasmid, John Zeind for help with HPLC, and L. Cantley for recombinant PKC $\alpha$ and for useful discussions.

\section{REFERENCES}

Alexander, C.M., F. Reichsman, M.T. Hinkes, J. Lincecum, KA. Becker, S. Cumberledge, and $M$. Bernfeld. 2000. Syndecan-1 is required for wnt-1induced mammary tumorigenesis in mice. Nat Genet. 25:329-32.

Baciu, P.C., and P.F. Goetinck. 1995. Protein kinase $C$ regulates the recruitment of syndecan- 4 into focal contacts. Mol Biol Coll. 6:1503-13.

Bernfield, M., M. Gotte, P.W. Park, O. Reizes, M.L. Fitzgerald, J. Lincecum, and M. Zako. 1999. Funcrions of cell surface heparan sulfate proteoglycans. Annu Rev Biocbem. 68:729-77.

Besson, A., and V.W. Yong. 2000. Involvement of p21(Waf1/Cip1) in protein kinase C alpha-induced cell cycle progression. Mol Cell Biol. 20:4580-90.

Cai, H., U. Smola, V. Wixler, I. Eisenmann-Tappe, M.T. Diaz-Meco, J. Moscat, U. Rapp, and G.M. Cooper. 1997. Role of diacylglycerol-regulated protein kinase C isotypes in growth factor activation of the Raf-1 protein kinase. Mol Cell Biol. 17:732-41.

Cohen, A.R., D.F. Woods, S.M. Marfatia, Z. Walther, A.H. Chishti, J.M. Anderson, and D.F. Wood. 1998. Human CASK/LIN-2 binds syndecan-2 and protein 4.1 and localizes to the basolateral membrane of epithelial cells. J Cell Biol. 142:129-38.

Echtermeyer, F, M. Streit, S. Wilcox-Adelman, S. Saoncella, F. Denhez, M. Detmar, and P.F. Goetinck. 2001. Delayed wound repair and impaired angiogenesis in mice lacking syndecan-4. J Clin lnvest. 107:R9-R14. Ethell, I.M., K. Hagihara, Y. Miura, F. Irie, and Y. Yamaguchi. 2000. Synbindin, A novel syndecan-2binding protein in neuronal dendritic spines. $/$ Cell Biol. 151:53-68.

Ethell, I.M., and Y. Yamaguchi. 1999. Cell surface heparan sulfate proteoglycan syndecan- 2 induces the maturation of dendritic spines in rat hippocampal neurons. J Cell Biol. 144:575-86.

Gabev, E., J. Kasianowicz, T. Abbott, and S. McLaughlin. 1989. Binding of neomycin to phosphatidylinositol 4,5bisphosphate (PIP2). Biochim Biophys Acta. 979:105-12. Gallo, R.L., M. Ono, T. Powsic, C. Page, E. Eriksson, M. Klagsbrun, and M. Bernfield. 1994. Syndecans, cell surface heparan sulfate proteoglycans, are induced by a proline-rich antimicrobial peptide from wounds. Proc Natl Acad Sci US A. 91:11035-9.

Gao, Y., M. Li, W. Chen, and M. Simons. 2000. Synectin, syndecan-4 cytoplasmic domain binding PDZ protein, inhibits cell migration. / Cell Physiol. 184:373-379.

Godi, A., P. Pertile, R. Meyers, P. Marra, G. Di Tullio, C. 
lurisci, A. Luini, D. Corda, and M.A. De Matteis. 1999. ARF mediates recruitment of PtdIns-4-OH kinase-beta and stimulates synthesis of PtdIns(4,5)P2 on the Golgi complex. Nat Cell Bial. 1:280-7.

Grootjans, J.J., P. Zimmermann, G. Reekmans, A. Smets, G. Degeest, J. Durr, and G. David. 1997. Syntenin, a PDZ protein that binds syndecan cytoplasmic domains. Proc Natl Acad Sci US A. 94:13683-8.

Harringron, E.O., J. Loffler, P.R. Nelson, K.C. Kent, M. Simons, and J.A. Ware. 1997. Enhancement of migration by protein kinase Calpha and inhibition of proliferation and cell cycle progression by protein kinase Cdelta in capillary endothelial cells. J Biol Chem. 272:7390-7.

Hawley, R.G., F.H. Lieu, A.Z. Fong, and T.S. Hawley. 1994. Versatile retroviral vectors for potential use in gene therapy. Gene Ther. 1:136-8.

Horowitz, A., M. Murakami, Y. Gao, and M. Simons. 1999. Phosphatidylinositol-4,5-bisphosphate mediates the interaction of syndecan-4 with protein kinase C. Biochemistry. 38:15871-7.

Horowitz, A., and M. Simons. 1998a. Phosphorylarion of the cytoplasmic tail of syndecan-4 regulates activation of protein kinase Calpha. / Biol Chem. 273:25548-51.

Horowitz, A., and M. Simons. 1998b. Regulation of syndecan-4 phosphorylation in vivo. $/$ Biol Chem. 273:10914-8.

House, C., and B.E. Kemp. 1987. Protein kinase C contains a pseudosubstrate prototope in its regulatory domain. Science. 238:1726-8.

Hsueh, Y.P., F.C. Yang, V. Kharazia, S. Naisbitt, A.R. Cohen, R.J. Weinberg, and M. Sheng. 1998. Direct interaction of CASK/LIN-2 and syndecan heparan sulfate proteoglycan and their overlapping distribution in neuronal synapses. / Cell Biol. 142:139-51.

Ishiguro, K., K. Kadomatsu, T. Kojima, H. Muramatsu, S. Tsuzuki, E. Nakamura, K. Kusugami, H. Saito, and T. Muramatsu. 2000. Syndecan-4 deficiency impairs focal adhesion formation only under restricted conditions. $J$ Biol Chem. 275:5249-52.

Jones, D.H., J.B. Morris, C.P. Morgan, H. Kondo, R.F. Irvine, and S. Cockcroft. 2000. Type I phosphatidylinositol 4-phosphate 5-kinase directly inreracts with ADP-ribosylation factor 1 and is responsible for phosphatidylinositol 4,5-bisphosphate synthesis in the golgi compartment. I Biol Chem. 275:13962-6.

Kato, M., H. Wang, M. Bernfield, J.T. Gallagher, and J.E. Turnbull. 1994. Cell surface syndecan-1 on distinct cell types differs in fine structure and ligand binding of its heparan sulfate chains. J Biol Chem. 269:18881-90.

Kojima, T., N.W. Shworak, and R.D. Rosenberg. 1992.
Molecular cloning and expression of two distinct cDNAencoding heparan sulfate proteoglycan core proteins from a rat endothelial cell line. J Biol Chem. 267:4870-7.

Kolch, W., G. Heidecker, G. Kochs, R. Hummel, H. Vahidi, H. Mischak, G. Finkenzeller, D. Marme, and U.R. Rapp. 1993. Protein kinase $C$ alpha activates RAF1 by direct phosphorylation. Nature. 364:249-52.

Kolch, W., A. Philipp, H. Mischak, E.M. Dutil, T.M.

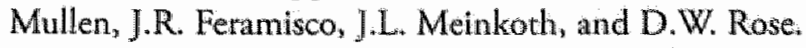
1996. Inhibition of Raf-1 signaling by a monoclonal antibody, which interferes with $\operatorname{Raf}-1$ activation and with Mek substrate binding. Oncogene. 13:1305-14.

Lallena, M.J., M.T. Diaz-Meco, G. Bren, C.V. Paya, and J. Moscat. 1999. Activation of IkappaB kinase beta by protein kinase C isoforms. Mol Cell Biol. 19:2180-8.

Lee, D., E.S. Oly, A. Woods, J.R. Couchman, and W. Lee. 1998. Solution structure of a syndecan -4 cytoplasmic domain and its interaction with phosphatidylinositol 4,5-bisphosphate. J Biol Chem. 273:13022-9.

$\mathrm{Li}_{4}$ J., L.F. Brown, R.J. Laham, R. Volk, and M. Simons. 1997. Macrophage-dependent regulation of syndecan gene expression. Circ Res. 81:785-96.

Martiny-Baron, G., M.G. Kazanietz, H. Mischak, P.M. Blumberg, G. Kochs, H. Hug, D. Marme, and C. Schachtele. 1993. Selective inhibition of protein kinase C isozymes by the indolocarbazole Go 6976. J Biol Chem. 268:9194-7.

Nakamura, N. C. Rabouille, R. Warson, T. Nilsson, N. Hui, P. Slusarewicz, T.E. Kreis, and G. Warren. 1995. Characterization of a cis-Golgi matrix protein, GM130. J Cell Biol. 131:1715-26.

Nikkari, S.T., H.T. Jarvelainen, T.N. Wight, M. Ferguson, and A.W. Clowes. 1994. Smooth muscle cell expression of extracellular matrix genes after arterial injury. $A m$ J Pathol. 144:1348-56.

Oh, E.S., A. Woods, and J.R. Couchman. 1997a. Multimerization of the cytoplasmic domain of syndecan4 is required for its ability to activate protein kinase C. I Biol Chem. 272:11805-11.

Oh, E.S., A. Woods, and J.R. Couchman. $1997 \mathrm{~b}$. Syndecan-4 proteoglycan regulates the distribution and acrivity of protein kinase C. J Biol Chem. 272:8133-6.

Oh, E.S., A. Woods, S.T. Lim, A.W. Theibert, and J.R. Couchman. 1998. Syndecan-4 proteoglycan cytoplasmic domain and phosphatidylinositol 4,5- bisphosphate coordinately regulate protein kinase $\mathrm{C}$ activity. J Biol Chem. 273:10624-9.

Rapraeger, A.C., A. Krufka, and B.B. Olwin. 1991. Requirement of heparan sulfate for bFGF-mediated fibroblast growth and myoblast differentiation. Science. 
252:1705-8.

Schonwasser, D.C., R.M. Marais, C.J. Marshall, and P.J. Parker. 1998. Activation of the mitogen-activated protein kinase/extracellular signal- regulated kinase pathway by conventional, novel, and atypical protein kinase $C$ isotypes. Mol Cell Brol. 18:790-8.

Shworak, N.W., M. Shirakawa, R.C. Mulligan, and R.D. Rosenberg. 1994. Characterization of ryudocan glycosaminoglycan acceptor sites. I Biol Chem. 269:21204-14.

Simons, M., and A. Horowitz. 2001. Syndecan-4. mediated signalling. Cell Signal. 13:855-62.

Songyang, Z., A.S. Fanning, C. Fu, J. Xu, S.M. Marfatia, A.I-I. Chishti, A. Crompton, A.C. Chan, J.M. Anderson, and L.C. Cantley. 1997. Recognition of unique carboxylterminal motifs by distinct PDZ domains. Science. 275:73-7.

Tang, S., K.G. Morgan, C. Parker, and J.A. Ware. 1997. Requirement for protein kinase $\mathrm{C}$ theta for cell cycle progression and formation of actin stress fibers and filopodia in vascular endothelial cells. / Biol Chem. 272:28704-11.

Volk, R., J.J. Schwartz, J. Li, R.D. Rosenberg, and M. Simons. 1999. The role of syndecan cytoplasmic domain in basic fibroblast growth factor-dependent signal transduction. J Biol Chem. 274:24417-24.

Wang, A., M. Nomura, S. Patan, and J.A. Ware. 2002. Inhibition of protein kinase Calpha prevents endothelial cell migration and vascular tube formation in vitro and myocardial neovascularization in vivo. Circ Res. 90:60916.

Woods, A. and J.R. Couchman. 1994. Syndecan 4 heparan sulfate proteoglycan is a selectively enriched and widespread focal adhesion component. Mol Biol Cell. 5:183-92. 


\section{Chapter 4}

Clustering induces redistribution of syndecan-4 core protein into raft membrane domains

Eugene Tkachenko and Michael Simons

Journal of Biological Chemistry 2002; 277: 19946-19951. 


\section{Abstract}

Syndecan-4 is a heparan sulfate carrying core protein that has been directly implicated in fibroblast growth factor 2 (FGF2) signaling. Recent studies have suggested that most signaling proteins localize to the raft compartment of the plasma cell membrane. To establish if syndecan 4 is present in the raft compartment, we have studied the distribution of the core protein and an Fc receptor (FcR)-syndecan-4 chimera prior to and following clustering with FGF2 or antibodies. While unclustered syndecan-4 was present predominantly in the non-raft membrane compartment, clustering induced extensive redistribution to the rafts as demonstrated by the sucrose gradient centrifugation and live confocal microscopy. At the same time, while syndecan4 and caveolin-1 moved in tandem, syndecan-4 was not present in caveolae, a major subset of raft compartments. We conclude that syndecan4 clustering induces its own redistribution to the non-caveolae raft compartment. This process may play an important role in syndecan-4 mediation of FGF2 signaling.

\section{Introduction}

Syndecans, a four member family of transmembrane proteoglycan core proteins, are found in a wide spectrum of cells and engage in a variety of interactions including binding growth factors, growth factor receptors, matrix proteins such as fibronectin and vitronectin, lipids and other with biologically active molecules $(1,2)$. All syndecans carry both heparan sulfate and chondroitin sulfate chains on their extracellular domain and engage in PDZ-dependent interaction via conserved intracellular domains $(1,2)$. Syndecan- 4 is a unique member of the syndecan core protein family. Unlike other syndecans, it possesses a PIP2 binding site in its cytoplasmic tail that allows it to bind and activate PKCa $(3,4)$. Syndecan-4 is found on endothelial cells and is directly involved in regulation of FGF2-induced cell growth and migration (5).

While previous studies have shown that syndecan-4 is predominantly found on the baso-lateral plasma cell membrane and focal adhesions $(6,7)$, litcle information is available regarding its association with various membrane sub-domains. Recent studies have suggested that rafts, lipid-ordered microdomains entiched by cholesterol and sphingolipids, act as platforms for conducting a variety of cellular functions, such as vesicular trafficking and signal transduction $(8,9)$. We have conducted this study, therefore, to derermine whether activation of syndecan- 4 signalings initiated by its oligomerization on the plasma cell membrane, leads to irs appearance in the membrane rafts.

Several protein families have been reported to modify lipid rafts structurally and functionally. These include integral membrane proteins such as caveolins and fotillins, exoplasmic GPI-linked proteins such as Thy-1 and alkaline phosphatase, and receptor tyrosine kinases among others $(9)$. Caveolin integration into the microenviroment of a lipid raft leads to raft's invagination and formation of caveolae (9-11). Caveolae are formed in many cell types, including endothelial cells (12) and they may play a role in modulation of cell signaling. One hypothesis suggests that interactions of caveolins with signaling molecules regulate their activation status.

Since FGF2-induced syndecans-4 dependent signaling requires the presence of heparan sulfate chains on core protein's extracellular domain (13), it is reasonable to hypothesize that FGF2 induces aggregation of syndecans-4 complexes in the plasma cell membrane. However, since FGF2 induces a number of other signaling events that may affect syndecans- 4 movement in the plasma cell membrane in manner independent of oligomerization of its extracellular domains, we linked the extracellular domain of the human $F c$ receptor (FCR) to the transmembrane/cytoplasmic domains of syndecans- 4 . The resultant chimera can then be aggregated with an immunoglobulin, mimicking FGF2-induced syndecans4 oligomerization. We found that such an aggregation of syndecan- 4 cores leads to a shift of syndecans- 4 complexes from the non-taft to raft microdomains of the plasma cell membrane. At the same time, while syndecans- 4 motion was synchronous with movements of caveolin-1, syndecans -4 was not present in the caveolae portion of the plasma membrane rafts.

\section{Materials and Methods}

\section{Antibodies and Reagents}

Polyclonal rabbit antisera against cytoplasmic and extracellular domains of syndecan-4 were described elsewhere (14). Polyclonal chicken IgY against extracellular domains of syndecan-4 was produced (Aves Labs) using the same peptide as previously used for generation in rabbits (14). Anti-FcR (CD64) monoclonal antibody was purchased from $\mathrm{Abcam}$ (UK). $\mathrm{Cy}-3$ and biotin-SP conjugated non-immune human IgG, Cy-3 conjugated goat anti-human $\mathrm{F}(\mathrm{ab})_{2}$, fragment, $\mathrm{Cy}-5$ conjugated streptavidin and goat anti-chicken $F\left(a b^{3}\right) 2$ fragment were 
purchased from Jackson Immunoresearch. Secondary antibodies conjugated to Alexa-594, and a nuclear stain ToPro3 were from Molecular Probes. Alexa-488-labelled proaerolysin variant (FLAER) was purchased from Protox Biotech (Victoria, BC). Secondary antibodies conjugated. to horseradish peroxidase (HRP) were purchased from Vector Labs and immobilized streptavidin and HRPconjugated streptavidin were from Pierce. Protein Cholera toxin $\beta$ subunit conjugated HRP conjugated was purchased from Sigma. HRP-conjugated cholera toxin $\beta$ subunit was purchased from Sigma.

\section{cDNA constructs \& transfection}

Fc receptor/syndecan-4 chimera (FcR-S4) was constructed by linking the ectoplasmic domain (amino acids 1-288) of human Fc receptor Ia (CD64) cDNA and the transmembrane and cytoplasmic domains of rat syndecan-4 (amino acids 150-202). The chimera and full-length Syndecan- 4 construct were inserted into $\mathrm{PCR}$ 3.1-Uni expression vector (Invitrogen). Caveolin-1EGFP (caveolin-1 fused by its C-term to EGFP) cDNA construct (15), was a gift of Dr. L. Pelkmans (Institute of Biochemistry, Swiss Federal Institute of Technology).

RFPEC were cultured in DMEM medium (Life Technologies) as described (16). Stable expression of FcR-S4 chimera was achieved by transfecting the CDNA construct into wild type RFPEC using LipofectAmine 2000 (Life Technologies) according to the manufacture protocol. Cells were selected for neomycin resistance ( $0.4 \mathrm{mg} / \mathrm{ml}$ Geneticin, Life Technologies) and pooled populations were used for all studies. To enrich each pool with cells having high expression levels of FcR-S4 protein, cells were subjected to two Auorescent-activated sorting (see below) to select cells in the top $10 \%$ of the population.

Transient expression of caveolin-1-EGFP and pEGFP$\mathrm{N} 1$ (Clonetech) in RFPEC was achieved by transfection using LipofectAmine 2000 (Life Technologies). Cells were used within 48-72 hours after transfection.

\section{Fluorescence-assisted cell sorting (FACS)}

Cells were dissociated from plates using nonenzymatic solution (Sigma) and labeled for $20 \mathrm{~min}$ with FITC-conjugated human non-immune $\operatorname{IgG}(0.1$ $\mu \mathrm{g} / \mathrm{ml}$, Rockland) in Dulbecco's phosphate buffered saline (DPBS) with $1 \%$ bovine serum albumin (BSA), thus specifically detecting the transfected $F_{C}$ receptor, which is not endogenously expressed in endothelial cells.
To detect endogenous syndecan-4, cells were incubated wirh $1 \mu \mathrm{g} / \mathrm{ml}$ chicken antibody against extracellular domain of syndecan 4 for $20 \mathrm{~min}$ at room temperature, washed twice in $1 \%$ BSA-DMEM and then incubared with a secondary ancibody (Cy-5-conjugated $F\left(a b^{3}\right) 2$ fragment, $1 \mu \mathrm{g} / \mathrm{ml}$ ) for $20 \mathrm{~min}$ at room temperature, followed by another wash wich 1\%BSA-DMEM. Cell sorting was carried out on a MoFlo sorter (Cytomation) with a FACScan (Becron Dickinson, San Jose, CA) and analyzed using WinMDI v2.8 (Scripps, CA) software.

\section{Cell surface biotinylation}

The cells were washed twice with ice-cold DMEM and incubated with $0.5 \mathrm{mg} / \mathrm{m}$ l sulfo- $\mathrm{N}$-hydroxysuccinimide easter-long chain-biotin (Pierce Chemical Co.) in PBS, $\mathrm{pH} 7.4$ for $15 \mathrm{~min}$ at $40 \mathrm{C}$. The biotinylation reaction was quenched with ice-cold $1 \%$ BSA-DMEM.

\section{Syndecan clustering}

For antibody clustering studies, RFPEC expressing FicR-S4 construct were grown overnight in 10\% FBSDMEM. The cells were washed twice in DMEM and then incubared with human non-immune $\operatorname{lgG}(1 \mu \mathrm{gg} / \mathrm{ml})$ for 15 minutes in $1 \%$ BSA-DMEM at $37^{\circ} \mathrm{C}$. The cells were then washed again ( $\mathrm{x} 2$ ) with DMEM and incubared for another 15 minutes at $37^{\circ} \mathrm{C}$ wich anti-human $F\left(a b^{\prime}\right) 2$ $(2 \mu \mathrm{g} / \mathrm{ml})$ in $1 \%$ BSA-DMEM.

For FGF2 clustering, RFPEC cultured in $10 \% \mathrm{FBS}$ DMEM were washed rwice witt DMEM and then incubated with $25 \mathrm{ng} / \mathrm{m}$ | FGF2 (Chiron Corp, Sunnyvale, CA) in 1\%BSA-DMEM for 15 minutes at $37^{\circ} \mathrm{C}$.

\section{Isolation of lipid raft membrane fractions}

Raft membrane microdomains from cell surface biotinylated RFPEC were isolated using flotation on discontinuous sucrose gradients as described (17). In brief, adherent cells in confluent $15 \mathrm{~cm}$ dish were washed with ice-cold PBS and lysed for $30 \mathrm{~min}$ on ice in $1 \%$ Titon X-100 in MNE buffer $(150 \mathrm{mM} \mathrm{NaCl} / 2 \mathrm{mM}$ EDTA/25mM, pH 6.5) containing a protease inhibitor mixture (Roche Diagnostics). The lysis solution was homogenized, and nuclei and cellular debris were pelleted by centrifugation at $10,000 \mathrm{~g}$ for $30 \mathrm{~min}$. For sucrosegradient centrifugation, $1 \mathrm{ml}$ of the cleared supernatant was mixed with $1 \mathrm{ml}$ of $85 \%$ sucrose in MNE buffer and transferred to the bottom of a centrifuge tube. The diluted lysate was overlaid with $2 \mathrm{ml}$ of $30 \%$ sucrose and $1 \mathrm{ml}$ of $5 \%$ sucrose in MNE buffer. The samples were 
centrifuged in an SW55 rotor at $200,000 \mathrm{~g}$ at $4^{\circ} \mathrm{C}$ for $16 \mathrm{~h}$. Seven fractions of $700 \mu \mathrm{l}$ were collected from the top of the gradient and studied using immunoblotting (see below).

Detergent extraction of lipid rafts was carried as described (18). Briefly, cells were grown to confluence in a 6-well plate, rinsed with $1 \mathrm{ml}$ ice-cold TNE (Tris/ $/ \mathrm{NaCl}$ / EDTA) buffer (25 mM Tris-Cl, $\mathrm{pH} 7.4,150 \mathrm{mM} \mathrm{NaCl}$, $5 \mathrm{mM}$ EDTA ), placed on ice and then lysed by addition $1 \%$ Triton-X100 and protease inhibitor mixture in TNE buffer for $20 \mathrm{~min}$. Lysates were scraped and centrifuged for $5 \mathrm{~min}$ at $4^{\circ} \mathrm{C}$ and the supernatant was transferred to the fresh tube. To recover membrane rafts proteins, Triton X-100 pellet was resuspended in $100 \mu \mathrm{l}$ pellet lysis buffer ( $50 \mathrm{mM}$ Tris- $\mathrm{HCl}, \mathrm{pH} 8.8,5 \mathrm{mM}$ EDTA, $1 \%(\mathrm{w} / \mathrm{v})$ SDS). The mixture was diluted with $1 \mathrm{mlTNE}-$ $1 \%$ Triton X-100 and centrifuged for $2 \mathrm{~min}$ at $4^{\circ} \mathrm{C}$. Supernatant was then analyzed by immunoprecipitation, SDS-PAGE and immunoblotting. Glycosaminoglycan chains were digested as described (4).

Plasma membrane cholesterol depletion was accomplished by pretreatment of cultured cells with $\beta$-cyclodextrin $(10 \mu \mathrm{M})$, which removes unesterified cholesterol from the cell membrane (19), for $30 \mathrm{~min}$ at $37^{\circ} \mathrm{C}$, immediately followed by chilling the cells to $4^{\circ} \mathrm{C}$.

\section{Immunoprecipitation, immunoblotting and dot blotting}

Immunoprecipitation(IP) of syndecan-4fromcellysates was carried by incubation of $500 \mu \mathrm{l}$ of total cell lysates with $10 \mu \mathrm{l}$ of anti-syndecan- 4 cytoplasmic tail antiserum in the presence of Protein G/ Protein A agarose ( $30 \mu \mathrm{l})$. Prior to immunoblotting, glycosaminoglycan chains were digested as described (4). The immunoprecipitated material was then subjected to SDS-PAGE and transferred to the polyvinylidene difluoride (PVDF) membrane (Millipore). Syndecan-4 detection was performed using HRP-conjugated streptavidin $(0.2 \mu \mathrm{g} / \mathrm{ml})$ for cell surface biotinylated samples or by anti-syndecan- 4 antiserum $(1 \mu \mathrm{l} / \mathrm{ml})$ followed by incubation with a secondary HRPconjugated goat antibody specific for the primary antisyndecan -4 antibody.

Immunoprecipitation of syndecan-4 from sucrose gradient fractions was performed in the similar manner. The precipitated material was then dor blotted on the nitrocellulose membrane (Schleicher\&Schuell) and syndecan- 4 was detected by HRP-conjugated streptavidin.

For GM1 sphingolipid detection in sucrose gradient fractions, $100 \mu \mathrm{l}$ of each fraction were applied to the nitrocellulose membrane and GM1 was then detected using HRP-conjugated cholera toxin subunit $\beta(0.2$ $\mu \mathrm{g} / \mathrm{ml})$. GM1 detection in Triton $\mathrm{X}-100$ soluble and insoluble fractions was carried out by blotting 20 or 200 $\mu \mathrm{l}$ of each fraction on the nitrocellulose filter, which was then probed with HRP-conjugated cholera toxin subunit $\beta(0.2 \mu \mathrm{g} / \mathrm{ml})$. All blots were developed using enhanced SuperSignal Wet Pico chemiluminescent substrate (Pierce).

\section{Live fluorescent microscopy}

For live fluorescent microscopy, cells were grown on gelatin $0.1 \%$ PBS coated cover slips (Fisher Scientific.) to confluence. Staining for FcR-S4 was done using biotinylated non-immune $\mathrm{IgG}$ and the biotin label was then visualized by incubation with $\mathrm{Cy}-5$ conjugated streptavidin $(5 \mu \mathrm{g} / \mathrm{ml})$ at $37^{\circ} \mathrm{C}$ for $15 \mathrm{~min}$. Glycosylpho sphatidylinositol (GPI) anchored proteins were detected by cell incubation with $10-8 \mathrm{M}$ of Alexa- 488 conjugated inactive variant of the protein proaerolysin (FLAER) at $37^{\circ} \mathrm{C}$ for $1 \mathrm{~h}$. FLAER binds selectively to GPI anchors (20).

Cover slips were removed from the staining solution and mounted on a microscope slide. All microscopy imaging was done using Bio-Rad (Hercules, CA) MRC1024 Krypton/Argon laser confocal system microscope using $63 \mathrm{x}$ lens by Ziess. Time lapse microscopy was carried out at $20^{\circ} \mathrm{C}$. Image analysis was done using Adobe Photoshop 6.0 (Adobe Systems Inc.) and ImageJ software (NIH).

\section{Results}

To study the distribution of syndecan- 4 core protein in the plasma cell membrane and examine the effect of ligand clustering on its spatial localization, we linked the cytoplasmic and the transmembrane domains of syndecan-4 to the extracellular domain of the Fc receptor. To demonstrate the expression of the FcR-S4 chimera on the cell surface, FcR-S4 construct and empty vectortransfected cells were subjected to FACS using FITClabeled non-immune IgG that specifically recognizes Fc receptor, and anti-syndecan- 4 ectoplasmic domain antibodies. FcR expression was noted only on the FcRS4 construct transfected cells (Fig. 1A). Furthermore, expression of the native syndecan- 4 was not affected by FcR-S4 expression (Fig. 1A). To demonstrate that the cytoplasmic tails of FCR-S4 chimeras interact with native syndecan- 4 proteins, RFPEC cells expressing FcR-S4 construct were decorated with non-immune 


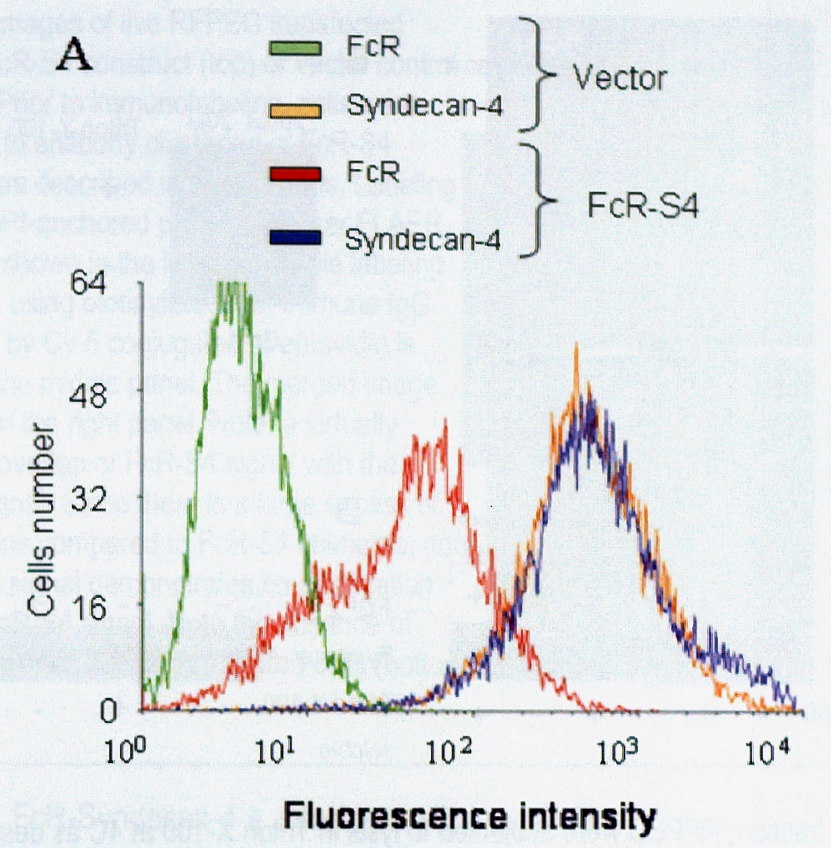

B

$\mathrm{IP}$ : Syndecan-4

WB: FCR-S4

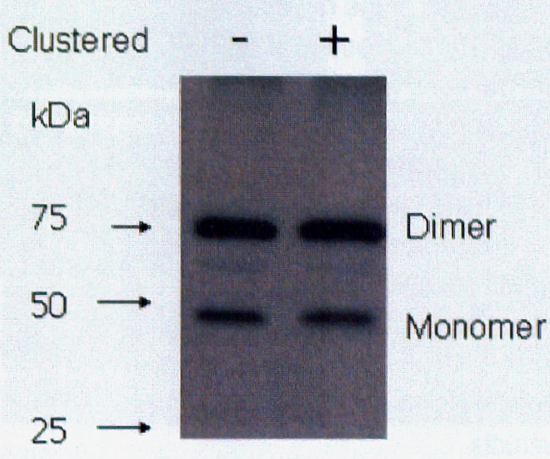

FCR-S4-Syndecan-4

complexes

Figure 1. FcR-syndecan-4 chimera interaction with endogenous syndecan-4 on the cell surface.

(A) Flow cytometry analysis of FcR-S4 and native syndecan-4 expression in RFPEC.

Fiuorescent intensity of antibody staining for the FcR and native syndecan-4 in cells transfected with the FcR-S4 construct (red) or vector control (green). Note the absence of signal for the FcR (non-immune $\mathrm{ggG}$ ) in the vector transfected cells (shown in green). The expression of the native syndecan-4 is the same in vector-transfected (orange) and FCR-S4 transfected (blue) cells.

(B). FcR-S4 forms complexes with native syndecan-4. Total cell lysates from cells transfected with FcR-S4 construct prior to (-) or after $(+)$ antibody clustering of FCR-S4 chimeras, were subjected to immunoprecipitation with the anti-ectoplasmic domain syndecan-4 antibody, followed by Western blotting of the precipitate with anti-FCR (CD64) antibody. Note the presence of bands corresponding to FcR-S4syndecan -4 monomer and dimer.

IgG. Clustering of FcR-syndecan-4 complexes was then performed with the anti-IgG antibody. Clustered and unclustered RFPEC were then lysed and subjected to immunoprecipitation with the antibody against the ectoplasmic domain of syndecan-4 followed by Western blotting with an anti-FcR (CD64) antibody. Both clustered and unclustered cells demonstrated the presence of FcR-S4-syndecan-4 complexes (Fig. 1B).

The distribution of syndecan- 4 in the plasma cell membrane was examined by subjecting whole cells lysates of RFPEC expressing FCR-S4 construct to sucrose density gradient centrifugation. Blotting of the syndecan- 4 antibody immunoprecipitated material from various sucrose gradient fractions demonstrated the core protein presence in both heavy ( $40 \%$ sucrose) and light (10-15\% sucrose) fractions (Fig. 2A, right panel). The lighter fractions contain plasma membrane raft proteins as shown by blotting with HRP-conjugated cholera toxin subunit that specifically binds to the raft marker GM1 (Fig. 2A, left panel). In the absence of antibody clustering, most of syndecan- 4 appeared in the non-raft membrane fractions. Antibody clustering of FcR-S4 chimeras induces a pronounced shift towards the raftcontaining fractions (Fig. 2A, right panel). The specificity of HRP-conjugated cholera toxin subunit $\beta$ GM 1 binding for detection of raft fractions of the membrane was tested by dot blot analysis of Triton X-100 soluble and insoluble portion of the plasma cell membrane (Fig. 2B). As expected, only the Triton X-100-insoluble fraction was labeled with the cholera toxin.

To further explore the relationship between clustering and syndecan- 4 redistribution into the raft compartment, we studied syndecan-4 appearance in the Triton X100insoluble (raft) and soluble (non-raft) fractions of plasma cell membranes. Equal numbers of FcR-S4 expressing cells were subjected to lysis in Triton X-100 as described 
Figure 2. Clustering induces syndecan-4 redistribution into the lipid rafts.

(A) Sucrose gradient analysis. Raft membrane microdomains from cell surface biotinylated RFPEC were isolated using flotation on discontinuous sucrose gradients. Gradient fractions containing rafts were detected using HRP-conjugated cholera toxin subunit $\beta$ that identifies the presence of the raft marker GM1 (left panel). The distribution of FCR-S4 in the gradient fractions was determined by immunoprecipitation of each fraction with the anti-syndecan-4 cytoplasmic domain antibody. The precipitated material was then dot blotted and syndecan-4 detected by HRP-conjugated streptavidin (right panel). Note that prior to clustering most of syndecans -4 is present in the non-raft sucrose fractions with a shift toward the raft fraction following antibody clustering of FCR-S4 constructs.

(B). Raft microdomains are present in Triton $X-100$ insoluble fractions. To demonstrate the
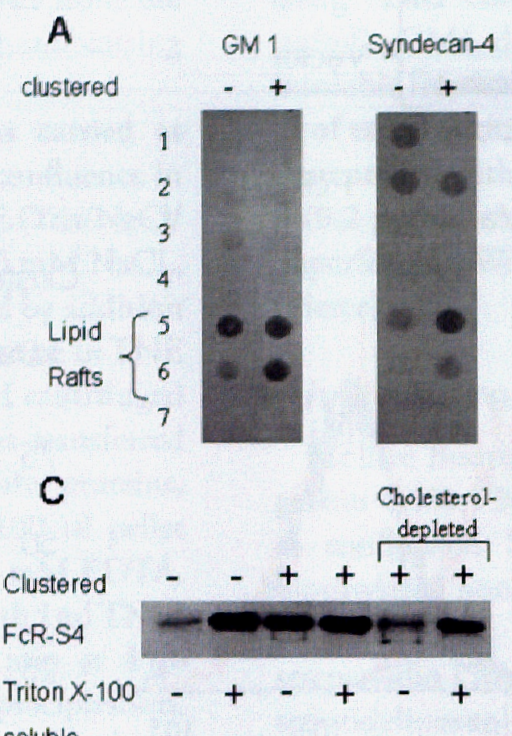

B
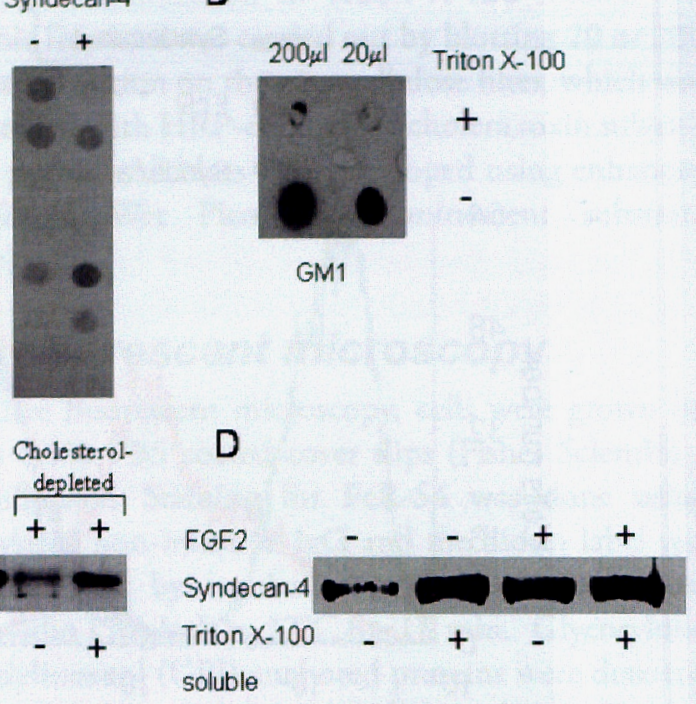
presence of raft microdomains in the Triton X-100-insoluble fraction, RFPEC were subjected to lysis in Triton X-100 at 4C as described in the Methods. 20 or $200 \mu$ lof each fraction were blotted on the nitrocellulase filter, which was then probed with the HRP-conjugated cholera toxin subunit $\beta$. Note the presence of GM1 signal only in Triton $X-100$-insoluble fractions.

(C). Antibody clustering induces the shift of FCR-S4 chimeras from non-raft to raft membrane microdomains. RFPEC expressing FcRsyndecan-4 decorated with non-immune IgG were subjected to cold Triton X-100 extraction followed by IP with antibodies against the cytoplasmic domain of syndecans-4 and Western blotting with HRP-streptavidin. Prior to clustering (-), syndecan-4 is predominantly found in the soluble (non-raft) fraction (lanes 1,2) while antibody clustering of FCR-syndecan-4 chimeras $(+)$ induces pronounced shift towards the insoluble (raft) fraction (lanes 3,4 ) lipid rafts. Cholesterol depletion of the plasma cell membrane with b-cyclodextrin led to a pronounced reduction in clustering induced shift of syndecans-4 towards the raft fraction (lanes 5,6).

(D) FGF2 treatment shifts native syndecan-4 to the raft microdomains. RFPEC treated with FGF-2 were cell surface biotinylated and then subjected to Triton X-100 extraction at $4 \mathrm{C}$ followed by IP with antibodies against the cytoplasmic domain of syndecans-4 and Western blotting with HRP-streptavidin. Note paucity of syndecans-4 protein in the raft fraction prior to FGF2-induced clustering (lanes 1,2$)$ and a pronounced shift towards the raft fraction following FGF2 treatment (lanes 3,4 )

in the Methods. The Triton X100-soluble and insoluble fractions were then immunoprecipitated with antisyndecan -4 antibody, separated on SDS-PAGE and subjected to Western blotting with HRP-streptavidin. Prior to antibody clustering of FcR-S4 chimeras, essentially all of syndecan-4 was in the Triton-X100 soluble fraction (Fig. 2C). Antibody clustering induced redistribution of $-50 \%$ of the total cellular syndecan -4 (cell surface only) to the Triton X-100 insoluble fraction. Since the formation of membrane rafts depends on high local cholesterol ester content, we disrupted raft formation by depleted membrane cholesterol by treating cells with $\beta$-cyclodextrin. Such cholesterol depletion almost fully prevented clustering-induced syndecan- 4 redistriburion into the rafts compartment (Fig. 2C).

Since clustering of the native syndecan -4 with its natural ligands, such as FGF2, may potentially have a different effect on its plasma membrane dispersal than antibody clustering of FCR-S4 chimeras, we have examined the effect of FGF2 treatment on syndecan-4 distribution in RFPEC cells. Similar to the FcR-S4 chimera antibody clustering studies, FGF2 induced a significant redistribution of syndecan- 4 from Triton-X100 soluble to insoluble fraction (Fig. 2D).

To confirm localization of clustered syndecan- 4 to plasma membrane rafts, we used vital confocal microscopy with anti-syndecan- 4 antibody and the GPIanchor marker FLAER in RFPEC. Following antibody clustering of FCR-S4 chimeras, FLAER imaging demonstrated prominent raft clusters on the apical plasma cell membrane (Fig 3, top left panel). Staining with a labeled non-immune IgG that detects FcR-S4 chimeras demonstrated equally prominent FcR- $\$ 4$ clusters on the apical plasma cell membrane (Fig. 3, top middle panel). The merged image demonstrates that essentially all FcRS4 chimeras overlapped with FLAER-labeling (Fig. 3, 
Figure 3. FCR-Syndecan-4 co-localizes with the GPI-anchored protein marker FLAER in RFPEC.

Confocal images of live RFPEC transfected with the FcR-S4 construct (top) or vector control (bottom). Prior to immunalabeling, cells were subjected to antibody clustering of FCR-S4 chimeras as described in the Methods. Labeling with the GPI-anchored proteins marker FLAER (green) is shown in the left panel while labeling of FCR-S4 using biotinylated non-immune lgG visualized by $\mathrm{Cy}-5$ conjugated streptavidin is shown in the middle panel. The merged image is shown in the right panel. Note a virtually complete overlap of FcR-S4 signal with the FLAER signal. Since there is a large excess of GPI proteins compared to FcR-S4 chimeras, not all FLAER signal demonstrates co-localization with the FcR-S4 signal. Note the absence of FCR-S4 signal in vector-transfected cells (bottom panels).
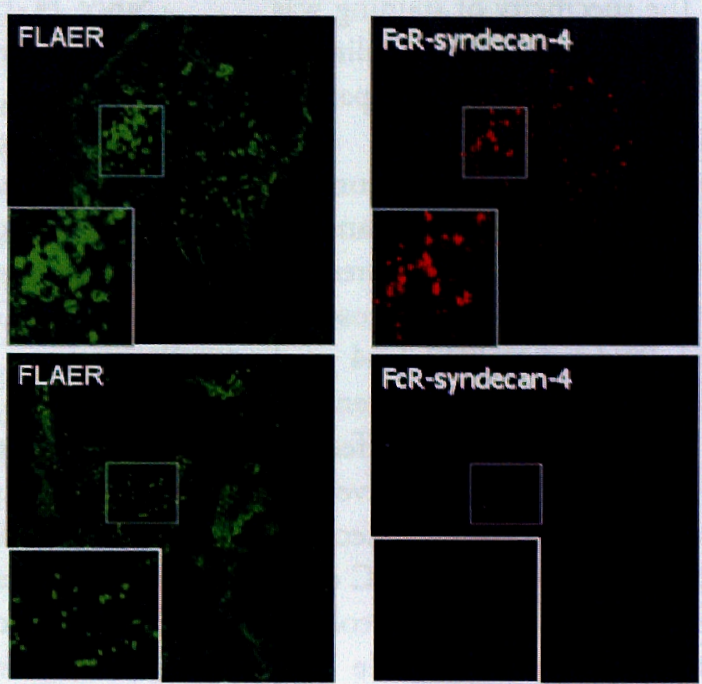
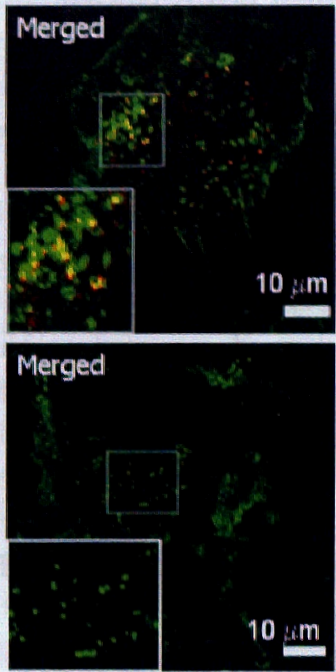

Figure 4. FcR-Syndecan-4 a ssociates with caveolae.

(A) Syndecan-4 association with caveolae. Differential Interference Contrast (DIC) image of live RFPEC cotransfected with caveolin-1EGFP and FCR-S4 constructs is overlaid by images of caveolin1-EGFP (green) and clustered FCR-S4 (red). Note a lack of overlap of caveolin-1-EGFP and FCR-S4 signals. Inset: digitally magnified view of the indicated region. An associated movie file demonstrates co-movement of syndecan and caveolin-1. Time-lapse series of 48 images from the inset were acquired with 2.5 second interval. Note association (but not an overlap) of syndecan-4 and caveolin-1 signals.

(B) Spatial analysis of caveolin-syndecan-4 movement. Movement of the caveolin-1EGFP (green) and syndecan (red) signals were tracked over time in $X$ and $Y$ planes. The graphs display the relative motion along the $Y$ (top) and $X$ (bottom) axis over time. Note the tandem movement but lack of overlap, of the two proteins.

(C) EGFP expression in RFPEC. To control for the effect of EGFP expression on the behavior of caveolin-1-EGFP construct, RFPEC cells were transfected with EGFP vector. The DIC image of live RFPEC expressing EGFP is overlaid with the EGFP (green) and FCR-S4 (red) signals. Note a diffuse cytoplasmic distribution of EGFP, quite distinct from the appearance of caveolin-1-EGFP. Syndecan-4 staining (red) is present along the cell border.
A
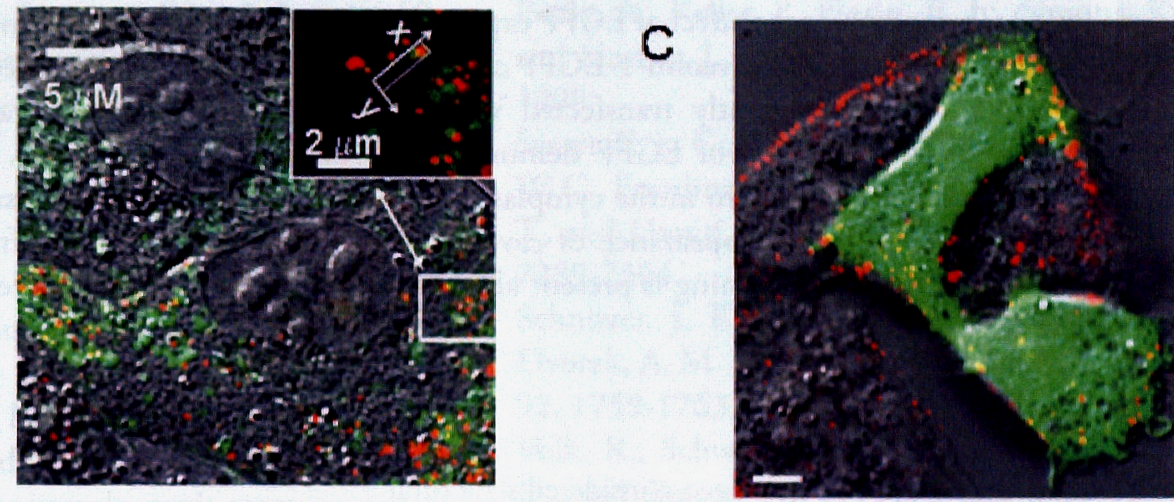

Time (sec) 
top right pand), consistent with syndecan-4 presence in the FLAER-labeled rafts. The specificity of staining was confirmed by FLAER and non-immune IgG labeling of the vector-transfected RFPEC (Fig. 3, botrom panels) that demonstrated the absence of FCR-S4 signal.

Caveolae constitute a distinct subpopulation of cholesterol-rich rafts. In order to see if syndecan-4 is present in caveolat, we generared RFPEC cells expressing EGFP-tagged caveolin-1. Live confocal microscopy showed nó co-localization between syndecan-4 and caveolin-1 (Fig. 4A) and coordinated movement of the two proteins (nowie file). To explore the effect of syndecan-4 clustering on its association with caweolae, we used time-lapse microscopy to visualize syndecan-4 movement in caveolin-1-EGFP expressing RFPEC cells. Reconstruction of time stacks of syndecan-4-caveolin-1 images in the $\mathrm{XY}$ plane demonstrated that while both proreins moved together, they did not localize to the same cellular compartment (Fig. 4B). Western blors with an anti-caveolin-1 antibody failed todetecrits presenceamong proteins present in the syndecan- 4 immunoprecipitations (not shown). To control for the effect of EGFP expression on the cellular distribution of caveolin-1-EGFP chimeric protein, RFPEC were transiently transfected with an EGFP construct. Visualization of EGFP demonstrated diffuse distribution of the protein in the cytoplasm (Fig. 4C), quite distinct from the appearance of caveolin-1EGFP protein. Syndecan 4 staining is present along the cell border (Fig, 4C).

\section{Discussion}

While syndecans have largely been considered structural proteins, recent data suggest that they play a variery of roles including lipoprotein upake (21), cell adhesion (6) and regulation of FGF2 signaling $(5,22)$. However, the molecular events involved in these activities are not well understood. Previous studies have shown that in $\mathrm{CHO}$ cells syndecan-1 is found, upon clustering, in the Triton $\mathrm{X}-100$-insoluble regions of the membrane (23), and that this event may play a role in syndecan-1-mediated lipid endocytosis $(21,24)$. While syndecan- 1 and syndecan- 4 share significant homologies in the transmembrane and cytoplasmic regions domains, the regions thought to play a role in clustering-induced aggregation in membrane rafts, there are also significant differences. Syndecan- 4 is a unique member of the syndecan core protein family because of its ability to engage in FGF2 signal transduction. Furrhermore, no data have previously been available regarding the effect of FGF2 binding on syndecan-4 clustering and the occurrence of this event in polarized endorhelial cells.

Since FGF2 treatment induces a number of cellular events that can potentially affect membrane syndecan4 trafficking, we employed FcR-syndecan-4 chimeras to study the effect of syndecan clustering on its localization in the plasma cell membrane. The use of extracellular domain of Fc receptor is particularly convenient because Fc receptor is not expressed in endothelial cells and nonimmune IgG can be used to decorate cells expressing Fc receptor. The chimera protein behaves in a mode analogous to the native syndecan-4: it is present on the cell surface, it forms complexes with the native syndecan4 and its expression does nor affect expression of the native protein. Therefore, FCR-S4 clustering behavior can for appear representative of ligand clustering of the native syndecan-4.

We find that in quiescent endothelial cells, FCRS4 chimeras as well as native syndecan-4 are present mostly in the non-raft fraction of the membrane and that aggregarion of FCR-S4 chimeras with antibodies, or syndecan-4 with FGF2, leads to a rapid redistribution of the proteins to the membrane rafts. Several independent pieces of data are consistent with this interpretation, including sucrose gradients, Western blotting of various membrane fractions, and live confocal microscopy.

Two principle raft sub-domains are caveolae-containing and caveolae-free rafts. Interestingly, syndecan -4 did nor co-localize with caveolin-1, suggesting that it was nor present in the caveolae but rather in the non-caveolae rafts. The absence of caveolin-1 in the syndecan-4 immunoprecipitated material further argues against direct interaction between these proteins. At the same time, clustering of FCR-S4 chimeras, led to close apposition (bur, apparently, nor binding) of syndecan-4 and caveolae and a complex coordinated movement of both proteins.

While we have not examined which portion of the syndecan-4 molecule mediates its association with plasma membrane rafts, by analogy with syndecan1, the transmembrane domain and the immediately adjacent highly cationic cytoplasmic domain are the likely candidates. Of note, the presence of the PIP 2 binding domain in syndecan-4 (absent in syndecan-1) did not inhibit its localization to the raft subdomain. The presence of plasma membrane cholesterol is clearly required for this event as its depletion led to a virtually complete loss of syndecan- 4 enrichment in Triton X100 -insoluble regions.

While syndecan-4 clustering with its signaling agonist, FGF2, induces its redistribution to non-caveolae rafts, 
the functional significance of this event is undear. One possibility is that this serves to bring syndecan- 4 in close contact with FGF receptors. Since FGF receptordependent activation of a protein phosphatase is needed for activation of syndecan-4 signaling (16), this would serve to facilitate this connection. Alternatively, raft localization of syndecan-4 complexes may bring it in close contact with other signaling complexes thereby promoting cross-talk between various receptor pathways.

In summary, ligand-dependent clustering of syndecan4 in primary endothelial cells leads to its concentration in mon-caveolae rafts. This event may play a role in regulation of syndecan- 4 signaling.

\section{Acknowledgements}

We thank K. Williams for Fc receptor Ia-SyndecanI cDNA, N. Shworak for syndecan-4 antiserum, Dr. L. Pelkmans for caveolin-1-GFP expression vector, Dr. Justin D. Pearlman for developing plugins for Image], Dr. Arie Horowitz for helpful discussions of the results, Alice Givan and Ken Orndorff, Imaging Core Lab, Dartmouth Medical School, for help with live confocal microscopy.

\section{REFERENCES}

1. Tumova, S., Woods, A., and Couchman, J. R. (2000) Int J Biochem Cell Biol 32, 269-288

2. Zimmermann, P, and David, G. (1999) Faseb J $13,591-\$ 100$

3. Oh, E. S., Woods, A., and Couchman, J. R. (1997) J Biol Chem 272, 8133-8136

4. Horowitz, A., and Simons, M. (1998) J Biol Chem 273, 255.48-25551

5. Simons ${ }_{\Downarrow}$ M., and Horowitz, A. (2001) Cell Signal $13,855-862$

6. Couchman, J. R., Chen, L., and Woods, A. (2001) Int Rev Cytol 207, 113

7. Woods, A., and Couchman, J. R. (2001) Curr Opin Cell Biol 13, 578-583

8. Waugh, M. G., Minogue, S., Anderson, J. S., dos Santos, M., and Hsuan, J. J. (2001) Biochem Soc Trans 29, 509-511

9. Galbiati, F, Razani, B., and Lisanti, M. P. (2001) Cell 106, 403-411

10. Pralle, A., Keller, P., Florin, E. L., Simons, K., and Horber, J. K. (2000) J Cell Biol 148, 997 1008

11. Smart, E. J., Graf, G. A. McNiven, M. A., Sessa, W. C., Engelman, J. A., Scherer, P. E., Okamoto, T., and Lisanti, M. P. (1999) Mol Cell Biol 19, 7289-7304

12. Schnitzer, J. E., Oh, P., Jacobson, B. S., and Dvorak, A. M. (1995) Proc Natl Acad Sci U S A 92, 1759-1763

13. Volk, R, Schwartz, J. J., Li, J., Rosenberg, R. D., and Simons, M. (1999) J Biol Chem 274, 24417-24424

14. Shworak, N. W., Shirakawa, M., Mulligan, R. C., and Rosenberg, R. D. (1994) I Biol Chem 269, 21204-21214

15. Pelkmans, L., Kartenbeck, J., and Helenius, A. (2001) Nat Cell Biol 3, 473-483

16. Horowiz, A., and Simons, M. (1998) J Biol Chem 273, 10914-10918

17. Kabouridis, P. S., Magee, A. I., and Ley, S. C. (1997) Embo J 16, 4983-98

18. (2001) Preparation of detergent resistant membranes by centrifugation. Current Protocols in Immunology Online, Chapter 11. Biochemistry of Cell Activarion, John Wiley 8 Sons

19. Rodrigueza, W. V., Williams, K. J., Rothblat, G. H., and Phillips, M. C. (1997) Arterioscler Thromb Vasc Biol 17, 383-393 
20. Brodsky, R. A., Mukhina, G. L., Li, S, Nelson, K. L., Chiurazzl, P. L. Buckley, J. T., and Borowitz, M. J. (2000) Am J Clin Parhol 114, 459-466

21. Fuki, L. V., Meyer, M. E., and Williams, K. J. (2000) Biochem J 351 Pt 3, 607-612

22. Rapraeger, A. C. (2000) J Cell Biol 149, 995998

23. Carey, D. J., Bendt, K. M., and Stahl, R. C. (1996) J Biol Chem 271, 15253-15260

24. Williams, K. J. (2001) Methods Mol Biol 171, $457-477$ 


\section{Chapter 5}

Fibroblast Growth Factor 2 Endocytosis In Endothelial Cells Proceed Via Syndecan-4dependent Activation of Rac1 and a Cdc42dependent Macropinocytic Pathway

Eugene Tkachenko, Esther Lutgens, Radu-Virgil Stan, and Michael Simons

Journal of Cell Science 2004; 117(15): 3189-3199. 


\section{Abstract}

Full activity of fibroblast growth factors (FGFs) requires their internalization in addition to the interaction with cell surface receptors. Recent studies have suggested that the transmembrane proteoglycan syndecan-4 functions as a FGF2 receptor. In this study we investigated molecular details of syndecan endocytosis and its role in FGF2 internalization in endothelial cells. We find that syndecan-4 uptake, induced either by treatment with FGF2 or by antibody clustering, requires the integrity of plasma membrane lipid rafts for its initiation, occurs in a non-clathrin, non-dynamin dependent manner and involves Rac1 which is activated by syndecan-4. FGF2 is internalized in a complex with syndecan-4 in 70 kD dextran-containing endocytic vesicles. FGF2 and syndecan-4 but not dextran endocytosis is blocked by the dominant negative Rac1 while amiloride and the dominant-negative Cdc42 blocked internalization of dextran in addition to FGF2 and syndecan-4. Taken together, these results demonstrate that FGF2 endocytosis requires syndecan-4 clustering-dependent activation of Rac1 and the intact CDC42-dependent macropinocytic pathway.

\section{Introduction}

Fibroblast growth factors (FGFs) play a multitude of roles in modulation of cell growth, migration and differentiation (Ornitz and Itoh, 2001). The signaling activity of FGFs inwolves interaction with high affinity tyrosine kinase receptors and cell surface heparan sulfites. The latter molecules have long been thought to play a role as co-receptors for heparin binding growth factors such as FGFs. In particular, studies of FGF2 signaling established its dependence on the presence of cell surface heparan sulfates (Rapraeger et al., 1994) that are carried on membrane-bound core proteins, syndecans and glypicans (Rosenberg et al., 1997 ; Zimmermann and David, 1999). However, more recent studies have suggested that some core proteins themselves, and not just their heparan sulfate chailns, may play an important role in signal transduction. Of these, syndecan-4 has emerged as a signaling receptor because of its ability to bind and activate protein kinase $\mathrm{C}$ (PKC) upon FGF2-induced oligomerization (Simons and Horowitz, 2001 ). This association of syndecan-4 with PKC purs the proteoglycan in a category similar to other transmembrane receptors, such as integrins, that do nor possess intrinsic caralytic activity, but are associated with kinases or phosphatases.

A substantial body of literarure suggests that full activity of FGFs requires not only receptor interactions but also their internalization (Goldfarb, 2001) and thar the latter may proceed via heparan sulfate proteoglycansdependent and -independent pathways (Citores et al., 1999 ; Gleizes et al., 1995 ; Grieb and Burgess, 2000 ; Roghani and Moscatelli, 1992). Internalization of transmembrane proteins plays an important role in multiple cellular processes. In particular, syndecan endocytosis has been suggested as an important regulator of lipoprorein uptake (Fuki et al., 1997 ; Williams, 2001). At the same time, the details of FGF endocytosis and the involvement of specific proteoglycans have not been established.

Recent studies demonstrating direct syndecan4 involvement in FGF2 signaling (Horowitz et al., 2002 ; Volk et al., 1999 ) raise the possibility that this proteoglycan may also play a role in its internalization thereby providing an additional avenue for regulation of its activiry. This possibility is bolstered by observations that syndecan-4 binding to soluble (e.g. growth factors) or extracellular matrix ligand or cell exposure to mechanical stress results in its endocytosis ( $\mathrm{Li}$ and Chaikof, 2002 ; Tkachenko and Simons, 2002 ). However, the link between syndecan- 4 endocytosis and FGF2 internalization as well as molecular mechanisms of this process have not been defined.

To gain further insighe into syndecan- 4 function, we studied its clustering-induced endocytosis in endothelia! cells. We find that following oligomerization, the core protein is internalized from the plasma membrane in a lipid raft-dependent, clathrin- and dynaminindependent manner by a process that is amiloride sensitive and requires activation of the small GTPase Rac1. Furthermore, syndecan-4 clustering induced by FGF2 resulted in FGF2 internalization together with syndecan-4 and $70 \mathrm{kDa}$ dextran in the same endocytic vesicles. FGF2 and syndecan-4 but not dextran internalization was blocked by dominant negative Rac1, while amiloride and dominant-negative Cdc42 blocked internalization of not only FGF2 and syndecan4 but also of $70 \mathrm{kDa}$ dextran. This set of conditions shows that FGF2-induced syndecan-4 clustering leads to internalization of both proteins that proceeds via a macropinocytic parhway. Activation of Racl is required for the initiation of syndecan-4 endocytosis that also requires a fully functional macropinocytic pathway. 


\section{Materials and Methods}

\section{Antibodies and reagents}

Human non-immune $\mathbb{I g G}$ and $\mathrm{F}(\mathrm{ab}) 2$ fragmentspecific goat anti-human Igb $F\left(a^{\prime}\right) 2$ antibodies were purchased from Jackson Immunoresearch Laboratories (West Grove, PA, USA). Alexa-488 and Alexa-647 labeling kits, anti-HA epitope antibodies directly labeled by Alexa-488 and Zenon Alexa Fluor-488 mouse IgG1 labeling kit, BODIPY FL C5-ganglioside GM1 complexed to bovine serum albumin (BSA) and dextranrhodamineB $70 \mathrm{MW}$ were purchased from Molecular Probes. Alexa-488-conjugated inactive variant of the protein proaerolysin (FLAER) was purchased from Protox Biotech (Victoria, British Columbia, Canada). Mouse anti-c-myc epitope-tagged monoclonal antibody $(\mathrm{mAb})$ was purchased from Sigma. Chicken IgY antiextracellular domain of syndecan- 4 was fluorescently labeled with Alexa-488 according to the manufacturer's protocol (Molecular Probes). Human recombinant FGF2 was courtesy of Chiron Corporation (Sunnyvale, CA, USA). All other reagents were purchased from Sigma.

\section{CDNA constructs and transfections}

Fc receptor-syndecan-4 chimera (FcR-S4) construct was previously described (Tkachenko and Simons, 2002), eGFP-Cdc42-N17 (dominant negative), eGFPCdc42-I61(constitutively acrive), eGFP-Raclb-N17 (dominant negative), eGFP-Raclb-161 (constitutively positive) and GPI-GFP plasmids were provided by $M$. Way (Cancer Research UK) and S. Mayor (Sabharanjak et al., 2002) (National Centre for Biological Sciences, Bangalore, India). RhoA T19N (dominant negative) and RhoA G14V (constitutively active) were purchased from Guthrie Research Institute and were recloned into pIRES2-eGFP bicistronic vector (Clontech, CA, USA). eGFP-clathrin light chain construct was a kind gift from J. Keen (Thomas Jefferson University, Philadelphia, PA, USA), AP180C was from H. McMahon, dynamin $1 \mathrm{~K} 44 \mathrm{~A}$ from S. Schmid (Scripps Research Insritute, La Jolla, CA, USA) and dynamin $2 \mathrm{k} 44 \mathrm{a}$ construct was from $M$. A. McNiven (Cao et al., 1998). Rat fat pad endothelial cells (RFPEC) were cultured in DMEM (Invitrogen, CA, USA) as described previously (Horowitz et al., 2002).

\section{Endocytosis assays}

To label vesicles that undergo mactopinocytosis, rat fat pad endorhelial cells (RFPEC) were incubated on ice in $1 \%$ BSA-DMEM for 30 minutes. Neutral 70 -
kDa Dextran ( $\mathrm{rDx}$ )-Rhodamine $\mathrm{B}$ was added to a final concentration of $0.5 \mathrm{mg} / \mathrm{ml}$ and incubated with cells at $37^{\circ} \mathrm{C}$ in $5 \% \mathrm{CO} 2$ for 20 minutes. To label clathrincoated endocytic vesicles cells were incubated in $1 \%$ BSA-DMEM and then loaded with $1 \mu \mathrm{g} / \mathrm{ml}$ of Dil-LDL or $25 \mathrm{\mu g} / \mathrm{ml}$ of transferrin-Alexa647 (TRR) followed by incubation for 30 minutes on ice, washed once and then incubated at $37^{\circ} \mathrm{C}$ for 20 minutes in $5 \% \mathrm{CO} 2$. Labeling of endogenous GPI-anchored proteins by FLAER was done as previously described (Tkachenko and Simons, 2002).

\section{FGF2 labeling with Alexa Fluor 647}

In order to protect the syndecan-4 binding sites, FGF2 (1 mg) was adsorbed to $0.5 \mathrm{ml}$ bed-volume heparin-Sepharose beads (Amersham Blosciences). The beads were washed with ice-cold $0.1 \mathrm{M} \mathrm{NaHCO} 3$, resuspended in $1 \mathrm{ml}$ of ice-cold $0.1 \mathrm{M} \mathrm{NaHCO} 3, \mathrm{pH} 8.2$. Alexafluor 647 succinimidyl ester was added $(0.5 \mathrm{mg}$ in $0.2 \mathrm{ml} 0.1 \mathrm{M} \mathrm{NaHCO} 3$ ) and the mixture was shaken for 1 hour at $4^{\circ} \mathrm{C}$. The supernatant was drained and the column washed with $4 \mathrm{mlTBS}$ and $2 \mathrm{ml} 10 \mathrm{mM}$ Tris $/ 0.3$ $\mathrm{M} \mathrm{NaCl} \mathrm{pH} \mathrm{7.5.} \mathrm{Labeled} \mathrm{FGF2} \mathrm{was} \mathrm{eluted} \mathrm{with} 2 \mathrm{ml} 10$ $\mathrm{mM}$ Tris/2 $\mathrm{M} \mathrm{NaCl} \mathrm{pH} 7.5$ and desalted using two HiTrap desalting cartridges connected in series and elution with Tris-buffered saline. The FGF2-containing fraction was concentrated in an Amicon 10-kDa centrifugal filter (Millipore) and protein concentration was derermined by spectrophotometry. The labeling ratio dye:FGF2 was $0.5: 1$, which was intended to be low as not to interfere with the biological function of $\mathrm{FGF} 2$.

\section{Syndecan clustering}

Antibody and FGF2 clustering were performed as described previously (Tkachenko and Simons, 2002 ). Briefly, RFPEC stably expressing FcR-syndecan-4 were plated and grown overnight in $10 \%$ FBS-DMEM. For antibody clustering, cells were washed with DMEM and incubated in the presence of biotinylated non-immune IgG $(1 \mu \mathrm{g} / \mathrm{ml})$ for 15 minutes in DMEM supplemented with $1 \% \mathrm{BSA}$ at $37^{\circ} \mathrm{C}$. Then cells were washed with icecold DMEM and incubated for another 30 minutes on ice with anti-human $\mathrm{F}(\mathrm{ab}) 2-\mathrm{Cy}^{3}(3 \mu \mathrm{g} / \mathrm{ml})$ in DMEM$1 \%$ BSA followed by wash as above and incubation at $37^{\circ} \mathrm{C}$ with $5 \% \mathrm{CO} 2$ in DMEM 1\% BSA for various times. To distinguish plasma membrane syndecan- 4 from internalized syndecan-4, the cells were then washed with ice cold medium and incubated with steptavidinCy5 or streptavidin-Alexa488 (1:400 dilution) for 30 minutes at $4^{\circ} \mathrm{C}$. Ar this temperature, streptavidin has 
access only to the surface bound biotinylated IgG, or the IgG that is in vesicles open to the cell surface. For FGF2 labeling, cells were washed with ice-cold DMEM twice and incubated for 30 minutes on ice in DMEM in the presence of $50 \mathrm{ng} / \mathrm{ml}$ of FGF2-Alexa Fluor. After washing cells were incubated in DMEM-1\% BSA for various times. To remove remaining cell surface FGF2, cells were place on ice and incubated with $10 \mathrm{mg} / \mathrm{ml}$ of heparin in DMEM.

\section{Immunofluorescence microscopy}

RFPEC were plated in chamber slides (Nalge Nunc), fixed with $2 \%$ paraformaldehyde for 10 minutes at room temperature, then washed twice with phosphate-buffered saline (PBS), permeabilized with $0.1 \%$ Triton X-100/PBS for 10 minutes, washed again as above, blocked with $3 \%$ $\mathrm{BSA} / \mathrm{PBS}$ for 30 minutes, and incubated with primary antibodies $(1 \mu \mathrm{g} / \mathrm{ml})$ in $1 \% \mathrm{BSA} / \mathrm{PBS}$ overnight at $4^{\circ} \mathrm{C}$. The slides were then washed four times as above, and incubated for 1 hour with $10 \mu \mathrm{g} / \mathrm{ml}$ of the appropriate reporter-conjugated secondary antibodies, washed again as before, and mounted with ProLong medium (Molecular Probes). Fluorescence microscopy was carried out on live cells as described previously (Tkachenko and Simons, 2002 ). Imaging was carried out using Bio-Rad MRC-1024 and Ziess LSM 510 Meta laser confocal system microscopes with Zeiss $63 \mathrm{x}$ objectives. Image analysis was done using Adobe Photoshop 7.0 (Adobe Systems Inc.), AutoDeblur 9.1 (Auto Quant Imaging Inc.) and Image J software (NIH).

\section{Toxin treatment and plasma membrane cholesterol depletion}

RFPEC were incubated with $20 \mathrm{ng} / \mathrm{ml}$ of Clostridium difficile toxin B for 3 hours or $100 \mathrm{ng} / \mathrm{ml}$ exotransferase C3 for 12-16 hours in the normal growth medium. 5(N-ethyl-N-isopropyl) amiloride treatment of RFPEC was performed as described previously (Muro et al., 2003 ). Plasma membrane cholesterol depletion was accomplished by pretreatment of cultured cells with 10 $\mathrm{mM}$ methyl B-cyclodextrin (MBCD), for 30 minures at $37^{\circ} \mathrm{C}$ followed by a wash with DMEM and standard clustering procedure. $\mathrm{MBCD}$ removes unesterefied cholesterol from the cell membrane (Rodrigueza et al., 1997 ).

\section{Quantitative measurements of endocytic uptake}

\author{
Endocytic uptake of dextran, transferrin, GPI-
}

GFP, GM1-BODIPY, FCR-syndecan 4 and FGF2 was quantified as previously described (Sabharanjak et al., 2002 ). In brief, 10-15 images were acquired from two wells of the same experiment and the number of cells showing high level of uptake relative to untransfected cells was scored. The data are presented as mean of three or four independent experiments, each with 20 or more cells.

In addition, the effect of various toxin treatments on syndecan- 4 and transferrin uptake was measured by flow cytometry. For these experiments $(n=3)$ cells were grown to $70-80 \%$ confluence on 24 -well plates. Toxin treatments, FcR-syndecan 4 and transferrin uptake assays were performed as described above. At the end of the experiment plates were placed on ice, washed once with ice-cold PBS pH 7.4 and then twice with ice-cold acidic PBS pH 2.5 for 30 seconds to remove cell-surface bound fluorescent ligands (Fuki et al., 2000). Cells were then trypsinized, washed once with PBS $\mathrm{pH} 7.4$ and resuspended in DPBS pH 7.4 with $1 \%$ BSA. Flow cytometry was performed and analyzed as previously described (Tkachenko and Simons, 2002 ).

\section{Rho GTPase pulldown assays}

To determine activation of Rho, Rac and Cdc42 after FcR-S4 clustering, EZ-detect Rho and Racl activation kits (Pierce) were used. In brief, cells were seeded on fibronectin-coated $100 \mathrm{~mm}$ dishes and grown to $80 \%$ confluency then starved for 24 hours in DMED 0.5\% FBS. Following antibody clustering performed as described above, cells were lysed in $250 \mu$ lysis/binding/ washing buffer including proteinase inhibitors (Pierce). As positive and negative controls, four clarified nonclustered cell lysates $(500 \mu \mathrm{g})$ were treated with either $0.1 \mathrm{mM}$ GTP $S$ or $1.0 \mathrm{mM}$ GDP in the presence of 10 $\mathrm{mM}$ EDTA, $\mathrm{pH} 8.0$ at $30^{\circ} \mathrm{C}$ for either 15 minutes (to activate or inactivate Racl and Cde42) or 30 minutes (to activate or inactivate Rho). The nucleotide exchange reaction was terminated by adding $\mathrm{MgCl} 2$ and placing samples on ice.

The cell lysates $(500 \mu \mathrm{g})$ were then incubated with either GST-Pak1-PBD (to pull down active Cdc42 or Rac1) or GST-Rhotekin-RBD (to pull down active Rho) in the presence of SwellGel-immobilized glutathione at $4^{\circ} \mathrm{C}$ for 1 hour in a spin column. After incubation, the mixture was centrifuged at $8,000 \mathrm{~g}$ to remove the unbound proteins. The resins were washed three times with lysis/binding/wash buffer and the sample was eluted by adding $50 \mu \mathrm{l}$ of $2 \mathrm{x}$ SDS sample buffer and boiling at $95^{\circ} \mathrm{C}$ for 5 minutes. Half $(25 \mu \mathrm{l})$ of the sample volumes 


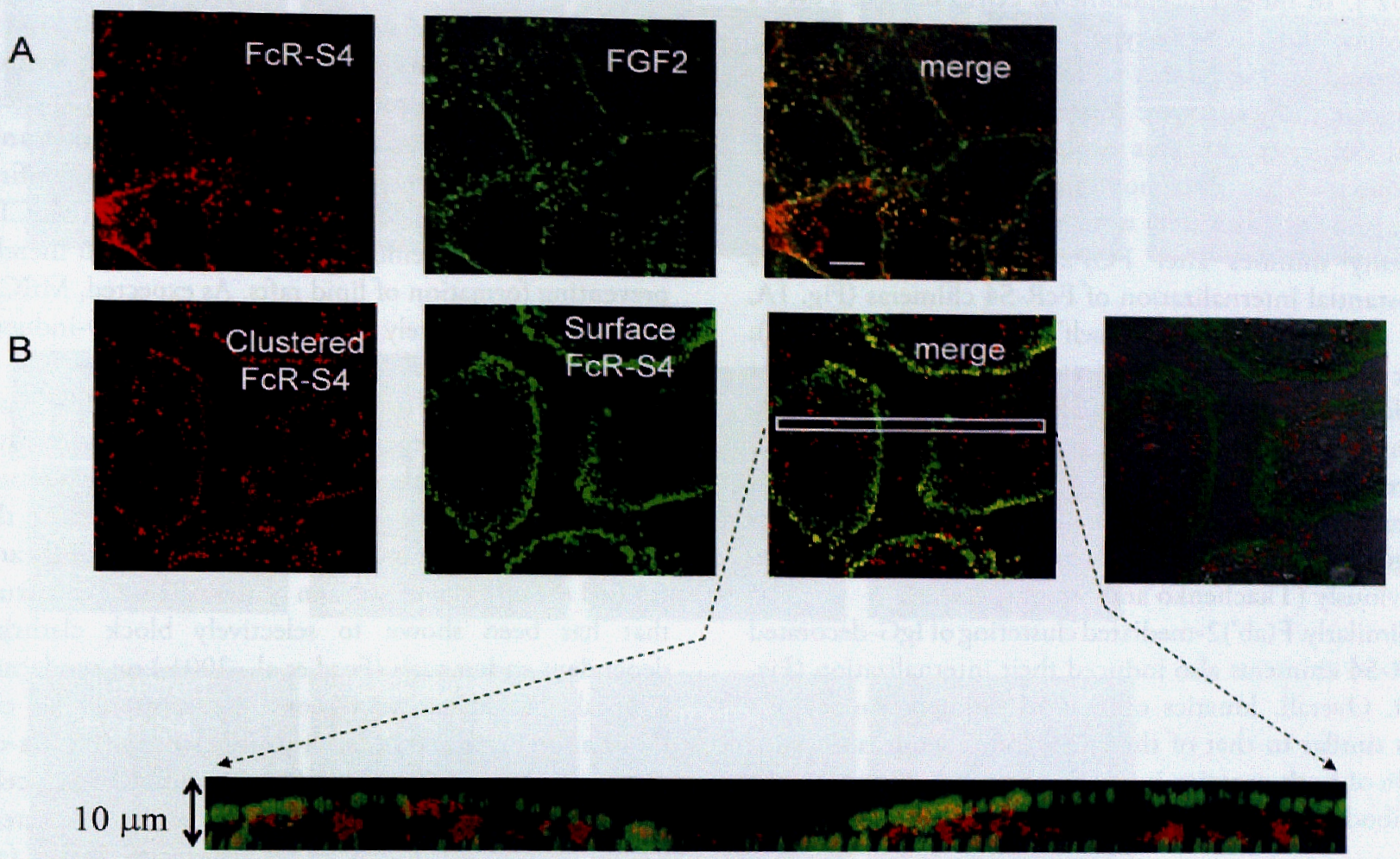

Figure 1. Internalization of the native and chimera syndecan-4 proteins

(A) RFPEC cells expressing FCR-S4 construct were decorated with Cy3 (red)

labeled human non-immune IgG (nilgG) and then clustered with AlexaFluor 647 (green) labeled FGF2. IgG decorated FcR-S4 chimeras are present on the cells surface and in the cytoplasm 20 min after FGF2 clustering (red). FGF2 is present both on the cell surface and in the cytoplasm. Note co-localization (yellow) of internalized FGF2 and FCR-S4 chimeras (merged images). This observation is consistent with FGF2-induced oligomerization of FcR-S4- native S4 heterodimers. Scale bars, $10 \mu \mathrm{m}$.

(B) FCR-S4 expressing cells decorated with biotinylated nilgG followed by clustering with Cy3 labeled clustering antibodies (red). Biotinylated nilgG remained on the cell surface was visualized by streptavidin-Cy5 (green). Dual stain on the merged image shows cell surface localized FCR-S4 whereas single red stain shows internalized one. Right figure shows merged colors image overlaid with DIC. Lower figure shows Z-plane projection of the area in white rectangle.

were analyzed by SDS-PAGE and transferred to a PDVF membrane. The active Racl and Rho were detected by western blotting using a specific mouse monoclonal antibody. A goat anti-mouse antibody conjugated with HRP was used as the secondary antibody. For the detection of Cdc42, anti-Cdc42 monoclonal antibody (Upstate) was labeled using the Zenon Alexa-488 mouse IgG1 labeling kit and applied to the rac1/cdc42 PVDF membrane. Detection was performed using West Pico Chemiluminescent Substrate (Rho and Rac1) (Pierce) or fluorometry (Cdc42) followed by exposure to X-ray film or detection of fluorescence in a Typhoon 9410 (Amersham Biosciences) detector, respectively.

\section{Results}

\section{Clustering initiates syndecan-4 endocytosis}

To study plasma membrane syndecan- 4 internalization, we used live confocal laser microscopy to track the core protein in endothelial cells before and after FGF2 and/ or antibody-induced clustering. To help visualize the fate of the native syndecan- 4 , we took advantage of heterodimerization between the wild-type syndecan- 4 and the FCR- $\$ 4$ chimeras previously demonstrated in the FcR-S4-expressing RFPEC (Tkachenko and Simons, 
2002 ). In quiescent endothelial cells both the FirR-S4 chimera and the wild-type syndecan-4 were similarly expressed on the plasma membrane (Fig. 1A). FcR-S4expressing RFPEC were treated with Cy3-labeled IgG. This decorates chimeras expressed on the cell plasma membranes but does not initiate their internalization (not shown). The cells were then treated with FGF2. Twenty minutes after FGF2 exposure, there was a substantial internalization of FcR-S4 chimeras (Fig. 1A, left panel) and of FGF2 itself (Fig. 1A, middle panel). The merged image demonstrates significant intracellular co-localization of FGF2 and FcR-S4 signals (Fig. 1A, right panel). This suggests that FcR-S4 chimeras that have formed heterodimers with the native syndecan4 core protein, were internalized when the latter was oligomerized by the FGF2 treatment, as we have shown previously (Tkachenko and Simons, 2002 ).

Similarly, F(ab')2-mediated clustering of IgG-decorated FcR-S4 chimeras also induced their internalization (Fig. 1B). Overall, kinetics of FCR-S4 chimera endocytosis was similar to that of the endogenous syndecan- 4 with $50 \%$ of both proteins internalized within 20 minutes of antibody-mediated clustering.

\section{Syndecan-4 endocytosis depends on the integrity of the lipid rafts and occurs in a clathrin and dynamin- independent manner}

We have previously shown that FGF2-induced syndecan-4 or antibody-induced FCR-S4 chimera oligomerization result in redistribution of approximately $50 \%$ of the total plasma membrane content of these proteins to the lipid rafts (Tkachenko and Simons, 2002 ). To determine wherher syndecan -4 endocytosis proceeds from the rafts or a non-raft portion of the plasma membrane, we used confocal microscopy of live cells to track internalized FcR-S4 chimeras as well as BODIPY-GM1, a lipid raft marker.

Within 5 minutes after clustering with $\mathbb{F}\left(a b^{\prime}\right) 2$ fragments, most if not all internalized FcR-S4 chimeras co-localized with BODIPY-GM1 (Fig. 2a-e). To confirm this finding, we examined syndecan- 4 endocytosis in RFPEC-expressing GPI-anchored GFP. Following antibody clustering of the FcR-S4 chimera, confocal microscopy of live cells demonstrated considerable colocalization between the internalized syndecan- 4 chimeras and GPI-GFP (Fig. 2f-i). To confirm co-localization of internalized syndecan- 4 with rafts proteins, we used FLAER to detecr GPI-anchored proteins (Brodsky et al.,
2000 ; Tkachenko and Simons, 2002 ). As in the GPIGFP studies, we observed a high level of colocalization of internalized syndecan- 4 with FLAER-labeled endogenous GPI-anchored proteins (Fig. 3). These results suggest, therefore, that essentially all internalized syndecan- 4 originated from a region rich in lipid rafts. To confirm this conclusion, we used methyl B-cyclodextrin (MBCD) to deplete plasma membrane cholesterol content thereby preventing formation of lipid rafts. As expected, MBCD treatment completely prevented antibody-induced internalization of FcR-S4 chimeras (Fig. 2j-m).

Internalization of plasma membrane receptors can occur via clathrin-dependent or independent pathways. To determine the role played by clathrin in syndecan4 internalization, we examined co-localization of the endocytosed syndecan-4 and clathrin-LC-eGFP and studied the effect of expression of the AP180C construct that has been shown to selectively block clathrindependent endocytosis (Ford et al., 2001) on syndecan4 uptake. Confocal microscopy demonstrated no colocalization between syndecan-4 and clathrin (Fig. 4a-c). After transient transfection of AP180C into RFPEC, cells demonstrating AP180C expression showed, as expected, inhibition of clathrin-dependent transferrin uptake (a). Syndecan-4 endocytosis, however, was not affected by AP180C expression (Fig. 4d-h, Fig. 5a). These results suggest that syndecan- 4 endocytosis occurs via a clathrinindependent pathway.

To further define the endosomal pathway involved in syndecan-4 trafficking, dynamin dominant-negative constructs specific for both dynamins, dyn $1 \mathrm{~K} 44 \mathrm{~A}$ and dyn2K44A were transiently expressed in RFPEC. While expression of either dynamin construct had little effect on syndecan-4 endocytosis (Fig. 4i-1, Fig. 5a), both dynamin dominant negatives inhibited clathrindependent transferrin uptake (Fig. 5a).

\section{Syndecan-4 endocytosis requires Rac1}

Rho GTPases are involved in a number of endocytic processes. To examine the involvement of these GTPases in oligomerization-induced syndecan- 4 uptake, we first studied the effect of syndecan oligomerization on activation of different Rho family members. To this end, we examined the time course of activation of RhoA, Cdc42 and Racl in RFPEC expressing the FcR-S4 construct following antibody-induced chimera oligomerization. While there was no change in RhoA or Cdc42 activity, within 5 minutes there was a significant activation of Racl that gradually declined to baseline 

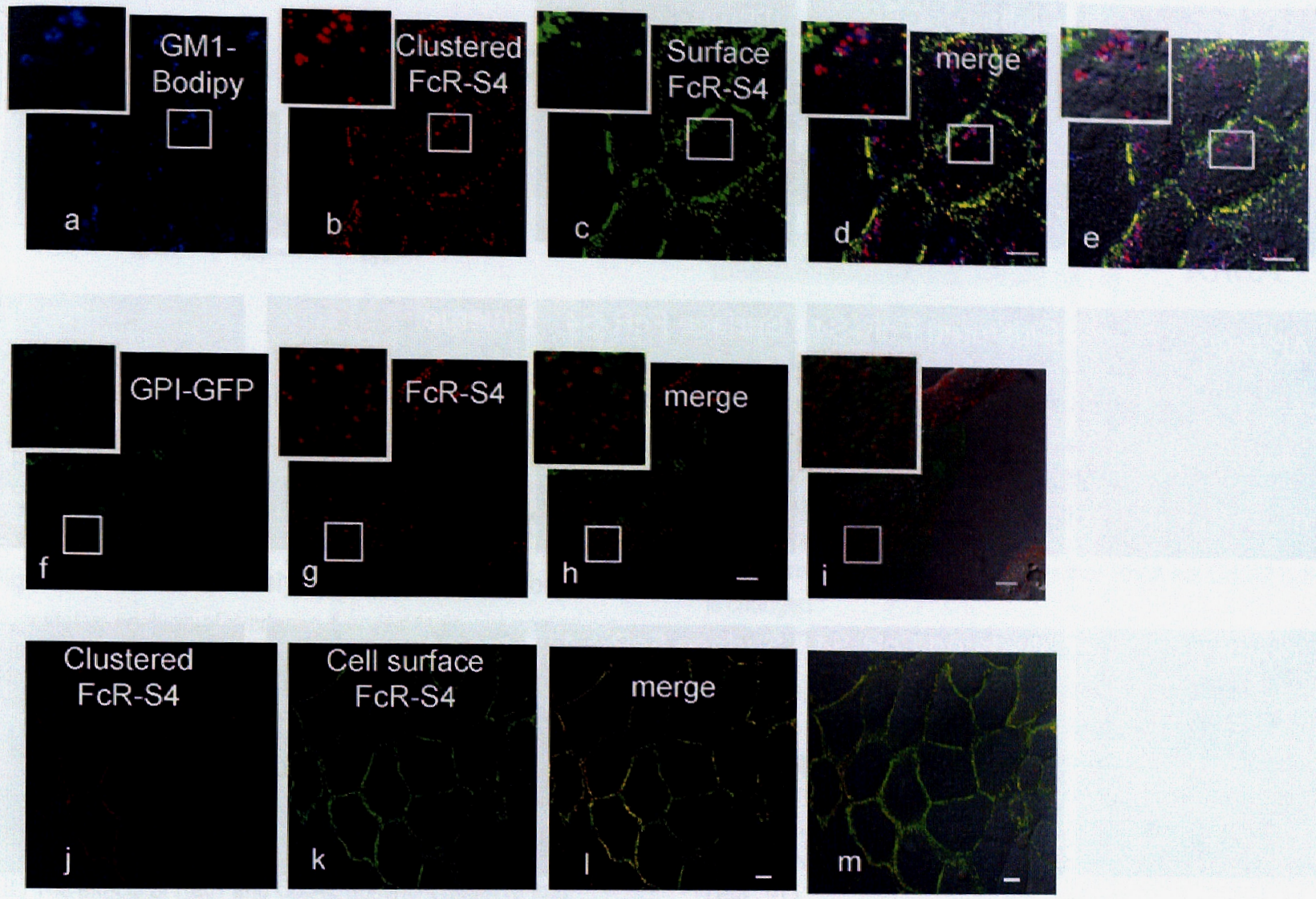

Figure 2. Syndecan-4 is internalized from lipid rafts region of the plasma membrane.

Confocal microscopy analysis of syndecan-4 endocytosis was carried out in RFPEC cells expressing FCR-S4 chimera. The rafts portion of the plasma cell membrane was labeled with BODIPY GM1 (blue) (Panel a) or by transient expression of GPI-GFP construct (Panel f). FcR-S4 chimeras were decorated with biotinylated nilgG and clustering was then initiated with the addition of Cy3-F(ab)2 fragments (red). Five minutes after the initiation antibody clustering all internalized FcR-S4 chimeras (Panel b) were noted in close association with GM1BODIPY (magenta, Panels a,d,c) membrane domains or with GPI-GFP (yellow, Panels $h$ and i). Merged colors image (Panels $d$ and $h$ ) overlaid with DIC are shown in panels e and i, respectively. The depletion of membrane cholesterol with M $\beta C D$ fully blocks clusteringinduced FcR-S4 internalization (Panels $, \mathrm{k}, \mathrm{l}, \mathrm{m}$ ). Scale bars, $10 \mu \mathrm{m}$.

Figure 3. Syndecan-4 is internalized with endogenous GPI-anchored proteins.

FCR-S4 expressing RFPES were labeled with FLAER, decorated by biotinylated nilgG an $d$ clustered by $\mathrm{Cy}-3-\mathrm{F}(\mathrm{ab})^{2}$ (Panel a). Five minutes after clustering cells were placed on ice and cell surface remained FcR-S4 stained with streptavidin-Cy5 (Panel b). FLAER-labeled GPI-anchored proteins are shown in panel $c$. Cell surface (Panels $d$ and $f$ ) and internalized (Panels e and f) FcR-S4 demonstrate high level of colocalization with GPI-anchored proteins. Arrows (panel $f$ ) point to examples of FcR-S4 and FLAER labeled internalized vesicles.

Scale bars, $10 \mu \mathrm{m}$.
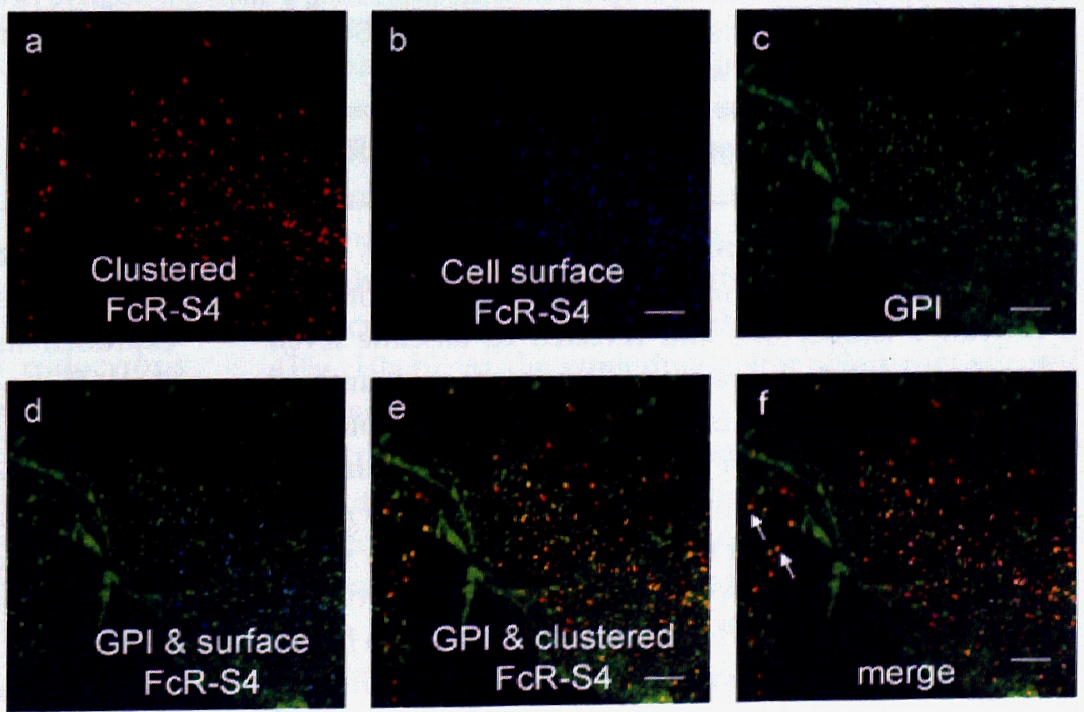

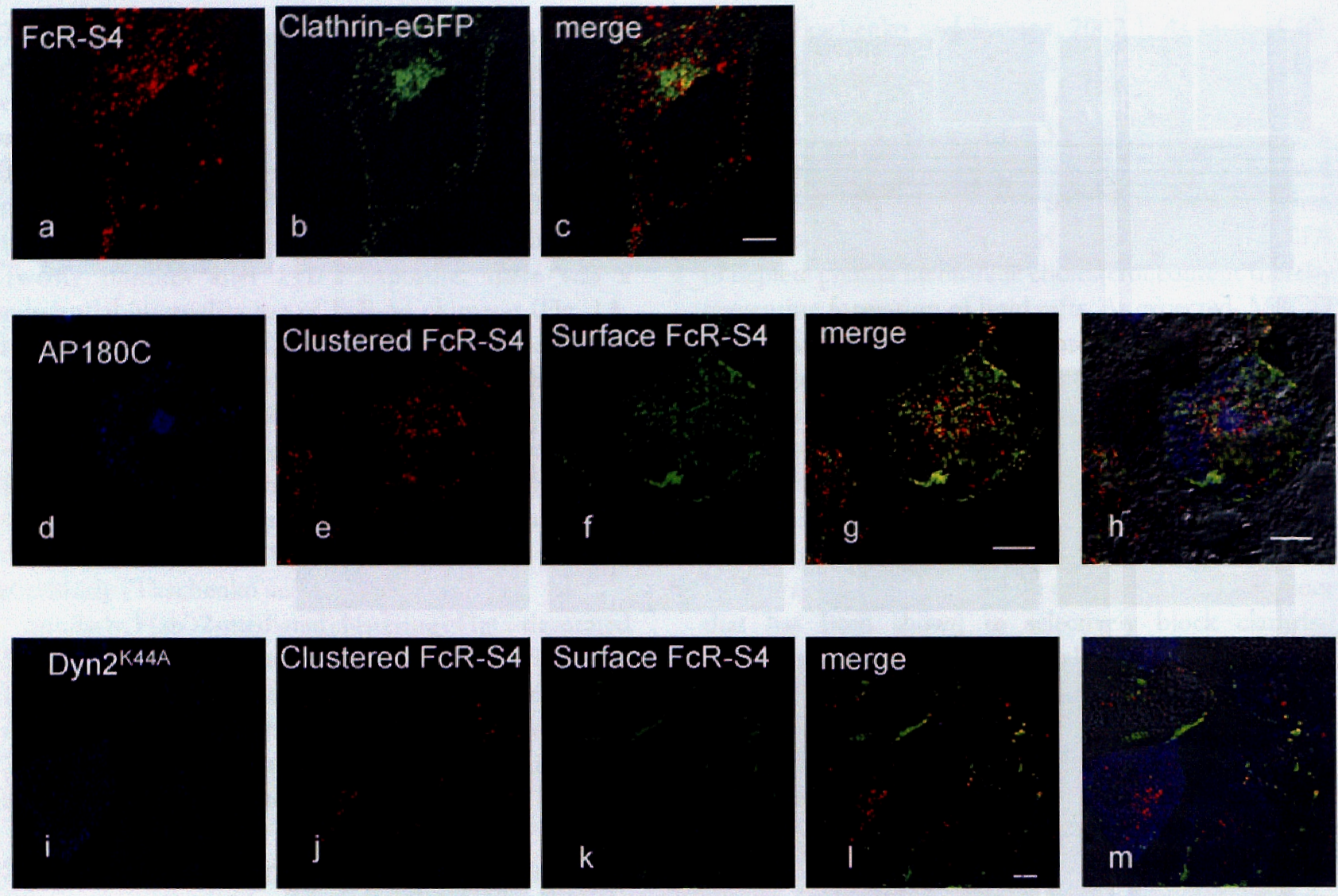

Figure 4. Syndecan-4 is internalized in the clathrin- and dynamin-independent manner.

Syndecan-4 endocytosis was studied in FcR-S4 expressing RFPEC transiently transfected with various constructs.

Antibody clustering of FCR-S4 chimeras carried out as described in Fig 1 and 2 previously leads to internalization of syndecan-4 (Panel a). Note the absence of co-localization of internalized syndecan-4 with clathrin in cells expressing clathrin-eGFP (Panels $b$ and c) 5 min after clustering

The effect of clathrin dominant negative was studied in cells transiently expressing c-myc tagged AP180C construct (Panel d). Cell expressing AP180C demonstrates the same FcR-S4 internalization as non-transfected cells (Panels e,f,g,h). In the panels FcR-S4 remaining on the cell surface is shown in green and internalized in red.

The role of dynamin was studied in cells transiently expressing a dominant-negative HA-tagged dyn $2^{\text {KaAA }}$ construct (Panel i). Note that the cell expressing Dyn2 ${ }^{144 A}$ demonstrates high level of FcR-S4 internalization (Panels r, $, 1, \mathrm{~m}$ ). Panels $\mathrm{h}$ and $\mathrm{m}$ show merged color images $\mathrm{g}$ and I, respectively overlaid with DIC.

Panels g, h,l: red color shows internalized FcR-S4.

Panels $t, g, h, k, l$ : yellow and green colors correspond to FCR-S4 constructs remaining on the cell surface. Scale bars, $10 \mu m$.

levels over the next 60 minutes (Fig. 6).

Since Racl activation preceded the activation of syndecan- 4 endocytosis and reverted to baseline levels when its endocytosis was complete, we next examined whether Racl activation is indeed required for this process. Treatment of cells with $\mathrm{C}$. difficile toxin B, inhibitor of all Rho GTPases, completely abolished all FcR-S4 endocytosis (Fig. 7a). At the same time, treatment with a RhoA inhibitor, C3 exocransferase, had no effect on this process (Fig. $7 \mathrm{~b}$ ). To further investigate which Rho family member is involved in syndecan endocyrosis, dominant negative Racl and RhoA as well as constitutively active mutants of Racl, Cdc42 and RhoA were transiently expressed in RFPEC expressing FcR-S4 chimeras and their effect on clustering-induced syndecan- 4 endocytosis was then examined. Transient expression of a Rac1DN construct completely blocked FcR-S4 endocytosis while the expression of a Rac1 constitutively active construct markedly accelerated it (Fig. 8a, Fig. 5b). Transient expression of a Cdc42 dominant also downregulated syndecan-4 endocytosis while a Cdc42 constitutively active construct had no effect (Fig. 8b, Fig. 5b). At the 
A
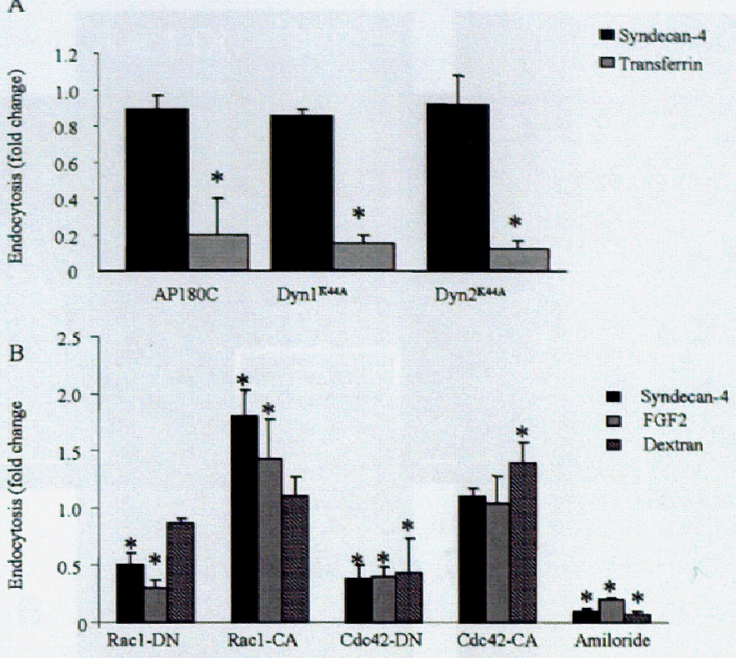

Figure 5. Quantitative analysis of syndecan-4 endocytosis Quantitative analysis of syndecan-4 endocytosis was carried out using confocal microscopy as described in Methods. The results are presented as a fold change from baseline for each substance.

(A) Effect of dominant negative constructs inhibited clathrindependent uptake (AP180C) and dynamins 1 and 2 function (Dyn1 ${ }^{\mathrm{K} 4 \mathrm{AA}}$ and Dyn2 $2^{\mathrm{K} 4 \mathrm{AA}}$ ) an syndecan-4 (black bars and transferrin (grey bars). Note inhibition of transferrin but not syndecan-4 uptake. ${ }^{*} p<0.05$ vs. baseline.

(B) The effects of Rac1 and Cdc42 dominant negative and constitutively active constructs as well as amiloride treatment on FcR-syndecan-4 (black bars), FGF2 (grey bars) and dextran (striped bars) uptake was examined in RFPEC. Note a significant inhibition of syndecan-4 and FGF2 uptake in Rac1-DN expressing cells and increased uptake in Rac1-CA expressing cells. Cdc42-

DN and amiloride inhibited uptake of all three substances. ${ }^{*} p<0.05$ vs. baseline endocytosis.

same time, expression of RhoA dominant negative or constitutively active constructs had no effect on FcR-S4 internalization (Fig. 8c, Fig. 5b).

\section{Syndecan-4 and FGF2 internalization proceeds via macropinocytosis}

The involvement of Rac1 in syndecan- 4 endocytosis suggests that the latter might proceed via a macropinocytic pathway. To evaluate this possibility FcR-S4-expressing RFPEC were treated with fluorescently labeled $70 \mathrm{kDa}$ dextran and then syndecan clustering was induced by an antibody or by addition of fluorescently labeled FGF2 (Fig. 9a-c). Confocal microscopy of live cells demonstrated partial co-localization of internalized

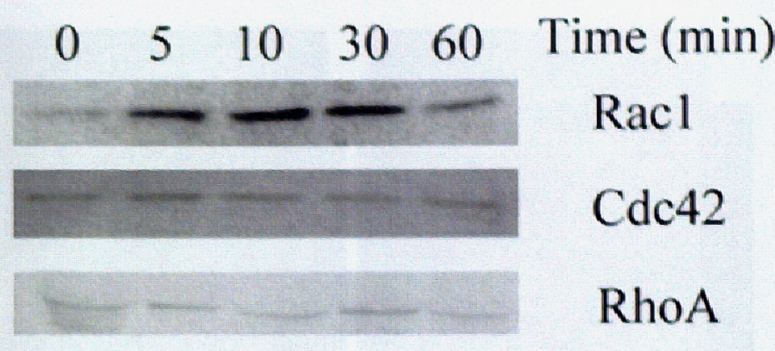

Figure 6 . Rac1 activation by syndecan-4 clustering

Time course of Rac1, RhoA and Cdc42 activation following antibody oligomerization of FCR-S4 chimeras. GST pull down assays with specific substrates were performed as described in the Methods. Note activation of Rac1 5 min following initiation of syndecan-4 oligomerization while neither RhoA nor Cdc42 activity is changed.

dextran and FcR-S4 (Fig. 9d) following antibody clustering, a finding consistent with the presence of FcR-S4 chimera in macropinocytic vesicles. Similarly, following FGF2 treatment of endothelial cells exposed to dextran, there was considerable co-localization of dextran and FGF2 signals (Fig. 9e) and both FGF2 and dextran were observed in syndecan-4-containing vesicles (Fig. 9f).

Since macropinocytosis is sensitive to amiloride, we examined the effect of this inhibitor on both syndecan4 and FGF2 endocytosis. Pretreatment of cells with amiloride completely inhibited internalization of dextran, as expected (Fig. 5b). At the same time, it also inhibited both the antibody clustering-induced FcR-S4 chimera endocytosis (Fig. 9g-j) and FGF2 endocytosis (not shown, see Fig. 5b for quantification). However, amiloride did not inhibit uptake of GM1 and GPI-GFP (not shown).

Since modulation of Racl activity affected syndecan4 endocytosis, we examined its effect on FGF2 uptake as well as macropinocytosis as defined by dextran internalization. Transient expression of a dominant negative Racl construct significantly inhibited FGF2 endocytosis while a constitutively active Racl increased it (Fig. 10a,b). At the same time neither construct affected dextran uptake (Fig. 5b).

To contrast effects of membrane cholesterol depletion and amiloride and clathrin-dependent uptake of transferrin and clathrin-independent endocytosis of syndecan- 4 and to corroborate confocal microscopy data, we used flow cytometry to quantitate these processes. In agreement with the confocal microscopy 


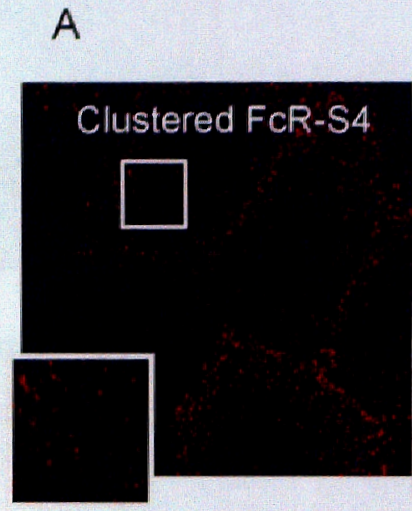

B
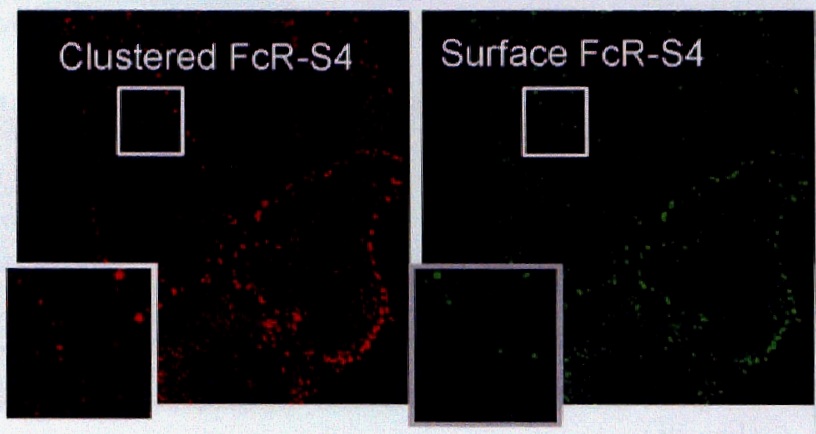
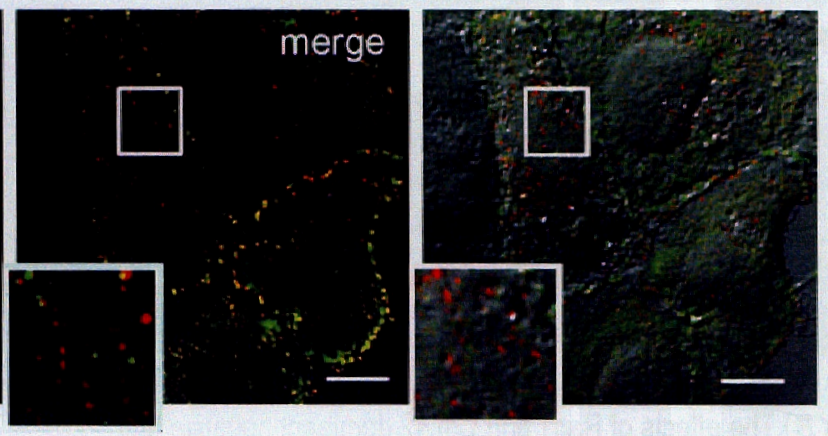

\section{C3 Exotransferase}

Figure 7. Role of Rho family GTPases in syndecan-4 endocytosis.

The effect of pre-treatment with $C$. difficile toxin $B(A)$ and $C 3$ exotransferase $(B)$ on syndecan-4 endocytosis was examined in antibodyclustered FcR-S4 chimeras. Note that while toxin B treatment completely inhibited FCR-S4 endocytosis, C3 exotransferase had no effect. Scale bars, $10 \mu \mathrm{m}$.

results, cyclodextrin treatment virtually completely inhibited syndecan -4 uptake while reducing transferrin endocytosis to a lesser degree (Fig. 11). This is consistent with similar published results (Rodal et al., 1999 ; Subril et al., 1999). However, the possibility of a yet undefined effect of cyclodextrin on macropinocytosis cannot be excluded. Amiloride also fully inhibited syndecan-4 uptake as expected for a macropinocytic process, while mildly stimulating transferrin entry into cells (Fig. 11). Finally, to explore whether syndecan- 4 clustering affects the rate of macropinocytosis, we measured dextran uptake following antibody clustering of FCR- $\$ 4$ chimeras, native syndecan- 4 or following FGF2 trearment. In all cases, dextran uptake was not affected (not shown) suggesting that syndecan-4 clustering or FGF2 treatment does not stimulate macropinocytosis.

\section{Discussion}

The results of this study demonstrate that FGF2 internalization proceeds in a syndecan-4-dependent manner and document the endocytic pathway of syndecan- 4 uptake. The parhway is initiated by the cell plasrna membrane syndecan- 4 clustering that results in Racl activation and proceeds in a caveolae-, clathrin- and dynamin-independent manner. Moreover, it is amiloride and Cdc42 sensitive and results in dextran and FGF2 internalization in the syndecan-4-containing vesicles. These data are consistent with the notion that syndecan4 clustering initiates its endocytosis via activation of Racl that allows syndecan- 4 to detach from the actin cytoskeleton, enter the macropinocytic pathway and to internalize FGF2.

Receptor endocytosis can proceed in a clathrindependent and -independent manner (Conner and 

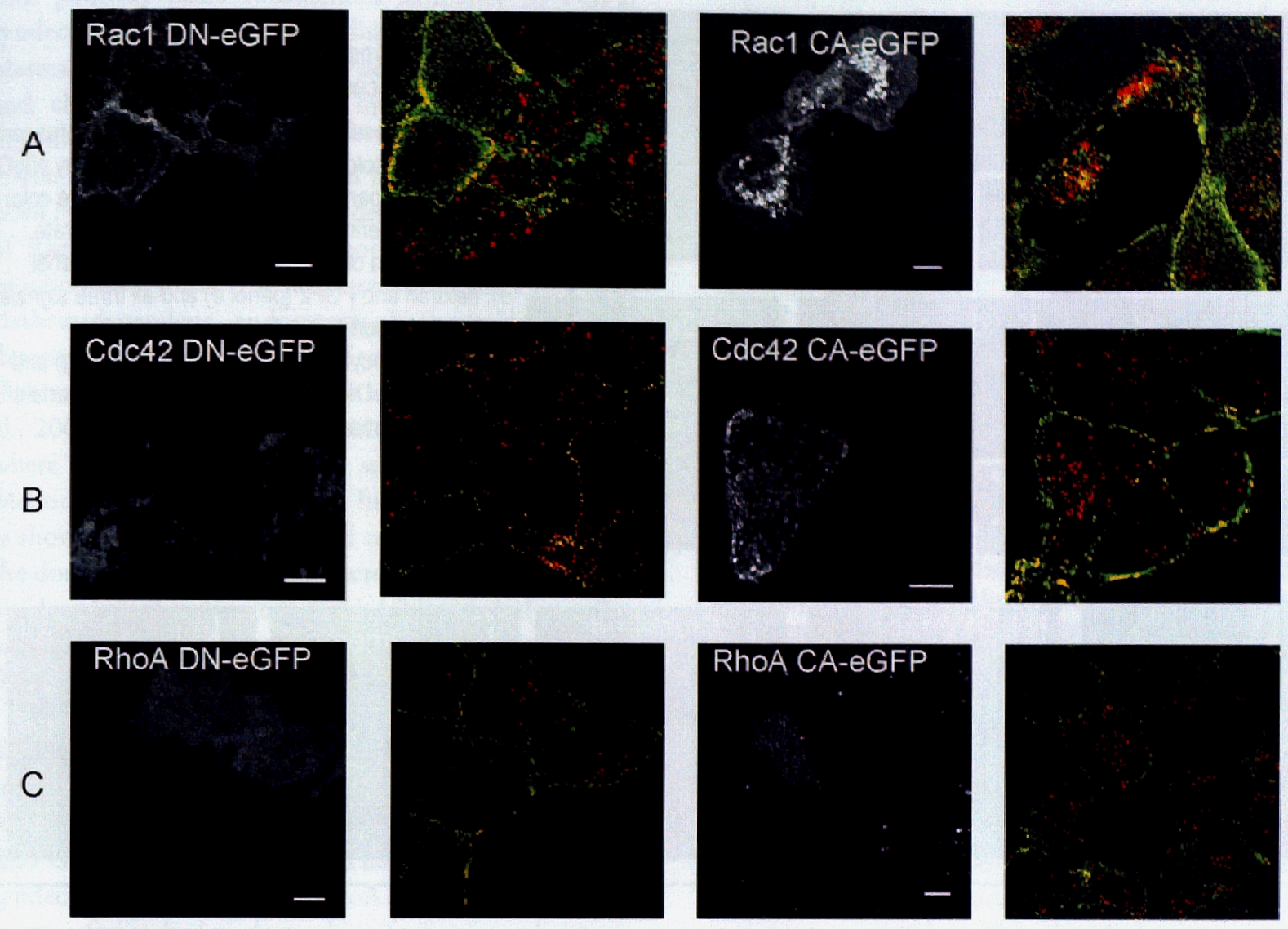

Figure 8. Specific role of Rho GTPases in syndecan-4 endocytosis

The contributions of Rac1, Cdc42 and RhoA GTPases to syndecan-4 endocytosis were studied in FCR-S4 expressing RFPEC transiently transfected with respective eGFP-tagged dominant negative and constitutively active constructs.

(A) dominant negative Rac1 completely inhibited (left panels) while a constitutively active Rac1 stimulated (right panels) FcR-S4 endocytosis.

(B) The expression of a dominant negative Cdc42 construct (left panels) somewhat inhibited FcR-S4 endocytosis while a constitutively active (right panels) $\mathrm{Cdc} 42$ constructs had no effect.

(C) The expression of either dominant negative (left panels) or constitutively active (right panels) RhoA constructs had no effect on FcRS4 endocytosis.

CA-constitutively active. DN- dominant negative. Scale bars, $10 \mu \mathrm{m}$.

Schmid, 2003). While endocytosis of most receptors, including G protein-coupled (Pierce et al., 2000) and tyrosine kinase receptors (Vieira et al., 1996) was originally described as clathrin-dependent, recent studies have clearly shown that clathrin-independent receptor endocytosis plays an equally important role (Nichols and Lippincott-Schwartz, 2001). To date a number of different clathrin-independent internalization pathways have been described that typically involve GTPase dynamin, different Rho GTPases and either caveolae or non-caveolar lipid raft portion of the plasma cell membrane. One such pathway is the internalization of interleukin-2 receptor from the plasma membrane rafts. The process is rapid and requires the GTPase dynamin and a small GTPase RhoA in an activated state (Lamaze et al., 2001). The latter observation is in marked contrast to the clathrin-mediated endocytosis where RhoA and Racl act as negative regulators.

An example of another pathway is folate uptake via its receptor, a GPI-anchored protein, that is accomplished in a clarhrin, dynamin- and caveolae-independent manner and is regulated by Cdc42 (Sabharanjak et al., 2002). 


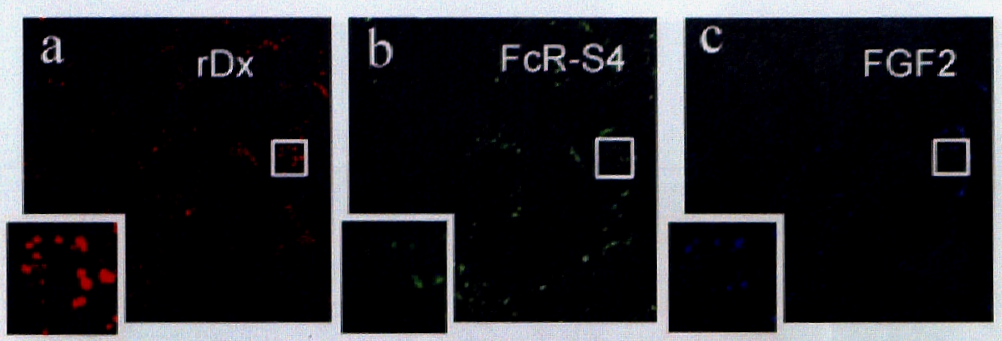

Figure 9. Syndecan-4 and FGF2 uptake proceed via macropinocytosis

FCR-S4 expressing RFPEC cultured with fluorescent dextran (red color, panel a) were decorated by nilgG (green color, panel b) followed by FGF2 (blue color, panel c) clustering. Merged images demonstrate co-localization of dextran and syndecan-4 (panel

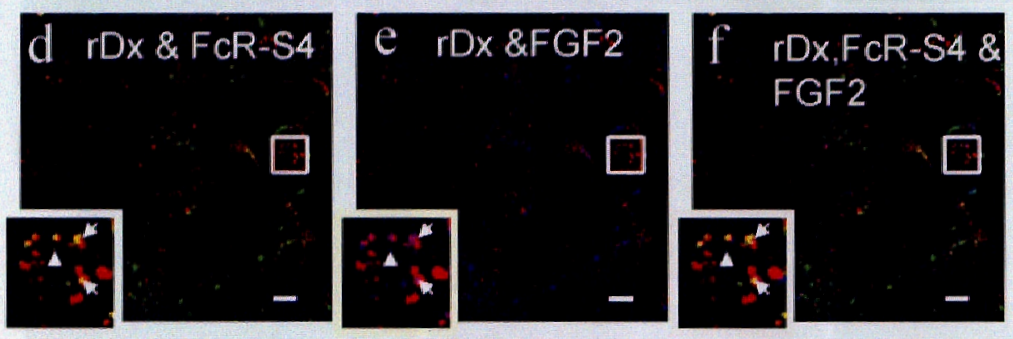
d), dextran and FGF2 (panele) and all three signals (panel f). Amiloride pre-treatment completely inhibited endocytosis of both dextran (panel g) and FcR-S4 (panel h-j). Panel k- merge image overlaid with the DIC image. Scale bars, $10 \mu \mathrm{m}$.
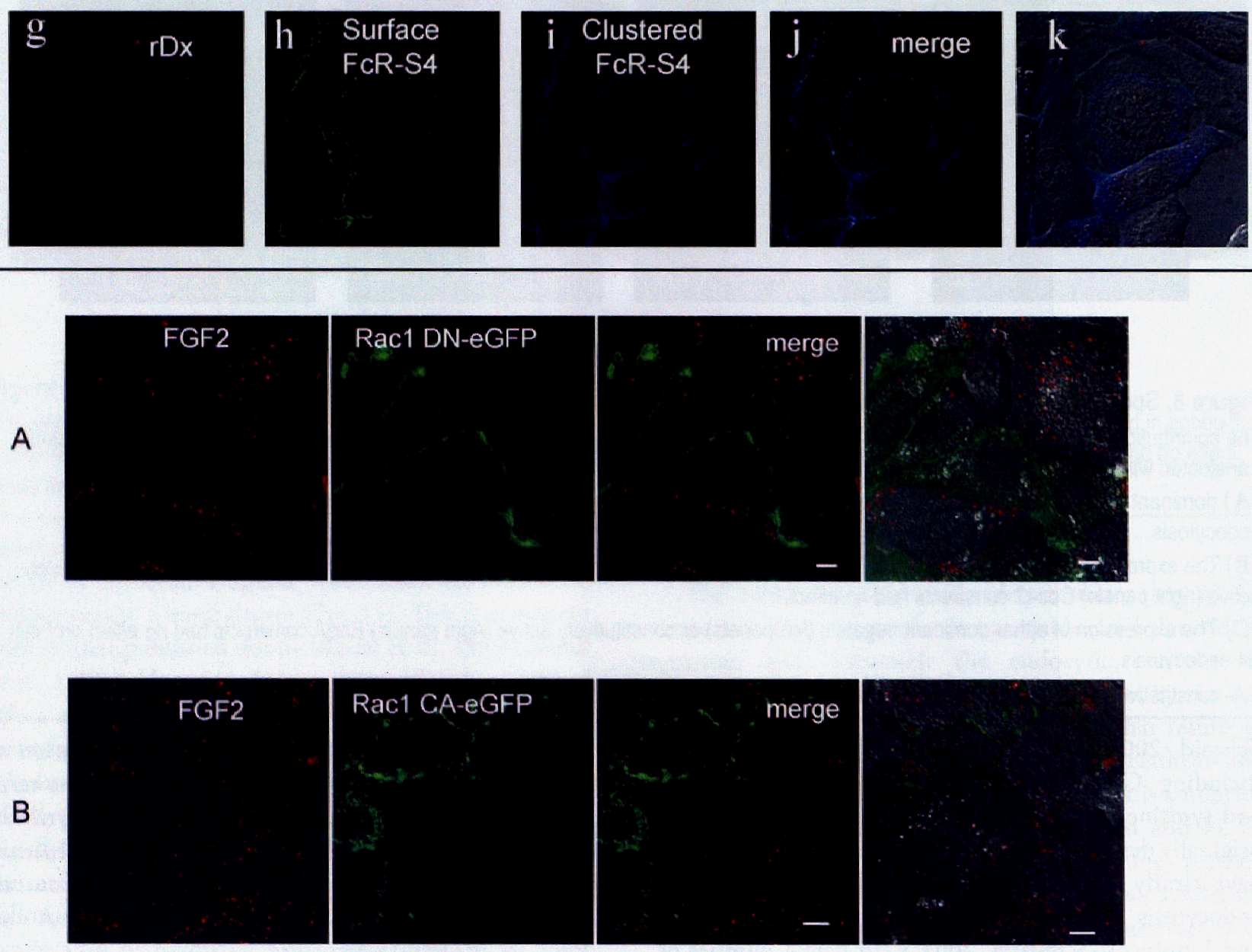

Figure 10. Rac1 regulates FGF2 endocytosis

The effect of transient expression of Rac1 dominant negative (Rac1 DN-eGFP, panel A) and constitutively active (Rac1 CA-eGFP, panel B) constructs on FGF2 endocytosis was examined in RFPEC treated with fluorescently labeled FGF2 (red). Note decreased FGF2 uptake in cells expressing Rac1 DN-eGFP and increased uptake in cells expressing Rac1 CA-eGFP. Scale bars, 10 $\mu \mathrm{m}$. 
This pathway bears considerable similarity to FGF2/ syndecan-4 endocytosis including its origin from the plasma membrane rafts, lack of dependence on dynamin and clathrin and inhibition by a $\mathrm{Cdc} 42$ dominant negative.

The major difference between the two processes arises from FGF2/syndecan-4 uptake dependence on activation of Racl that has not been reported for the folate/GPI protein endacytosis. The involvement of Racl in a nonclarhrin-dependent endocytosis has previously been described but it has been limited to fuid phase pinocytosis that seems also to involve Pakl (Dharmawardhane et al., 2000 ). Racl is also involved in type 1 phagocytosis where it acts in conjunction with Cdc42 (Ellis and Mellor, 2000 ). However, Racl function is very complex as shown by studies in epithelial cells where expression of the dominant negative Racl decreased the rates of apical and basolateral endocytosis and inhibited apical recycling of IgA whereas the constitutive active Racl mutant had the opposite effect (Jou et al., 2000)

In the case of syndecan-4, Racl activation is required for its endocytosis while the activity of RhoA does not affect this process. This conclusion is supported by several observations. First, is the observation that a panRho GTPase inhibitor, C. difficile toxin $B$, inhibited all syndecan- 4 uptake while a RhoA specific inhibitor, C3 exotransferase, had no detectable effect on its endocytosis. Second, a dominant negative Racl mutant completely inhibited syndecan -4 uptake while a constitutive active Racl mutant markedly accelerated it. At the same time, dominant negative and constitutive active forms of RhoA had no effect on syndecan-4 endocytosis. Of note, the time course of Racl activation by syndecan4 oligomerization is in keeping with its above described role in syndecan- 4 uptake since its activation precedes the initiation of the core protein internalization and its activity returns to normal when the process is complete. The capacity of syndecan- 4 clustering to activate Racl is in keeping with the known syndecan-4 oligomerizationdependent activation of PKC (Horowitz and Simons, 1998 ; Oh et al., 1997) and the ability of PKC agonist PMA to activate Racl and to induce macropinocytosis (Grimmer et al., 2002 ).

There are several possible explanations for the role of Racl in syndecan-4-dependent endocytosis. In quiescent cells plated on fibronectin syndecan -4 participates in formation of focal adhesions and is found in association with the actin cytoskeleton (Saoncella et al., 1999). This linkage to actin may involve recently described syndecan4 binding to $\alpha$-actinin (Greene et al., 2003 ). Prior to

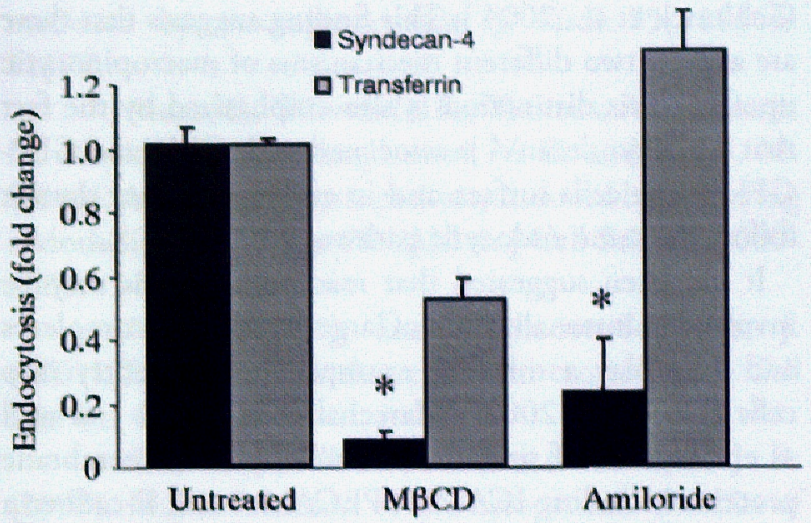

Figure 11. Flow cytometry analysis of syndecan-4 endocytosis.

The effects of membrane cholesterol depletion by treatment with methyl- $\beta$-cyclodextrin $(M \beta C D)$ and amiloride on uptake of transferrin and FCR-syndecan-4 were analyzed using flow cytometry as described in Methods. The data are presented as fold change from baseline. $M \beta C D$ treatment almost fully blocked syndecan uptake while significantly reducing the level of transferrin internalization. Amiloride treatment inhibited syndecan uptake but increased the rate of transferrin endocytosis. ${ }^{*} p<0.05$ vs. baseline.

clustering, syndecan- 4 is absent from the raft plasma membrane domain and it moves there in response to FGF2 or antibody-induced oligomerization (Tkachenko and Simons, 2002 ). This data is in agreement with the finding that more than $50 \%$ of cell surface bound FGF2 is found in lipid rafts (Chu et al., 2004). Such a movement probably requires breaking of the syndecan-4actin cytoskeleton association, an event accomplished by Racl activation. Once translocated to the raft domain, syndecan- 4 endocytosis proceeds in a manner similar to that of the folate receptor. This is suggested by colocalization of syndecan-4 and BODIPY-GMl and GPIGFP markers of raft region proteins and by the effect of dominant-negative CDC42. This finding is also in agreement with a previously reported co-localization of syndecan -4 and the inactive variant of proaerolysin, a marker of GPI-associated proteins (Tkachenko and Simons, 2002).

The sensitivity of syndecan- 4 uptake to inhibition with amiloride and the presence of dextran in syndecan4-containing vesicles suggest that it proceeds via macropinocytosis, a process that proceeds by formation of large endocytic vesicles brought about by the closure of lamellopodia at ruffling membrane domains and is usually thought of in the context of bulk fluid uptake. A recent study demonstrated that dynamin 2 is required for PDGF-induced but not constitutive macropinocytosis 
(Schlunck et al, 2004). This finding suggests that there are at least two different mechanisms of macropinocytic uptakes. This distinction is also emphasized by the fact that while syndecan -4 is associated with GM1 and GFPGPI on the cells surface and in endosomes they do not follow the same endocytic parhway.

It has been suggested that macropinocytosis may be involved in internalization of large multimeric complexes and may play a tole, for example, in viral entry into cells (Liu et al., 2002; Marechal et al., 2001) as well as endocytosis of several endothelial plasma membrane proteins including ICAM-1, PECAM-1 and E-cadherin (Muro et al., 2003 ; Paterson et al., 2003 ). Finally, macropinocytosis is an attractive pathway for syndecan internalization given the typical large sizes of its heparan sulfate chains. This role of rafts in recruitment for macropinocytosis may be similar to the recruitment of cholera and anthrax toxins for uptake via the clathrin pathway (Abrami et al., 2001 ; Shogomori and Futerman, $2001)$.

FGF2 internalization is an important consequence of syndecan-4 endocytosis. In the cell type under study the majority of FGF2 uprake occurred via the syndecan -4 parthway. The dependence of FGF2 uptake on syndecan4 endocyrosis is in keeping with previously published results that suggested that both FGF1 and FGF2 enter cells via an endocytic process involving heparan sulfate proteoglycans (Citores et al., 1999 ; Gleizes et al., 1995 "Roghani and Moscatelli, 1992 ). Such proteoglycandependent uptake has been localized to uncoared pits, in keeping with our finding of non-clathrin-dependent uptake, and proceed at a relatively slow pace, once again consistent with the kinetics of syndecan-4 internalization observed in this study (Gleizes et al., 1995). The functional significance of syndecan-4-dependent FGF2 internalization has not been established but previous studies have suggested that FGF1 uptake is required for its full mitogenic effect (Grieb and Burgess, 2000).

In summary, we describe macropinocytosis of syndecan4 triggered by its oligomerization on endothelial cell membranes that results in internalization of the clustering agent, in this case FGF2, and involves both Racl and Cde42 GTPases. The biological function of this pathway is the subject of future studies.

\section{Acknowledgments}

We would like to thank Dr. Warran Kent (Dartmouth Medical School) for labeling of antibodies and FGF2 with fluorescent dyes.

\section{REFERENCES}

Abrami, L., Fivaz, M., Kobayashi, $T_{\text {, Kinoshita, }}$ T., Parton, R. G. and van der Goot, Fu G. (2001). Crosstalk berween caveolae and glycosylphosphatidylinositolrich domains. I Biol Chem 276, 30729-30736.

Brodsky, R. A., Mukhina, G. L., Li, S., Nelson, K. L., Chiurazzi, P. L., Buckley, J. T. and Borowitz, M. J. (2000). Improved detection and characterization of paroxysmal nocturnal hemoglobinuria using fuorescent aerolysin. Am J Clin Pathol 114, 459-466.

Cao, H., Garcia, F. and McNiven, M. A. (1998). Differential distribution of dynamin isoforms in mammalian cells. Mol Biol Cell 9, 2595-2609.

Chu, C. L., Buczek-Thomas, J. A. and Nugent, M. A. (2004). Heparan sulphate proteoglycans modulate fbroblast growth factor-2 binding through a lipid raftmediated mechanism. Biochem ] 379, 331-341.

Citores, L., Wesche, J., Kolpakova, E. and Olsnes, S. (1999). Uptake and intracellular transport of acidic fibroblast growth factor: evidence for free and cytoskeleton-anchored fibroblast growth factor receptors. Mol Bial Cell 10, 3835-48.

Conner, S. D. and Schmid, S. L. (2003). Regulated portals of entry into the cell. Nature 422, 3744.

Dharmawardhane, S., Schurmann, A., Sells, M. A., Chernoff, J., Schmid, S. L. and Bokoch, G. M. (2000). Regulation of macropinocytosis by p21-activated kinase-1. Mol Biol Cell 11, 3341-3352.

Ellis, S. and Mellor, H. (2000). Regulation of endocytic traffic by rho family GTPases. Trends Cell Biol 10, 85-88.

Ford, M. G., Pearse, B. M., Higgins, M. K., Vallis, Y., Owen, D. J., Gibson, A., Hopkins, C. R., Evans, P. R. and McMahon, H. T. (200l). Simultaneous binding of Ptdins(4,5)P2 and clathrin by AP180 in the nucleation of clathrin lattices on membranes. Science 291, 1051-1055.

Fuki, I. V., Kuhn, K. M., Lomazov, I. R., Rochman, V. L., Tuszynski, G. P., Iozzo, R. V., Swenson, T. L., Fisher, E. A. and Williams, K. J. (1997). The syndecan family of proteoglycans. Novel receptors mediating internalization of atherogenic lipoproteins in vitro. J Clin Invest 100, 1611-1622.

Fuki, I. V., Meyer, M. E. and Williams, K. J. (2000). Transmembrane and cytoplasmic domains of syndecan mediate a multi-step endocytic pathway involving detergent-insoluble membrane rafts. Biochem J $351 \mathrm{Pt} 3,607-612$.

Gleizes, P. E., Noaillac-Depeyre, J., Amalric, 
F. and Gas, N. (1995). Basic fibroblast growth factor (FGF-2) internalization through the heparan sulfate proteoglycans-mediated parhway: an ultrastructural approach. Eur 【 Cell Biol 66, 47-59.

Goldfarb, M. (2001). Signaling by fibroblast growth factors: the inside story. Sci STKE 2001, PE37.

Greene, D. K., Tumova, S., Couchman, J. R. and Woods, A. (2003). Syndecan-4 Associates with alpha -Actinin. J. Biol. Chem. 278, 7617-7623.

Grieb, T. A. and Burgess, W. H. (2000). The mitogenic activity of fibroblast growth factor-1 correlates with its internalization and limited proteolytic processing. J Cell Physiol 184, 171-182.

Grimmer, S., van Deurs, B, and Sandvig, K. (2002). Membrane ruffing and macropinocytosis in A431 cells require cholesterol. J Cell Sci 115, 29532962.

Horowitz, A. and Simons, M. (1998). Phosphorylation of the Cytoplasmic Tail of Syndecan4 Regulates Activation of Protein Kinase Calpha. J Biol Chem 273, 25548-25551.

Horowitz, A., Tkachenko, E. and Simons, $M$. (2002). Fibroblast growth factor-specific modulation of cellular response by syndecan-4. J Cell Biol 157, 715725 .

Jou, T. S., Leung, S. M., Fung, L. M., Ruiz, W. G., Nelson, W. J. and Apodaca, G. (2000). Selective alterations in biosynthetic and endocytic protein traffic in Madin-Darby canine kidney epithelial cells expressing mutants of the small GTPase Rac1. Mol Biol Cell 11, 287-304.

Lamaze, C., Dujeancourt, A., Baba, T., Lo, C. G., Benmerah, A. and Dautry-Varsat, A. (2001). Interleukin 2 receptors and detergent-resistant membrane domains define a clathrin-independent endocytic pathway. Mol Cell 7, 661-671.

Li, L. and Chaikof, E. L. (2002). Mechanical stress regulates syndecan- 4 expression and redistribution in vascular smooth muscle cells. Arterioscler Thromb Vasc Biol 22, 61-68.

Liu, N. Q., Lossinsky, A. S., Popik, W., Li, X., Gujuluva, C., Kriederman, B., Roberts, J., Pushkarsky, T., Bukrinsky, M., Witte, M. et al. (2002). Human immunodeficiency virus type 1 en ters brain microvascular endorhelia by macropinocytosis dependent on lipid rafts and the mitogen-activated protein kinase signaling parhway. J Virol 76, 6689-6700.

Marechal, V., Prevost, M. C., Petit, C., Perret, E., Heard, J. M. and Schwartz, O. (2001). Human immunodeficiency virus type 1 entry into macrophages mediated by macropinocytosis. \Vhrol 75, 1116611177.

Muro, S., Wiewrode, R., Thomas, A., Konniaris, L., Albelda, S. M., Muzykantov, V. R. and Koval, M. (2003). A novel endocytic parthway induced by clustering endothelial ICAM-1 or PECAM-1.J Cell Sei 116, 15991609.

Nichols, B. J. and Lippincott-Schwartz, J. (2001). Endocytosis without dathrin coars. Trends Cell Biol 11, 406-412.

Oln, E. S., Woods, A. and Couchman, J. R. (1997). Multimerization of the cytoplasmic domain of syndecan-4 is required for its ability to activate protein kinase C. J Biol Chem 272, 1.1805-11811.

Ornitz, D. M. and Itoh, N. (2001). Fibroblast growth factors. Genome Biol 2.

Paterson, A. D., Parton, R. G., Ferguson, C. Stow, J. L. and Yap, A. S. (2003). Characterization of E-cadherin endocytosis in isolated MCF-7 and chinese hamster ovary cells: the initial fate of unbound $\mathrm{E}$ cadherin. J Biol Chem 278, 21050-21057.

Pierce, K. L., Maudsley, S., Daaka, Y., Luttrell. L. M. and Lefkowitz, R. J. (2000). Role of endocyrosis in the activation of the extracellular signal-regulated kinase cascade by sequestering and nonsequestering $\mathrm{G}$ proteincoupled receptors. Proc Nat Acad Sci U S A 97, 1489 1494.

Rapraeger, A. C., Guirnond, S., Krufta, A. and Olwin, B. B. (1994). Regulation by heparan sulfate in fibroblast growth factor signaling. Merhods Enzyrnöl 245, 219-240.

Rodal, S. K., Skretting, G, Garred, O., Vilhardt, F., van Deurs, B. and Sandwig, K. (1999). Extraction of cholesterol with methyl-beta-cyclodextrin percurbs formation of clathrin-coared endocytic vesicles. Mol Biol Cell 10,961-974.

Rodrigueza, W. V., Williams, K. J., Rothblar, G. H. and Phillips, M. C. (1997). Remodeling and shutrling. Mechanisms for the synergistic effects between different acceptor particles in the mobilization of cellular cholesterol. Arterioscler Thromb Vasc Biol 17, 383-393.

Roghani, M. and Moscatelli, D. (1992). Basic fibroblast growth factor is internalized through both receptor-mediated and heparan sulfate-mediated mechanisms. J Biol Chem 267, 22156-22162.

Rosenberg, R. D., Shworak, N. W/, Liu, J., Schwartz, J. J. and Zhang, L. (1997). Heparan sulfate proteoglycans of the cardiovascular system. J Clin Invest $99,2062-2070$.

Sabharanjak, S., Sharma, P., Parton, R. G. and 
Mayor, S. (2002). GPl-anchored proteins are deliwered to recycling endosomes via a distinct odc42-regulared clathrin-independent pinocytic pathway. Developmental Cell 2, 411-423.

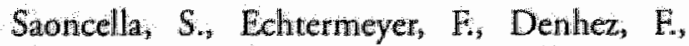
Nowlen, ]. K., Mosher, D. F., Robinson, S. D., Hynes, R. O. and Goetinck, P. Fu (1999). Syndecan-4 signals cooperatively with integrins in a Rhodependent manner in the assembly of focal adhesions and actin stress fibers. Proc Nat Acad Sci U S A 96, 2805-2810.

Schlunck, G., Damke, H., Kiosses, W. B., Rusk, N., Symons, M. H., Waterman-Storer, C. M., Schmid, S. L. and Scliwartz, M. A. (2004). Modularion of rac localization and function by dynamin. Mol Biol Cell 15 , 256-267.

Shogomori, H. and Futerman, A. H. (2001). Cholera toxin is found in detergent-insoluble rafts/ domains at the cell surface of hippocampal neurons but is internalized via a raft-independent mechanism. J Biol Chem 276, 9182-9188.

Simons, M. and Horowitz, A. (2001). Syndecan4-mediated signaling. Cell Signal 13, 855-862.

Subtil, A., Gaidarov, I., Kobylarz, K., Lampson, M. A., Keen, J. H. and McGraw, T. E. (1999). Acute cholesterol depletion ínhibits clachrin-coated pit budding. Proc Natl Acad Sci U S A 96, 6775-6780.

Tkachenko, E. and Simons, M. (2002). Clustering induces redistribution of syndecan-4 core protein in to raft membrane domains. J Biol Chem 277 , 19946-19951.

Vieira, A. V., Lamaze, C. and Schmid, S. L. (1996). Control of $\mathrm{EGF}$ recepror signaling by clathrinmediated endocytosis. Seience 274, 2086-2089.

Volk, R. Schwartz, J. J., Li, J*, Rosenberg, R. D. and Simons, M. (1999). The role of syndecan cytoplasmic domain in basic fibroblast growth factor-dependent signal transduction. I Biol Chem 274, 24417-24424.

Williams, K. J. (2001). Interactions of lipoproteins with proteoglycans. Methods Mol Biol 171, $457-477$.

Zimmermann, P. and David, G. (1999). The syndecans, tuners of transmembrane signaling. Faseb J 13, S91-S100. 


\section{Chapter 6}

Syndecan-4 clustering induces migration in a synectin-dependent manner

Eugene Tkachenko, Arye Elfenbein, Daniela C. Tirziu, and Michael Simons

(submitted for publication) 


\section{Abstract}

Gell migration is a dynamic process involving formation of leading edge in the direction of moration and achesion points from which tension s generated to move the cell body forward. A. the sane time, disassembly of adhesion points ocerts at the back of the cell, a region known as the trailing edge. Syndecan-4 (S4) is a Transmembrane proteoglycan thought to be Involved in formation of focal adhesions. Recent studies have shown that its cytoplasmic domain can engage in signal transduction, making $\mathbf{S 4}$ a bona fide receptor. Here we show that ligand chustering of cell surface 54 on endothelial cells initiates a signaling cascade that results in activation of Rac1, induction of cell polarization and stimulation of cell migration that depends on S4 interaction with its PDZ binding partner synectin. Expression of a $\mathbf{S 4}$ mutant lacking its PDZ-binding region (S4-PDZ-) leads to decreased cell motility and a failure to form a trailing edge. Similarly, cells lacking synectin, a S4-binding PDZ domain-containing protein, also fail to migrate in response to $\mathbf{S 4}$ clustering. Upon clustering, both the full length $\$ 4$ and S4-PDZ- forms colocalize with the active form of Rac1. However, S4, but not S4-PDZ-, targets activated Rac1 to the leading edge of live cells in a synectin-dependent manner. Thus, our data suggest that syndecan-4 promotes endothelial cell migration in response to ligand binding by activating Rac1 and localizing It to the leading edge, and that these processes are dependent on its interaction with synectin.

\section{Introduction}

Syndecans are a family of four transmembrane proteoglycans carrying both heparan sulfate and chondroitin sulfate chains. Different family members are expressed in various cell types with syndecan-4 demonstrating a nearly ubiquitous expression. Syndecans have been thought to play the role of co-receptors for various heparin-binding growth factors such as fibroblast growth factors (FGFs) and vascular endorhelial growth Factors (VEGFs) or fibronectin-binding integrins (Couchman et al., 2001; Simons and Horowitz, 2001; Couchman, 2003; Tkachenko et al., 2005). However, recent studies have suggested that syndecans' intracellular domains, and in particular, the syndecan-4 intracellular domain, can directly engage in signal transduction (Oh et al., 1997b; Oh et al., 1997a; Volk et al., 1999; Horowitz et al., 2002; Keum et al., 2004).

The syndecans' cytoplasmic tail contains two highly conserved domains. The first (CI) is the membrane- proximal region that binds rubulin, Src kinase, ezrin and cortactin (Tkachenko et al., 2005). The second (C2) is a $\mathrm{C}$-terminal region that contains a $\mathrm{PDZ}$-domain binding motif. The part of the molecule between the two conserved domains has been termed the variable domain and its sequence is unique to each syndecan family member.

The variable domain of syndecan- 4 binds to the PIP2/ PKC $\alpha$ complex, $\alpha$-actinin and syndesmos (Tkachenko et al., 2005). These interactions are responsible for the prewiously demonstrated syndecan-4 role in cytoskeleton regulation that includes formation of focal adhesions, of dynamic of stress fibers and of cell protrusions (Baciu and Goetinck, 1995; Couchman and Woods, 1999; Longley et al., 1999; Baciu et al,, 2000; Keum et al, 2004; Midwood et al., 2004; Saoncella et al., 2004).

Syndecan -4 is an acute response molecule, highly expressed in ischemic tissues, vascular tissues after injury (Geary et al., 1995; Li et al., 1997) and in a variery of solid tumors(Geary et al., 1995; Li et al., 1997; Oh and Couchman, 2004). Its potential role in postnatal angiogenesis is supported by delayed dermal wound healing observed in syndecan-4 null mice (Echtermeyer et al., 2001). Several reports have implicared syndecan-4 as a mediator of growth factor-induced migration (Volk et al., 1999; Horowitz et al., 2002; Cornelison et al., 2004; Charnaux et al., 2005). For example, mutations of either PIP2 or PDZ-interacting regions resulted in impaired endothelial cell migration and proliferation in response to FGF2 (Horowitz et al., 2002), and the presence of the syndecan-4 cytoplasmic tail was necessary for FGF2 responsiveness (Volk et al., 1999). Similarly, regeneration of muscles in syndecan- 4 null mice is impaired because of the inability of satellite cells to migrate in response to FGF2 or HGF (Cornelison et al., 2004).

Evidence of direct proteoglycan signaling ability also comes from studies in smooth muscle cells where, despite the presence of a dominant-negative FGF receptor 1, FGF2 activated Erk1/2 and promoted cell migration (Chu et al., 2004). Using a more direct approach in the investigation of $\$ 4$ induced signaling that involved antibody clustering, we previously demonstrated syndecan-4-dependent activation of Racl, a RhoGTPase, in endorhelial cells (Tkachenko et al., 2004) Also, antibody clustering of syndecan-4 facilitates cell spreading in a Rho-dependent manner (Saoncella et al., 1999). Finally, increased baseline Racl activity was reported in syndecan-4- $/$ - fibroblasts, thus suggesting syndecan's role in its regulation (Saoncella et al., 2004).

Since formation of the leading edge of migrating 
cells is known to be associated with activation of Racl (Waterman-Storer and Salmon, 1999; Ridley, 2001), we have ser out to explore the role of syndecan-4-dependent activation of Racl in cell migration and the contribution of its PDZ-dependent interactions to this process. The PDZ domain-containing protein synectin was considered as a potential critical partner in $\$ 4$-induced migration because of its ability to bind to $S 4$ and to mediate the migratory response of endothelial cells (Gao et al., 2000). We found that syndecan-4 induced migration of endothelial cells require localization of active form of Racl in a manner dependent on syndecan- 4 interaction with synectin.

\section{Materials and methods}

Antibodies and Reagents. Polyclonal goat IgG against extracellular domains of syndecan-4 were from Santa Cruz Biotechnology (Santa Cruz, CA). Anti-HAFluorescein and high affinity Fab fragments of IgG1 were purchase from Roche (Indianapolis, IN). AntiFAK antibodies were from Cell Signaling Technology (Beverly, MA). Anti-FcR (CD64) monoclonal antibody was purchased from Abcam (Cambridge, United Kingdom). Non-immune human IgG, Cy-3-conjugated and unlabelled goat anti-human $F\left(a^{\prime}\right) 2$ fragment and Cy-5-conjugated streptavidin were purchased from Jackson ImmunoResearch (West Grove,PA). Secondary antibodies conjugated to horseradish peroxidase (HRP) were purchased from Vector Laboratories (Burlingame, CA). Fluorescently labeled secondary antibodies were provided by Molecular Probes (Eugene, OR).

cDNA Constructs. Fe receptor-syndecan-4 chimera (FcR-S4) was previously described (Tkachenko and Simons, 2002). Mutation of PDZ binding sites of the chimera and the full length constructs by removal of the C-terminal alanine 202 was done using a PCR $3^{*}$-end primer TCA CTC CTC TGG GTT GGA GTC A . $P C R$ reaction and cloning of the chimera into pCR3.1Uni vector (Invitrogen) were done as previously described (Tkachenko and Simons, 2002). Full length syndecan4 and syndecan-4 PDZ- used to build adenoviral constructs were previously described (Horowitz et all, 2002). Adenoviruses were prepared by Harvard Gene Therapy Initiative (Boston, MA). Constructs encoding CFP-PAK-YFP (monitor of Racl/CDC42 activity), and CFP-PAK-Racl-YFP (monitor of Racl activity) were a gift from Michiyuki Matsuda (Osaka University, Japan).

Cell culture, transfection and transduction. HUVECs (Cambrex Corporation, East Rutherford, NJ) were cultured in EGM-2 medium (Cambrex). RFPEC were cultured as previously described (Horowizz and Simons, 1998). One day prior to experiments, cells were plated on fibronectin coated dishes. A solution of $10 \mu \mathrm{g} / \mathrm{ml}$ of fibronectin in PBS was used to coat dishes for 30 minutes at room temperature. Stable expression of FCR-S4 and FcR-PDZ-chimeras was done as previously described (Tkachenko and Simons, 2002). Transient transfections were performed using Genejammer (Stratagene, La Jolla, CA) according to manufacture's protocol. For transduction of HUVECs, we used 10 MOI of adenovirus.

Murine endothelial cells from lung tissue were isolated as previously described (Allport et al, 2002).

Cell "wounding" assay. For all experiments, cells were seeded on fibronectin coated tissue culture dishes (Corning, Acton, MA). Cell migration was measured by 3 to 4 independent "wounding" assays as described previously (Horowitz et al., 2002).

Syndecan clustering. Antibody clustering of FCRSyndecan-4 chimeras and FGF2 treatment were performed as described previously (Tkachenko and Simons, 2002; Tkachenko et al., 2004). For clustering of endogenous syndecan -4 , cells were starved prior to stimulation overnight in high glucose DMEM containing $0.5 \%$ serum. $3 \mu \mathrm{g} / \mathrm{ml}$ of anti-syndecan-4 antibodies (Santa Cruz) were then addled to the starvation media.

Rho GTPase pulldown assays was done as described previously (Tkachenko et al., 2004).

Live Fluorescent Microscopy was done using the previously described microscopy system with climate control (Stan et al,, 2004). To measure cell velocity, viraly transduced cells were seeded on glassbotom dishes (MatTek, Asthland MA) for 12 hours and then labeled by adding $3 \mathrm{~kg} / \mathrm{ml}$ of anti-HA FITC-Fab antibodies. After 15 min of incubation at $370 \mathrm{C}$, cells were washed with prewarmed culture media. Images were acquired every 5 minutes using a $20 \times 0.5 \mathrm{NA}$ phase objective. Indiwidual cell velocity was measured using the ImageJ program (NIH, Berhesda). In every experiment, velocities of 12 to 20 cells were analyzed. For FRET experiments, a dual splitter from Oprical Insights (Tucson ${ }^{\text {AZ) }}$ with Chroma (Rockingham, VT) filter set 1505 dexi, HQ 465/30m, HQ 560/55m) was used. Microscope excitation and dichroic filter for CFP (brightlight FF458) was from Semrock (Rochester, NY). For FRET experiments, 20x $0.75 \mathrm{NA}$ and 60x $1.45 \mathrm{NA}$ TIRF objectives from Olympus (Japan) were used. Ration analysis was performed using ImagePro software from Media Cybernetics (Silver Spring, MD) using a method that was previously described (Yoshizaki et al, 2003). For TIRF acquisition, a 15 watt argon 488 laser from 
Spectra-Physics (Irvine, CA) and illumination sideport from Olympus (Japan) were used. For TIRF experiments, 60x 1.45 NA TIRF objective from Olympus (Japan) was used. For colocalization studies, we used $100 \times 1.4 \mathrm{NA}$ objective from Olympus (Japan).

\section{Online Supplemental Material}

Movie file Fig3Videol.mov shows syndecan-4 redistribution into the leading edge of RFPEC upon clustering by antibody. One frame per minute was acquired using TIRF microscopy.

\section{Results}

A variety of growth factors are able to bind and cluster syndecan-4. The resulting signaling events combine the elements of syndecan -4 signaling proper with the growth factors tyrosine kinase receptors signaling. Similarly, cell binding to extracellular matrix proteins combines the elements of syndecan-4 and integrin-dependent signaling. In order to completely isolate signaling events dependent solely on the syndecan- 4 ligand binding and clustering, we used an anti-syndecan -4 extracellular domain antibody to cluster syndecan -4 on the surface of microvascular endothelial cells derived from the wild type and syndecan-4- mice. Anti-syndecan -4 antibody clustering of wild type endothelial cells induced a significant migratory response while syndecan $-4 \%$ endothelial cells showed no increased migration (Figure 1A). The magnitude of syndecan-4-clustering induced migration was comparable to that induced by FGF2 (Figure 1A).

To further demonstrate that the observed stimulation of migration was due to syndecan-4 cytoplasmic domain oligomerization-initiated signaling, we employed an FcRS4 chimera construct consisting of an FcR extracellular and transmembrane domains linked to syndecan- 4 cytoplasmic domain (Tkachenko and Simons, 2002) stably expressed in a rat fat pad endothelial cell (RFPEC) line. Treatment of cells with an IgG by itself did not increase cell migration (not shown). However, subsequent oligomerization of IgG-decorated FCR-S4 expressing cells with an $F(a b) 2$, but not $F(a b)$ stimulated cell migration (Figure 1B). To explore the role of PDZdependent interaction in the initiation of syndecan-4mediated cell migration, we expressed an FcR-S4-PDZchimera in the same RFPEC line. Following antibody clustering, only the FcR-S4 chimera induced migration above basal levels, implying that the PDZ-binding domain is required to effect syndecan-4-dependent migration (Figure 1B).

To further examine the role of $\mathrm{PDZ}$ interactions in

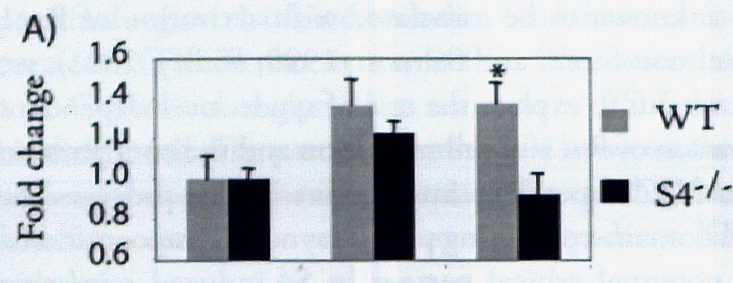

$\begin{array}{llll}\text { FGF-2 } & - & + & - \\ \text { antibody } & - & - & + \\ \text { clustering } & & & \end{array}$

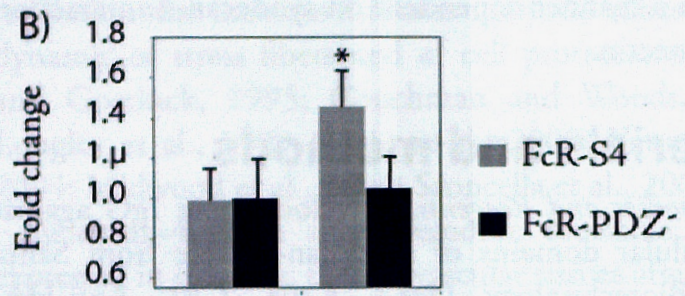

antibody $\quad-\quad++$ clustering

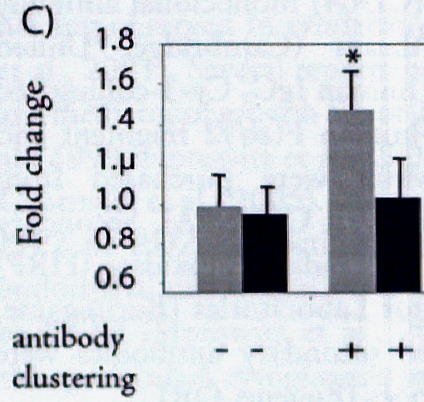

Figure 1. Syndecan-4 clustering induces migration of endothelial cells in a PDZ-dependent manner.

A. Primary lung endothelial cells from wild type (WT) and syndecan-4 - mice $\left(\mathrm{S} 4 \psi^{-}\right.$) were stimulated with FGF2 or by antibody clustering of native $\mathrm{S4}$. Note migration response induced by anti-S4 antibody similar in magnitude to that of FGF2 response in WT endothelial cells. S4 - endothelial cells do not migrate in response to anti-S4 antibody ( $* 0=0.018$ ).

B. RFPEC expressing FCR-S4 or FCR-PDZ' constructs were decorated by human nilgG followed by binding to Fab or clustering by $F(a b) 2$ portions of anti-human IgG. Note significantly enhanced migration response in FcR-S4 vs. FCRPDZ expressing cells ( ${ }^{*} p=0.015$ ).

C. Primary lung endothelial cells from WT and synectin ${ }^{-1}$ mice were stimulated with anti-S4 antibody clustering. Note significantly better migratory response in WT cells (" $p=0.03$ ). All data are shown as mean $\pm S E$ of the fold change from baseline. 

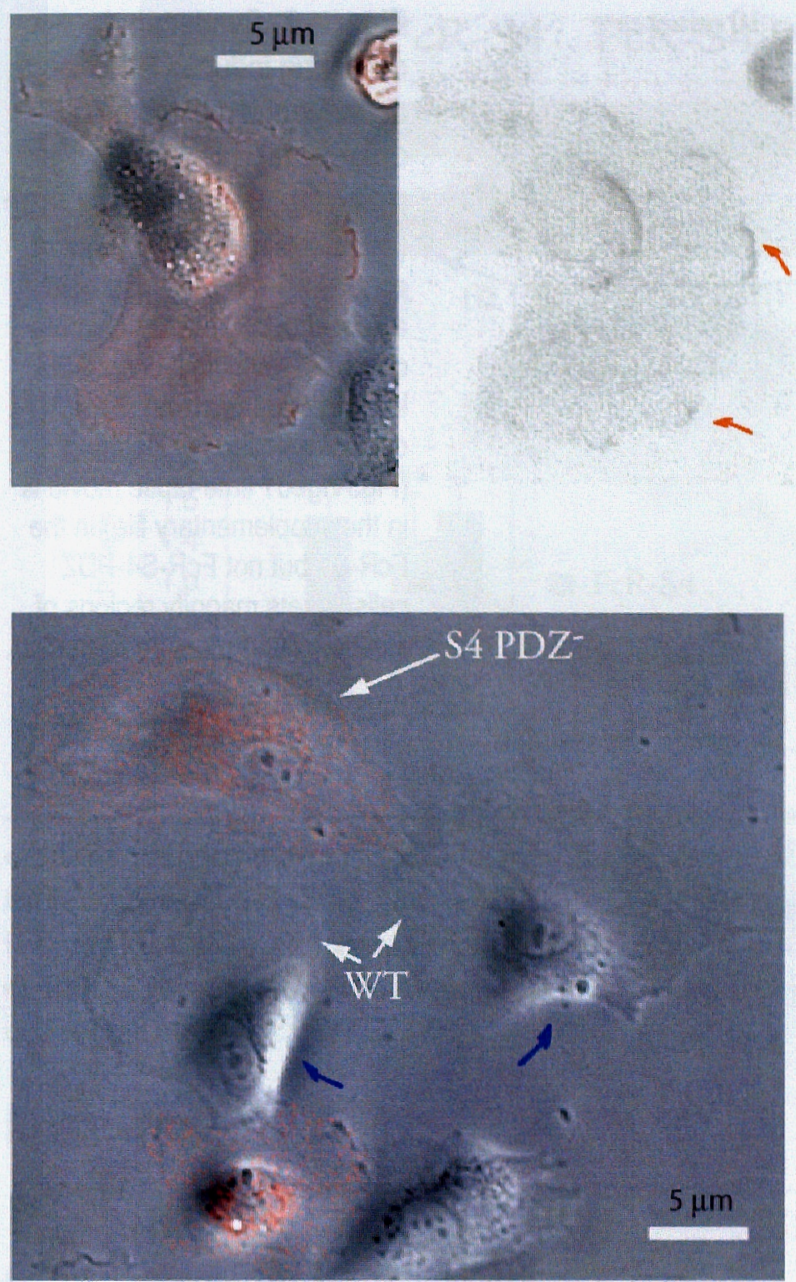

\section{Cell velocity}

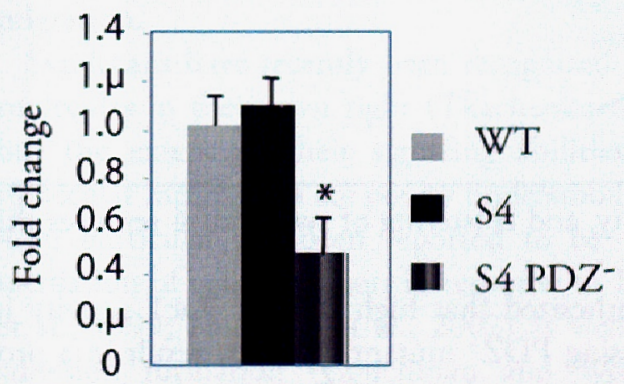

Figure 2. Syndecan-4 matrix binding induces PDZdependent cell polarization.

\section{A. HUVEC overexpressing syndecan-4 were plated on} fibronectin-coated cover slips for $3 \mathrm{hr}$. Phase image overlaid with the syndecan-4 stain (red) is shown in the left panel, and the syndecan-4 only stain is shown in the right panel only. Arrows syndecan-4-dependent migration, we evaluated the response of primary endothelial cells from synectin ${ }^{-1}$ mice. Unlike endothelial cells from synectin $+/+$ littermates controls, cells from synectin $-1-$ mice failed to enhance migration above basal levels upon antibody syndecan- 4 clustering (Figure IC). These data suggest that syndecan4 promotes cell migration in response to clustering by a ligand and that this is specifically dependent upon its interaction with synectin.

In order to monitor endothelial cell migration following binding to fibronectin, a native syndecan- 4 ligand, full-length syndecan-4 and S4-PDZ- constructs were transiently expressed in human umbilical vein endothelial cells (HUVEC). Upon attachment to a fibronectin-coated surface, full-length syndecan-4 became concentrated in lamellipodia (Figure 2A). In contrast, cells expressing S4-PDZ ${ }^{-}$while also forming lamellipodia, failed to form trailing edges and exhibited a significant decrease in random migration velocity when compared with cells expressing GFP or syndecan- 4 (Figure 2B-C).

In unstimulated endothelial cells, syndecan- 4 is diffusely distributed over the cell surface. Following antibody clustering, a punctate distribution is observed (Tkachenko and Simons, 2002; Tkachenko et al., 2004). To further study cellular distribution of S4 following antibody clustering, we used total internal reflection fluorescence (TIRF) microscopy, a technique that allows detection of a fluorescent signal that originates only from the basal surface of the cell. Following antibody clustering, the FcR-S4 chimera localized to cell protrusions on the leading edge (Figure 3, upper panels; Fig3Video1). This is in contrast to cells expressing the FCR-S4-PDZ" chimera, where increased basal surface concentrations of the fusion protein are found subsequent to clustering, although without the accompanying formation of cell protrusions (Figure 3, lower panels).

We have previously demonstrated that antibody clustering of FcR-S4 chimeras leads to Rac1 activation (Tkachenko et al., 2004). However, the role of the syndecan-4 PDZ domain in this process has not been established. Therefore, we have studied Rac1 activation in FcR-S4 and FcR-S4-PDZ-expressing RFPEC. In

indicate regions of syndecan-4 concentration on the lamellopodia. B. Phase contrast image of HUVEC overexpressing syndecan-4 $\mathrm{PDZ}^{-}$(red). Note the failure to form trailing edges (arrows).

C. Cell velacity of HUVEC expressing S4 or S4-PDZ' constructs. Note decreased velocity of S4-PDZ-expressing cells ( $" p=0.0017$, S4 PDZ- vs. control). 

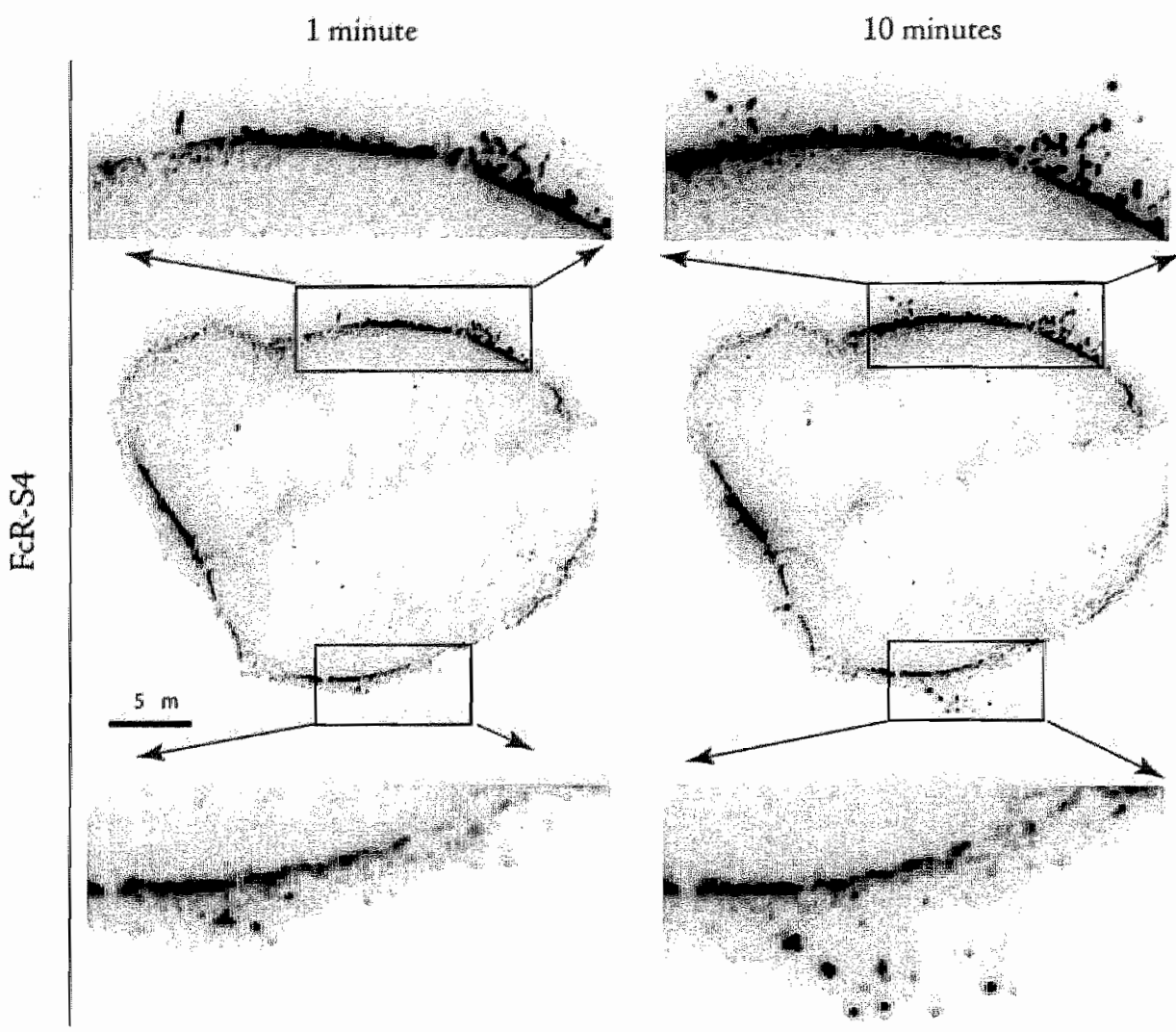

Figure 3. Syndecan-4 clustering induces PDZdependent lamellipodia outgrowth.

RFPEC expressing FCR-S4-PDZ (left panels) or FCR-S4 (right panels) were $F(a b) 2$ clustered as described. Note the chimera construct redistribution into the leading edge (arrows) of the cell upon antibody clustering (Fig 3Vigeol time-lapse movie is in the supplementary file) in the FCR-S4 but not FCR-S4-PDZ" cells. Insets magnify regions of lamellipodia protrusion formation.
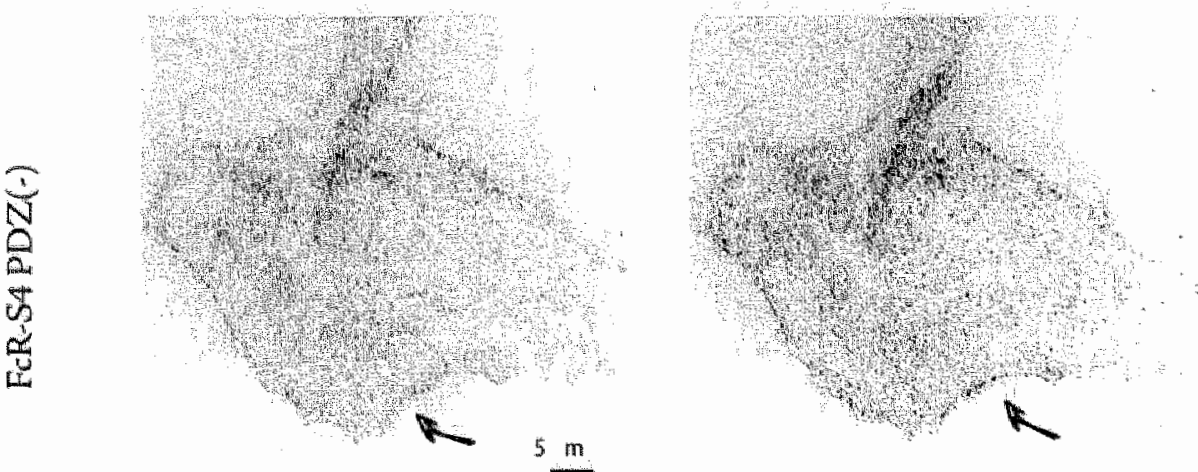

contrast to FcR-S4 expressing cells, clustering of FCR-S4PDZ- expressing cells did not significantly increase the amount of GTP-bound Racl (Figure 4a,b). Interestingly, baseline RFPEC expressing the PDZ- mutant construct had much higher levels of activated Racl than cells expressing FcR-S4. Similarly, syneccin ${ }^{-1-}$ cells also exhibir a high basall level of Racl activity and no acrivation in response to dustering (Figure $4 \mathrm{c}$ ). These observarions are in agreement with the reported high level of activated Racl in syndecan-4- fibroblasts (Saoncella er al, 2004). Thus, syndecan-4-synectin interaction inhibits
Racl acriviry, and clustering of syndecan- 4 removes this intibition.

We hyporthesized that high level of Racl activity in cells expressing $\mathrm{PDZ}^{-}$mutant does not result in a promigratory phenotype because of incorrecr localization of the acrive form of Racl. To study localization of active Racl after syndecan-4 clustering, two independent monitors of Racl activity (Yoshizaki et al., 2003) were transiently overexpressed in FcR-S4 and FcR-S4 PDZcell lines (Figure 5A). Using these constructs we observed that antibody clustering of FCR-S4 results in polarization 
A)

\section{Rac1-GTP}

Total Rac

time $(\min$.

\section{FcR-S4}
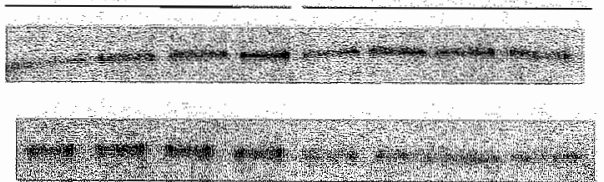

0

10

30

10

30
B)

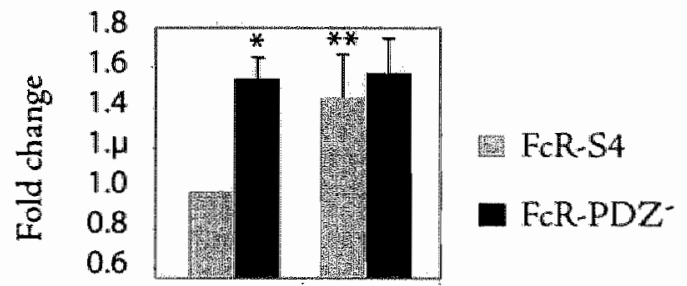

time (min.)

\section{5}

of Racl activity within a cell, an event that preceded formation of the trailing and leading edges of the cell (Figure 5B-C). In contrast, FCR-S4-PDZ- cells did not exhibit a comparable cellular polarization.f endorhelial cell migration.

\section{Discussion}

The principal findings of this study are that syndecan4 clustering on the endothelial cell surface that leads to the activation of Racl, results in cell polarization and migration. The presence of the dominant-negative syndecan-4 construct lacking a PDZ binding domain or the absence of the syndecan-4 PDZ binding partner synectin results in mislocalized high basal level activity of Racl and cell inability to polarize and initiate migration.

Syndecans have recendy been recognized as signaling molecules in their own right (Tkachenko et al., 2005) but the extent of their signaling abilities and there molecular mechanism are poorly understood. Syndecan4 in particular has been reported to be involved in mediation of cell migration in response to FGF2 (Volk et al., 1999; Horowitz et al., 2002) as well as in focal adhesion formation (Couchman and Woods, 1999; Woods and Couchman, 2001). Furthermore, we have previously demonstrated that syndecan-4 clustering induces Racl acrivation in endorhelial cells (Tkachenko et al., 2004) while its absence has been reported to also result in increased Racl activity.

The present study was carried out to reconcile rhese findings and to explore the functional effect of syndecan-4

Figure 4. Rac1 activation following syndecan-4 clustering is PDZ-dependent.

Ract activity was measured by GST pull-down assays. Total Rac1 expression was used as a control for gel loading.

A. Ractl activity at the indicated time points after clustering of FCR-S4 (left) and FCR-S4 PDZ' (right) constructs in RFPEC.

B. Quantitative analysis of Rac1 GST pull-down assays $(n=3)$. Data are shown mean $\pm S E$ of the fold change of the unstimulated FoR-S4 expressing RFPEC. " $p=0.054$ and $* * 0=0.06$ (t-test)

Note the high basal level of active Rac1 in S4 PDZ" cells. C. Rac1 activity in lung endothelial cells from the wild type $(+/ t)$ and synectin- ${ }^{-/}$mice 10 min after treatment with antiS4 (clustering) or non-immune (no clustering) antibody. Note the high basal Rac1 activity in synectin-f-cells and its activation in WT cells.

clustering on endothelial cell migration. Since syndecan4 clustering with its natural ligands such as FGF2 or fibronecrin results nor only in "pure" syndecan-4 signaling. but also in signaling events mediated by FGF-RI and $\alpha 5 \beta 1$ integrin respectively, we have used antibodies against either the extracellular domain of syndecan -4 or against the FCR portion of the FCR-S4 chimera. In both cases, syndecan-4 clustering induced endothelial cell migration that was comparable in magnitude to that induced by $F G F 2$, a potent stimulator of cell motility.

The prominent fearure of syndecan- 4 clustering was rapid cell polarization, including formation of leading and trailing edges and syndecan-4 concentration on the leading edge and in the lamellipodia within $10 \mathrm{~min}$ of cell stimulation. This did not occur in cells expressing the $44-\mathrm{PDZ}^{-}$chimera suggesting thar syndecan-4-PDZdomain containing protein interaction was required for this event. Furthermore, while in wild rype cells syndecan-4 clustering led to Racl acriwarion and its concentration near the leading edge, in S4-PDZ- cells Rac1 remained diffusely distributed. Taken together, these results demonstrate that syndecan-4-PDZ-domain containing protein interaction is tequired for transport of the activated Racl to the leading edge and initiation of cell migration.

Our results are similar to previously reported effects of dynamin-2 on the cellular localization of active Racl. (Schlunck et al., 2004). In that study, expression of a dominant negative mutant of dynamin-2 (dynamin$\left.2^{\mathrm{K} 44 \mathrm{~A}}\right)$ affected the trafficking of Racl, resulting in high basal level of Racl acrivity due to an improper targeting of the active enzyme for recycling. Furthermore, microinjection of dynamin-2 $2^{\mathrm{K} 4 \mathrm{~A}}$ impairs epithelial cell 
A)

Inactive
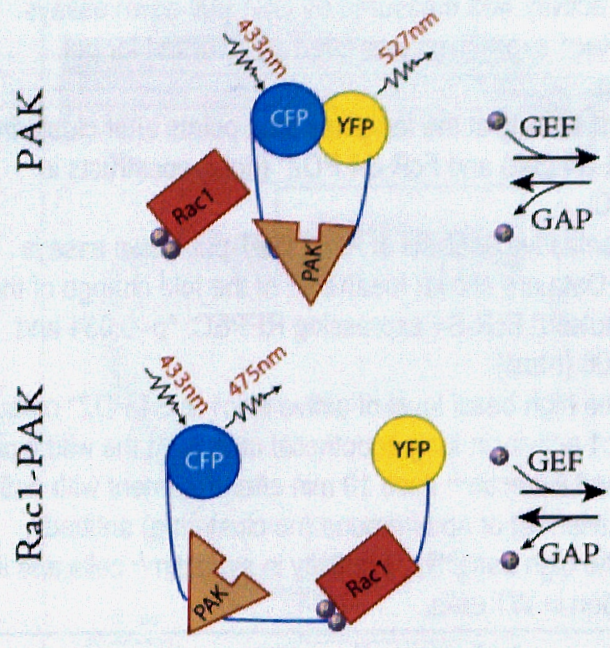

B)

FcR-S4

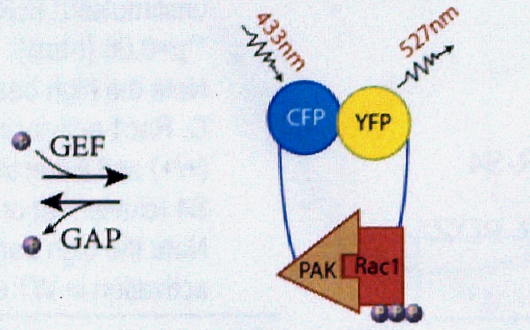

Active

FcR-S4 PDZ (-)

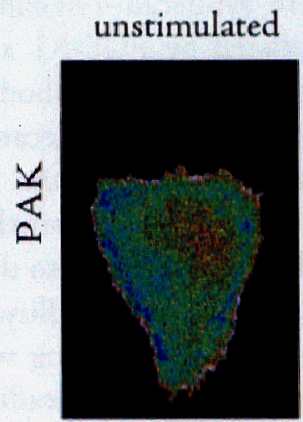

clustered
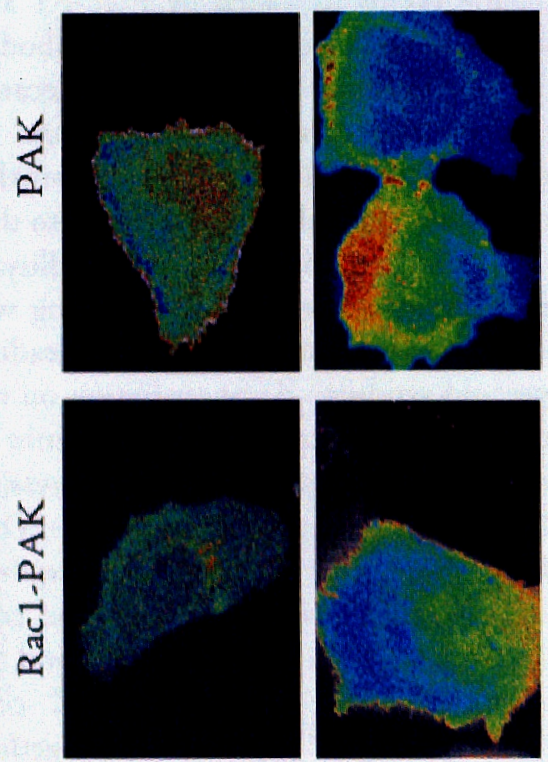

C)

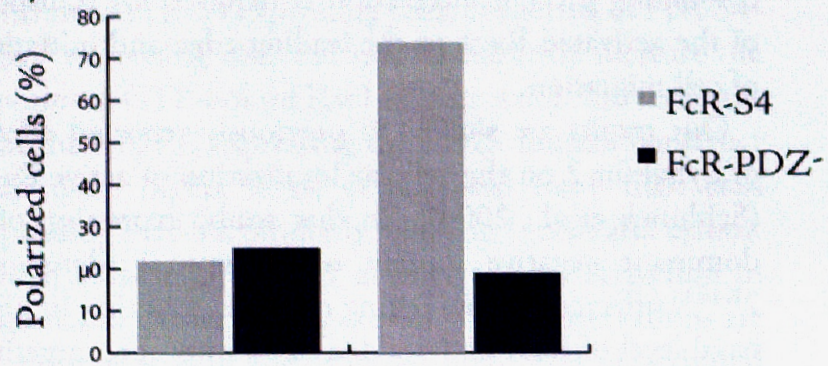

antibody - $-\quad+\quad+$

clustering 
ability to form the trailing edge during wound healing (Ezratty et al., 2005). Interestingly, dynamin has been shown to associate with macropinosomal vesicles containing the active form of Racl (Schlunck et al., 2004) while we have found that syndecan -4 is also present in macropinosomes (Tkachenko et al., 2004). Finally, a recent study has shown a direct interaction between syndecan-4 and dynamin-2 (Yoo et al., 2005).

One possible explanation for the similar phenotypes observed in syndecan-4-PDZ- or dynamin-2 ${ }^{\mathrm{K} 44 \mathrm{~A}}$ expressing cells may be that intracellular targeting of dynamin-2 necessary for migratory cell polarization (Schlunck et al., 2004; Ezratty et al., 2005) is dependent on syndecan-4-synectin interaction.

Another interesting finding of this study is that syndecan- 4 clustering is required for Racl activation in wild type, but not in synectin ${ }^{-/-}$or S4-PDZ- expressing endothelial cells with high basal level of Racl activity. The mechanism of syndecan- 4 clustering-dependent activation of Racl has not been established. One possible explanation of both syndecan-4 clustering-dependent Racl activation and the high baseline Racl activity in synectin ${ }^{-1-}$ and S4-PDZ- cells is that syndecan-4 dissociation from synectin upon clustering results in removal of a synectin-associated Racl GAP.

Other proteins, in addition to fibronectin that have been implicated in promotion of cell spreading in a syndecan-4 dependent manner, are disintegrins from the ADAMs family (Thodeti et al., 2003). ADAM12 uses syndecan- 4 as a primary cell surface receptor to trigger focal adhesions disassembly and $\beta 1$ integrinmediated cell spreading. Clustering of another syndecan family member, syndecan-1, also results in the enhanced cell spreading and formation of lamellipodia, but in independent of PDZ-binding domain nteractions (Chakravarti et al., 2005).

In summary, our results suggest that a syndecan4-synectin protein complex inhibits Racl activation. Clustering of syndecan- 4 locally releases this inhibition resulting in targeting of the active Racl to the leading edge of the cell thus promoting cell migration. These findings, therefore, establish syndecan -4 as a regulator of endothelial cell migration.

\section{Acknowledgments}

We would like to thank Dr. Michiyuki Matsuda from Osaka University, for Racl activity monitors constructs. We also want to thank Dr. Ty Lanahan for isolation of lung primary endothelial cells and Drs. Radu-Virgil Stan and John M. Rhodes for the help in preparation of this manuscript. 


\section{REFERENCES}

Alport, J.R., Lim, Y.C., Shipley, J.M., Senior, R.M. Shapiro, S.D., Matsuyoshi, N., Vestweber, D., and Luscinskas, FW. (2002). Neutrophils from MMP-9or neutrophil elastase-deficient mice show no defect in transendothelial migration under flow in vicro. J. Leukoc. Biol. 71, 821.-828.

Baciu, P.C, and Goetinck, P.F (1995). Protein kinase $C$ regulates the recruitment of syndecan -4 into focal contacts. Mol Biol Cell 6, 1503-1513.

Baciu, P.C., Saoncella, S., Lee, S.H., Denhez, F., Leuthardt, D., and Goetinck, PE. (2000). Syndesmos, a protein that interacts with the cytoplasmic domain of syndecan -4 , mediates cell spreading and actin cytoskeletal organization. J Cell Sci 113 Pt 2, 315-324.

Chakravarti, R., Sapountzi, V., and Adams, J. (2005). Functional Role of Syndecan-1 Cytoplasmic V Region in Lamellipodial Spreading, Actin-bundling, and Cell Migration. Mol. Biol, Cell.

Charnaux, N., Brule, S., Hamon, M., Chaigneau, T, Saffar, L., Prost, C., Lievre, N., and Gattegno, L. (2005). Syndecan- 4 is a signaling molecule for stromal cellderived factor-1 (SDF-1)/ CXCL12. FEBS Journal 272, $1937-1951$.

Chu, C.L., Buczek-Thomas, J.A., and Nugent, M.A. (2004). Heparan sulphate proteoglycans modulate fibroblast growth factor- 2 binding through a lipid raftmediated mechanism. Biochem. J. 379, 331-341.

Comelison, D.D., Wilcox-Adelman, S.A, Goetinck, P.F., Rauvala, H., Rapraeger, A.C., and Olwin, B.B. (2004). Essential and separible roles for Syndecan-3 and Syndecan-4 in skeletal muscle development and regeneration. Genes Dev. 18, 2231-2236.

Couchman, J.R. (2003). Syndecans" proteoglycan regulators of cell-surface microdomains? Nat Rev Mol Cell Biol 4, 926-937.

Couchman, J.R., Chen, L., and Woods, A. (2001). Syndecans and cell adhesion. Int. Rev. Cytol. 207, 113150.

Couchman, J.R., and Woods, A. (1999). Syndecan -4 and integrins: combinatorial signaling in cell adhesion. J Gell Sci 112, 3415-3420.

Echtermeyer, F., Streit, M., Wilcox-Adelman, S., Saoncella, S., Denhez, F, Detmar, M. and Goetinck, P. (2001). Dellayed wound repair and impaired angiogenesis in mice lacking syndecan-4. J Clin Invest 107, R9-R14. Ezratty, E.J., Partridge, M.A., and Gundersen, G.G. (2005). Microtubule-induced focal adhesion disassembly is mediated by dynamin and focal adhesion kinase. Nat Cell Biol 7, 581-590.
Gao, Y., Li, M. Chen, W., and Simons, M. (2000), Synectin, syndecan-4 cytoplasmic domain binding PDZ protein, inhibits cell migration. J. Cell. Physiol. 184, 373-379.

Geary, RL., Koyama, N., Wang, T.W, Vergel, S, and Clowes, A.W. (1995). Failure of heparin to inhibit intimal hyperplasia in injured baboon arteries. The role of heparin-sensitive and -insensitive pathways in the stimulation of smooth muscle cell migrarion and proliferation. Circulation 91, 2972-2981.

Horowitz, A., and Simons, M. (1998). Phosphorylation of the Cytoplasmic Tail of Syndecan-4 Regulates Activation of Protein Kinase Calpha. J Biol Chem 273, 25548-25551.

Horowitz, A., Tkachenko, E., and Simons, M. (2002). Fibroblast growth factor-specific modulation of cellular response by syndecan-4. J Cell Biol 157, 715-725.

Keum, E., Kim, Y., Kim, J., Kwon, S., Lim, X., Han, I., and Oh, E.S. (2004). Syndecan-4 regulates localizarion, activity and stability of protein kinase C-alpha. Biochem J 378, 1007-1014.

Li, J., Brown, L.E., Laham, R.J., Volk, R., and Simons, M. (1997). Macrophage-dependent regulation of syndecan gene expression. Circ Res 81, 785-796.

Longley, R.L., Woods, A., Fleetwood, A., Cowling, G.J., Gallagher, J.T., and Couchman, J.R. (1999). Control of morphology, cytoskeleton and migration by syndecan-4. J Cell Sci 112, 3421-3431.

Midwood, K.S., Valenick, L.V., Hsia, H., and Schwarzbauer, J.E. (2004). Co-Regulation of Fibronectin Signaling and Matrix Contraction by Tenascin-C and Syndecan-4. Mol Biol Cell.

Oh, E.S., and Couchman, J.R. (2004). Syndecans-2 and -4 ; close cousins, but not identical twins. Mol Cells 17 , 181-187.

Oh, E.S., Woods, A., and Couchman, J.R. (1997a). Multimerization of the cytoplasmic domain of syndecan4 is required for its ability to activate protein kinase C. I Biol Chem 272,11805-11811.

Oh, E.S., Woods, A., and Couchman, J.R. (1997b). Syndecan -4 proteoglycan regulates the distribution and acrivity of protein kinase C. J Biol Chem 272, 81338136.

Ridley, A.J. (2001). Rho family proteins: coordinating cell responses. Trends Cell Biol 11, 471-477.

Saoncella, S., Calautti, E., Neveu, W., and Goetinck, P.F. (2004). Syndecan-4 regulates ATF-2 transcriptional activity in a Racl-dependent manner. J Biol Chem 279 , $47172-47176$.

Saoncella, S., Echtermeyer, F., Denhez, F, Nowlen, 
J.K, Mosher, D.F, Robinson, S.D., Hynes, R.O., and Goetinck, P.F. (1999). Syndecan-4 signals cooperatively with integrins in a Rhodependent manner in the assembly of focal adhesions and actin stress fibers. Proc Nat Acad Sci U S A 96, 2805-2810.

Schlunck, G., Damke, H., Kiosses, W.B., Rusk, N., Symons, M.H., Waterman-Storer, C.M., Schmid, S.L., and Schwartz, M.A. (2004). Modulation of rac localization and function by dynamin. Mol. Biol. Cell 15, 256-267.

Simons, M., and Horowitz, A. (2001). Syndecan-4mediated signaling. Cell, Signal. 13, 855-862.

Stan, R.V., Tkachenko, Ex, and Niesman, I.R. (2004). PV1 is a key structural component for the formation of the stomatal and fenestral diaphragms. Mol Biol Cell 15, 3615-3630.

Thodeti, C.K., Albrechtsen, R., Grauslund, M., Asmar, M., Larsson, C., Takada, Y., Mercurio, A.M., Couchman, J.R, and Wewer, U.M. (2003). ADAM12/syndecan4 signaling promotes beta 1 integrin-dependent cell spreading through protein kinase Calpha and RhoA. J. Biol. Chem. 278, 9576-9584.

Tkachenko, E., Lutgens, E., Stan, R.V., and Simons, M. (2004). Fibroblast growth factor 2 endocytosis in endothelial cells proceed via syndecan-4-dependent activation ofRacl anda Cdc42-dependentmacropinocytic pathway. J. Cell Sci. 117, 3189-3199.

Tkachenko, E., Rhodes, J.M., and Simons, M. (2005). Syndecans: New Kids on the Signaling Block. Circ. Res. 96, 488-500.

Tkachenko, E., and Simons, M. (2002). Clustering induces redistribution of syndecan-4 core protein into raft membrane domains. J. Biol. Chem. 277, 1994619951.

Volk, R, Schwartz, J.J., Li, J., Rosenberg, R.D., and Simons, M. (1999). The role of syndecan cytoplasmic domain in basic fibroblast growth factor-dependent signal transduction. J. Biol. Chem. 274, 24417-24424.

Waterman-Srorer, C.M., and Salmon, E. (1999). Positive feedback interactions between microtubule and actin dyrnamics during cell morility. Curr. Opin. Cel! Biol. 11, 61-67.

Woods, A., and Couchman, J.R. (2001). Syndecan-4 and focal adhesion function. Curr. Opin. Cell Biol. 13, 578-583.

Yoo, J., Jeong, M.J., Cho, H.J., Oh, E.S., and Han, M.Y. (2005). Dynamin II interacts with syndecan-4, a regulator of focal adhesion and stress-fiber formation. Biochem. Biophys. Res. Commun. 328, 424-431.

Yoshizaki, H., Ohba, Y., Kurokawa, K., Itoh, R.E.,
Nakamura, T., Mochizuki, N., Nagashima, K., and Matsuda; M. (2003). Activity of Rho-family GTPases during cell division as visualized with FRET-based probes. J. Cell Biol. 162, 223-232. 

Chapter 7

Summary 
To date, syndecan- 4 is the best described member of the syndecan family. Cell signaling events regulated by ligand binding to the extracellular part of this protein trigger actin cytoskeleton rearrangement resulting in the modulation of cell functions, such as cell migration and proliferation. Furthermore, syndecan-4 trafficking has been implicated in the uptake of natural ligands, that include growth factors, cell matrix proteins, LDL, and infectious agents including retroviruses.

Chapter 1 contains a review of signaling events regulated by syndecan. It also describes phenotypes of animal models lacking one of the syndecan family proteins. It appears that one syndecan subfamily (syndecan-1,-3) plays a mainly negative role in promotion of growth factor response, whereas another (syndecan-2,-4) enhances those responses. The main difference between syndecan-2 and -4 functions is in the time and location of their expression. Generally, syndecan-2 plays a major role in development, while syndecan- 4 in acute response to tissue injury. For this reason, we studied syndecan-4's role in tissue injury-induced angiogenesis.

In Chapter 2, we investigated the effect of increased heparan sulfate mass due to overexpression of syndecan4 in cardiomyocytes, on heart microvascular function. We found that the expressing animals demonstrated a significant increase in nitric oxide release in the coronary effluent in response to FGF-2. In vitro, coronary microvessels derived from those transgenic mice demonstrated increased relaxation response to FGF2 compared to control mice. Addition of exogenous heparan sulfate enhanced FGF-2 induced vasodilation in microvessels from control mice. Thus, we demonstrated that alteration of heparan sulfate production has a profound effect on microvascular homeastasis.

Further chapters are almost exclusively dedicated to the role of syndecan -4 cytoplasmic tail in the cell signaling.

In Chapter 3, the role of different cytoplasmic domains in FGF-2 signal modulation was investigated. Murations in the cytoplasmic tail that either reduced its affinity to $\mathrm{PIP}_{2}$, or disrupted its PDZ-binding motif, produced an FGF2-specific dominant-negative phenotype in endothelial cells that demonstrated a marked decline in their migration and proliferation rates. Those cells also exhibited impaired capacity to form tubes on Matrigel. This molecular mechanism was determined to consist of a decrease in the syndecan-4-dependent activation of PKC $\alpha$.

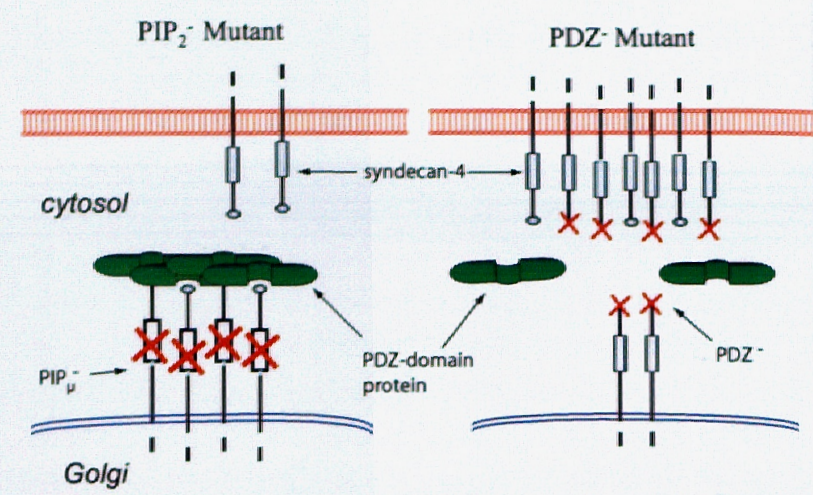

Figure 1. Dominant-negative effect of syndecan-4 mutants. Overexpression of the mutant with disrupted $\mathrm{PIP}_{2}$ binding site (left) results in its accumulation in the Golgi region and leads to the sequestering of PDZ-interacting protein(s) from the plasma membrane. In contrast, syndecan-4 with a mutated PDZ-binding motif (right) forms oligomers with endogenous protein thus preventing its binding to PDZ-domain containing protein(s).

Thus, PDZ-binding partner(s) of syndecan-4 play a critical role in the modulation of FGF2 signaling. Interestingly, a syndecan- 4 mutant lacking the PIP binding motif failed to be expressed on the cell surface. The mutant accumulates in the Golgi region, instead. Therefore, we hypothesized that depletion of the PDZbinding partner by competitive binding due to the overexpression of the Golgi-retained syndecan mutant resulted in dominant negative cell phenotype (Figure 1). Indeed, in contrast to single mutations, mutations of the syndecan -4 cytoplasmic tail that resulted in the reduced affinity of the mutant to both PDZ domain and $\mathrm{PIP}_{2}$, generated a phenotype that respond normally to FGF-2 stimulation. The role of the PDZ-binding motif as well as an identification of the critical interacting protein is further discussed in Chapter 6.

In Chapter 4, we studied the membrane distribution of the core protein using an Fc receptor $(\mathrm{FcR})$-syndecan4 chimera prior to and following FGF2- or antibodiesinduced clustering. Previously described cholesterol rich compartments called lipid rafts were shown to contain a variety of signaling proteins that include syndecan- 4 binding partners Src and PKC $\alpha$. We found that while unclustered syndecan- 4 was present predominantly in the non-raft membrane compartment, clustering induced extensive redistribution to the non-caveolae lipid rafts. Clustering of syndecan- 4 also induces its endocytosis. Interestingly, syndecan-4 positive endocytic vesicles can travel in tandem with caveolae vesicles. The role of this interaction remains unknown. FGF2 induced syndecan4 uptake may play an important role in modulation of growth factor signaling. 


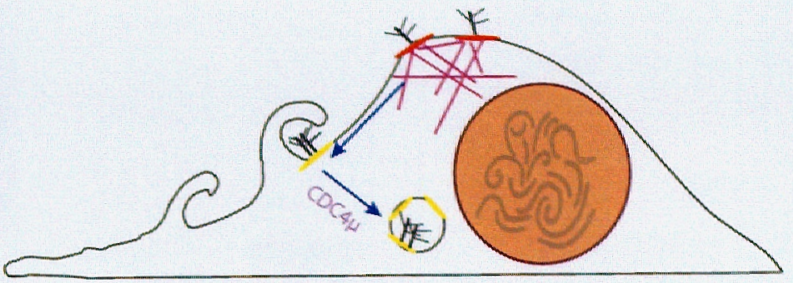

Figure 2. Mechanism of syndecan-4 induced endocytosis.

FGF2 binding to syndecan-4 results in a shift of the FGF2/ syndecan-4 complex to lipid rafts and this complex is then internalized via the constitutive $\mathrm{CDC}-42$ dependent macropinocytic pathway.

In Chapter 5, the initial steps of syndecan-4 endocytosis and its role in FGF2 internalization were characterized. We found that syndecan-4 uptake, induced either by treatment with FGF2 or by antibody clustering, requires the integrity of plasma membrane lipid rafts for its initiation and occurs in a non-clathrin, nondynamin dependent manner. Our results demonstrate that FGF2 endocytosis needs syndecan-4 clusteringdependent activation of Racl and the intact CDC42dependent macropinocytic pathway. Therefore, we have two steps in syndecan- 4 uptake. First, syndecan is shifted to the lipid rafts followed by clustering. As a result of this shift, syndecan assembles a signaling complex that activates Racl. Second, syndecan -4 containing lipid rafts undergo endocytosis using constitutive, CDC42 driven macropinocytosis (Figure 2).

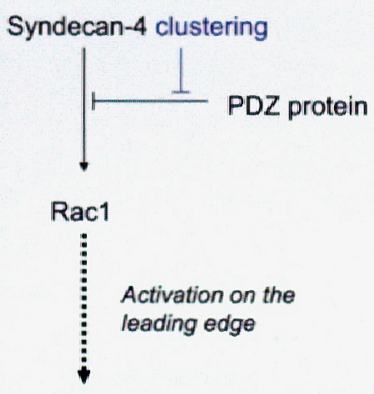

Cell migration

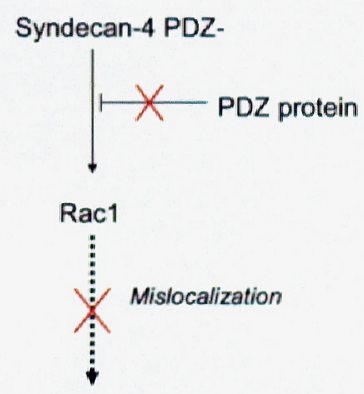

Cell migration

Figure 3. Mechanism of syndecan-4 induced cell migration. The syndecan-induced signaling complex is capable of activating Rac1. Interaction of syndecan-4 with PDZ-domain-containing protein inhibits this activation. Syndecan clustering results in activation of Rac1 by selective removal of this inhibition which leads to the increase of cell migration (left). PDZ-binding domain mutation leads to inability of the PDZ-domain containing protein to inhibit Rac1 activation and results in the high basal level of Rac-1 activity (right).
Activation of Racl is a critical step in migratory polarization of cells. In Chapter 6, we investigated the migratory response of endothelial cells to clustering of syndecan-4. We showed that syndecan-4 promotes cell migration upon ligand binding by activating Racl and localizing it to the leading edge of the cell. Cells expressing syndecan- 4 with a mutated PDZ-binding region or cells lacking synectin, a PDZ domain containing protein that interacts with syndecan-4, fail to migrate in response to syndecan-4 clustering (Figure 3 ). Thus, the syndecan- 4 / synectin interaction is critical in clustering-induced cell migration.

In conclusion, our studies show regulation of cellular and organ functions by syndecan- 4 ranging from effects due to the simple increase of its heparan sulfate mass to complex intracellular interactions. The described trafficking and signaling properties of syndecan-4 contribute to the understanding of growth factor and cell matrix induced angiogenesis. 
Chapter 7

Samenvatting 
Syndecan 4 is het best beschreven lid van de syndecanfamilie. De signaaltransductie van syndecan-4, die gereguleerd wordt door binding van het ligand aan het extracellulaire deel van het molecuul, induceert herschikking van het actine-cytoskelet hetgeen cellulaire functies, zoals celmigratie en -proliferatie, moduleert. Verder is syndecan-4 betrokken bij de opname van 'natuurlijke liganden' waaronder groeifactoren, celmatrix eiwitten en LDL, alsmede infectieuze agentia zoals retrovirussen.

In hoofdstuk 1 worden signaaltransductie-pathways die door syndecan- 4 wordt gereguleerd beschreven. Verder worden fenotypes van de diermodellen beschreven die deficient zijn voor een van de syndecan-familieleden. Een van de syndecan subfamilies (syndecan-1 en 3) speelt een negatieve rol in het activeren van de respons op groeifactoren, terwijl een andere subfamilie (syndecan 2 en 4) deze net stimuleert. Het voornaamste verschil tussen syndecan 2 en 4 betreft tijdsspanne en localisatie. Syndecan-2 speelt een rol in de ontwikkeling, terwijl syndecan-4 een rol speelt in de acute respons na weefselbeschadiging. Het doel van dit proefschrift was dan ook het bestuderen van de rol van syndecan- 4 in de angiogenese die optreedt na weefselschade.

In hoofdstuk 2 hebben we het effect van een toegenomen heparan-sulfaat massa op de microvasculatuur van het hart onderzocht. Dit is uitgevoerd door syndecan- 4 tot overexpressie te brengen in de cardiomyocyten. Het bleek dat de dieren die syndecan- 4 tot overexpressie brachten, meer NO tot expressie brachten in het coronair effluent na toediening van FGF2. In vitro toonden de coronaire microvasculatuur van deze muizen een toegenomen relaxatie na FGF2 toediening in vergelijking met controle muizen. Toediening van exogeen heparansulfaat versterkte de FGF-2 geinduceerde vasodilatatie in microvaten van controle muizen. In dit hoofdstuk hebben we laten zien dat verschillen in heparansulfaatproductie een duidelijk effect heeft op de homeostase van de microvasculatuur.

De volgende hoofdstukken hebben betrekking op de rol van de C-terminale deel van syndecan-4 in de cel signaaltransductie.

In hoofdstuk 3 hebben we de rol van verschillende cytoplasmatische domeinen van syndecan- 4 onderzocht tijdens de modulatie van FGF-2 signaaltransductie. Muraties in het $\mathrm{PIP}_{2}$ bindingsdomein of het PDZbindingsdomein resulteerde in een FGF2-specifiek

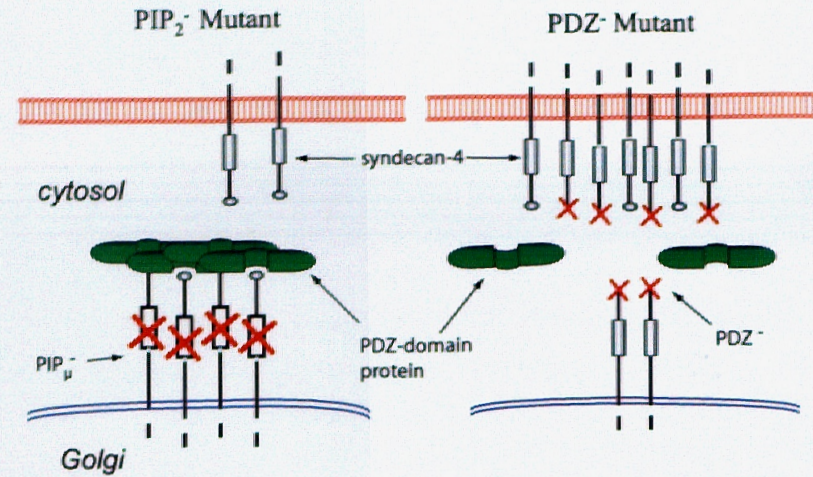

Figuur 1. Effect van 'dominant-negatieve' syndecan-4 mutaties.

Overexpressie van een gemuteerd syndecan 4 gen met een verstoorde sequentie voor de PIP2 bindingsplaats (links) veroorzaakt accumulatie van syndecan 4 in het Golgi gebied en leidt tot sequestratie van de PDZ bindende eiwitten van de plasma membraan. In tegenstelling tot dit effect vormt syndecan4 met een gemuteerd PDZ-bindings motief (rechts) oligomeren met endogeen eiwit waardoor het niet kan binden met de PDZ bevattende eiwitten.

dominant negatief fenotype in endotheelcellen dat gekenmerkt werd door een afname van hun proliferatie en migratie capaciteit. Verder toonden deze cellen verstoring in buis-formatie in matrigel-assays. Dit effect werd veroorzaakt door een afname in de syndecan- 4 geinduceerde activatie van PKC $\alpha$.

Dus, PDZ-bindende partners van syndecan- 4 spelen een belangrijke rol in de modulatie van FGF-2 signaaltransductie. Een syndecan- 4 mutant met een deficiente $\mathrm{PIP}_{2}$ - bindingsplaats werd niet tot expressie gebracht aan het oppervlak, maar accumuleerde in het golgi-gebied. We hebben daarom de hypothese opgesteld dat depletie van de PDZ-bindingspartner door competatieve binding aan het in het golgi-gebied gelegen syndecan-4, verantwoordelijk is voor het beschreven fenotype (Figuur 1). In tegenstelling tot enkelvoudige mutaties, resulteerden mutaties met verlaagde affiniteit van FGF2 voor zowel de PIP2 bindingsplaats als het PDZ domein in een fenotype met een normale respons op FGF2 stimulatie. De rol van het PDZ bindingsmotief alsmede de identificatie van het kritische interactie-eiwit wordt verder beschreven in hoofdstuk 6 .

In hoofdstuk 4 werd de membraandistributie van het syndecan-4 transmembraan en C-terminale gedeelte onderzocht door gebruik te maken van een $F c$ receptor $(\mathrm{FCR})$-syndecan-4 chimera vóór en na FGF-2 of antilichaam geinduceerde clustering. De voorheen beschreven cholesterol-rijke compartimenten, lipid rafts 


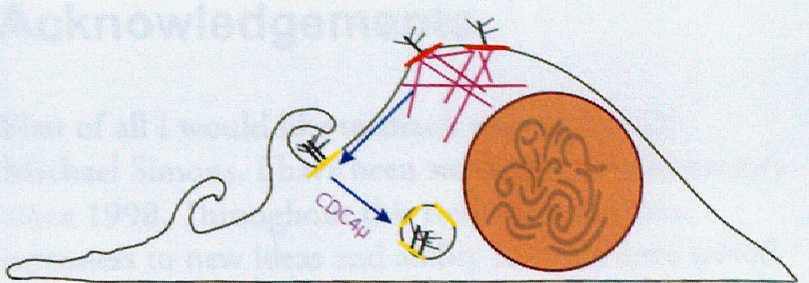

Figuur 2. Mechanisme van syndecan-4 geïndiceerde endacytose.

Binding van FGF2 aan syndecan-4 resulteert in een verplaatsing van het FGF2/syndecan-4 complex naar 'lipid rafts' en het complex wordt dan geïnternaliseerd via constitutieve, CDC-42 afhankelijke macropinocytose.

genoemd, bevatten een variatie aan signaaltransductiemo leculen waaronder de syndcan- 4 bindingspartners Src en PKC $\alpha$. Terwijl ongeclusterd syndecan-4 vooral aanwezig was in de non-raft compartimenten, zorgde clustering voor redistriburie van syndecan-4 naar non-caveolae lipid rafts.

Clustering van syndecan-4 resulteerde eveneens in endocytose. Syndecan-4 positieve vesikels migreerden in tandem migreren met caveoline-vesikels. De rol van deze interactie blijft onbekend. FGF-2 geinduceerde syndecan-4 opname speelt hoogstwaarschijnlijk een belangrijke rol in de modulatie van de signaaltransductie van groeifactoren.

In hoofdstuk 5 werden de initiele stappen van syndecan4 endocytose, alsmede zijn rol in FGF2 internalizatie gekarakteriseerd. We zagen dat syndecan-4 opname na FGF2 of antilichaam geinduceerde clustering, de integriteit van de plasmamembraan en de lipid rafts vereist voor de initiatie van de internalizatie, en dat de internalizatie onafhankelijk is van clathrin en dynamin. Onze resultaten tonen dat FGF2 endocytose afhankelijk is van clustering van syndecan-4 waarna racl activatie optreedt. Verder is een intacte CDC42-afhankelijke macropinocytose pathway noodzakelijk. Er zijn dus 2 stappen tijdenssyndecan-4 opname. Eerstwordtsyndecan4, na clustering, verplaatst naar de lipid rafts. Vervolgens assembleert syndecan- 4 een signaaltransductie-complex dat leidt tot de activatie van racl. Vervolgens ondergaan de syndecan- 4 bevattende lipid rafts endocytose en maken ze hierbij gebruik van CDC42 geinduceerde macropinocytose (Figuur 2).

Activatie van racl is een kritische stap in de polarisatie en migratie van cellen. In hoofdstuk 6 hebben we de migratie van endotheelcellen na clustering van syndecan4 onderzocht. We hebben aangetoond dat syndecan -4 ,

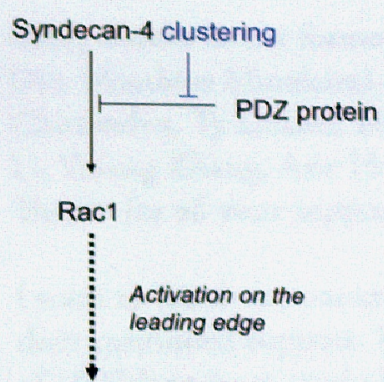

Cell migration

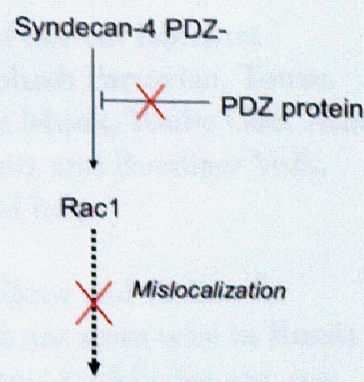

Cell migration
Figuur 3. Mechanisme van syndecan-4 geïnduceerde cell migratie.

Het syndecan-4 geïnduceerde signaal transductie complex is in staat om Rac1 te activeren. Interactie van syndecan-4 met PDZ-domein bevattend eiwit remt deze activatie. Clustering van syndecan-4 leidt tot activering van Rac1 door selectieve onderbreking van dit remmend effect, hetgeen leidt tot een toename van cel migratie(links). Mutatie van het PDZ-bindings motief leidt er toe dat het PDZ-domein bevattende eiwit activatie van Rac1 niet kan onderbreken en resulteert in een hoog basaal niveau van Rac1 activiteit (rechts).

na ligand binding, celmigratie versterkt door activatie van racl, dat vervolgens aan de rand van de cel lokaliseert. Cellen die syndecan- 4 mer een gemuteerd PDZbindingsdomein tot expressie brengen, en cellen deficient in syntenin, een eiwit dat een PDZ-domein bevat dat een interactie aangaat met syndecan- 4 , migreren niet na syndecan-4 clustering (Figuur 3). Hieruit kunnen we concluderen dat syndecan-4/syntenin interacties cruciaal zijn voor syndecan- 4 clustering geinduceerde migratie.

Sammenvattend beschrijft dit proefschrift de regulatie van cellulaire en orgaanfuncties door syndecan-4. Dit varieert van de eenvoudige toename van heparan sulfaat massa tot complexe intracellulaire interacties. De beschreven 'trafficking' en signaaltransductie eigenschappen van syndecan- 4 dragen bij aan het begrijpen van groeifactor en cel-matrix geinduceerde angiogenese. 


\section{Acknowledgements}

First of all I would like to thank my mentor Dr. Michael Simons. I have been working in his laboracory since 1998. Throughout this time his optimism, openness to new ideas and ability to focus have served a great example to me. Thanks to him, I have gained more and more independence in my projects, leading to my transformation from a technician to a graduate student.

I want to thank my thesis advisor Dr. Mark Post. He was a part of our research center both at Harvard and Dartmouth. Now he is the head of the Physiology Department in Universiry of Maastricht. Dear Mark, we really miss you on our lab meetings. Thanks a lot for your help in preparation of my thesis.

When our laboratory was still in Boston, Dr. Jian Li was my true mentor. Dear Jian, thank you for your patience and willing to teach me. Your training was tough, but it served me well.

I am very grateful to Dr. Nicholas Shworak. I find his presence in the angiogenesis research center at Dartmouth absolutely essential. Nick is the best consultant you may ever imagine. He is very helpful, once you filter his ideas. Dear Nick, I always enjoyed working next to youl.

For a long time Dr. John Rhodes was the only American in the lab. He helped me to break some stereotypes about Americans, and contributed to the building of several new ones. Dear John, ic was always fun to work with you. Thanks for talking with me. Lots of ideas would not be generated without our discussions.

I want to thank my collaborator Dr. Radu Stan. We started to work (and to talk) with him after ASCB meeting in 2001. Bona Radu, thank you for your help and friendship.

For less than a year we had a visiting postdoctoral fellow from Maastricht, Dr. Esther Lutgens. She happened to be the best co-worker I ever had. It was very rewarding to work with you, Esther.

I really enjoyed company of graduate student Arye Elfenbein and former grad Rohit Khurano. It was fun co work and party with you.
Many thanks to my former and current labmates Drs. Masahiro Murakami, Chohreh Partovian, Tomas Chittenden, Ty Laham, Ebo de Munk, Youke Gao, Min $\mathrm{Li}$, Yufeng Zhang, Arie Horowite and Ruediger Volk. Thanks for all your support and help.

I want to thank my parents: Vikror and Galina for their continued support. It did not seem wise in Russia of 1990th to go to study Biology. Luckily for me, iny parents did not object to my decision.

And, finally, I want to thank my wife Natasha. She is and has always been a great support and inspiration for me. 


\section{Curriculum vitae}

\section{Eugene V. Tkachenko}

1972 Born in Irkutsk, Russia

\section{Education}

1994 Master of Science in Physiology. Irkutsk State University, Irkutsk, Russia. Mastex" Thesis: "Influence of 2-Oxothiozomizine-4-Carboxilate on the Concentration of Glutathion and Surviving of Mice with Lethal Doze of Paracetomol." Bachelor of Science in Biology. Irkutsk State University, Irkutsk, Russia.

\section{Professional Positions}

2001-pres Research Associate, Angiogenesis Research Center, Dartmouth Medical School (Hanover, NH)

1998-2001 Research Assistarnt, Angiogenesis Research Center, Beth Israel Deaconess Medical Center (Boston, MA)

1997-1998 Research Assistant, Department of Pediatric Oncology, Dana-Farber Cancer Institute (Boston, MA)

1993-1997 Researcher, Department of Biochemistry, Irkutsk Medical Institute (Irkutsk, Russia)

\section{Awards and Professional Activities}

2005 Junior Investigator Award. Annual North American Vascular Biology Organization meeting in Chicago, IL.

2003 Finalist for the Scientific Sessions Poster Competition in Basic Science. American Heart Association, Orlando, FL.

2002 North American Vascular Biology Organization travel award. XII International Vascular Biology meeting in Karuizawa, Japan.

\section{Publications}

- Tkachenko E, Elfenbein A, Tirziu DC, Simons M. Syndecan-4 clustering induces migration in synectin dependent manner.(submitted)

- Tkachenko E, Rhodes JM, Simons M. Syndecans. Endothelial Biomedicine. W. C. Aird. Cambridge, MA, Cambridge U Press. (submitted)

- Tkachenko E, Rhodes JM, Simons M. Syndecans- new kids on the signaling block.. Review. Circ Res 96(5):488-500.18 March 2005

- Stan RV, Tkachenko E, Niesman I. PV1 Is a Key Structural Component for the Formation of the Stomatal and Fenestral Diaphragms. Mol Biol Cell 2004 15: 3615-3630, August 2004

- Tkachenko E, Lutgens E, Stan RV, Simons M. Fibroblast growth factor 2 endocytosis in endothellial cells proceeds via syndecan-4-dependent activation of rac 1 and a cdc42-dependent macropinocytic pathway. Journal of Cell Science 1 17: 3189-3199, 1 July 2004

- Tkachenko E, Simons M. Clustering induces redistribution of syndecan-4 core protein into raft membrane domains. Journal of Biological Chemistry. 277(22): 19946-51, 31 May 2002 
- Horowitz A, Tkachenko E, Simons M. Fibroblast growth factor-specific modulation of cellular response by syndecan-4. Journal of Cell Biology. 157(4): 715-25, 13 May 2002

- Li J, Partovian C, Li J, Hampton TG, Metais C, Tkachenko E, Sellke FW, Simons M. Modulation of microvascular signaling by heparan sulfate matrix: studies in syndecan-4 transgenic mice. Microvascular Res. 64(1): 38-46., July 2002

Oral Presentations

2005 Eugene Tkachenko, Arye Elfenbein, Daniela Tirziu, Michael Simons. Syndecan-4 clustering induces migration in synectin-dependent manner. North America Vascular Biology Organization, Chicago, IL.

2002 Eugene Tkachenko, Michael Simons. Synectin is an essential PDZ protein involved in FGF-2 signaling mediated by syndecan-4. American Society of Cell Biology, San Francisco, CA.

2002 Eugene Tkachenko, Michael Simons. Role of Syndecan-4 in modulation of FGF2 signaling. University of Washington, Seattle, WA.

Poster Presentations

- Radu V. Stan, Eugene Tkachenko. (2004) PV1 is a necessary and sufficient component for the formation of the stomatal and fenestral diaphragms. European Life Science Organization, Nice, France.

- Eugene Tkachenko, Arye Elfenbein, Daniela Tirzui, Ty Lanahan, Michael Simons. (2004). Syndecan4 clustering results in endothelial cell migration. Intemational Society of Vascular Biology, Toronto, Ontario, Canada.

- Eugene Tkachenko, Esther Lutgens, Radu-Virgil Stan, Michael Simons.(2003). Fibroblast growth factor 2 endocytosis in endothelial cells proceeds via syndecan-4-dependent activation of racl and a cdc42dependent macropinocytic pathway. American Society of Cell Biology, San Francisco, CA.

- Esther Lutgens, Eugene Tkachenko, Michael Simons.(2003).Intemalization of Syndecan-4 is clatlurin, caveolin and dynamin independent and requires activation of Racl. American Heart Association, Orlando, FL.

- Eugene Tkachenko, Esther Lutgens, Radu-Virgil Stan, Michael Simons. (2003). Syndecan-4 undergoes internalization via a clathrin- and caveolin-independent pathway. EuroConference on Lipid Rafts, Tomar, Portugal.

- Eugene Tkachenko, Arie Horowitz, Michael Simons. (2002).Synectin-dependent syndecan-4 translocation from lateral to apical plasma cell membrane specifically regulates FGF2 signaling. American Heart Association, Chicago, IL.

- Eugene Tkachenko, Michael Simons. (2002). Clustering of the Syndecan-4 induces PDZ-dependent apical targeting and rapid internalization. International Society of Vascular Biology, Karuizawa, Japan.

- Eugene Tkachenko, Michael Simons. (2002). Clustering of the Syndecan-4 induces PDZ-dependent apical targeting and rapid internalization. Keystone Conference on Angiogenesis, Banff, Alberta, Canada.

- Eugene Tkachenko, Nicholas W. Shworak, Arie Horowitz, Michael Simons. (2001) Syndecan-4, FGF2signaling receptor, is present in lipid rafts in endothelial cells. American Society of Cell Biology, Washington, DC. 